Florida International University FIU Digital Commons

$11-8-2011$

\title{
Sediment Dynamics of a Shallow Hypereutrophic lake: Lake Jesup, Florida, USA
}

Shauna Nielsen

Florida International University, sniel002@fiu.edu

DOI: $10.25148 /$ etd.FI11120617

Follow this and additional works at: https://digitalcommons.fiu.edu/etd

\section{Recommended Citation}

Nielsen, Shauna, "Sediment Dynamics of a Shallow Hypereutrophic lake: Lake Jesup, Florida, USA" (2011). FIU Electronic Theses and Dissertations. 511.

https://digitalcommons.fiu.edu/etd/511 


\title{
FLORIDA INTERNATIONAL UNIVERSITY \\ Miami, Florida
}

SEDIMENT DYNAMICS OF A SHALLOW HYPEREUTROPHIC LAKE:

LAKE JESUP, FLORIDA, USA

\author{
A thesis submitted in partial fulfillment of the \\ requirements for the degree of \\ MASTER OF SCIENCE \\ in \\ GEOSCIENCE \\ by \\ Shauna M. Nielsen
}

2011 
To: Dean Kenneth G. Furton

College of Arts and Sciences

This thesis, written by Shauna M. Nielsen, and entitled Sediment Dynamics of a Shallow Hypereutrophic Lake: Lake Jesup, Florida, USA, having been approved in respect to style and intellectual content, is referred to you for judgment.

We have read this thesis and recommend that it be approved.

Renè M. Price

Leonard J. Scinto

William T. Anderson, Major Professor

Date of Defense: November 8, 2011

The thesis of Shauna M. Nielsen is approved.

Dean Kenneth G. Furton
College of Arts and Sciences

Florida International University, 2011 


\section{DEDICATION}

I dedicate this thesis to my family. Without their love, support and constant motivation I would not have been successful. More importantly for always believing in me and believing with me. 


\section{ACKNOWLEDGMENTS}

I wish to express a special thank you towards my committee members for not only agreeing to be apart of this thesis project, but for their amazing help and individual support during the thesis writing process. Without them, this document would not have been possible. From this experience I have learned so much and I may not have been successful without each of their help.

Additionally, I would like to acknowledge those people outside of my committee, who made this thesis come together one piece at a time. Thank you to Carrie Rebenack, for her collective isotope analysis work and more importantly her amazing support throughout the thesis process, Diana Johnson for her general laboratory help and sample preparation, and Greg Losada, Robert Schroeder and Valentin Nechita for their support in the field. I must also thank Dr. Thomas Serge, Dr. David Fugate and Dr. D. Reide Corbett for sharing data relevant to this thesis. This study was funded in part by the St. Johns River Water Management District. Interpretations and conclusions are not necessarily those of the supporting agency. Thank you all so much for your help and time. 


\section{ABSTRACT OF THE THESIS \\ SEDIMENT DYNAMICS OF A SHALLOW HYPEREUTROPHIC LAKE: \\ LAKE JESUP, FLORIDA, USA}

by

\section{Shauna M. Nielsen}

Florida International University, 2011

Miami, Florida

\section{William T. Anderson, Major Professor}

Improved knowledge of sediment dynamics within a lake system is important for understanding lake water quality. This research was focused on an assessment of the vertical sediment flux in Lake Jesup, a shallow (1.3 m average depth) hypereutrophic lake of central Florida. Sediment dynamics were assessed at varying time scales (daily to weekly) to understand the transport of sediments from external forces; wind, waves, precipitation and/or runoff. Four stations were selected within the lake on the basis of water depth and the thicknesses of unconsolidated (floc) and consolidated sediments. At each of these stations, a 10:1 (length to diameter) high aspect ratio trap (STHA) was deployed to collect particulate matter for a one to two week period. The water and sediment samples were collected and analyzed for total carbon (TC), total phosphorus (TP) and total nitrogen (TN). Mass accumulation rates (MAR) collected by the traps varied from 77 to $418 \mathrm{~g} \mathrm{~m}^{-2} \mathrm{~d}^{-1}$ over seven deployments. TN, TP and TC sediment concentrations collected by the traps were consistently higher than the sediments collected by coring the lake bottom and is most likely associated with water column biomass. A yearly nutrient budget was determined from August 2009 to August 2010 with flux calculated as $2,033,882 \mathrm{mt} \mathrm{yr}^{-1}$. 


\section{TABLE OF CONTENTS}

CHAPTER PAGE

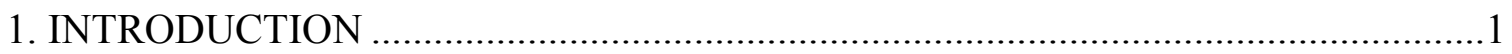

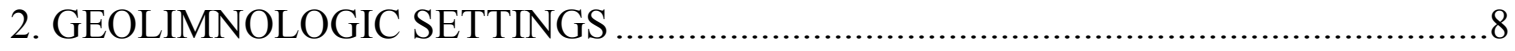

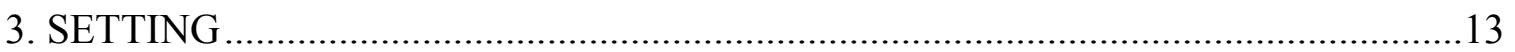

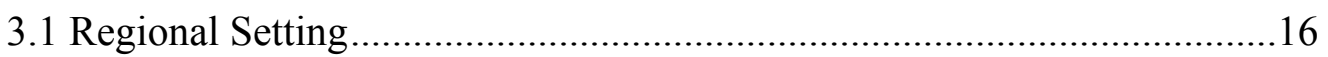

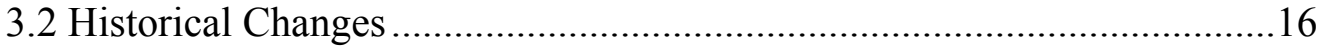

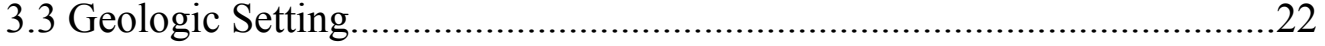

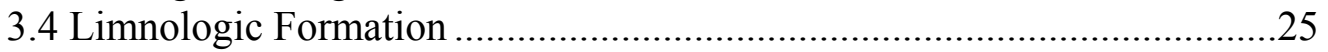

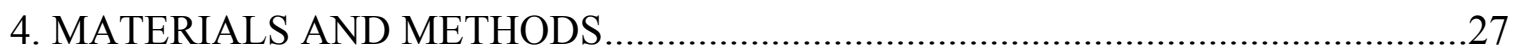

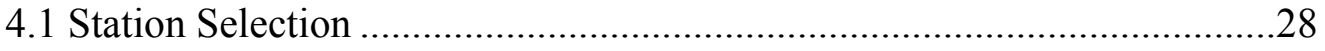

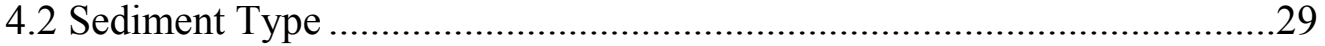

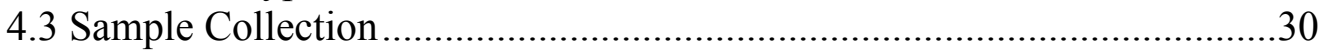

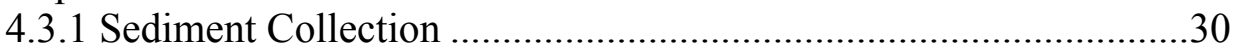

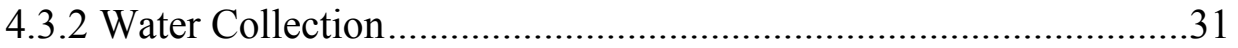

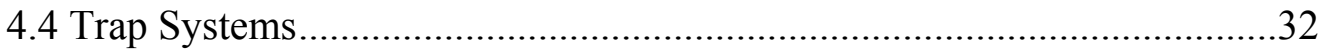

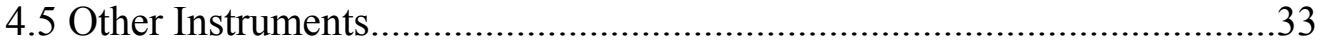

4.6 Deployments and Recovery Materials .........................................................

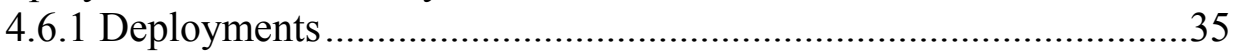

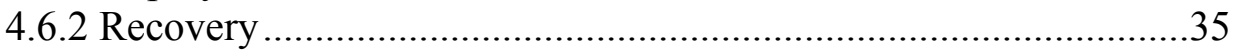

4.7 Sample Preparation ............................................................................

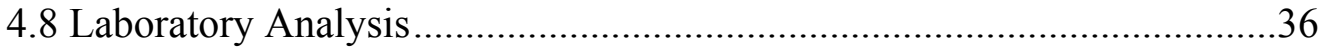

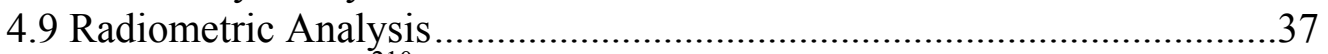

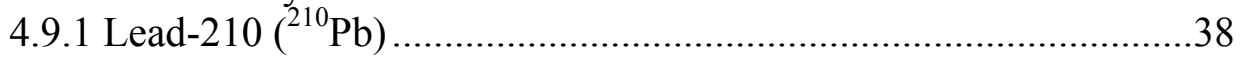

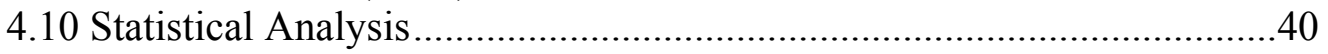

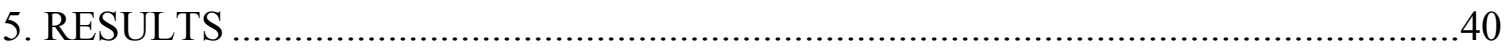

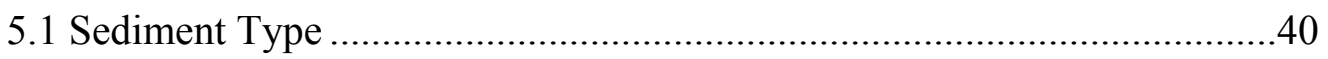

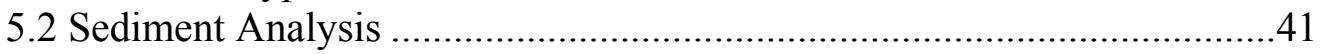

5.3 Sediment Characteristics........................................................................4

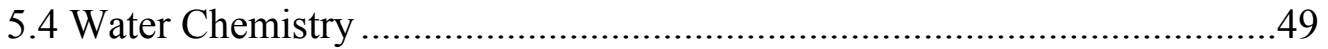

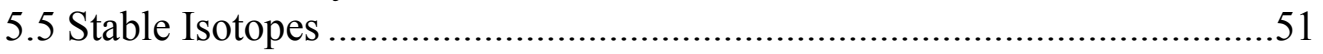

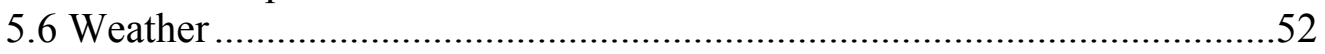

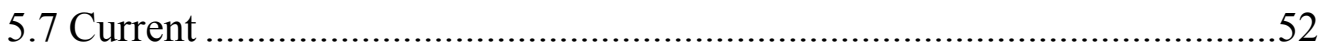

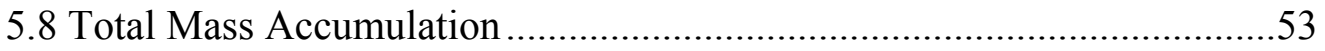

5.9 Nutrient Budget of Cycling Material Calculations .....................................53

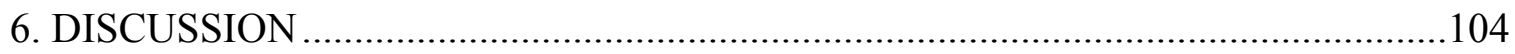

6.1 Sediment and Water Chemistry ………………….................................104

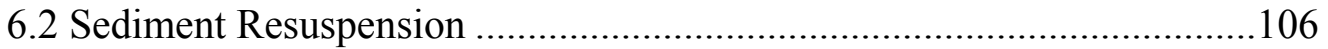

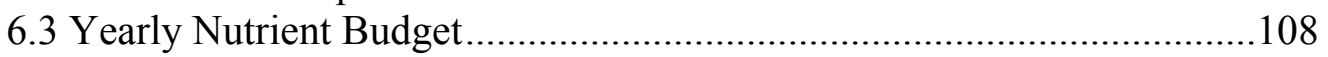




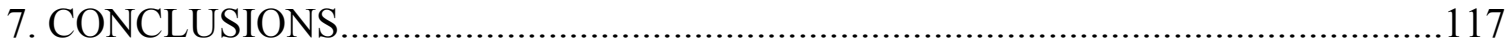

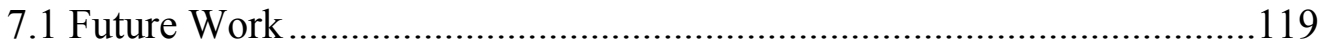

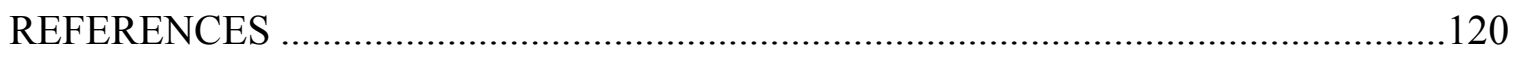

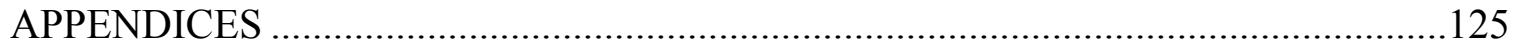




\section{LIST OF TABLES}

TABLE

PAGE

4.1 Deployment dates and successful samples collected for Grab samples (water and sediment), YSI ( $\mathrm{D}=$ deployed, $\mathrm{P}=$ profile), current, weather ( $\mathrm{S} 1$ = Station 1, "barge," S2

$=$ Station 2, by SR-46), STHA, STT (plate trap), STM8 (Mark8 trap) and Radiometric coring.

5.1 Mean and standard deviation of floc thickness for deployments 6, 7, 8 and 9.

Deployments 1 to 5 were not measured.

5.2 Correlation matrix of sediment analysis with $\mathrm{n}=117$ (except for $\mathrm{pH}, \mathrm{n}=116$ and bulk density, $\mathrm{n}=128$ ), for all sediments (floc, sediments, STHA, STM8 and STT). ${ }^{* *}=$ significant at $\mathrm{p}<0.01$

5.3 Mean, standard deviation and range of total phosphorus by sediment type. . .55

5.4 Mean, standard deviation and range of total nitrogen by sediment.

5.5 Mean, standard deviation and range of total carbon by sediment

5.6 Mean, standard deviation and range of bulk density by sediment

5.7 Mean, standard deviation and range of percent organic matter by sediment type.......73

5.8 Mean, standard deviation and range of percent water content by sediment type.. ......77

5.9 Matrix correlation between the water and different sediment types and there concentrations where $n=30$ or 31 .

5.10 Water nutrient correlation matrix for ISCO water samples where $n=73$ (except for $\mathrm{TP}, \mathrm{n}=72) .{ }^{* *}=$ significant at $\mathrm{p}<0.01$.

5.11 Mean, standard deviation and range for total phosphorus, nitrogen, organic carbon and chlorophyll-a by site location and sampling type.

5.12 Statistical analysis of dissolved oxygen in the surface water (depth around $0.5 \mathrm{~m}$ ) by deployment.

5.13 Statistical analysis of the total suspended solids within the water column (minimal depth $=0.5 \mathrm{~m}$ from water surface) by deployment.

5.14 Statistical analysis of stable isotopes, $\delta^{15} \mathrm{~N}$ and $\delta^{13} \mathrm{C}$ within the sediments by sediment type. 
5.15 Statistical analysis of wind velocity, direction temperature and rain by deployment from weather stations 1 and 2 (wind direction)........................................................102

5.16 Statistical analysis of lake current velocity and direction by deployment...............103

6.1 Matrix correlation between the ISCO water and the turbulent mechanisms. CSS,

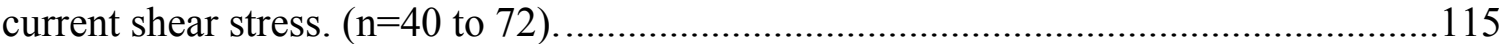

6.2 Matrix correlation between ISCO water samples and the turbulent mechanism with directional correlations ( $\mathrm{n}=11$ to 44 ). 116

6.3 Nutrient budget results for Lake Jesup. 


\section{LIST OF FIGURES}

FIGURES

PAGE

1.1 A comparison of natural eutrophication versus cultural eutrophication for a lake environment

1.2 The original STHA trap deployment method, which were deployed using PVC pipes. However, this approach proved to be un-workable as poles were never in the original position (e.g. hit by boat).

1.3 High-aspect ratio trap (STHA) system used for deployments 3 to 9 . This was the final design used for deployment ......................................................................................

1.4 Teller trap or plate trap (STT) system used for deployments 3 to 5 . This was the final design used for deployment, although was not a successful method within Lake Jesup, because the sample was often lost during recovery

2.1 The model of particle movement during sediment resuspension. Sediments are resuspended by lateral movements and eventually as particle velocities decrease particles will settle out of the water.

2.2 The two regions of sediment resuspension within a lake. a) is the main area of resuspension and b) is less frequent or below the wave base (from Evans 1994). Shallow lakes are more likely to fall under the main zone of sediment resuspension.

2.3 Model of nutrient release from sediments into the overlying water column. a) represents a simplified model of nutrient release with no turbulence, b) represents the release of nutrients from the sediment into the water column when resuspended by turbulence (from Brezonik et al. 1976). See text for model description.

3.1 Location of study site depicting the St. Johns River Water Management District (SJRWMD) boundary and the middle St. Johns River Basin (MSJRB) relative to the St. Johns River (SJR) (image created in ArcGIS with data from SJRWMD)........................14

3.2 The MSJRB and Lake Jesup watershed relative to Orlando and the locations of the three lake system: Lake Monroe, Lake Jesup and Lake Harney (image created in ArcGIS with data from SJRWMD).

3.3 The Lake Jesup Watershed relative to the St. Johns River containing roads, canals and creeks (image created in ArcGIS with data from SJRWMD). 
3.5 Land Cover use for 2004 (a) and 1973 (b) (image created in ArcGIS with data from SJRWMD) and Percent Distribution of land cover area for the Lake Jesup watershed (calculated from SJRWMD data for land cover)..

3.6 The geology of the Middle St. Johns River Basin (image created in ArcGIS with data from SJRWMD)

3.7 The physiographic districts within the SJRWMD boundary (image created in ArcGIS with data from SJRWMD).

4.1 Daily mean lake level height (blue) and total precipitation (red) from April 2009 to April 2011. Highlighted grey areas are representative of each deployment......................28

4.2 Sampling stations on Lake Jesup for the two year sampling period

4.3 Photograph of the barge located at LJ28 with deployed ISCO water sampler and Weather Station 1 .

5.1 Representative layering at depth of sediment within Lake Jesup with pictures. Top $=$ floc, middle $=$ gyttja and bottom $=$ peat. The core image is not to scale.. 45

5.2 Box and whisker for total phosphorus by sediment type. .55

5.3 Box and whisker for total phosphorus by deployment and sediment type.................56

5.4 Variations for total phosphorus by sediment type .57

5.5 Variations for total phosphorus by sampling trip.. . .58

5.6 Box and whisker for total nitrogen by sediment type.

5.7 Box and whisker for total nitrogen by deployment and sediment type..

5.8 Variations for total nitrogen by sediment type..

5.9 Variations for total nitrogen by sampling trip. 
5.10 Box and whisker for total carbon by sediment type..

5.11 Box and whisker for total carbon by deployment and sediment type.

5.12 Variations for total carbon by sediment type.

5.13 Variations for total carbon by sampling trip.

5.14 Variations for total in organic carbon by sediment type.....

5.15 Box and whisker for bulk density by sediment type. .68

5.16 Box and whisker for bulk density by deployment and sediment type..

5.17 Variations for bulk density by sediment type. .70

5.18 Variations for bulk density by sampling trip.. .71

5.19 Box and whisker for total $\mathrm{pH}$ by sediment type... .72

5.20 Box and whisker for percent organic matter by sediment.. .73

5.21 Box and whisker for percent organic matter by deployment and sediment type.......74

5.22 Variations for percent organic matter by sediment type.. .75

5.23 Variations for percent organic matter by sampling trip. .76

5.24 Box and whisker for percent water content by sediment type.

5.25 Variations for percent water content by sediment type.. .78

5.26 Variations for percent water content by sampling trip. .79

5.27 Box and whisker for total phosphorus in the water column by site location .81 
5.28 Box and whisker for total phosphorus in the water column by deployment and sampling type.

5.29 Variations for total phosphorus in water by sampling date. .84

5.30 Box and whisker for total nitrogen in the water column by site location. .85

5.31 Variations for total nitrogen in water by sampling date..

5.32 Box and whisker for total organic carbon in the water column by site location.

5.33 Variations for total organic carbon in water by sampling date. .88

5.34 Time series analysis for dissolved oxygen during deployment 1 where YSI was positioned $0.5 \mathrm{~m}$ below water surface.

5.35 Lake wide profile for dissolved oxygen. LJ22 does not have nearly as much oxygen available then LJ28. Grouping occurs because profile was made from 4 locations..........90

5.36 Box and whisker for chlorophyll-a in the water column by site location.

5.37 Bar graph of total suspended solids within the water column at a depth around 0.5 meters.

5.38 Box and whisker of stable isotopes, $\delta^{15} \mathrm{~N}(\mathrm{a})$ and $\delta^{13} \mathrm{C}(\mathrm{b})$ within the bottom sediments of Lake Jesup by sediment type....

5.39 Bar graph of daily precipitation from the National Climatic Data Center from Sanford Airport over the two-year sampling period.

5.40 Time-series analysis of hourly wind speeds from the National Climatic Data Center from Sanford Airport, located approximate $6 \mathrm{~km}$ north of Lake Jesup, over the two-year sampling period.

5.41 Stick plots for deployment 1, the top plot is weather data from Sanford Airport , middle plot is from the weather stations on the lake, and the bottom plot is current measured on the lake over time.

5.42 Variations in total mass accumulation rate (MAR) from deployments 3 to 9 .98 
5.44 Variations in mass accumulation rate (MAR) for TN from deployments 3 to $9 . \quad 100$

5.45 Variations in mass accumulation rate (MAR) for TP from deployments 3 to $9 . \quad 101$

$6.1 \delta^{13} \mathrm{C}$ vs. $\mathrm{C} / \mathrm{N}$ ratio for all sediments. Points plot slightly higher and to the right due to the high productivity within the lake (from Meyers 1999). 110

6.2 Hjulstrom Curve (1935) with color blocks representing the grain size range for Lake Jesup. Green is represented by clay, blue is silt and red is sands. The shaded area represents the range in current velocities for Deployment $7 . .$.

$6.3{ }^{210} \mathrm{~Pb}$ and ${ }^{137} \mathrm{Cs}$ inventories for down core changes through time for LJ28. This figure represents no net change for deployments 6 to $9 \ldots \ldots \ldots \ldots \ldots \ldots \ldots \ldots \ldots \ldots \ldots \ldots \ldots \ldots \ldots \ldots \ldots \ldots \ldots \ldots \ldots \ldots . . . . .112$

6.4 From Cable et al (1997) representing lake zones that were later modified to create the

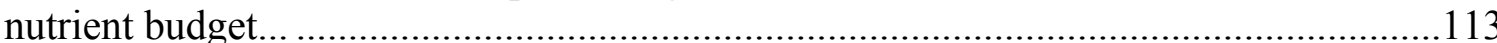

6.5 Zoning areas for the nutrient budget. a) represents the zoning when data is not available for LJ44, b) is the zooming with all four locations 


\section{INTRODUCTION}

Freshwater resources are critically important for life on earth, however they only amount to approximately $0.017 \%$ of the total global water volume available (Wetzel 2001). Therefore, studying and understanding these freshwater sources are important for current and future populations. Florida has approximately 7,700 lakes that are over $4 \mathrm{~km}^{2}$ in size and freshwater covers roughly $8 \%$ of the total area of the state (Ali et al. 1988). Lakes are also an extremely valuable natural resource, as they provide a habitat for Florida's diverse communities of flora and fauna, as well as, our domestic, industrial, agricultural and recreational activities and are a source for drinking water. Therefore, it is necessary to understand lake processes and what effects these internal processes have on water quality.

Unfortunately, the misuse of these lakes in previous years has caused unnatural shifts to increasingly eutrophic conditions, changing from macrophyte dominated to phytoplankton-dominated communities, as observed in Lake Harney and Lake Monroe (Anderson et al. 2004, 2006). The shift to phytoplankton-dominated communities increases the lakes productivity, which may cause anoxic events caused by algal blooms, which in turn, can cause fish kills within these lakes (Ali and Alam 1996).

Eutrophication is defined as a nutrient-rich lake environment where planktonic activity is high, water clarity is low, dissolved oxygen (DO) often drops below levels needed to support fish and high amounts of sediments accumulate at the lake bottom (Ali and Alam 1996). A shift to a eutrophic environment can be natural, however in some cases can be caused by the increase of nutrient supply into the lake by human activities, such as, urban or agricultural run-off (Phelps and German 1996). Nutrients that are 
associated with eutrophication are high levels of phosphorus and/ or nitrogen (in freshwater lakes TSI is associated with phosphorus).

Many Florida lakes and lakes around the world, have experienced increased nutrient loading over the recent century from the urban and agricultural run-off of the surrounding lands, producing eutrophication (Ali and Alam 1996). Lake Jesup is no exception. Human caused eutrophication is often referred to as cultural eutrophication, where run off from human activities causes lake productivity to increase (Carpenter et al. 1998). In natural settings, eutrophication takes centuries to occur, but cultural eutrophication can cause the lake to become eutrophic in decades, speeding up the process. Commonly

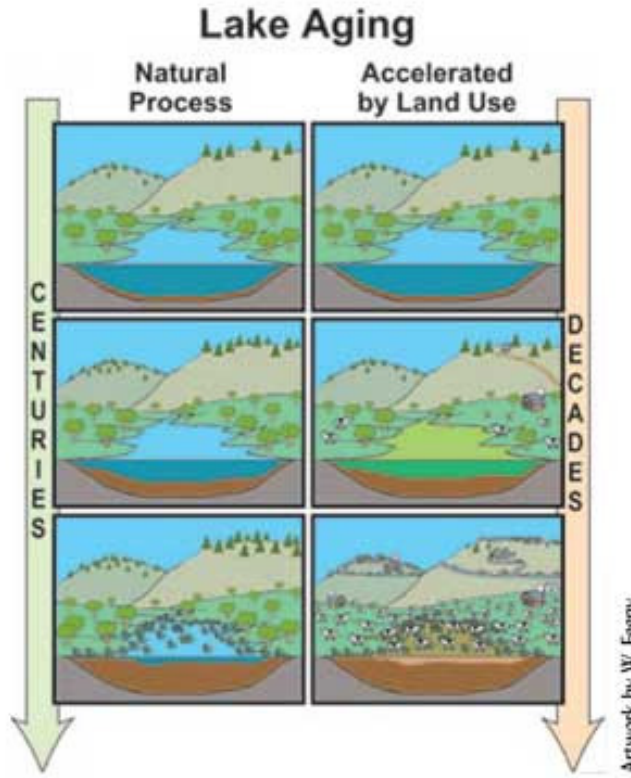

FIGURE 1.1 A comparison of natural eutrophication versus cultural eutrophication for a lake environment. intermittent algal blooms become more frequent (Henderson-Sellers and Markland 1987) (Fig. 1.1).

The Lake Jesup watershed has undergone intense urban development and agricultural activities since the 1920's (Cable et al. 1997), which has caused the lake to become hypereutrophic, because of nutrient loading (Keesecker 1992). In 1977, the U.S. Environmental Protection Agency (U.S EPA) stated that Lake Jesup was one of the most eutrophic water bodies in the state of Florida, associated with secondary wastewater inputs into the lake for over 20 years, beginning sometime in the 1960's (Keesecker 
1992). These inputs are thought to have contributed to a thick, muddy, nutrient-rich, organic layer on the lake bottom.

The floc or "fluid mud" layer is thought to form by the liquefaction of underlying sediments through wave action or by an imbalance between settling and current fluctuations often associated with rivers (Bachman et al. 2005). A study done in nearby, Lake Apopka (a shallow hypereutrophic lake, similar to Lake Jesup), suggested that the loss of macrophyte dominance within the lake exposed the bottom sediments to enhanced wave action, which made it easier for sediments to be disturbed through a process called liquefaction (Bachman et al. 2005). Liquefaction of consolidated sediments within lakes by wave action, is the process of waves acting on the finer grained bottom sediments, causing the sediments to break up and displace to form a fluid mud layer, which can easily be resuspended (Bachman et al. 2005).

Resuspended sediments of shallow lakes are a possible cause for poor water quality (Evans 1994; Lijklema et al. 1994; Bachmann et al. 2000). Wave action, water mixing, animals and currents, especially in shallow lakes, can cause resuspension of sediments (Evans 1994; Bloesch 1995). Resuspension can cause a recycling of nutrients, such as, phosphorus from the sediments (Newman and Reddy 1992) and meroplankton cells (Carrick et al. 1993; Bachmann et al. 2000), which can decrease water transparency by the resuspension of bottom sediments. The upper $10 \mathrm{~cm}$ of sediments are thought to be the sediments involved in the resuspension process into the overlying water column, (Tessenow 1972; Schindler et al. 1977; Newman and Reddy 1992); however, this depth can vary depending on sediment type and shear stress (Lee 1970; Newman and Reddy 1992). 
Sediment traps are possibly an excellent way to collect resuspended sediments, by measuring the gross sedimentation as they have the potential to collect settling of suspended sediments that deposit on the lake bottom (Kozerski 2003). High-aspect ratio traps are the most common traps used in lakes; however in order to achieve a differentiation between net and new sediment deposition, a second type of trap should be used, such as, a trap with a lower aspect ratio (Horppila and Nurminen 2005; Flower 1991), which can measure the horizontal flux (Kozerski and Leuschner 1999). Plate sediment traps are ideal for measuring horizontal flux and are best for shallow environments, such as, lakes or streams with slow moving currents (Kozerski and Leuschner 1999). In this lake system, a way of deploying different trap systems and deployment methods were tested (Fig. 1.2, 1.3 and 1.4).

Ultimately, understanding nutrients by their cycling, sources and migration can help to identify the interaction between the bottom sediments and the water column of a lake. Quantification of nutrients within the water column and bottom sediment, such as, nitrogen, phosphorus and carbon can help establish relationships between the chemistry of the sediments and the overlying water column (Ali and Alam 1996). Little research has taken place in shallow Florida lakes using sediment traps. This research will use sediment traps to help understand sediment resuspension in Lake Jesup and contribute to understanding the current conditions of the lake. Using the data collected from this research, and previous work done by Cable et al. (1997), a comparison will be made between current and previous lake conditions, contributing to an understanding of the current status of Florida lakes. 


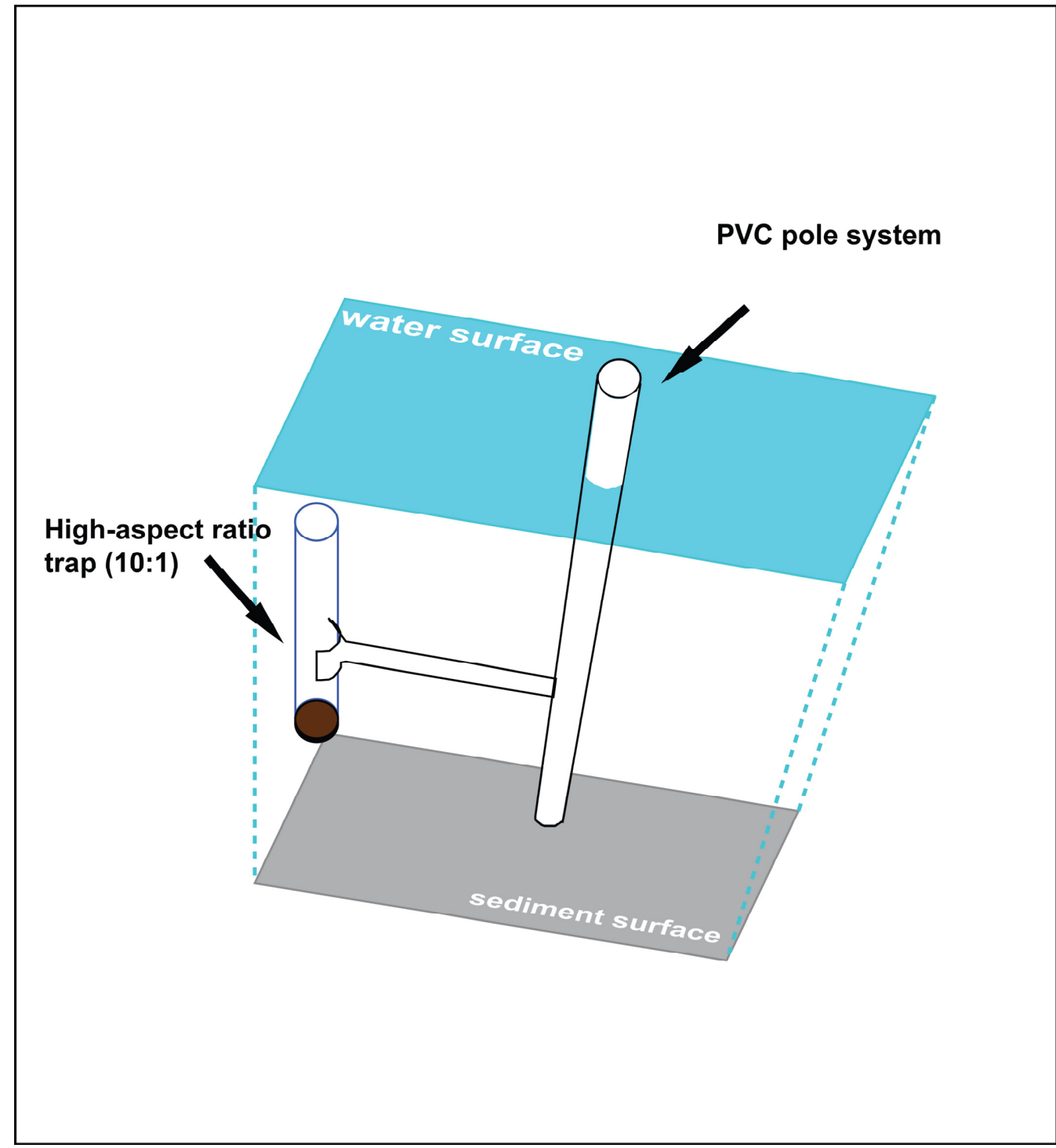

FIGURE 1.2 The original STHA trap deployment method, which were deployed using PVC pipes. However, this approach proved to be un-workable as poles were never in the original position (e.g. hit by boat). 


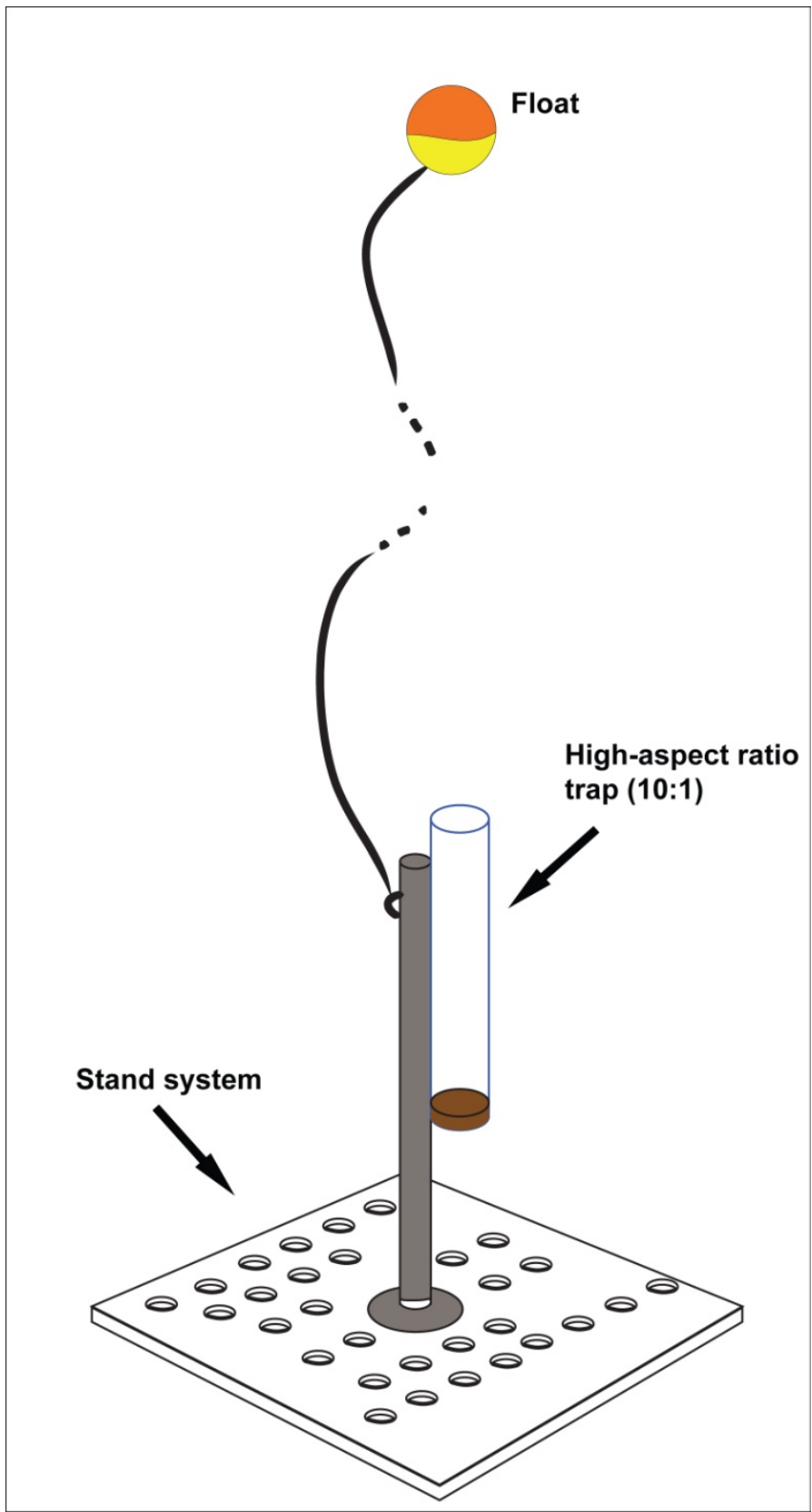

FIGURE 1.3 High-aspect ratio trap (STHA) system used for deployments 3 to 9 . This was the final design used for deployment. 


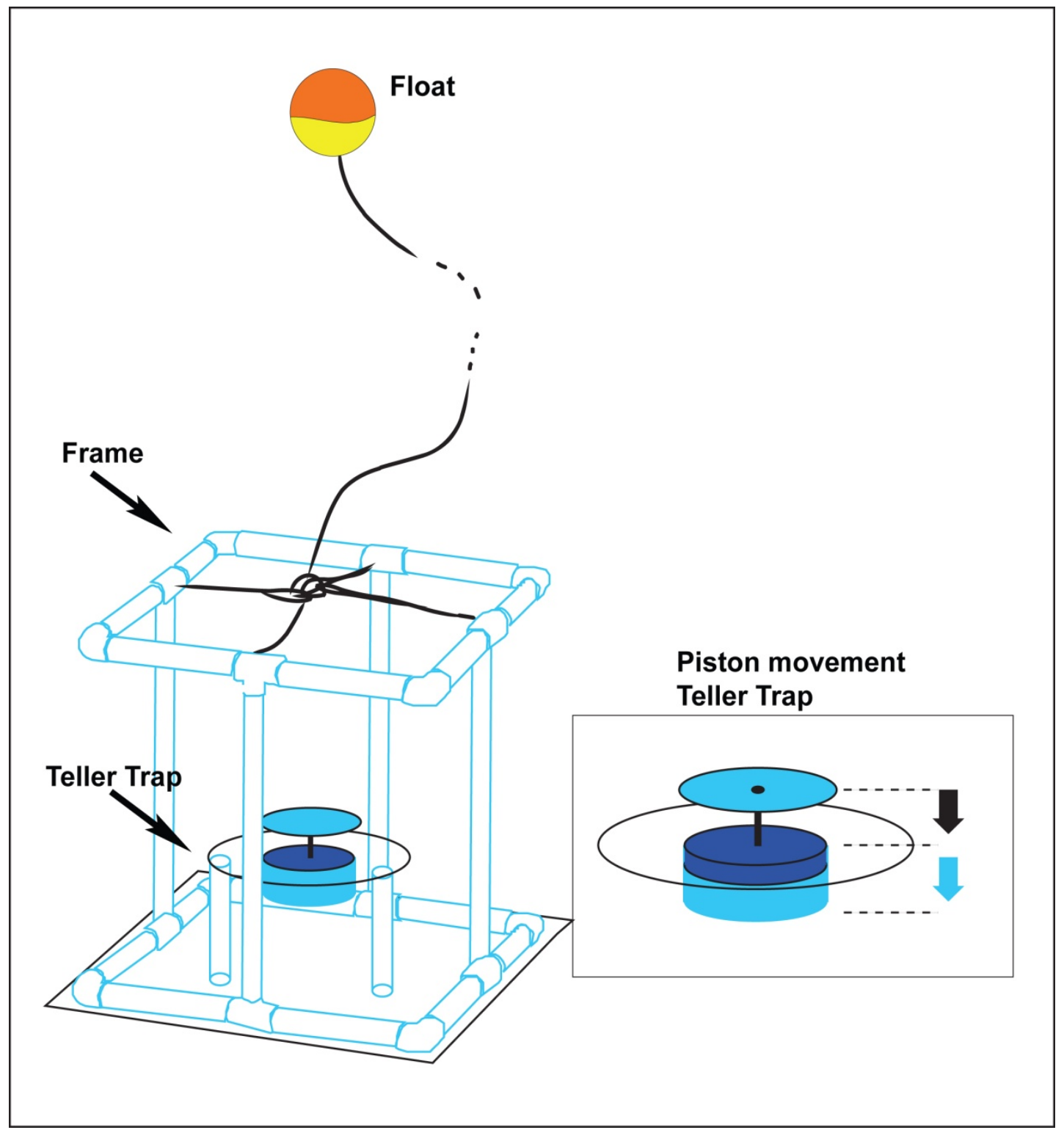

FIGURE 1.4 Teller trap or plate trap (STT) system used for deployments 3 to 5 . This was the final design used for deployment, although STT was not a successful method within Lake Jesup, because the sample was often lost during recovery. 


\section{GEOLIMNOLOGIC SYSTEMS}

Lakes receive water from many sources: rainfall directly into the lake, inflow from the land surface, or by groundwater seepage. All of these are possible sources of inputs by which nutrients can enter the system, which allow organisms to thrive in a lake environment. There are two types of nutrients: inorganic, which is found in an elemental state unassociated with carbon; and organic which is associated with carbon. Insufficient amounts of specific nutrients lead to a nutrient limited system, which restricts the growth of the lake biota. The most common limiting nutrients are phosphorus and nitrogen within a lake system (Guidford and Hecky, 2000).

Phosphorus is found in high concentrations within lake sediments, which can be 50 to 100 times greater in concentration than in the overlying water (Henderson-Sellers and Markland 1987). Therefore, sediments can be a potentially autochthonous source of phosphorus and can affect a lake's trophic state, especially in lake environments where sediment resuspension is high, such as shallow lakes. Phosphorus can enter the lake system though natural processes, such as runoff from the erosion of the rocks within the lakes watershed. Human's can cause phosphorus loading within the lake by use of phosphate fertilizers, ranching (i.e. animal waste) or municipal sewage treatment plants that discharge waste into the system directly or via tributaries.

Nitrogen, in an aquatic environment, is often found in many forms: ammonia $\left(\mathrm{NH}_{4}{ }^{+}\right)$, nitrite $\left(\mathrm{NO}_{2}^{-}\right)$, nitrate $\left(\mathrm{NO}_{3}{ }^{-}\right)$, organically bound nitrogen and as nitrogen gas $\left(\mathrm{N}_{2}\right)$. Atmospheric nitrogen $\left(\mathrm{N}_{2}\right.$ gas) is the main contributor of nitrogen into a lake system, however it can also enter the system through runoff. Humans have played an important role in increasing the amount of nitrogen in the aquatic system through the use 
of nitrogen-enriched fertilizers, fossil fuels, ranching (i.e. animal waste), sewage waste or septic tank leakage.

There are many factors that need to be considered in understanding sediment resuspension. In extremely shallow lakes resuspension is a whole lake process, as sediment can easily be disturbed by external forcings (wind, wave and currents). Other factors that need to be considered when understanding sediment resuspension are geographic location, surrounding topography, prevailing wind direction and speed, the lake size, morphometry and the lake depth (Bloesch 1995). Therefore, a shallow lake is more susceptible to sediment resuspension then a deep lake (Luettich et al. 1990; Kristensen et al. 1992; Lijklema et al. 1994).

Shallow lake environments can be more susceptible to sediment resuspension more than deep lakes because of turbulence caused by wind or wave events (Bloesch 1995). Resuspension of bottom sediments from the disruption of the overlying water column in an already nutrient rich environment may result in an algal bloom. An algal boom could then lead to low oxygen or even anoxic conditions within the water body, which may result in a lake wide fish kill.

Lake bottom currents can apply current shear stress $(\tau)$ to the sediments forcing the unconsolidated sediments to resuspend into the overlying water column. This can be quantified directly using the equation:

$$
\tau=\rho_{\mathrm{w}} \times \mathrm{C}_{\mathrm{d}} \times \mathrm{U}^{2} \quad\left[\mathrm{~N} \mathrm{~m}^{-2}\right]
$$

where $\rho_{\mathrm{w}}$ is the water density $\left(0.001 \mathrm{~kg} \mathrm{~m}^{-3}\right), \quad \mathrm{C}_{\mathrm{d}}$ is a drag coefficient $\left(1.1 \times 10^{-3}\right.$; Sternberg 1972) and $\mathrm{U}^{2}$ is current speed $\left(\mathrm{m} \mathrm{s}^{-1}\right)$ measured 1 meter above lake bottom (Bloesch 1995). Currents that are less then $0.02 \mathrm{~m} \mathrm{~s}^{-1}$ are not capable of resuspending 
non-cohesive particles $1 \mu \mathrm{m}$ in diameter (Bloesch 1995). Alternatively, current velocities greater then $0.07 \mathrm{~m} \mathrm{~s}^{-1}$ can resuspend non-cohesive particles up to $100 \mu \mathrm{m}$ in diameter. (Bloesch 1995). Figure 2.1 is a model of how sediments resuspened and settle in the water column under the influence of lateral currents.

Wind can be a driving force of sediment resuspension, creating large waves that are in depths shallower then one half the wavelength or wave base (Fig. 2.2 from Evans 1994). These waves can create a bottom scouring of the lake and cause sediments to resuspend. Wind speed sustained between 4.2 to $5.5 \mathrm{~m} \mathrm{~s}^{-1}$ (9.3 to $12.4 \mathrm{mph}$ ) is necessary before wind/wave induced resuspension can occur in most systems (Caper and Bachmann 1984).

The reintroduction of sediments into the water column is important, because it is a possible source of nutrients being released into the overlying water (Bloesch 1994; Qin et al. 2004). Figure 2.3 is a model of nutrient exchange between the sediments and the water column. This model is simplified to four sequential steps: 1) desorption, dissolution or decomposition of solid particles into pore water, 2) diffusion of the nutrient upward through the sediment, 3) diffusion into the overlying water and 4) mixing into the water column (Brezonik et al. 1976). Alternatively, when water is turbulent the model in Figure $2.3 \mathrm{~b}$ becomes a two-step process, 1) convection of sediment into the overlying water column and 2) release of nutrients into the water column (Brezonik et al. 1976). 


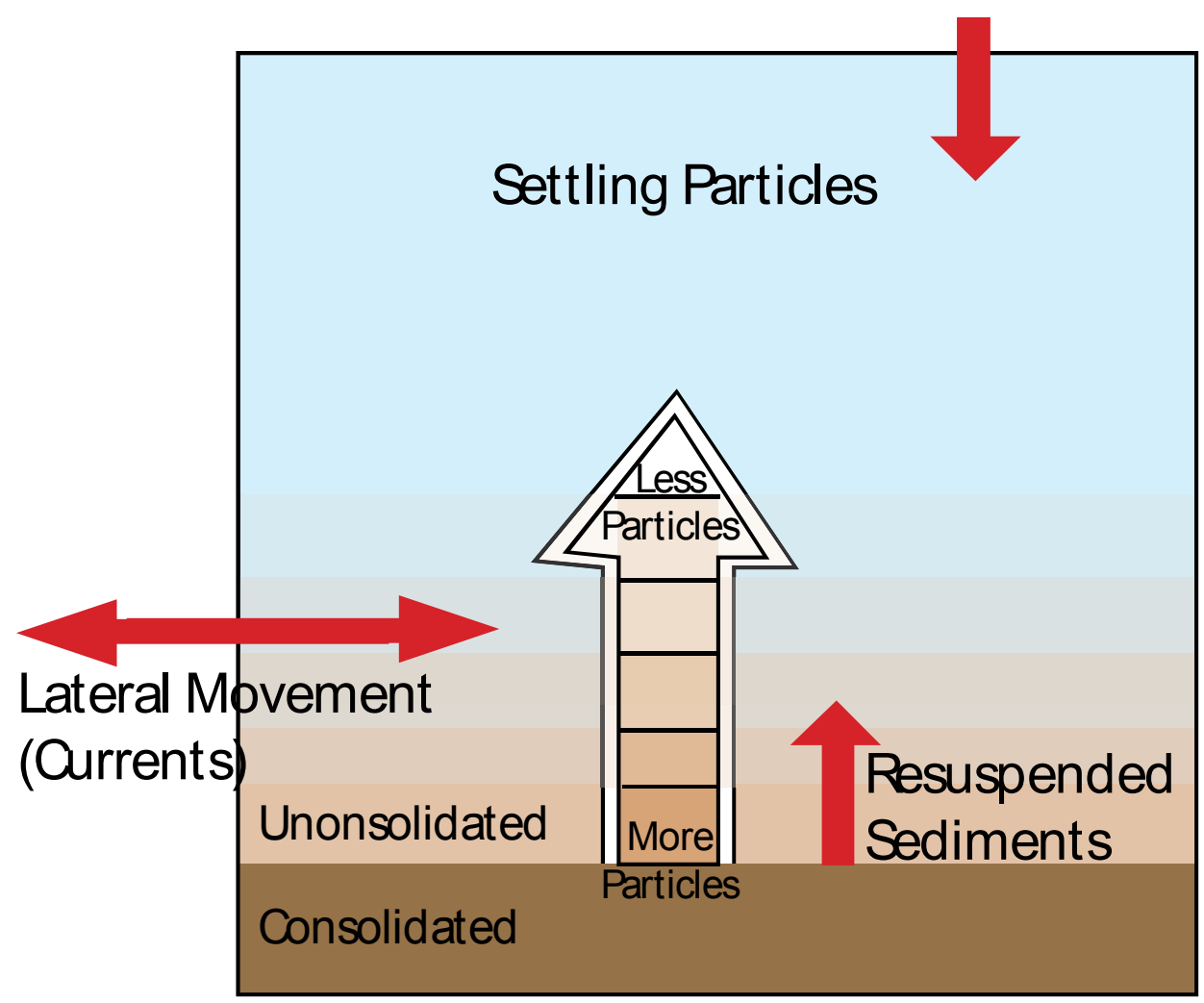

FIGURE 2.1 The model of particle movement during sediment resuspension. Sediments are resuspended by lateral movements and eventually as particle velocities decrease particles will settle out of the water.

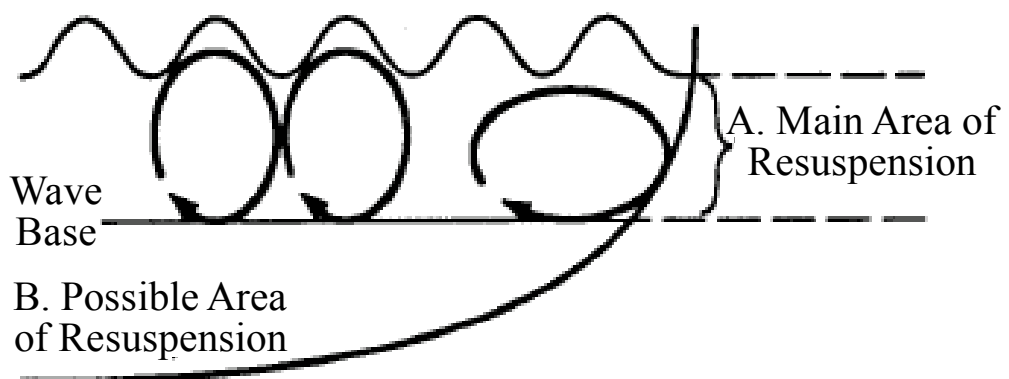

FIGURE 2.2 The two regions of sediment resuspension within a lake. A) is the main area of resuspension and B) is less frequent or below the wave base (from Evans 1994). Shallow lakes are more likely to fall under the main zone of sediment resuspension. 


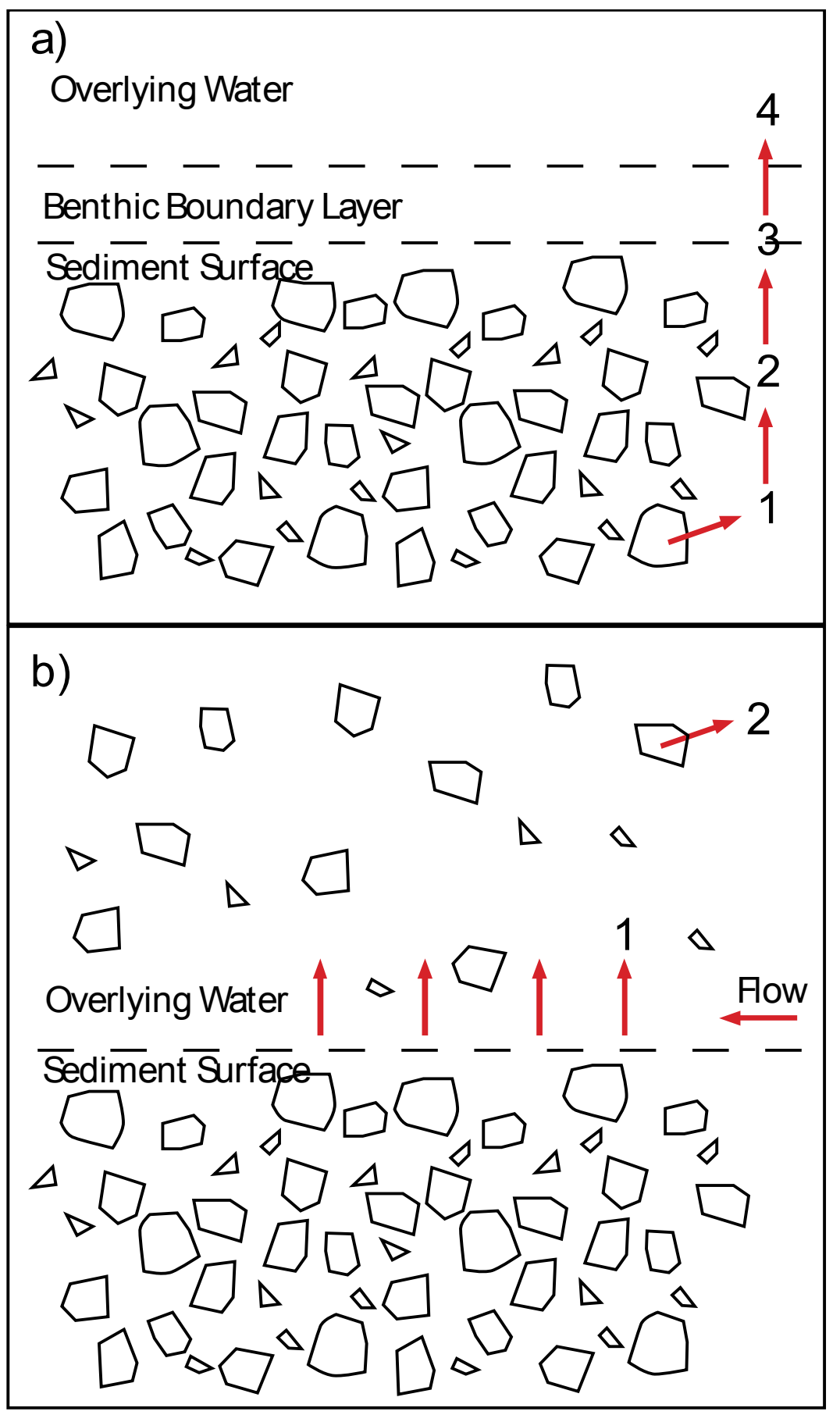

FIGURE 2.3 Model of nutrient release from sediments into the overlying water column. a) represents a simplified model of nutrient release with no turbulence, b) represents the release of nutrients from the sediment into the water column when resuspended by turbulence (from Brezonik et al. 1976). See text for model description. 


\section{SETTING}

The middle St. Johns River basin is located near Orlando, Florida and contains three large lakes: Lake Harney, Lake Jesup and Lake Monroe. These lakes are interconnected by the St. Johns River and are monitored and controlled by the St. Johns River Water Management District (SJRWMD). The SJRWMD is one of five water districts in the state of Florida and is responsible for managing the water resources and groundwater in the northeast, and north central region of the state. The St. Johns River is separated into three drainage basins: the upper, middle and lower St. Johns River. The upper St. Johns River is the area where the river begins in Indian River County and continues north to Lake Harney. The Middle St. Johns River contains the three-lake system previously described while the lower drainage basin extends from Lake Monroe towards Jacksonville where the river spills out into the Atlantic Ocean (Fig. 3.1).

Lake Jesup is located in the center of Seminole County, Florida $\left(28^{\circ} 44^{\prime} \mathrm{N}\right.$, $\left.81^{\circ} 14^{\prime} \mathrm{W}\right), 20 \mathrm{~km}$ northwest of the Orlando International Airport and is considered to be hypereutrophic (Cable et al. 1997). The St. John's River connects with Lake Jesup in the northeastern part of the lake with limited connection to the river. The average lake temperature ranges between $12{ }^{\circ} \mathrm{C}$ to $27^{\circ} \mathrm{C}$ and the lake has a residence time of 40 to 100 days (Kenney 2002). The lake has a surface area of $43 \mathrm{~km}^{2}$ with an average depth of 1.3 m. Lake mixing is polymictic. Lake Jesup has limited flushing as a result of poor circulation in the ellipse shaped lake, where the eastern and central regions of the lake do not mix well with the western region (Cable et al. 1997). Another contributing factor for poor lake circulation could be associated with state road 46 (SR-46), which cuts across 
the northeastern neck of the lake. However, as of January 2010 SR-46 has since been removed and an elevated bridge was built to take its place.

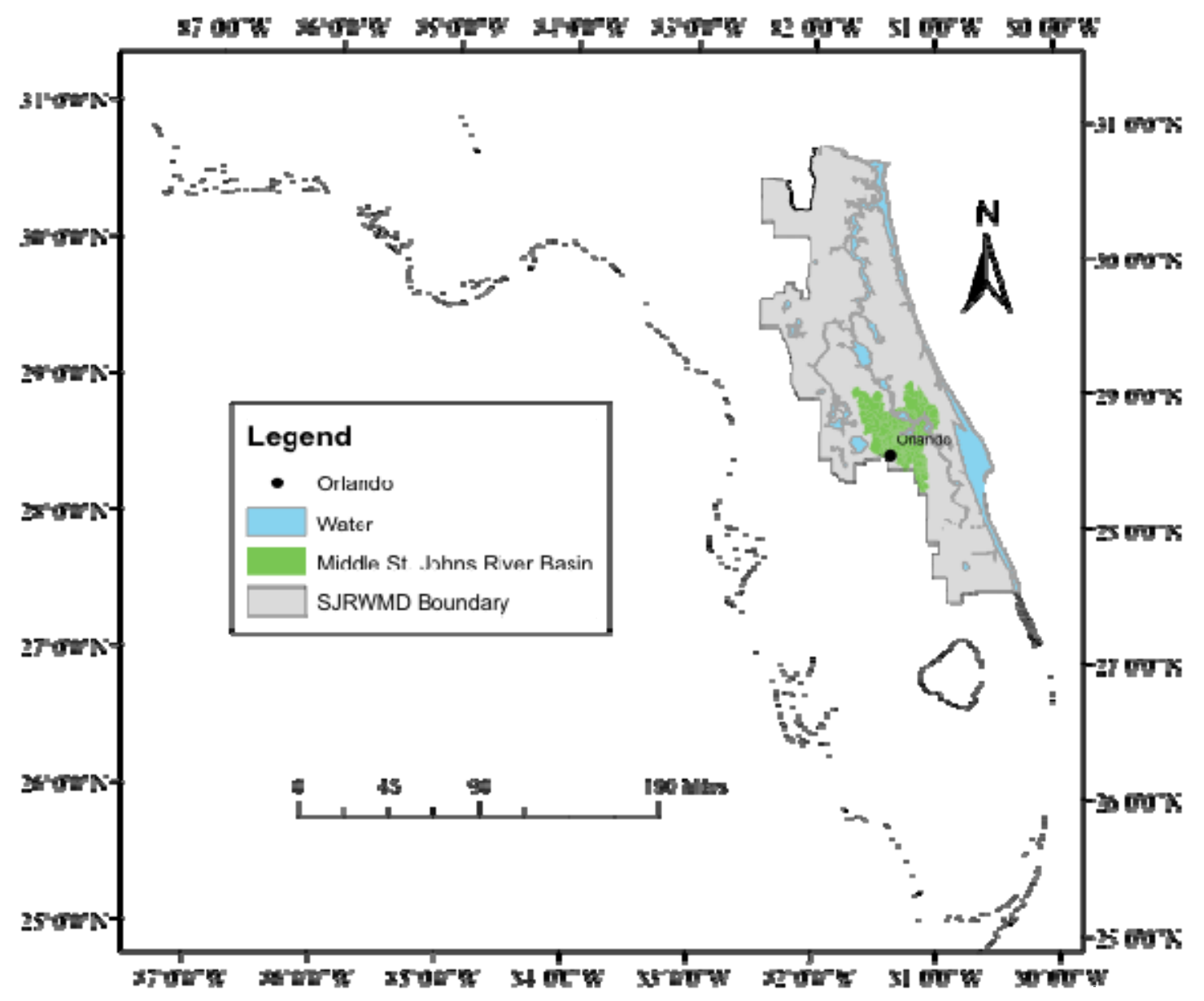

FIGURE 3.1 Location of study site depicting the St. Johns River Water Management District (SJRWMD) boundary and the middle St. Johns River Basin (MSJRB) relative to the St. Johns River (SJR) (image created in ArcGIS by data from SJRWMD). 


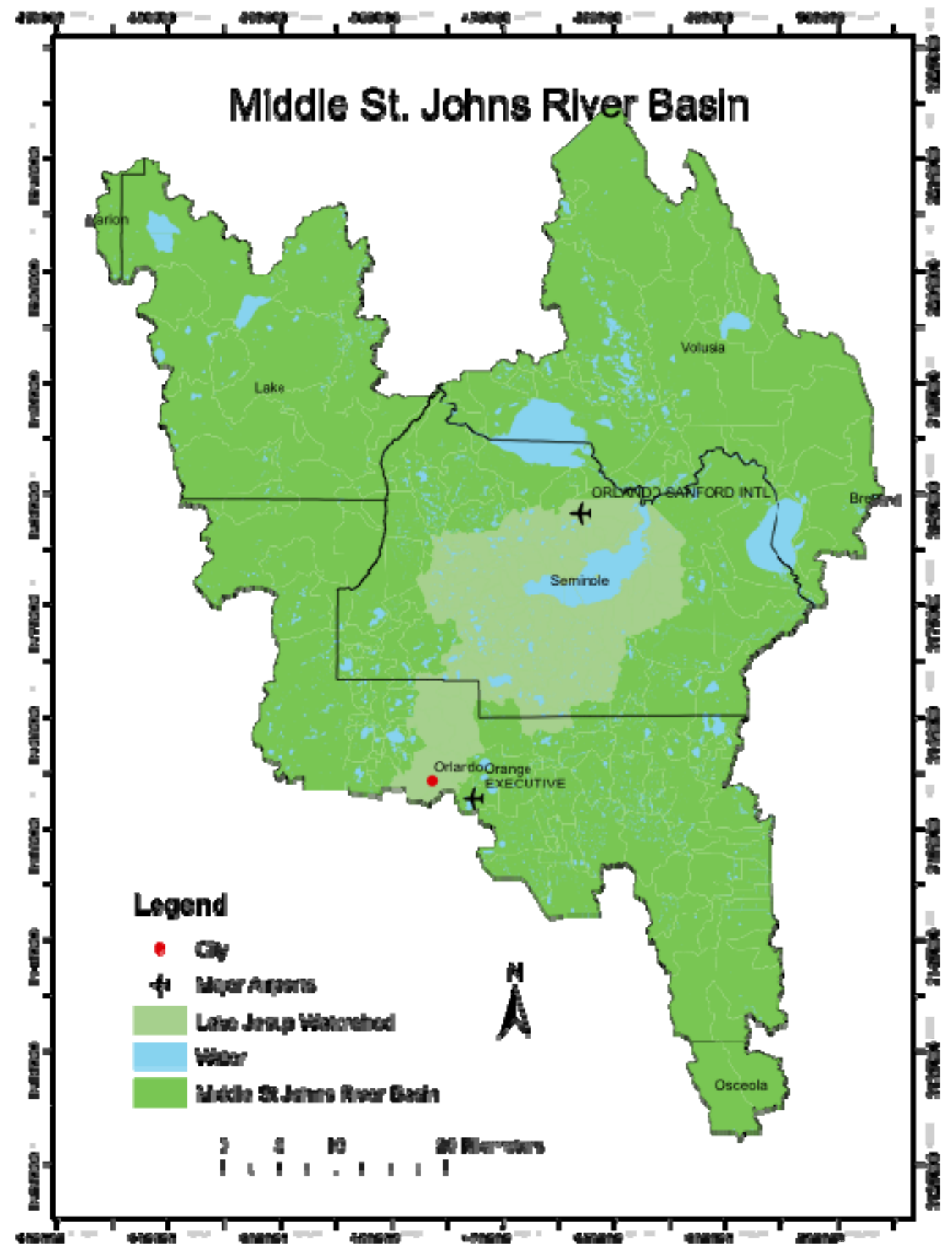

FIGURE 3.2 The MSJRB and Lake Jesup watershed relative to Orlando and the locations of the three lake system: Lake Monroe, Lake Jesup and Lake Harney (image created in ArcGIS by data from SJRWMD). 


\subsection{Regional Settings}

The Middle St. Johns River Basin (MSJRB) contains three watersheds interconnected by the St. Johns River. These watersheds are named after the large lakes they embody: Lake Monroe, Lake Jesup and Lake Harney (Fig. 3.2). Lake Jesup has poor connection with the St. Johns River, entering and exiting in the northeast portion of the lake. The St. Johns River is the main tributary into Lake Jesup, where Lake Harney drains into Lake Jesup and Lake Jesup drains into Lake Monroe all via the St. Johns River. There are many creeks and canals that drain into the lake within the Lake Jesup's 400 $\mathrm{km}^{2}$ (approximate) watershed, the three largest drain into the western part of the lake: Gee Creek, Howell Creek and Soldier Creek (Fig. 3.3).

\subsection{Historical Changes}

The climate in this area is considered humid subtropical with January having the coldest monthly average of $14.8^{\circ} \mathrm{C}$ and July the hottest at $27.5^{\circ} \mathrm{C}$, according to the National Climatic Data Center from 1971 to 2000 (Orlando Stanford station, 2848’N, $\left.81^{\circ} 16^{\prime} \mathrm{W}\right)$. The total average precipitation from 1971 to 2000 was $130 \mathrm{~cm}$ with the wettest months from May to October. The heaviest urbanized area within the Lake Jesup watershed is the city of Orlando, which is located in the southwest corner of the watershed area. The population has steadily increased in the last century within the watershed. According to the United States Census Bureau, population from 1970 was almost 100,000 people and increased to almost 250,000 people by the year 2000 (Fig. $3.4)$. 


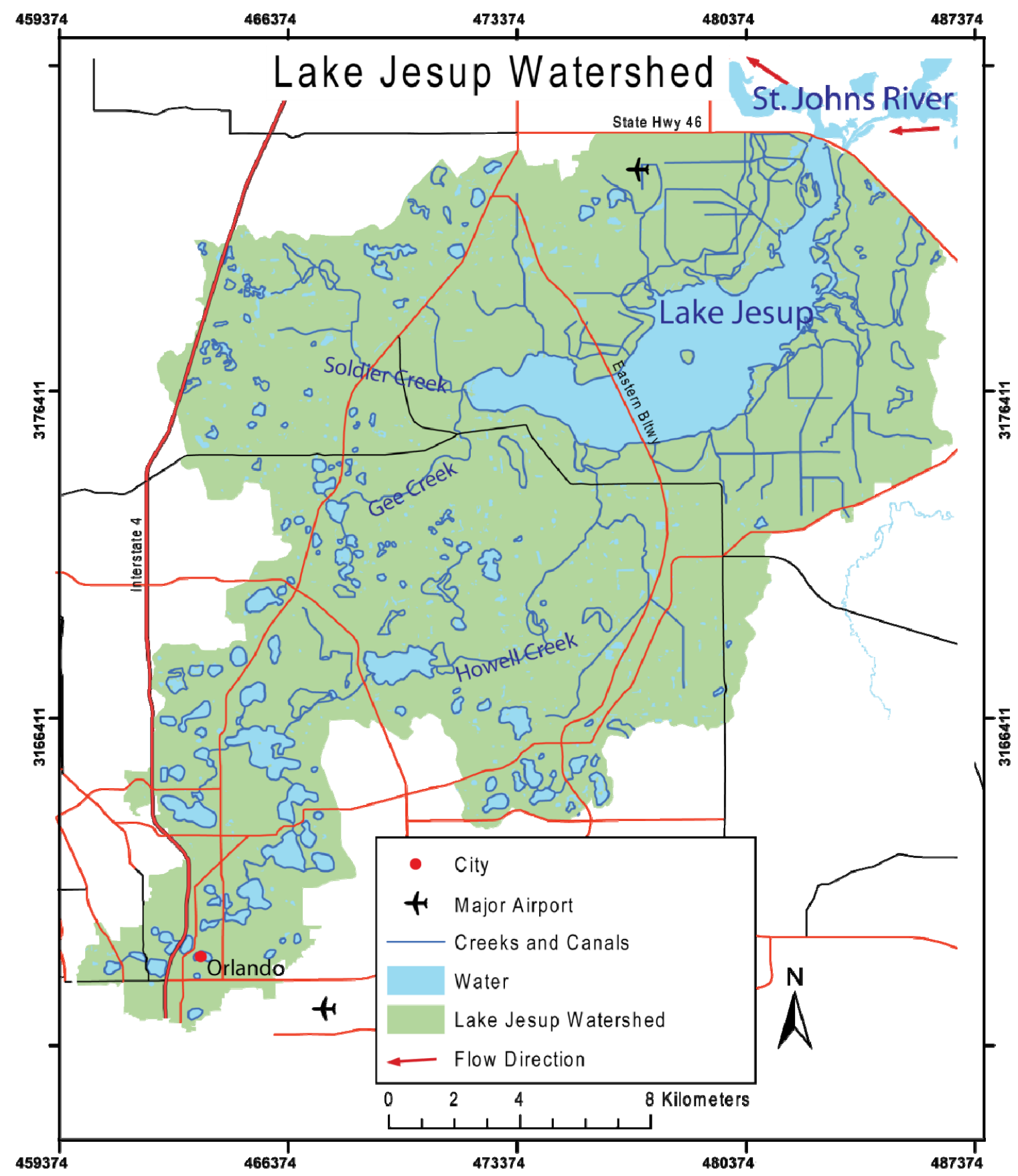

FIGURE 3.3 The Lake Jesup Watershed relative to the St. Johns River containing roads, canals and creeks (image created in ArcGIS by data from SJRWMD). 


\section{Lake Jesup Watershed Population}

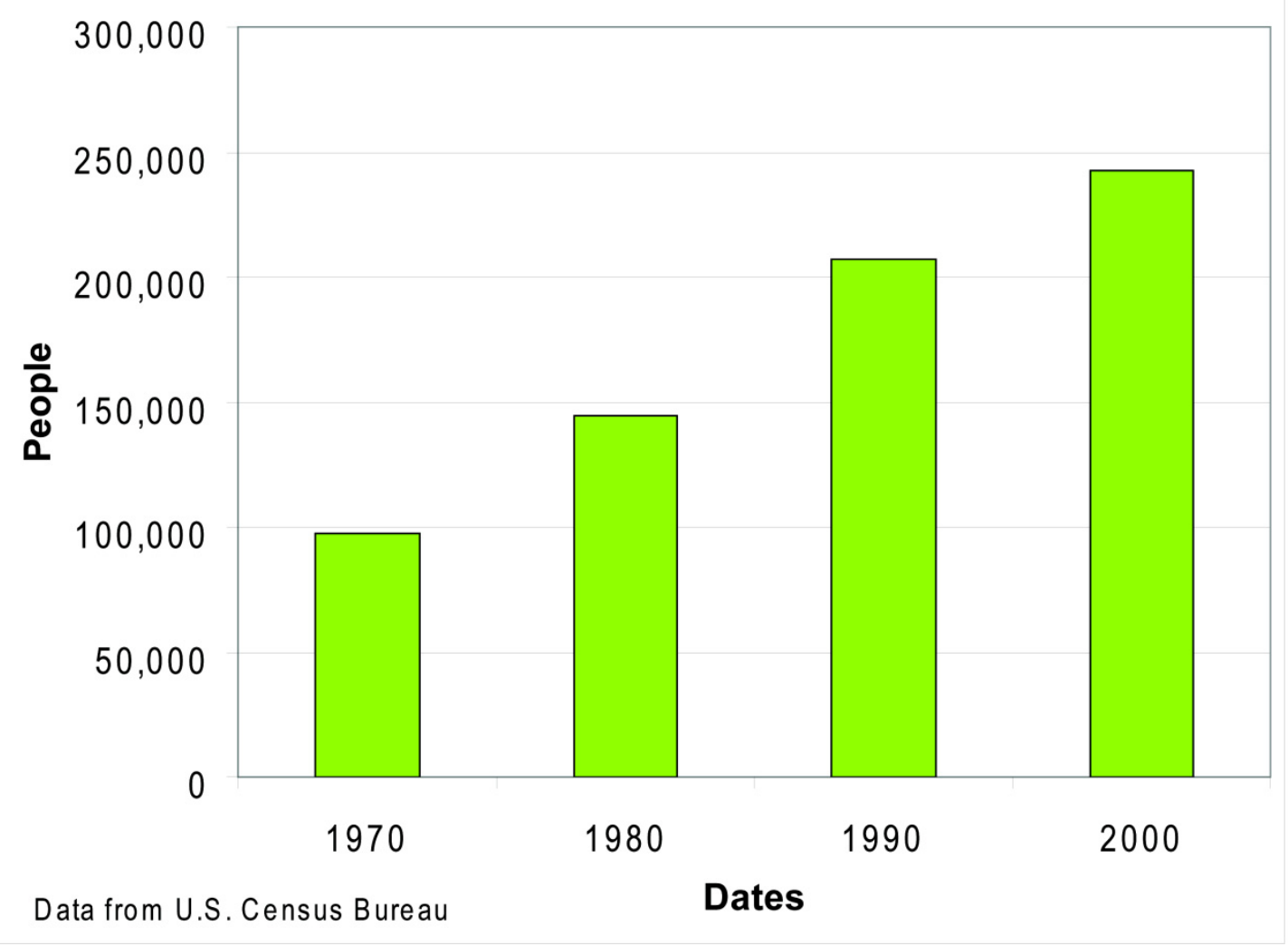

FIGURE 3.4 Population growth from 1970 to 2000.

The current land use within the Lake Jesup watershed according to the SJRWMD is roughly 50\% Urban (including utilities and transportation) and 31\% water and wetland areas. The remaining $19 \%$ is made up of open areas, pastures, rangelands, forests and agriculture (11\% of the remaining 19\%) (Fig. 3.5a, c). Historical land use suggests that the urban areas were smaller and agricultural, forests, rangelands, pastures and open lands were much larger. Using ArcGIS and data from SJRWMD, a potential land use assessment was made from aerial photographs suggesting that the land use in 1973 was $30 \%$ urban (including utilities and transportation), 15\% water and wetlands and 55\% 
remaining open areas, pastures, rangelands, forests and agriculture $(22 \%$ of the remaining $55 \%$ ) (Fig. 3.5b, d).

The area surrounding the Lake Jesup watershed was first settled post Native American colonization as early as the mid 1800's near the current town of Oviedo (Winn 2003). Farming became one of the major economic factors during this time. Initially farms began growing cotton and sugar cane, but were unsuccessful. After these efforts, the planting of vegetables and citrus were successful, marked an agricultural explosion in the area. Before 1895, the town of Sanford was the largest shipper of citrus in the world, however, there was a hard freeze in 1885 causing farmers to switch to vegetable crops, ferns and the raising of cattle. By 1950, almost one million crates of celery and 330,000 crates of citrus were being shipped annually with only 1,800 people populating Oviedo. Agriculture still takes place in this region, but has a much smaller role than in previous years. Besides the agricultural explosion that took place over the last century, there were also major modifications to Lake Jesup, particularly the construction of roads and canal modifications. As early as the 1910's the area where the St. Johns River enters the lake was modified by building a causeway now known as State Road 46 (SR46). Simultaneously two canals were built to allow for easy access for ferries and steamboats named the Old Ferry Canal and Government Cut Canal. These modifications are thought to have been the main cause for cutting off the circulation of inflow and outflow from the St Johns River into Lake Jesup. Since the 1960's, reports of four documented fish kills took place; 1960, 1968, 1981 and 1985 (Cable et al. 1997). 


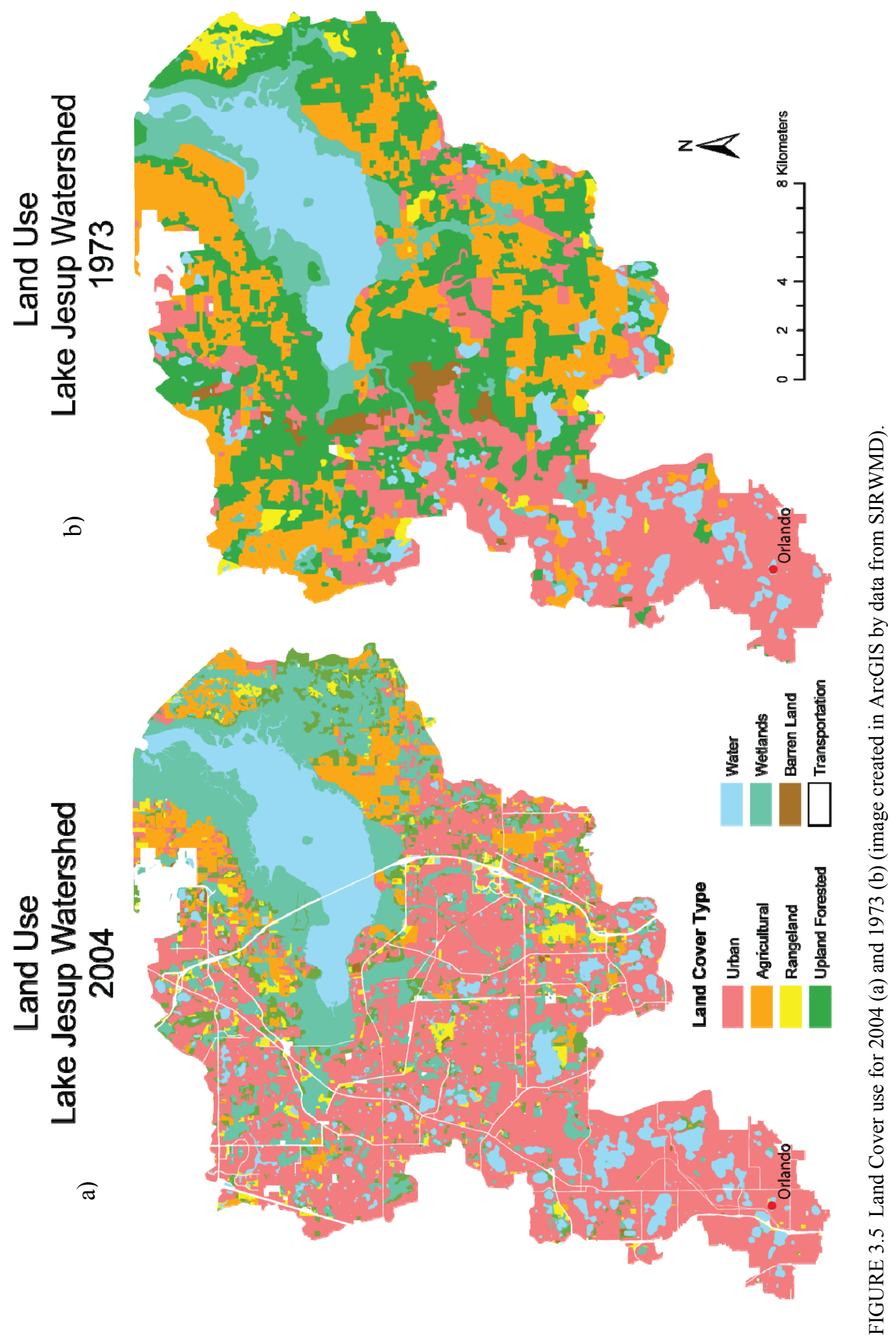




\section{Land Cover 1973}

c)

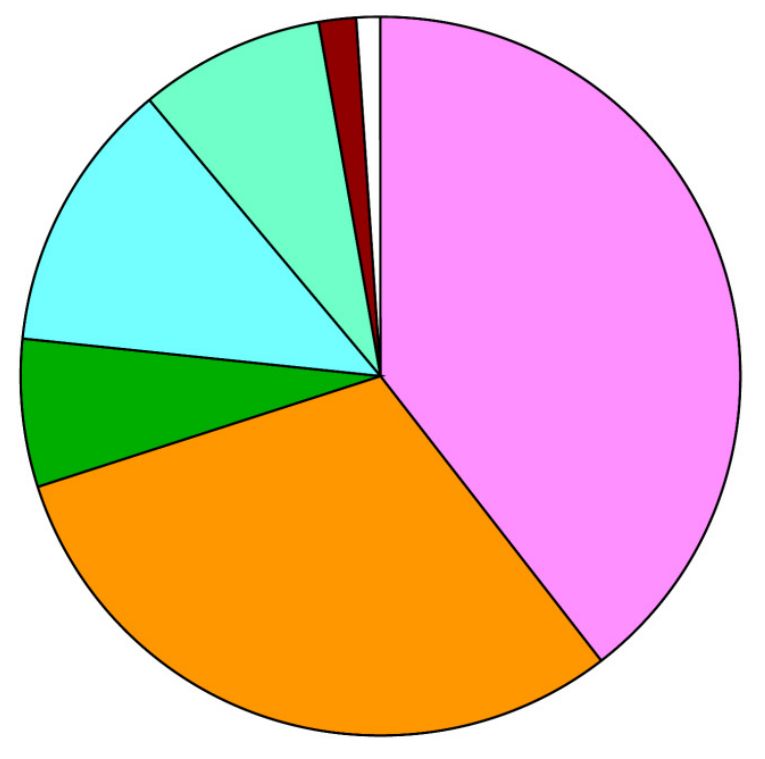

\begin{tabular}{|l|r|}
\cline { 2 - 2 } \multicolumn{1}{c|}{} & $\%$ \\
\hline$\square$ Urban & 39 \\
\hline$\square$ Agricultural & 31 \\
\hline$\square$ Rangeland & 7 \\
\hline$\square$ Upland Forested & $<1$ \\
\hline$\square$ W ater & 12 \\
\hline$\square$ W etlands & 8 \\
\hline$\square$ Barren Land & 1 \\
\hline$\square$ Transportation & 1 \\
\hline
\end{tabular}

d)

\section{Land Cover 2004}

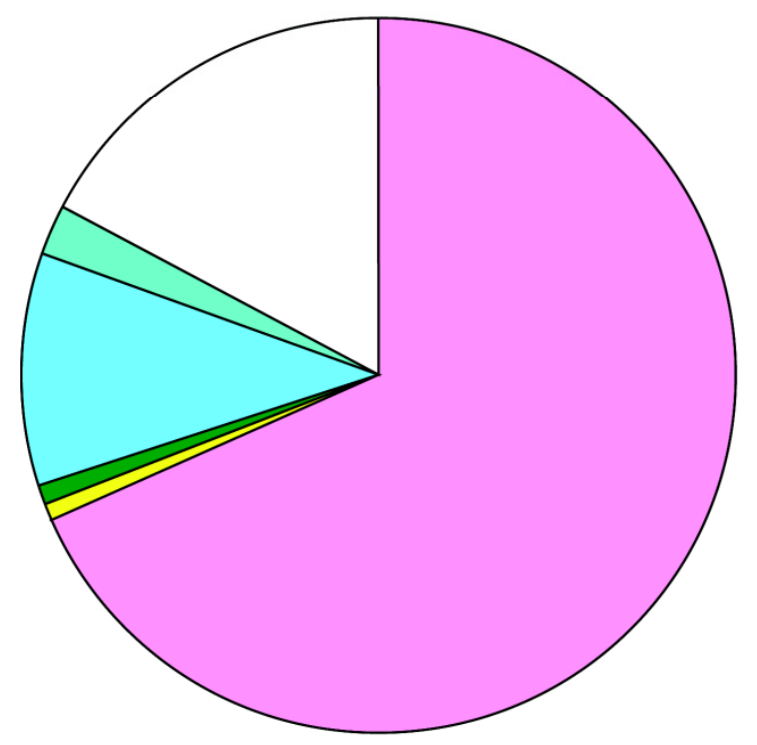

\begin{tabular}{|l|r|}
\cline { 2 - 2 } \multicolumn{1}{c|}{} & $\%$ \\
\hline$\square$ Urban & 68 \\
\hline$\square$ Agricultural & $<1$ \\
\hline$\square$ Rangeland & 1 \\
\hline$\square$ Upland Forested & 1 \\
\hline$\square$ W ater & 11 \\
\hline$\square$ W etlands & 2 \\
\hline$\square$ Barren Land & $<1$ \\
\hline$\square$ Transportation & 17 \\
\hline
\end{tabular}

FIGURE 3.5 Percent Distribution of land cover area for the Lake Jesup watershed (calculated from SJRWMD data for land cover). c) 1973, d) 2004. 
Water hyacinth caused major problems for the Lake Jesup fisheries. Cable et al (1997) stated that these hyacinths were first introduced to the St. Johns River in 1896 and reported to be all over the river by 1899 . Before 1983, Lake Jessup had large amounts of secondary wastewater that for over 20 years was input into the lake from three of the lakes' tributaries (EPA 1977; Seminole County 1991; Gao 1996). There were a total of six discharge pipes and one effluent pipe that entered into Lake Jessup from Howell Creek, Gee Creek and Soldier Creek (Cable et al. 1996). Gee Creek and Howell Creek each had three drainage pipes that carried storm water and runoff from the surrounding urban communities into Lake Jesup. Soldier Creek was the site of a water treatment plant that discharged into the creek and thus Lake Jesup. By 1984, the pipes had been diverted away from Lake Jesup and its tributaries. This wastewater input, coupled with the rapid development of the watershed following waste diversion and poor circulation are thought to be the cause of an accumulated layer of soft unconsolidated sediment on the bottom of the lake called floc (Cable et al. 1997). Cable et al. (1997) also observed that the areas where wastewater was diverted into the lake had thicker flocculent layers relative to other regions of the lake.

\subsection{Geological Setting}

The surrounding surface rock types within the MSJRB date back to as late as the Eocene (Approximately 35 million years old) with the deposition of the Oscala Limestone, which consists of skeletons of fossils in a silt to sand matrix (all descriptions from SJRWMD). Massive chert nodules occur near the top and small spherical fossils are found at the base of this unit (Fig. 3.6). Within the basin, this outcrop is found west of 
Lake Jesup near the MSJRB border. Two different deposits of the Hawthorn Group are found here, taking up a third of the western portion of the basin aging back to the Miocene (Approximately 6 to12 million years old). The older of the two deposits is from the Statenville Formation consisting of sand, silty sand and clay with phosphorite pebble and granule clasts. The younger Hawthorn Group deposits consist of interlaced quartz sand and quartzite gravel with a kaolinitic sandy clay basal unit. The central length of the basin consists of a Plio-Pleistocene aged deposit (2 to 3 Million years old) of deeply weathered sand and clayey sands. Located in the northeastern basin is the Fort Thompson Formation early to late Pleistocene in age (120 to $800 \mathrm{ka}$ ) consisting of clastic and shell limestone deposits formed in fresh water and marine environments. The Anastasia Formation, late Pleistocene in age (12,000 to 126,000 years old), is also present in the basin located northeast of Lake Harney consisting of high-energy beach and bar deposits of shelly sands, dune sands and coquina limestone. The Princess Ann Formation, late Pleistocene in age (12,000 to 126,000 years old) is present along the St. Johns River cutting across the MSJRB consisting of sand silt and clay representing lagoonal and estuarine facies.

The physiographic divisions of Florida according to Brooks (1981) were characterized using the natural features associated with rock and soil type, geologic structures of the underlying rock, geomorphic processes and relief. On the basis of these principles, ten Districts (Apalachicola Delta, Central Lake, Dougherty Karst, Eastern Flatwoods, Gold Coast-Florida Bay, Ocala Uplift, Sea Island, Southern Pine Hills, Southwestern Flatwoods and Tifton Uplands) were established with each district being 
broken into several sub-districts. The St. Johns River and its tributaries run through the Eastern Flatwoods, Central Lake, Oscala Uplift and Sea Island districts (Fig. 3.7).

\section{Middle St. Johns River Basin Geology}

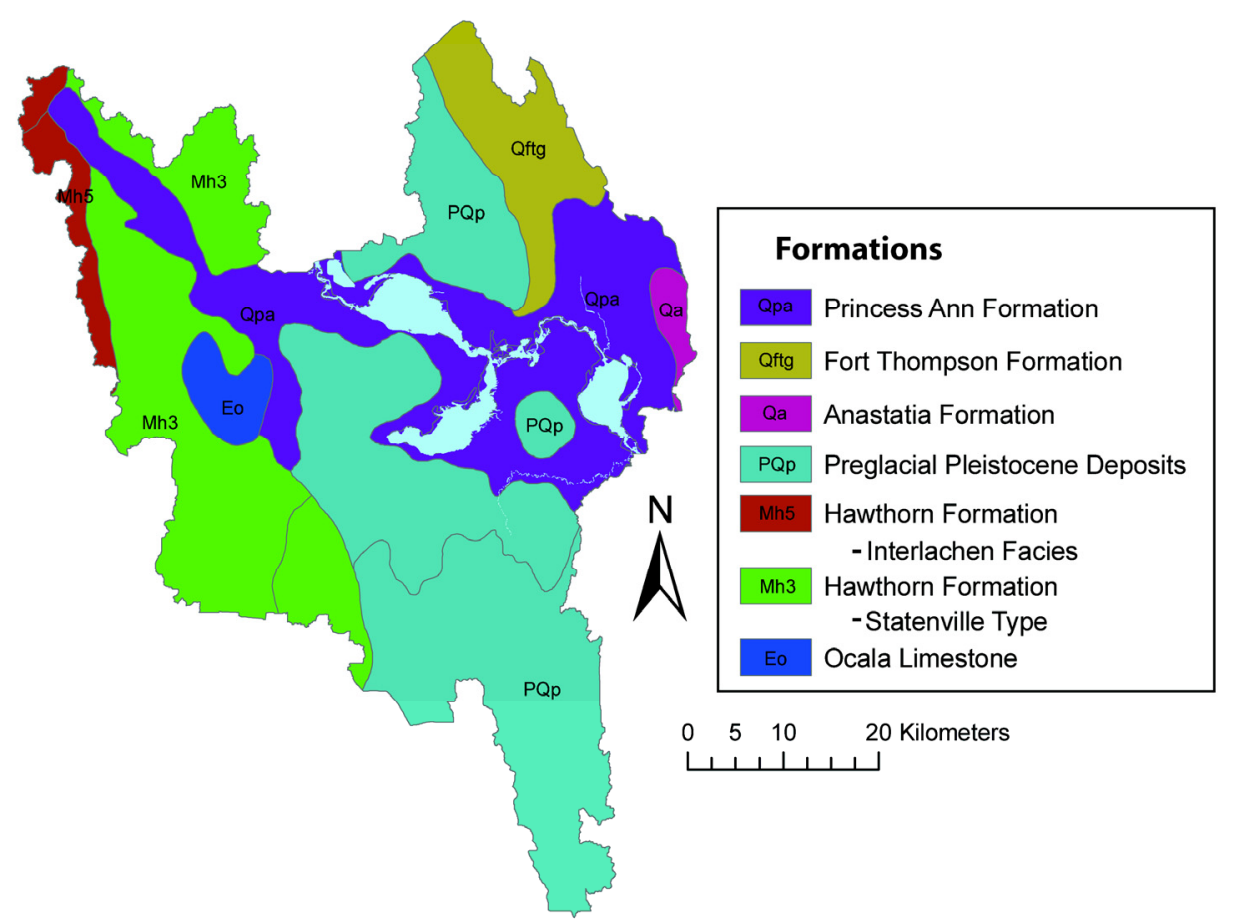

FIGURE 3.6 The geology of the Middle St. Johns River Basin (image created in ArcGIS by data from SJRWMD).

The Eastern Flatwoods District originated as barrier islands and lagoons and was formed during the Plio-Pleistocene era and recent times. The headwaters of the St. Johns Rivers can be found within the Eastern Flatwoods District in an area called the St. Johns Marsh (White 1970). To the east of the St. Johns River is the Central Atlantic Costal Strip, which is a series of ridges predominantly made up of coquinas that runs parallel to the river in this area.

As the river flows north, it then moves into the Central Lake District where the MSJRB is located. A sub-district called the St. Johns Offset is a Pleistocene estuarine 
deposit (Brooks 1981). This area is also thought to be older then the southern headwater area (Pirkle 1969; White 1970), where deposits are a part of an older river valley with estuarine fill deposits possibly as far back as the Tertiary (Brooks 1966; 1968; White 1970) era. Finally, the St. Johns River flows into the Sea Island District near Jacksonville and into the Atlantic Ocean.

\subsection{Limnologic Formation}

The St. Johns River was thought to have been formed during the deposition of the Anastasia Formation around 125,000 years ago when sea level was high during the Pleistocene, where a series of shallow lagoons formed (Winn 1975). Over time, sea level dropped and the lagoons became valleys that were then connected by streams eroding the land surface, thus creating the now named St. Johns River (Winn 1975). The lakes within the MSJRB were thought to have formed during the Pleistocene from relics of former estuaries rather then depressions from the dissolution of limestone (White 1970). 


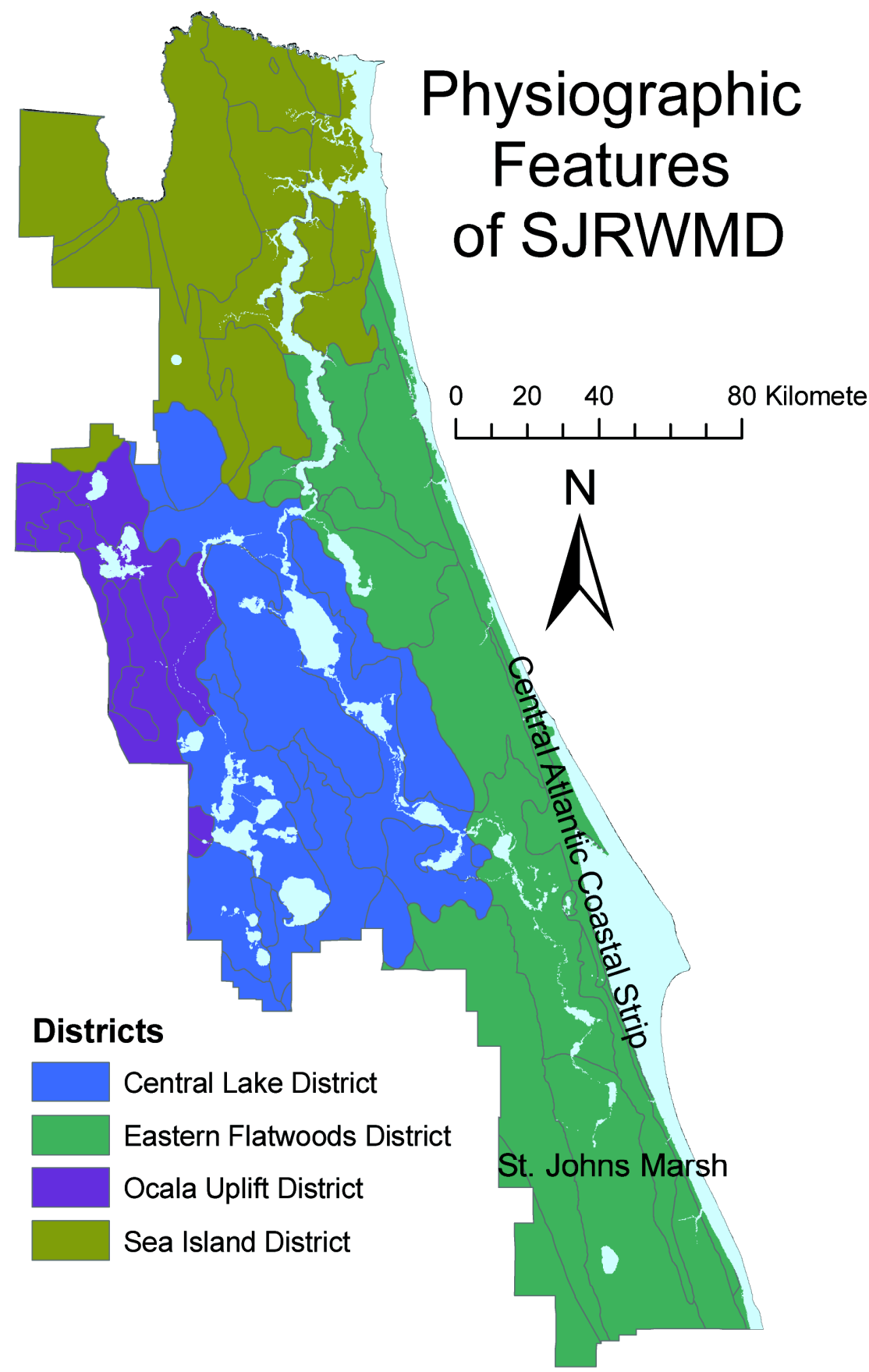

FIGURE 3.7 The physiographic districts within the SJRWMD boundary (image created in ArcGIS by data from SJRWMD). 


\section{MATERIALS AND METHODS}

Various geolimnologic approaches were used to understand the interactions between the water and the sediments. Samples of the unconsolidated flocculent organic matter (floc), lake bottom sediments (consolidated sediments), sediments from the water column and water samples were taken at various periods throughout the year ranging between one to two week intervals at three to four different sites on the lake. All sediment samples were collected by coring from a flat bottom skiff.

Lake Jesup's sample collection took place over nine deployment periods spanning two years from April 2009 to April 2011. Each deployment period lasted from one to two weeks and required a deployment and recovery of materials at each of the four sites. Lake level played a factor when deployment or recovering samples, because of various shallow locations on the lake (Fig. 4.1). All sediments (grab and trap samples) were analyzed for total nitrogen (TN), total phosphorus (TP), total carbon (TC), total inorganic carbon (TIC), $\mathrm{d}^{15} \mathrm{~N}, \mathrm{~d}^{13} \mathrm{C}, \% \mathrm{Ash}, \% \mathrm{OM}, \%$ Water, $\mathrm{pH}$ and bulk density. Piston (at depths less the $90 \mathrm{~cm}$ ) and short cores (a depth less then $36 \mathrm{~cm}$ ) were taken and split every $4 \mathrm{~cm}$ and analyzed for ${ }^{210} \mathrm{~Pb},{ }^{137} \mathrm{Cs},{ }^{234} \mathrm{Th}$, and ${ }^{7} \mathrm{Br}$ at each of the four sites. Beginning in August of 2010, the high aspect ratio traps were also analyzed for ${ }^{210} \mathrm{~Pb},{ }^{137} \mathrm{Cs},{ }^{234} \mathrm{Th}$, and ${ }^{7} \mathrm{Br}$. The surface water chemistry was analyzed at all four sites for TN, TP, chlorophyll-a (CHL-a), dissolved oxygen (DO) and total organic oxygen (TOC). An ISCO auto water sampler collected samples daily and analyzed for TN, TOC and TP (Table 4.1). 


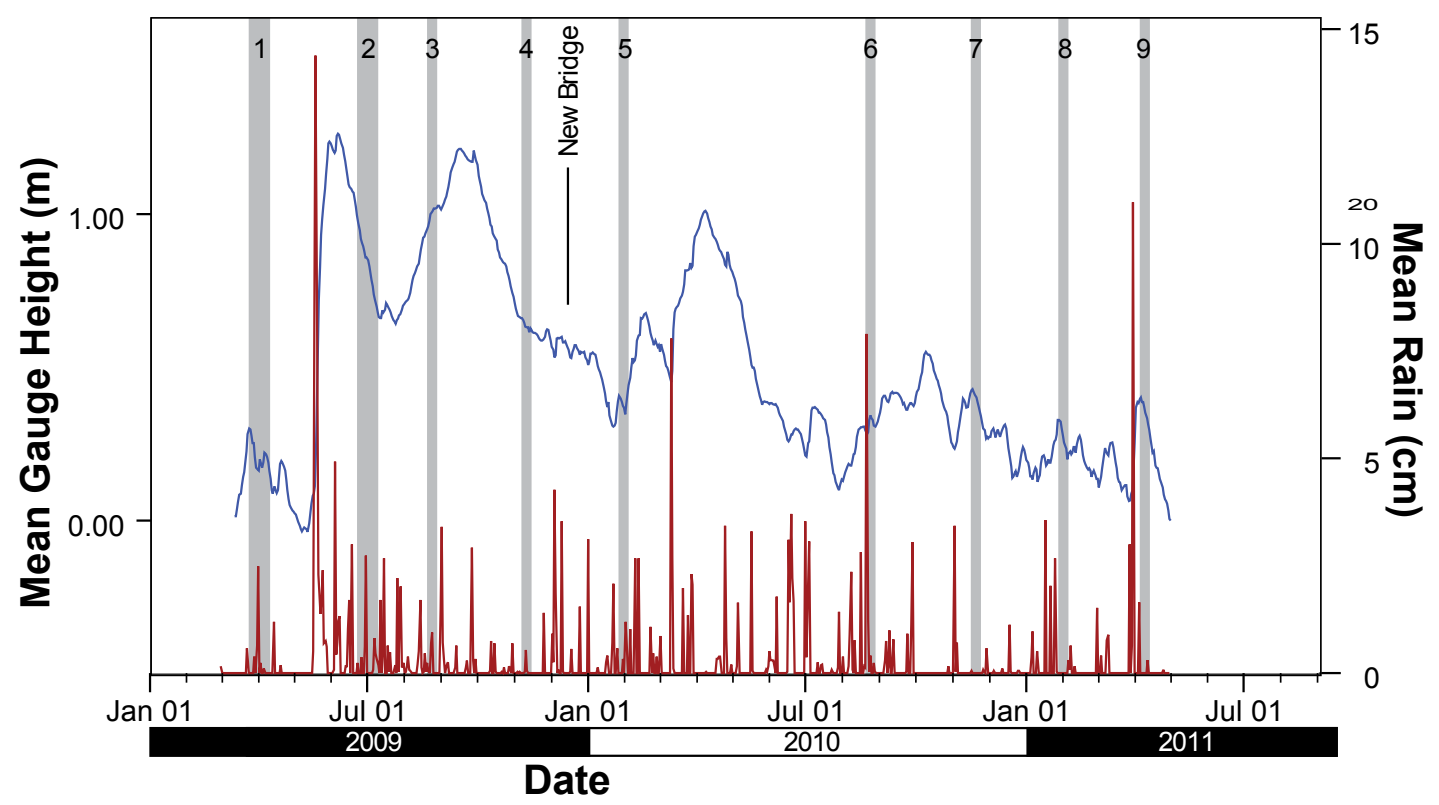

FIGURE 4.1 Daily mean lake level height (blue) and total precipitation (red) from April 2009 to April 2011. Highlighted grey areas are representative of each deployment.

\subsection{Station Selection}

Four stations were selected on the basis of previous work done by Cable et al. (1997), who selected stations by using an equal area grid of Lake Jesup. The four stations for this study were selected based on varying depth, location, floc thickness and accessibility. Stations LJ-14, LJ-22 and LJ-28 were selected at the beginning of the sampling cycle and LJ-44 was added in August of 2010. Sample site LJ-28 was selected as the barge location, because this location had a thin floc layer, was at the lakes center and was the deepest of the stations selected (Fig 4.2). 


\section{Lake Jesup and Study Sites}

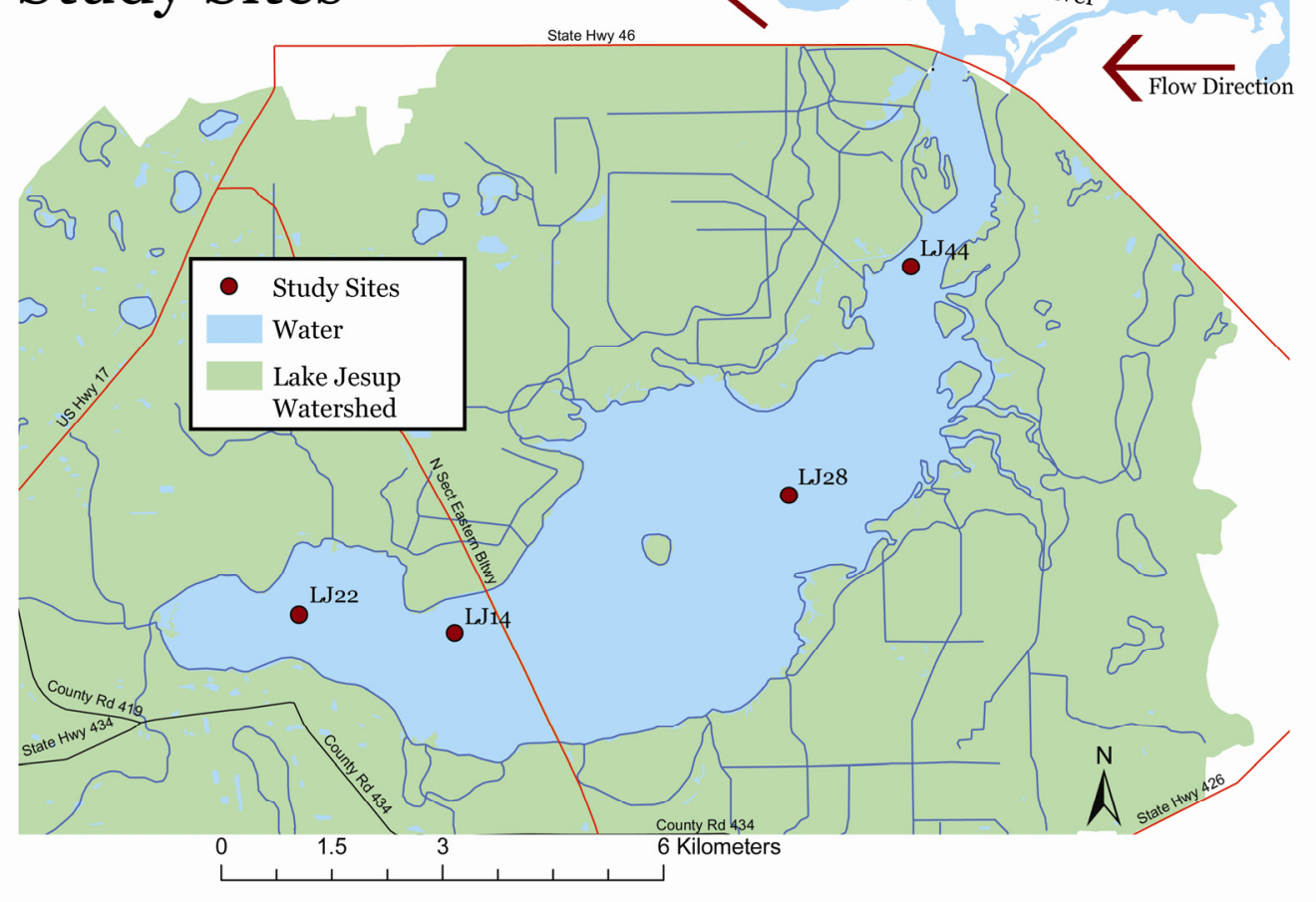

FIGURE 4.2 Sampling stations on Lake Jesup for the two year sampling period. Coordinates (decimal degrees): LJ22, $=28.7169,-81.2694, \mathrm{LJ} 14=28.7147,-81.2478$, $\mathrm{LJ} 28=28.7317,-81.2014$ and LJ44 $=28.7597,-81.1844$.

\subsection{Sediment Type}

Three main types of sediments were found in Lake Jesup: a) the top-most was floc, b) followed by gyttja and c) below that peat. Additionally, dependent on location, other sediment types we encountered including pink marl, blue clay and sands, but were found at depths which most likely exceed the area of resuspension. Shells can be found in any of the sediment layers with in the lake, but are rarely found in the floc layer. The floc layer is often called a fluid mud and is highly organic. Gyttja is more consolidated then floc and peat is more consolidated then gyttja, all types contain relatively high amounts 
of organic matter, low OM reflects samples that contained many shell fragments $(2.86 \%$ to $65.51 \%)$.

\subsection{Sample Collection}

\subsubsection{Sediment Collection}

Initial sampling periods lasted for two weeks, but were found to be problematic, because samples were lost either by theft, boats or alligators disrupting the sediment traps. After repeated trips where samples were lost a one-week sampling period was established.

Sediments were collected in three ways: grab samples, sediment traps and cores. The grab samples and cores taken for radiometric analysis were collected by using a coring device (push core), made of PVC piping with a detachable clear polycarbonate "barrel" roughly $10 \mathrm{~cm}$ in diameter for the radiometric samples and $5 \mathrm{~cm}$ for the grab samples. The coring device allows water to flow only one way with a check valve, as the core is pushed into the sediment. When the core was pulled upwards the one-way flow created suction that allowed the sediment to be brought to the surface. For the grab samples, the unconsolidated top sediments (floc) and the surficial $5 \mathrm{~cm}$ of consolidated sediments (immediately underlying the floc) were collected separately in whirl-pak bags and placed on ice. The remaining sediments in the core were discarded. The cores collecting the samples for radiometric analysis were split into $4 \mathrm{~cm}$ increments for the entire length of the collected core (between 20 to $32 \mathrm{~cm}$ depth), immediately following 
recovery from the lake bottom in the boat. Later, these samples were sent to Eastern Carolina University (ECU) for radiometric analysis.

Sediment traps were used to collect particle flux for time-series analysis. Three different trap systems were used to collect resuspended sediments in the water column: 10:1 (length to diameter) high aspect ratio sediment trap (STHA), modified plate or "teller" trap (developed by I.G.B. Berlin, pat.-Nr. 19737448.4) and the Mark8 autosampler (made by McLane Research Laboratories inc. located in East Falmouth, Massachusetts).

\subsubsection{Water Collection}

Water samples were collected in two ways, surface "grab" and with an automated water sampler (ISCO) daily. The water grab samples were collected at the same time as the sediment grab samples at all four sites during a deployment period. The collected water was split immediately following fieldwork at the dock, into filtered $(0.45 \mu \mathrm{m}$ nitrocellulose membrane filters), unfiltered samples, and, chlorophyll-a filtration $(25 \mathrm{~mm}$ GF/F glass microfiber filters) samples and placed on ice. An ISCO water sampler located on a floating stationary barge at site LJ-28 (Fig. 4.2), was set to collect daily water samples at 13:30 during each deployment period. These unfiltered samples were collected at the time of recovery. All water samples were frozen, until analysis, at the Soil/sediment Biogeochemistry Laboratory (SBL) at Florida International University (FIU). 


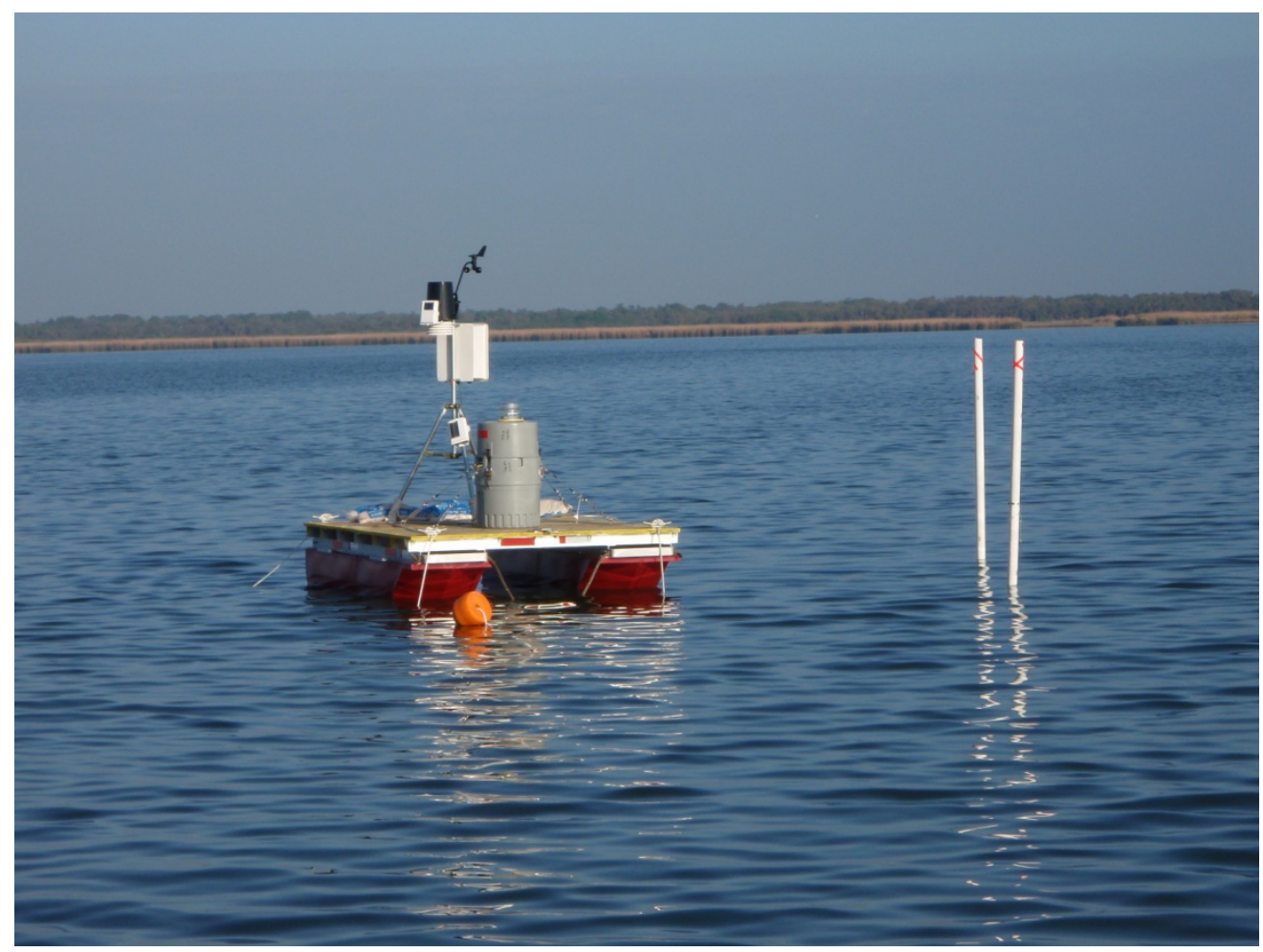

FIGURE 4.3 Photograph of the barge located at LJ28 with deployed ISCO water sampler and Weather Station 1.

\section{Trap Systems}

The STHA trap had a ratio of 10:1 (Bloesch and Burns, 1979) made of polycarbonate with an inside diameter of $5.3 \mathrm{~cm}$ and a length of $53 \mathrm{~cm}$ and measures vertical flux by trapping suspended sediment over a period of time. The STHA trap was established as the primary sediment trap system for this research effort and underwent a modification in August of 2009. The initial deployment design had the trap secured to a PVC pole that was visible at the water surface, this design was changed after poles were tilted or missing upon retrieval. The new system allowed the trap to rest on the lake bottom and was attached to a rope and float that was visible on the surface. The rope and float design was used for the high aspect ratio trap beginning August of 2009 to the April of 2011. 
The plate trap system had an outer ring diameter of $35 \mathrm{~cm}$ and an inner collection area of $14 \mathrm{~cm}$ and was designed to simulate sedimentation rates in moving waters with the consideration of gravity and bottom shear (Kozerski and Leuschner 1999). The trap functioned as a vertical moving piston, which presents the collection area when open and secures the sample when closed. The outer ring of the plate trap represents the boundary layer and the shear stress conditions of the lake bottom (Kozerski and Leuschner 2000). Particles then settle into the collection area based on shear stress and sinking velocities. Unfortunately, the plate trap system was not appropriate for the Lake Jesup environment, where lake water clarity is low and deployment procedures did not allow use to enter the water to effectively collect the sample. It is suggested that a redesign of the trap be implemented to close the trap and collect the sample more effectively or new collection procedures that implement diving.

The Mark8 autosampler has a funnel design that empties into bottles that rotate every 12 to 24 hours. The trap has a height of $116 \mathrm{~cm}$ with a funnel diameter of $53.7 \mathrm{~cm}$ that funnels into $250 \mathrm{~mL}$ bottles. The trap is similar to the high aspect ratio trap, except it collects the daily flux of settling particles. Attached to the Mark8 at the same height is a high aspect ratio trap to understand the settling particles at this height with in the water column. Unfortunately, the instrument was lost during sampling in November of 2010. Efforts to locate the Mark8 with side scan SONAR were not successful.

\subsection{Other Instruments}

To further understand the dynamics of the interactions between the water and the sediments other data collection instruments were used. An Aquadopp current meter 
(2MHz, P22042, Probe ID: APK 33942) was used to measure the water current and wave height. The current meter was attached to a mount and set to rest at the bottom of the lake around 0.75 meters above lake bottom and later was recovered at the end of the deployment period and the data was downloaded to a laptop.

Two weather stations were used to understand the effects that wave intensity and wind velocity have on sediment resuspension. One weather station was fixed in place on a constructed platform near the SR-46 Bridge (Fig 4.1) and the other was on the barge with the ISCO water autosampler. The weather stations collected wind velocity and direction, air temperature and precipitation, every 15 minutes continuously over the course of a deployment period. Of the two weather stations, the weather station on the barge (Station 1, around 2 meters above water surface) collected wind velocity, precipitation and temperature and the weather station near SR-46 collected wind direction (Station 2, around 4 meters above water surface).

Lastly, two YSI units were used: an auto sampling YSI (Model: 600QS-ORP-M) and a YSI (Model: ProODO) that measured the lake profile during the deployment period every $25 \mathrm{~cm}$. The Auto-sampling YSI unit was placed on the barge to collect dissolved oxygen (DO), $\mathrm{pH}$ and temperature in the water column every half hour during a deployment period. The YSI was used to potentially understand the effects of sediment resuspension on the DO and $\mathrm{pH}$ within a meter of the water surface. The YSI used for profiling collected the water temperature and DO every $25 \mathrm{~cm}$ until the device was in the floc layer for the day of deployment and recovery at all four sites. 


\subsection{Deployments and Recovery of Materials}

\subsubsection{Deployments}

During the deployments all instruments and traps were prepared for collection over a week to two week period. The AquaDopp current meter, YSI autosampler and ISCO autosampler were programmed to collect data over the course of the deployment period. The plate (only at three sites, did not deploy plate traps after January 2010), STHA traps (deployed at all four sites) and AquaDopp (deployed at LJ28 only) were deployed by dropping the systems over the side of the boat and left on the lake bottom. The YSI and ISCO autosampler were set up to operate from the barge at LJ-28. Also, during the deployments sediment (floc and $5 \mathrm{~cm}$ consolidated samples), water grab samples and DO profile were taken at all four sites and the downloading of weather data for both stations.

\subsubsection{Recovery}

During a recovery all traps, samples and instruments were collected (except for the weather stations and ISCO autosampler, which was affixed to the barge or permanent platform). The AquaDopp and YSI autosampler were collected and the data were downloaded. Both weather stations data were downloaded, ISCO water samples and/or Mark8 samples were collected. Beginning in August of 2010, coring samples for radioisotope analysis were collected, during the recovery, at each of the four sites and split on the boat every $4 \mathrm{~cm}$. These samples were placed in whirl-pak bags and put in a 
cooler on ice. Once back at FIU, these samples were refrigerated until they were shipped to ECU for radiometric analysis.

\subsection{Sample Preparation}

All sediment samples, except the radioisotope samples, were prepared and analyzed at the SBL/FIU. All water samples were frozen until they were sent to SERC Water Quality Lab (NELAC - E76930-12-07/01/2010) for analysis. Removal of the sediments in the traps took place within 5 days after they were collected from the lake. Before the sediments were removed the sediment height within the traps were measured. The grab samples were weighed in the whirl-pak bags and in cups where the volume was measured. After fresh weights were collected all sediment samples were dried $\left(80^{\circ} \mathrm{C}\right.$ until constant weight), cooled in a desiccator, ground using a mortar and pestle and weighed prior to geochemical analysis.

\subsection{Laboratory Analysis}

Samples were analyzed by several labs at FIU using standard analytical methods, except for radiometric analysis, which was sent to East Carolina University. Lake water was analyzed for soluble reactive orthophosphate (SRP; USEPA method 365.1) and total dissolved phosphorus (TDP; EPA 365.1), soluble nitrate, nitrite $\left(\mathrm{NO}_{3}, \mathrm{NO}_{2}\right.$; USEPA 353.2) and ammonium $\left(\mathrm{NH}_{4}\right.$; USEPA 350.1) on a Technicon Autoanalyzer II System (Pulse Instrument Ltd. Total Dissolved nitrogen (TDN; ASTM D5176) and dissolved organic carbon (DOC; USEPA 415.1) was determined on a shimadzu TOC-VCSH fitted with Shimadzu TNM-1 Total Nitrogen Analyzer. 
Total phosphorus in sediments was determined using the ashing/acid hydrolysis method of Solorzano and Sharp (1980) with the resulting soluble reactive phosphorus (SRP) being measured as above. Sediments were processed for dry weight $\left(80^{\circ} \mathrm{C}\right)$, field bulk densities ( $\mathrm{g}$ dry weight $\mathrm{cm}^{-3}$ ), fractional water content and percent organic matter by loss on ignition (LOI) at $550^{\circ} \mathrm{C}$ (as \% ash) (ASTM D2974-87). Sediment total C and N were analyzed using Perkin Elmer Series II 2400 CHNS/O Analyzer (Nelson and Sommers 1996). Radiometric analysis was analyzed at ECU under the methods used by Dail et al. (2007).

Carbon and nitrogen isotopes of the sediments were determined by standard elemental analyzer isotope ratio mass spectrometry (EA-IRMS) procedures. Carbon isotopes were measured using decarbonated samples, where they were reacted with $1 \mathrm{M}$ $\mathrm{HCl}$ for 24 hours, whereas, nitrogen analysis was measured on the untreated sample.

\subsection{Radiometric Analysis}

Radiometric analysis was conducted on a series of cores beginning in June of 2010 , using a piston core $(5.3 \mathrm{~cm}$ diameter) and push core $(8.1 \mathrm{~cm}$ diameter) (piston cores were initially used in June 2010, all sampling after this date used a push core). The June sampling collected two cores at all four sites and later split in the lab every $2 \mathrm{~cm}$ (ECU then determined the samples were too small and needed to be combined to $4 \mathrm{~cm}$ ). Beginning in August of 2010, one core was taken at all four sites using a push core and split, every $4 \mathrm{~cm}$, directly in the boat after collection and stored on ice. All cores were

dried, ground and analyzed for ${ }^{210} \mathrm{~Pb},{ }^{137} \mathrm{Cs},{ }^{234} \mathrm{Th}$, and ${ }^{7} \mathrm{Br}$ at ECU by direct gamma counting using one of four low-background, high-efficiency, high-purity Germanium 
detectors coupled with a multi-channel analyzer. Ultimately, evaluation of the radiochemical tracers, focusing on ${ }^{210} \mathrm{~Pb}$, will help to understand sediment deposition, accumulation, and potential removal processes in a Lake Jesup, Florida.

\subsubsection{Lead-210 $\left({ }^{210} \mathrm{~Pb}\right)$}

The removal of ${ }^{210} \mathrm{~Pb}$ (half life $\mathrm{t}_{1 / 2}=22.6$ year) from water into sediments is caused by inorganic and biochemical reactions that allows the dating of lacustrine and coastal marine sediments for approximately the previous 100 years (Goldberg 1963; Krishnaswami et al. 1971). Once the sediments settle and deposit on the lake bottom the decay of ${ }^{210} \mathrm{~Pb}$ begins. If erosion of the sediments into the lake and sediment accumulation is constant then it is assumed that the sediment layers will have the same initial amount of ${ }^{210} \mathrm{~Pb}$ concentration (Appleby and Oldfield 1983). This will result in an exponential decay of ${ }^{210} \mathrm{~Pb}$ with a linear trend when plotting ${ }^{210} \mathrm{~Pb}$ concentrations as activity $(\mathrm{dpm} / \mathrm{g})$ versus depth within the core on a logarithmic scale (Appleby and Oldfield 1983). However, in many cases, rates of erosion and sedimentation are often found to change from year to year, which results in non-linear trends and initial ${ }^{210} \mathrm{~Pb}$ concentrations to vary (Appleby and Oldfield 1983), therefore, models were created with certain assumptions that rule out variations in sediment accumulations. The rates of erosion, transition and/or deposition were based on the activities of the previous deployments. 


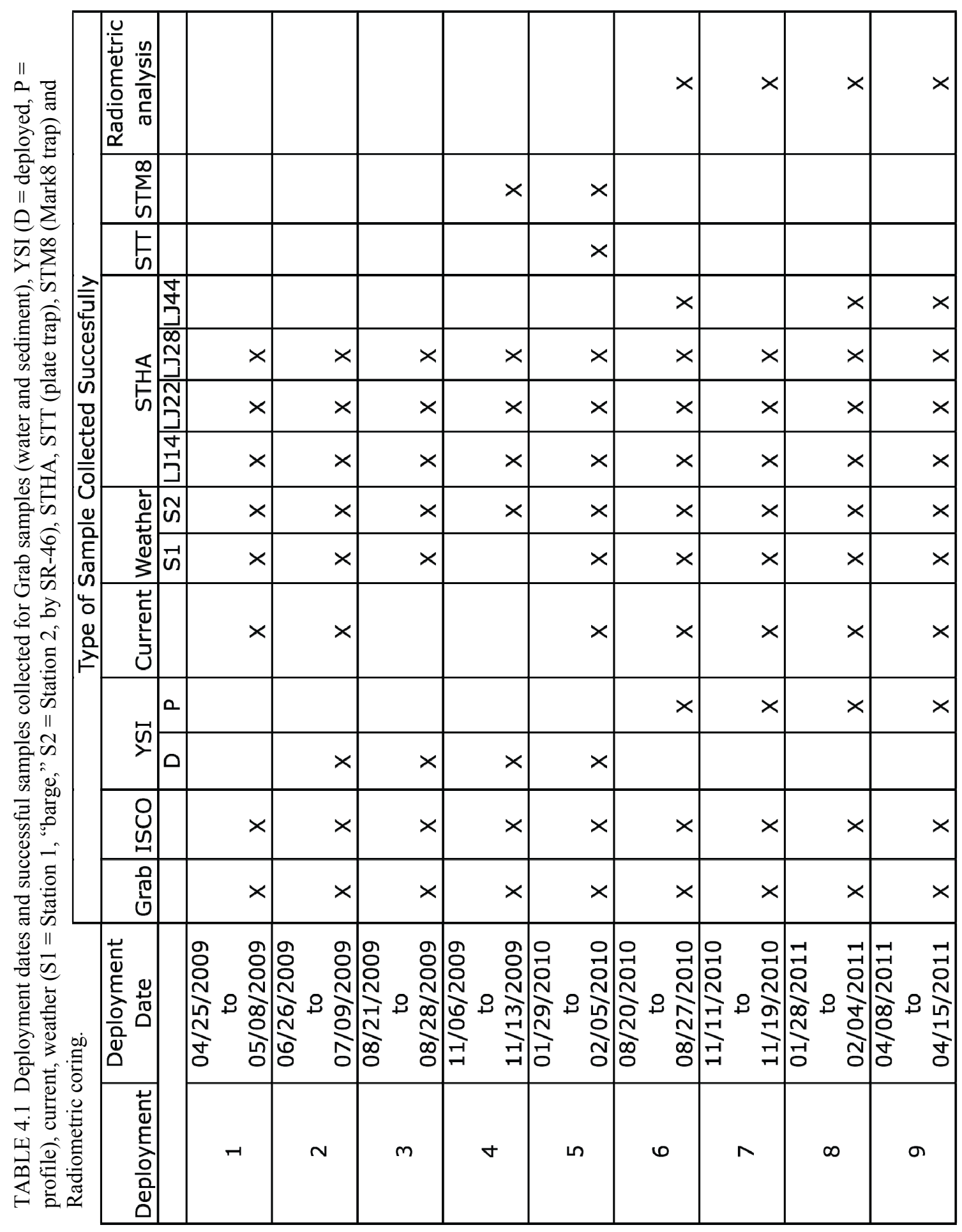




\subsection{Statistical Analysis}

Correlations were made using Pearson 2-tailed correlations to understand the relationships of the various data collected. One-way ANOVA's were conducted for all data with Post Hoc used with Dunnette's C or Tukey - REGWQ depending on the homogeneity of the variance. Box and whiskers were conducted from the results and labeled ( $\mathrm{a}, \mathrm{b}, \mathrm{c}$, etc.) representing a difference in variance. All statistical analysis was done using SPSS version 18.

\section{RESULTS}

\subsection{Sediment Type}

Sediment recovered by grab samples and cores were predominantly floc and gyttja (Fig. 5.1). Peat, sand, pink marl and blue clay were also observed in the lake sediments, but were not sampled or analyzed, because they exceeded the sampling depth or were not present at the sample location. Floc within Lake Jesup was observed to be rich in organic material $(\mathrm{OM})(7.57 \%$ to $42.59 \%)$, unconsolidated (fluid mud) and dark brown in color with a mean of $33.28 \%$. Floc was found at all sites during most deployments, except for deployment 8 (January, 2011) at sampling station LJ28. Thickness of the floc varied with each deployment and location, ranging from $0.0 \mathrm{~cm}$ to $5.0 \mathrm{~cm}$ (Average of $3.2 \mathrm{~cm}$ for deployments 6 to 9; Table 5.1). Floc thickness was not measured for deployments 1 through 5, but samples were collected.

Gyttja is a semi-consolidated sediment that is organic rich and dark brown to black in color with organic carbon $<50 \%$ (Wetzel 2001). Fresh gyttja is very soft and 
hydrous containing organic matter, mineral matter and inorganic precipitates. Hansen (1961) observed that gyttja is present in large eutrophic lakes where phytoplankton productivity dominates. In Lake Jesup, Gyttja is found directly bellow the floc layer when the gyttja was present and had a black-greenish color and often contained mollusk shells whole and fragmented.

\subsection{Sediment Nutrients}

Gyttja nutrient concentrations (TN, TC and TP) were lower then floc and trap sediments (Table 5.2). This difference was observed for organic matter, \%Water and with gyttja having higher values for bulk density. It is clear from box and whiskers in this chapter (e.g. Figs 5.2 etc.) that there is a distinct separation between the floc, sediments (gyttja) and trap samples with some mixing between floc and trap samples and floc and sediment (gyttja) samples. In essence there are differences between the trap samples, floc and grab sediments (top $5 \mathrm{~cm}$ of sediment, below the floc layer).

TP for all sediment concentrations are significantly correlated with TN, TC, $\% \mathrm{OM}$, and \%Water and inversely correlated for bulk density, TIC and $\mathrm{pH}$ (Table 5.2). $\mathrm{TN}$ for all sediments has a significant correlation with $\mathrm{TC}, \% \mathrm{OM}$, and \%Water and inversely correlates with TIC, bulk density and $\mathrm{pH}$. TC shows significant correlations between $\% \mathrm{OM}$ and $\%$ Water and inversely correlated with TIC, bulk density and $\mathrm{pH}$. TIC has an inverse correlation with \%OM, \%Water and bulk density and correlates significantly with $\delta^{15} \mathrm{~N}$ and $\mathrm{pH} . \delta^{15} \mathrm{~N}$ significantly correlates with $\delta^{13} \mathrm{C}$ and bulk density and inversely correlates with $\%$ Water. $\delta^{13} \mathrm{C}$ inversely correlates with $\%$ Water. $\% \mathrm{OM}$ 
correlates with \%Water and inversely correlates with bulk density and $\mathrm{pH} . \%$ Water is inversely correlated with bulk density and $\mathrm{pH}$ and bulk density correlates well with $\mathrm{pH}$.

Total phosphorus (TP) concentrations, of the lake sediments, varied by each deployment, site and sediment type ranging from 212 to $2721 \mu \mathrm{g} \mathrm{g}^{-1} \mathrm{dw}$ with a mean of $1496 \mu \mathrm{g} \mathrm{g}^{-1} \mathrm{dw}$ for the entire sampling period (Fig. 5.2). Floc grab samples ranged from 285 to $2209 \mu \mathrm{g} \mathrm{g}^{-1} \mathrm{dw}$ with a mean of $1282 \mu \mathrm{g} \mathrm{g}^{-1} \mathrm{dw}$ of TP (Table 5.3). Sediment grab samples collected bellow the floc layer had a relatively lower mean of $663 \mu \mathrm{g} \mathrm{g}^{-1} \mathrm{dw}$ with a range of 212 to $1923 \mu \mathrm{g} \mathrm{g}^{-1} \mathrm{dw}$ of TP. All trap samples were relatively higher in TP then the other sediment types collected. High aspect ratio traps (STHA) had a range from 982 to 2652 with a mean of $2028 \mu \mathrm{g} \mathrm{g}^{-1} \mathrm{dw}$ and Mark8 autosampler (STM8) had a range from 991 to $2720 \mu \mathrm{g} \mathrm{g}^{-1} \mathrm{dw}$ with a mean of $2199 \mu \mathrm{g} \mathrm{g}^{-1} \mathrm{dw}$ of TP (deployments 4 and 5 only). The Teller traps (STT), were not successful in collecting viable samples in most cases. Of the STT samples we collected, the range was 1014 to $2078 \mu \mathrm{g} \mathrm{g}^{-1} \mathrm{dw}$ with a mean of $1699 \mu \mathrm{g} \mathrm{g}^{-1} \mathrm{dw}$ (deployment 5 only). Although STT traps were not consistently reliable during the course of this study deployment 5 was successful in collecting samples for three sites (LJ14, LJ22 and LJ28). This is the only consistent data collected during the two-year study period for the plate traps and results may prove valuable for future work.

Over the course of nine deployments the TP concentrations fluctuate in a seasonal pattern with winter months having higher TP concentrations and then in summer months. Also, during the course of the deployments there was a well-defined variability between the sediment types per each deployment for TP. The trap samples had a relatively higher 
concentration of TP (982 to $2652 \mu \mathrm{g} \mathrm{g}^{-1} \mathrm{dw}$ ), followed by the floc (385 to $2209 \mu \mathrm{g} \mathrm{g}^{-1}$ $\mathrm{dw}$ ), with the grab sediments (212 to $1923 \mu \mathrm{g} \mathrm{g}{ }^{-1} \mathrm{dw}$ ) having the lowest concentrations (Fig. 5.4).

Total nitrogen $(\mathrm{TN})$ concentration analysis had similar results to $\mathrm{TP}$ with trap samples having the higher relative concentrations, followed by floc and then grab sediments having the lowest, ranging from 0.0 (or below detection) to $20.8 \mathrm{mg} \mathrm{g}^{-1}$ (Fig. 5.6). The floc samples had a range from 7.7 to $23.6 \mathrm{mg} \mathrm{g}^{-1}$ and a mean of $17.1 \mathrm{mg} \mathrm{g}^{-1}$. Sediment grab samples had a mean of $8.5 \mathrm{mg} \mathrm{g}^{-1}$, ranging from 0.0 (or below detection) to $15.7 \mathrm{mg} \mathrm{g}^{-1}$ (Table 5.4). STHA traps had $\mathrm{TN}$ concentrations ranging from 7.0 to 28.7 $\mathrm{mg} \mathrm{g}^{-1}$ with a mean of $24.0 \mathrm{mg} \mathrm{g}^{-1}$. STM8 concentrations have a mean of $24.9 \mathrm{mg} \mathrm{g}^{-1}$ (deployment 4 and 5 only) with a range of 20.0 to $28.27 \mathrm{mg} \mathrm{g}^{-1}$ and STT trap concentration ranged from 24.5 to 24.9 with a mean of 24.7 (deployment 5 only).

$\mathrm{TN}$ values over the course of the period varied by deployment, although with less variation then TP. The concentrations between sediment type is well defined, with sediment traps having the higher concentrations of $\mathrm{TN}$, grab sediments had the lower relative concentrations and floc somewhere between the sediment grab samples and the traps samples (Fig. 5.7).

Carbon analysis consisted of total carbon (TC) and total inorganic carbon (TIC) for the entire sampling period. TC concentrations had similar results to TN showing less variation in sample fluctuation then $\mathrm{TP}$ with $\mathrm{TC}$ concentrations ranging from 29.7 to $277.1 \mathrm{mg} \mathrm{g}^{-1}$ (Fig. 5.10). Floc TC concentrations ranged from 77.8 to $209.2 \mathrm{mg} \mathrm{g}^{-1}$ with a mean of $164.4 \mathrm{mg} \mathrm{g}^{-1}$. Sediments had the lowest relative TC concentrations ranging from 


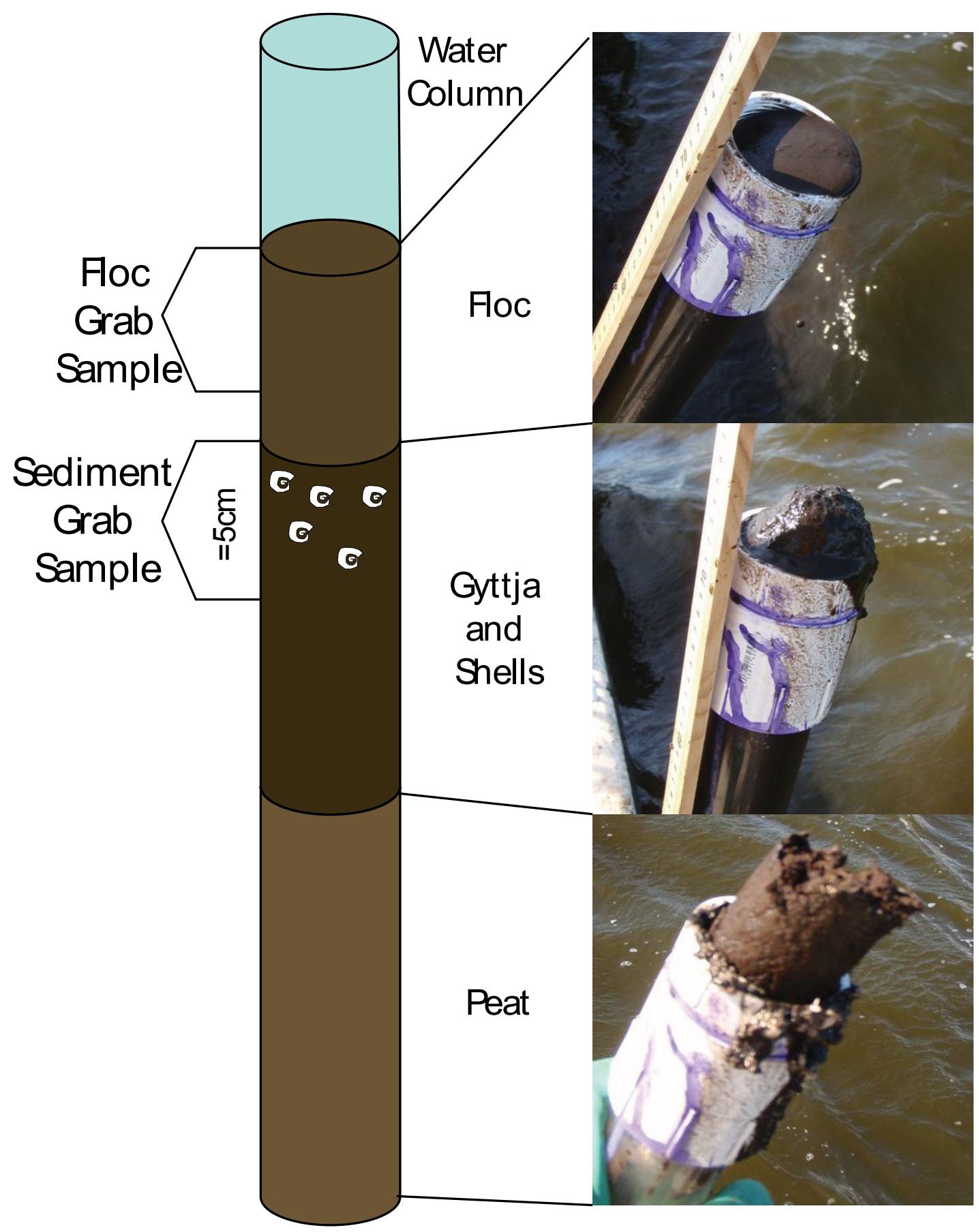

FIGURE 5.1 Representative layering at depth of sediment within Lake Jesup with pictures. Top photo is representative of floc, middle photo is representative of gyttja and the bottom photo is typical of peat. The core image is not to scale. 
Table 5.1 Mean and standard deviation of floc thickness for deployments 6, 7, 8 and 9. Deployments 1 to 5 were not measured.

\begin{tabular}{|c|c|c|c|c|}
\hline & \multicolumn{2}{|l|}{$8 / 20 / 10$ to $8 / 27 / 10$} & \multicolumn{2}{|l|}{$11 / 11 / 10$ to $11 / 19 / 10$} \\
\hline Site & Mean $(\mathrm{cm})+/-$ St. Dev. & $\mathrm{n}$ & Mean $(\mathrm{cm})+/-$ St. Dev. & $\mathrm{n}$ \\
\hline LJ14 & $3.03+/-0.13$ & 2 & $4.51+/-0.49$ & 2 \\
\hline LJ22 & $4.02+/-0.06$ & 2 & $3.34+/-0.08$ & 2 \\
\hline $\mathrm{LJ} 28$ & $2.21+/-0.00$ & 2 & $2.51+/-0.02$ & 2 \\
\hline \multirow[t]{2}{*}{ LJ44 } & $3.36+/-0.06$ & 2 & $4.26+/-0.22$ & 2 \\
\hline & \multicolumn{2}{|l|}{$1 / 28 / 11$ to $2 / 04 / 11$} & \multicolumn{2}{|l|}{$4 / 08 / 11$ to $04 / 15 / 11$} \\
\hline Site & Mean $(\mathrm{cm})+/-$ St. Dev. & $\mathrm{n}$ & Mean $(\mathrm{cm})+/-$ St. Dev. & $\mathrm{n}$ \\
\hline LJ14 & $4.64+/-0.04$ & 2 & $3.11+/-0.24$ & 2 \\
\hline LJ22 & $3.25+/-0.31$ & 2 & $3.20+/-0.06$ & 2 \\
\hline LJ28 & $0.00+/-0.00$ & 2 & $1.51+/-0.00$ & 2 \\
\hline LJ44 & $4.38+/-0.04$ & 2 & $3.61+/-0.69$ & 2 \\
\hline
\end{tabular}




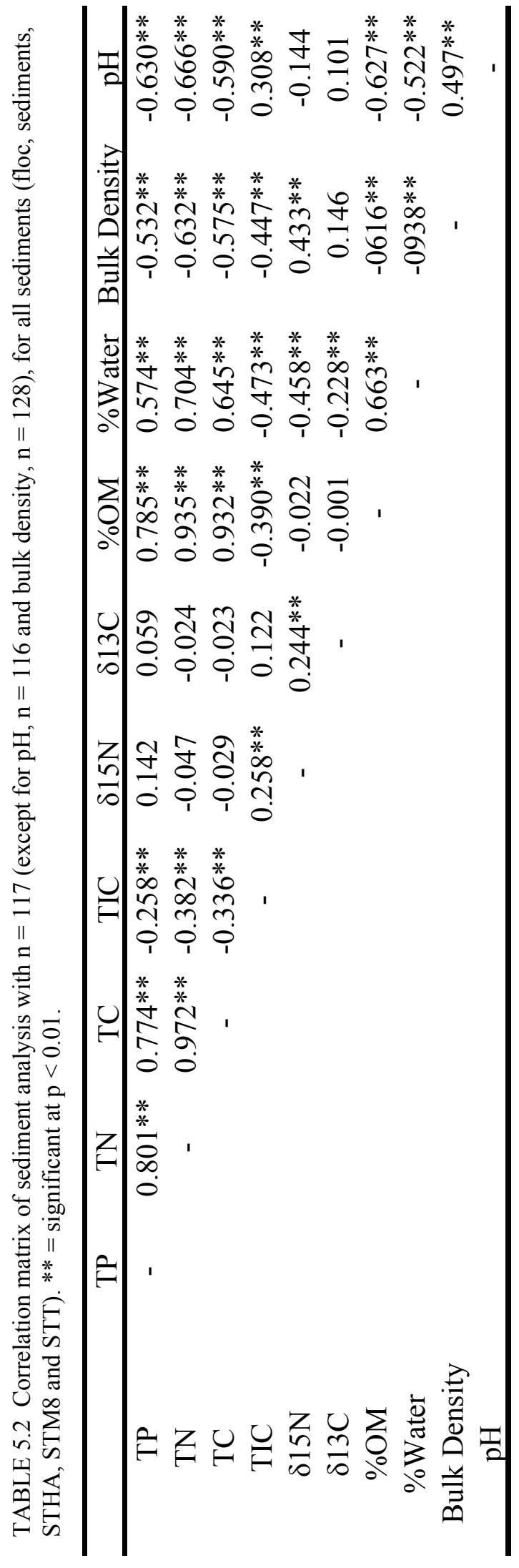


29.7 to $174.8 \mathrm{mg} \mathrm{g}^{-1}$ with a mean of $118.7 \mathrm{mg} \mathrm{g}^{-1}$ (Table 5.5). Trap samples had the highest TC concentrations, with STHA traps having a mean of $226.0 \mathrm{mg} \mathrm{g}^{-1}$, ranging from 68.5 to $277.1 \mathrm{mg} \mathrm{g}^{-1}$. STM8 had TC concentrations ranging from 189.7 to $253.6 \mathrm{mg}$ $\mathrm{g}^{-1}$ and a mean of $224.2 \mathrm{mg} \mathrm{g}^{-1}$ and STT concentrations ranging from 220.9 to $225.2 \mathrm{mg}$ $\mathrm{g}^{-1}$ with a mean of $223.5 \mathrm{mg} \mathrm{g}^{-1}$.

TC concentrations through the course of the nine deployment periods had some variation from trip to trip. There was a similar relationship with floc having the highest concentrations of TC and grab sediments with the least. In some cases the grab sediment and the floc layer are slightly similar in their concentrations, much more so then TN. The trap samples have much higher concentrations of TC then the floc or grab sediments (Fig. 5.11). TIC was relatively low through the course of the study. In most cases the TIC concentration was $0.0 \mathrm{mg} \mathrm{g}^{-1}$ or below detection limits. Sediments collected by grab sampling of TIC had a mean of $5.1 \mathrm{mg} \mathrm{g}^{-1}$ (Fig. 5.14).

\subsection{Sediment Characteristics}

Bulk density of the sediments had a wide range from 0.018 to $0.707 \mathrm{~g} \mathrm{dw} \mathrm{cm}^{-3}$ with a mean of $0.087 \mathrm{~g} \mathrm{dw} \mathrm{cm}^{-3}(\mathrm{n}=128)$ (Fig. 5.15). Grab sediments had the largest range from 0.076 to $0.707 \mathrm{~g} \mathrm{dw} \mathrm{cm}^{-3}$ and highest mean of $0.232 \mathrm{~g} \mathrm{dw} \mathrm{cm}^{-3}$ (Table 5.6). Floc and

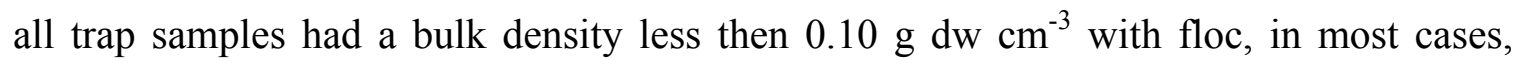
having a slightly higher bulk density then STHA and STM8 traps. Floc ranged from 0.021 to $0.082 \mathrm{~g} \mathrm{dw} \mathrm{cm}^{-3}$ with a mean of $0.049 \mathrm{~g} \mathrm{dw} \mathrm{cm}^{-3}$. STHA had a mean of $0.035 \mathrm{~g}$

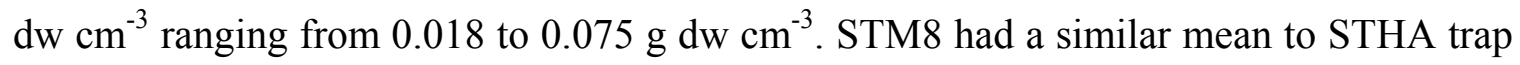


samples of $0.034 \mathrm{~g} \mathrm{dw} \mathrm{cm}^{-3}$ ranging from 0.021 to $0.046 \mathrm{~g} \mathrm{dw} \mathrm{cm}^{-3}$. STT trap samples had a mean of $0.076 \mathrm{~g} \mathrm{dw} \mathrm{cm}^{-3}$, ranging from 0.075 to $0.079 \mathrm{~g} \mathrm{dw} \mathrm{cm}^{-3}$.

Bulk density through the course of the study had little variation for floc and trap samples, but grab sediments had a very large range. The large range in bulk density by the grab samples were due to LJ28, which is most likely due to LJ28 having a different grab sediment type then the other three sites. This site had the largest range from 0.101 to $0.707 \mathrm{~g} \mathrm{dw} \mathrm{cm}^{-3}$ and highest mean $0.464 \mathrm{~g} \mathrm{dw} \mathrm{cm}^{-3}$ compared to the three other sites that had bulk densities less then $0.20 \mathrm{~g} \mathrm{dw} \mathrm{cm}^{-3}$ (Fig. 5.16).

The $\mathrm{pH}$ of the sediments ranged from 6.47 to 8.23 with a mean of 7.31. Like the nutrients TP, TN and TC, there were ranges in separation by sediment type. Floc had the lowest $\mathrm{pH}$, while grab sediments had the highest (Fig. 5.19). Floc had a mean $\mathrm{pH}$ of 7.40, grab sediments a mean of 7.71 and STHA sediments 7.18 (Table 5.7). STM8 and STT had the lowest $\mathrm{pH}$ mean values at 6.95 and $6.88 \mathrm{pH}$ of the sediments fluctuated by each deployment, but there doesn't seem to be a season pattern.

Organic matter content $(\% \mathrm{OM})$ was the highest in the trap sediments and the lowest in the grab sediments (Fig. 5.20). Percent organic matter (\%OM) of floc ranged from 7.6 to $42.6 \%$ with a mean of $33.3 \%$, while grab sediments ranged from 2.9 to $43.2 \%$ with a mean of $21.7 \%$ (Table 5.8). Trap samples ranged from 28.4 to $65.5 \%$ with STHA traps having a mean of 47.2 , STM $84.7 \%$ and STT 44.9 . During the course of the study the $\% \mathrm{OM}$ showed a fluctuation between sediment types and deployments. August, 2009 (deployment 3) had the highest \%OM means for STHA, January, 2011 (deployment 8) had the highest \%OM mean for floc and August, 2010 (deployment 6) had the highest 
$\% \mathrm{OM}$ mean for grab sediments, but in most cases by deployment STHA had the higher percents and sediments had the lower percents for \%OM (Fig. 5.21).

Percent water content (\%Water) in the sediments was very high for floc and trap sediments. The mean \%water for floc was $95.0 \%$ and $97.2 \%$ for the STHA, while the grab sediments had a mean \%water of $82.0 \%$ (Fig. 5.24). Grab sediments had the largest range of 47.9 to $92.8 \%$ (Table 5.8). Site LJ28 has the largest range for the grab sediments at 47.9 to $90.9 \%$, where as, site LJ14 had a range of 86.9 to $91.0 \%$. Over the course of the deployments there were little variations in \%Water.

Correlations between TP, TN and TC are very high for all sediments (Fig. 5.25 and 5.26) Sediment types are often zonal with trap sediments having the higher concentrations followed by floc and grab sediments. TN and TC correlate extremely well for all sediment samples. Correlations were also made for TN, TC and TP for floc, grab sediments and STHA samples (Table 5.9)

\subsection{Water Chemistry}

Total phosphorus (TP) concentrations within the water column fluctuated between 40 and $489 \mu \mathrm{g} \mathrm{L}^{-1}$ with a mean of $150 \mu \mathrm{g} \mathrm{L}^{-1}$ (Table 5.11). Site LJ44 had the lowest mean of $71 \mu \mathrm{g} \mathrm{L}^{-1}$ for TP within the water with a range of 40 to $100 \mu \mathrm{g} \mathrm{L}^{-1}$ (Fig 5.27). Site LJ28 had the highest relative TP concentrations with a mean of $124 \mu \mathrm{g} \mathrm{L}^{-1}$ and a range of 75 to $215 \mu \mathrm{g} \mathrm{L}^{-1}$ for the water grab samples. Also, for LJ28 the daily autosampler (ISCO) concentrations were higher then the water grab samples with a mean of $169 \mu \mathrm{g} \mathrm{L}^{-1}$ with a range of 44 to $489 \mu \mathrm{g} \mathrm{L}^{-1}$. Over the course of the study, the TP concentrations within the water column, based on grab samples, decreased (Fig. 5.28). 
Total Nitrogen (TN) within the water column fluctuated through the two-year period of this project, but overall has shown a slight increase over time. TN concentrations ranged from 0.50 to $7.67 \mathrm{mg} \mathrm{L}^{-1}$ with a mean of $1.65 \mathrm{mg} \mathrm{L}^{-1}$ (Table 5.11). LJ28 had the highest mean of $1.81 \mathrm{mg} \mathrm{L}^{-1}$ for water grab samples, while LJ22 had the least at a mean of $1.108 \mathrm{mg} \mathrm{L}^{-1}$ (Fig. 5.30).

Total organic carbon (TOC) for the two-year sampling period reflects a slight decrease over time with a mean of $16.56 \mathrm{mg} \mathrm{L}^{-1}$ with a range from 9.60 to $39.53 \mathrm{mg} \mathrm{L}^{-1}$ (Table 5.10). Grab water samples for LJ28 had the highest mean of $15.96 \mathrm{mg} \mathrm{L}^{-1}$ and LJ22 had the lowest mean TOC concentration of $14.42 \mathrm{mg} \mathrm{L}^{-1}$ (Fig. 5.31).

Dissolved oxygen (DO) was only available for a few of the deployments, because the instrument used to measure the DO often times failed to collect or log data. Deployments 2, 3, 4 and 5 collected data by YSI successfully every 30 minutes for the majority of the deployment which resulted in diurnal variations for DO concentrations (Fig. 5.34). Deployments 6, 7, 8, and 9 collected DO at depth, twice per trip, once on deployment and once on recovery of instruments and samples. Refer to Table 5.12 for the results of DO by the available deployments.

Profiles of daytime DO for Deployments 6, 7, 8 and 9 for each site (within a 2 hour period) showed that DO concentrations, in most cases, had a slight decrease at depth, until it reached the sediment or lake bottom. At the sediment layer oxygen concentrations declined rapidly, reaching nearly $0 \mathrm{mg} \mathrm{L}^{-1}$; however, was observed that the lake was oxygenated throughout the water column during the day (Fig. 5.35). DO concentrations could be at $18 \mathrm{mg} / \mathrm{L}$ at one site within the lake and $6 \mathrm{mg} / \mathrm{L}$ at another, suggesting that lake mixing is not always uniform laterally. This could be associated with 
the western half of the lake not mixing well with the eastern half of Lake Jesup (Cable et al. 1997).

Chlorophyll-a (Chl-a) results showed that there was a large fluctuation in concentrations over the two-year long study with a mean of $49.0 \mu \mathrm{g} \mathrm{L} \mathrm{L}^{-1}$, ranging from 6.9 to $138.3 \mu \mathrm{g} \mathrm{L}^{-1}$. Site $\mathrm{LJ} 28$ had the highest mean concentrations of Chl-a with a mean of $56.4 \mu \mathrm{g} \mathrm{L}^{-1}$ and a range from 8.6 to $103.6 \mu \mathrm{g} \mathrm{L}^{-1}$, while $\mathrm{LJ} 14$ had the lowest concentrations with a mean of $25.6 \mu \mathrm{g} \mathrm{L}^{-1}$, ranging from 7.4 to $79.0 \mu \mathrm{g} \mathrm{L}^{-1}$ (Fig. 5.36).

Total suspended solids (TSS) for Lake Jesup were analyzed from the ISCO water samples for each deployment by Florida Gulf Coast University. April 2009 (deployment 1) had the highest average TSS amounts at $0.08 \mathrm{~g} \mathrm{~L}^{-1}$ with a range of 0.048 to $0.111 \mathrm{~g} \mathrm{~L}^{-1}$ (Table 5.13). Deployment 3 had the least average TSS amounts of $0.023 \mathrm{~g} \mathrm{~L}^{-1}$ with a range of 0.009 to $0.039 \mathrm{~g} \mathrm{~L}^{-1}$ (Fig. 5.37).

\subsection{Stable Isotopes}

Results from $\delta^{15} \mathrm{~N}$ and $\delta^{13} \mathrm{C}$ are similar in that there isn't a clear distinction between the sediment types, although, sediment grab samples had the largest range for both $\delta^{15} \mathrm{~N}$ and $\delta^{13} \mathrm{C} . \delta^{15} \mathrm{~N}$ ranged from 0.94 to $4.94 \%$ with a mean of $2.61 \%$, while $\delta^{13} \mathrm{C}$ ranged from -24.05 to $-18.53 \%$ with a mean of $-22.37 \%$ (Fig. 5.38). Grab sediments for $\delta^{15} \mathrm{~N}$ ranged from 1.24 to $4.94 \%$ with a mean of $2.67 \%$, while $\delta^{13} \mathrm{C}$ had a range of -23.77 to $-18.53 \%$ with a mean of $-22.40 \%$ (Table 5.14 ). 


\subsection{Weather}

Over the course of this study (from April 2009 to April 2011) the total precipitation for the two-year period was $229.3 \mathrm{~cm}$ (data from NCDC- Sanford Airport), with April 2009 to April $2010(142.0 \mathrm{~cm})$ having close to twice the amount of precipitation then between May 2010 to April 2011 (87.3 cm) (Fig. 5.39 and 5.41). The average wind velocities for the two-year period were around $3.1 \mathrm{~m} \mathrm{~s}^{-1}(7 \mathrm{mph})$ with wind direction towards the south-southeast. The months with the highest average velocities occurred in the winter months while the lower average velocities were in the summer with an average monthly prevailing wind direction towards the south (NCDC - Sanford Airport and Stations 1 and 2 on the Lake) (Fig. 5.40 and 5.41).

November 2009 had a download error for weather station 1 (located on the barge at LJ28) therefore; data was used from weather station 2 (located near SR-46). Table 5.15 shows the averages collected by the weather stations by deployment (wind velocities, precipitation and temperature from weather station 1 and wind direction from weather station 2).

\subsection{Current}

Lake current within Lake Jesup at LJ28 resulted in currents that moved predominately in a southerly direction (Fig. 5.41). Two deployments (3 and 4) did not collect any data, because of instrument failure and theft. Deployment averages were, as far east as, 133 degrees or the southeastern direction (April, 2009; deployment 1) and as far west as 230 degrees or southwestern direction (June, 2009; deployment 2). August, 
2010 (deployment 6) had the highest deployment average at $0.099 \mathrm{~m} / \mathrm{s}$, while January, 2011 (deployment 8) had the slowest deployment average at $0.046 \mathrm{~m} / \mathrm{s}$ (Table 5.16).

\subsection{Total Mass Accumulation}

Total mass accumulation (MAR) was calculated using STHA trap samples for Total MAR, TP MAR, TN MAR and TC MAR. Deployments 1 and 2 were removed from the data, because the trap design for those deployments was flawed. Total MAR varied by deployment with deployment 4 at LJ22 having the highest $\left(419 \mathrm{~g} \mathrm{~m}^{-2} \mathrm{~d}^{-1}\right)$ and Deployment 3 at LJ28 having the least $\left(87 \mathrm{~g} \mathrm{~m}^{-2} \mathrm{~d}^{-1}\right.$; Figure 5.42). MAR TP, TN and TC reflected that of the results from total MAR (Figure 5.43 to 5.45).

\subsection{Nutrient Budget of Cycling Material Calculations}

The nutrient budget for Lake Jesup was calculated using the volume collected in the sediment traps. The volume was converted into mass accumulation rate (MAR; $\mathrm{g} \mathrm{m}^{-2}$ day $\left.^{-1}\right)$. The sediment traps were deployed for a week to two week long period, therefore calculations were made for MAR values weekly for the entire two- year study. The MAR for each week was then summed for a yearly interval and the nutrient budget was calculated from August, 2009 to August, 2010 and from April, 2010 to April, 2011.

Calculations were made to understand how often the floc layer recycles in Lake Jesup per year. The average floc thickness was used from deployments 6 to 9 for each site along with bulk density to obtain the mass per area. Mass per area was then multiplied for the calculated areas created in ArcGIS from figure 6.5 to determine the mass of floc for each zonation. The calculated masses for each zone were summed to 
arrive at the average total mass of floc $(42,922 \mathrm{mt})$ within Lake Jesup. The total flux for Lake Jesup was then divided by the average total mass of floc to determine the frequency of resuspension per year. 


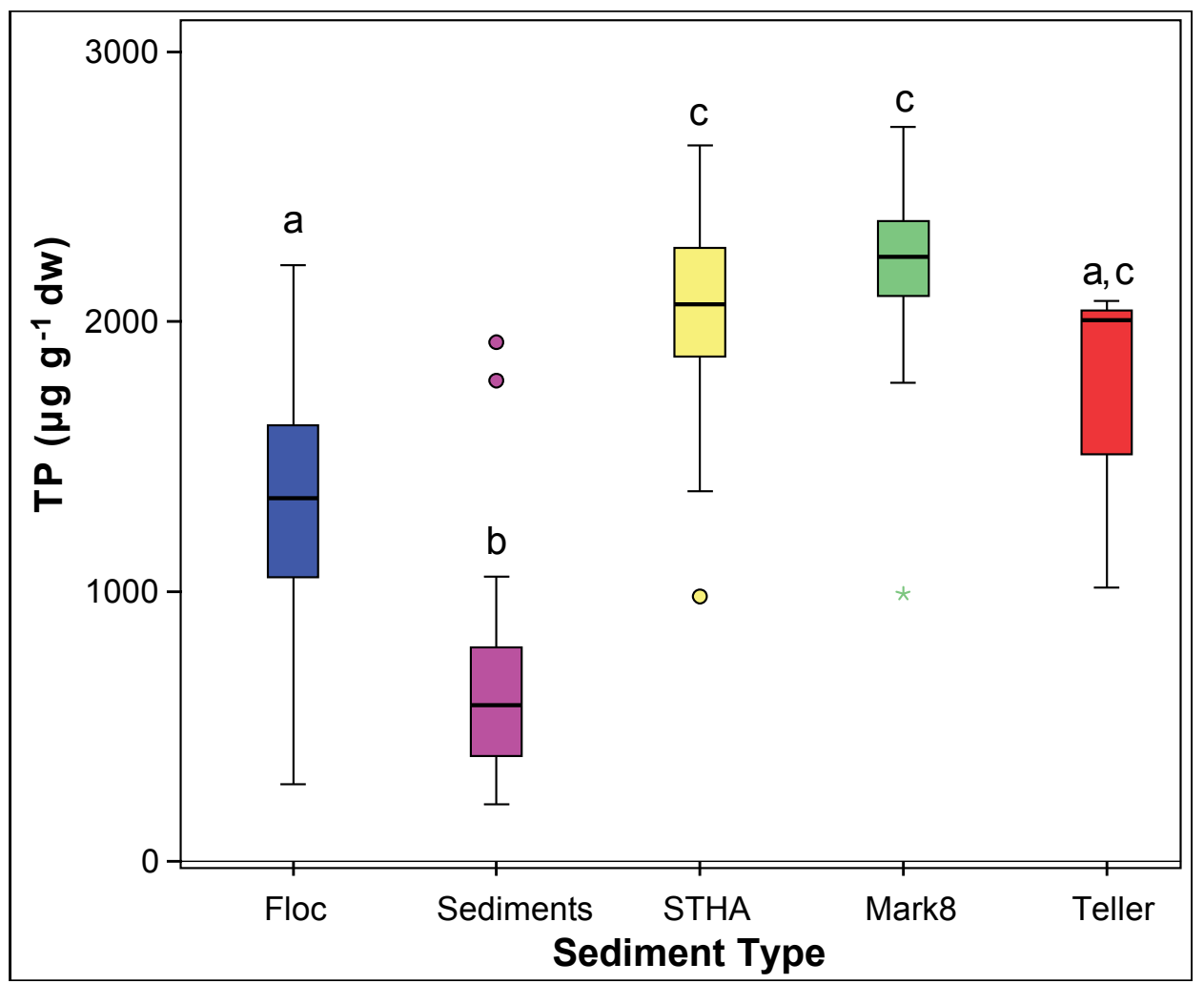

FIGURE 5.2 Box and whisker for total phosphorus by sediment type. Sample variance was statistically analyzed using ANOVA's and a POST HOC tests that is suitable to the sample. All other box plots have been analyzed in a similar fashion. The colored box area represents the upper and lower quartile, with the middle line as the median. The whiskers are the quartiles $+/-1.5$. Circles represent the out boundary, while an asterisk represents outliers for all box and whisker images.

TABLE 5.3 Mean, standard deviation and range of total phosphorus ( $\mu \mathrm{g} \mathrm{L}^{-1} \mathrm{dw}$ ) for floc, sediments and traps. Refer to figures 5.4 to 5.5 for additional graphs.

\begin{tabular}{|l|c|c|c|}
\hline Sediment Type & Mean +/- Std. Dev. & Range & $\mathrm{n}$ \\
\hline Floc & $1282+/-465$ & $285-2209$ & 30 \\
Sediments & $663+/-390$ & $212-1923$ & 31 \\
STHA & $2028+/-392$ & $982-2652$ & 31 \\
Mark8 & $2199+/-355$ & $991-2721$ & 20 \\
Teller & $1699+/-594$ & $1014-2078$ & 3 \\
All Sediments & $1496+/-724$ & $212-2721$ & 117 \\
\hline
\end{tabular}




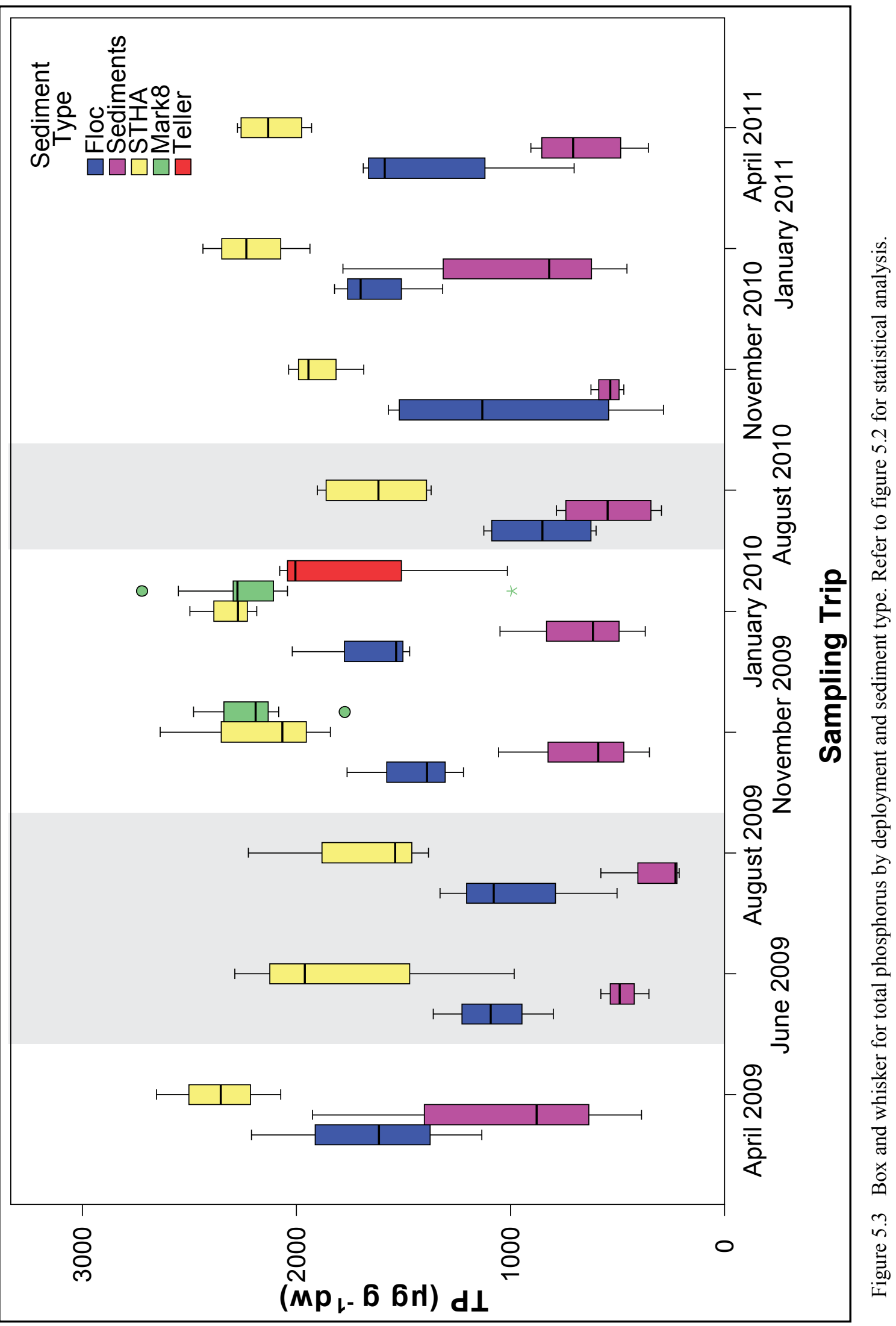




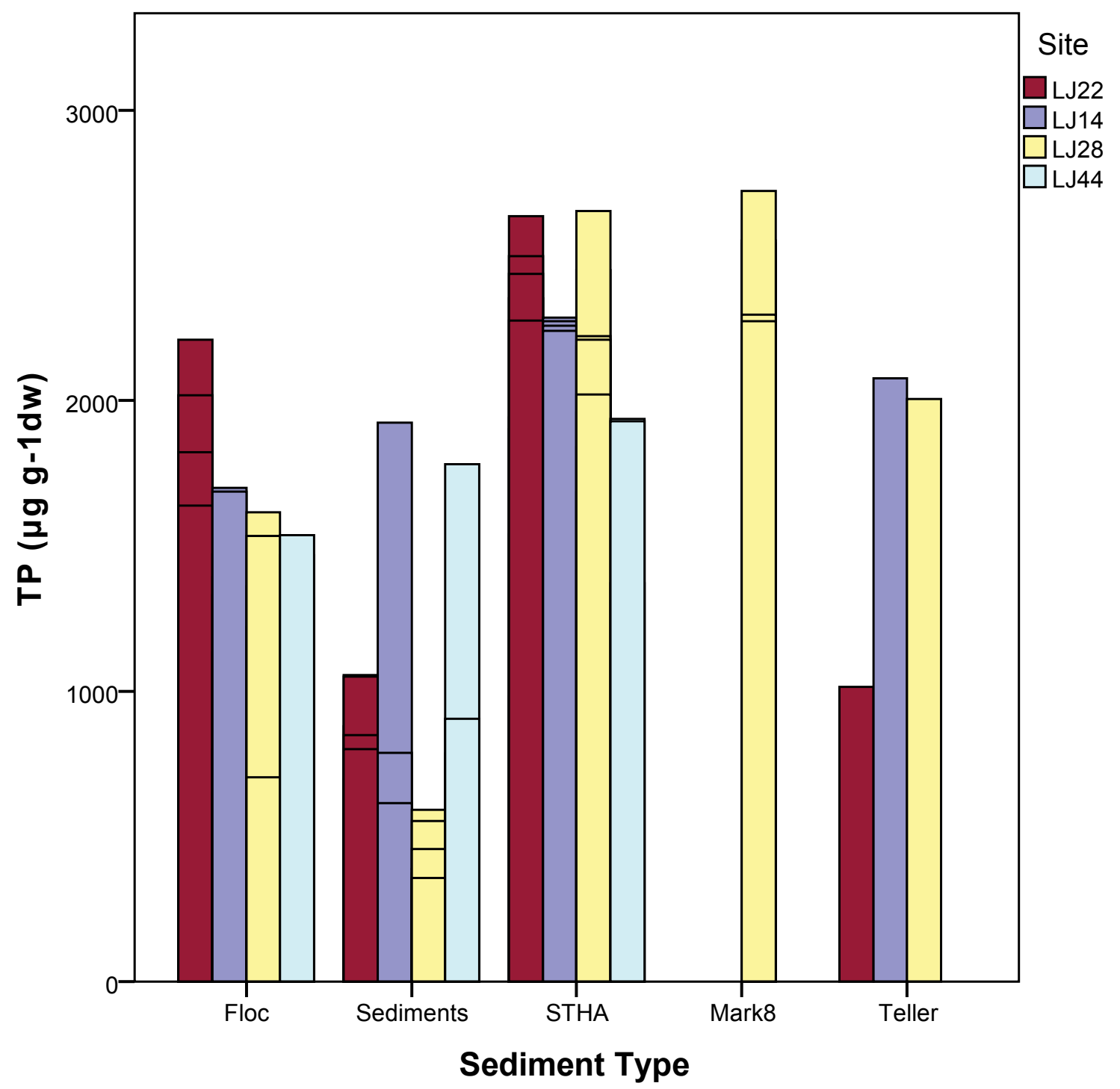

FIGURE 5.4 Variations for total phosphorus by sediment type. 


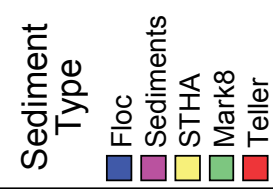

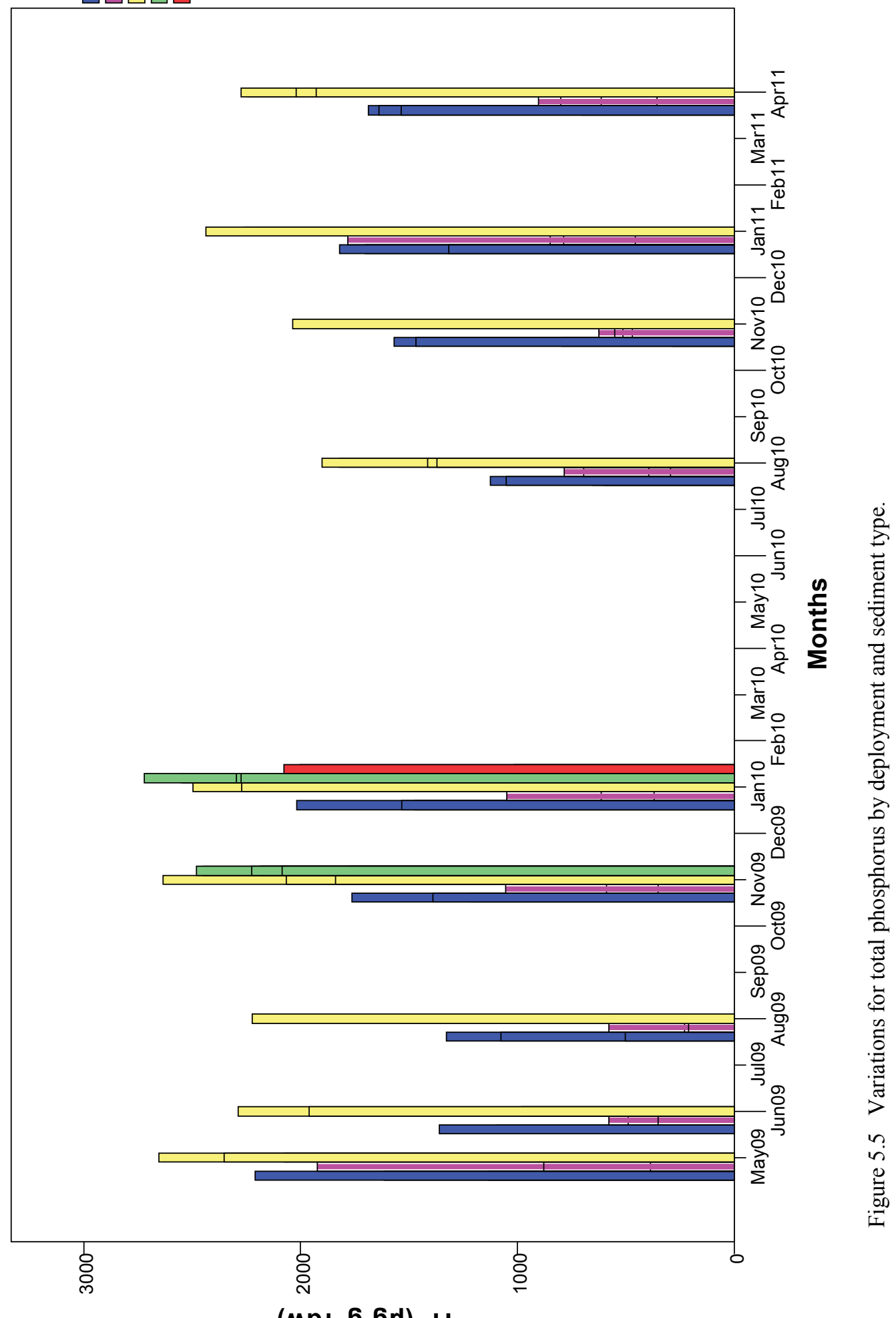

(мpL-6 6rl) dL 


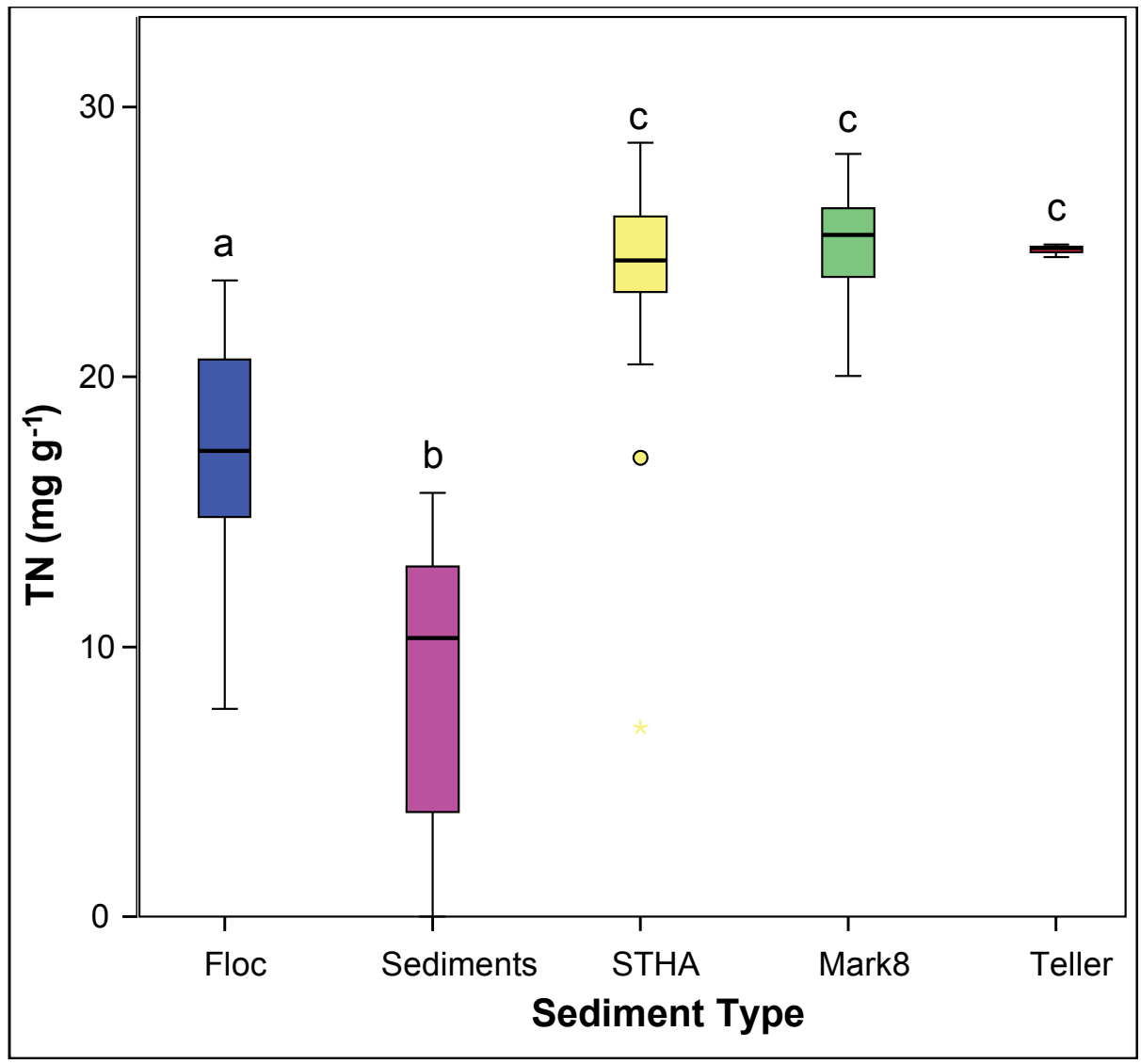

FIGURE 5.6 Box and whisker for total nitrogen by sediment type. Refer to figure 5.2 for statistical analysis.

TABLE 5.4 Mean, standard deviation and range of total nitrogen (mg L ${ }^{-1}$ ) by sediment type. Refer to figures 5.8 to 5.9 for additional graphs.

\begin{tabular}{|l|c|c|r|}
\hline Sediment Type & Mean +/- Std. Dev. & Range & \multicolumn{1}{c|}{$\mathrm{n}$} \\
\hline Floc & $17.07+/-4.15$ & $7.70-23.56$ & 30 \\
Sediments & $8.50+/-5.34$ & $0.00-15.70$ & 31 \\
STHA & $23.96+/-4.02$ & $7.00-28.67$ & 31 \\
Mark8 & $24.88+/-1.89$ & $20.04-28.27$ & 20 \\
Teller & $24.70+/-0.23$ & $24.45-24.89$ & 3 \\
All Sediments & $18.29+/-7.77$ & $0.00-28.67$ & 117 \\
\hline
\end{tabular}




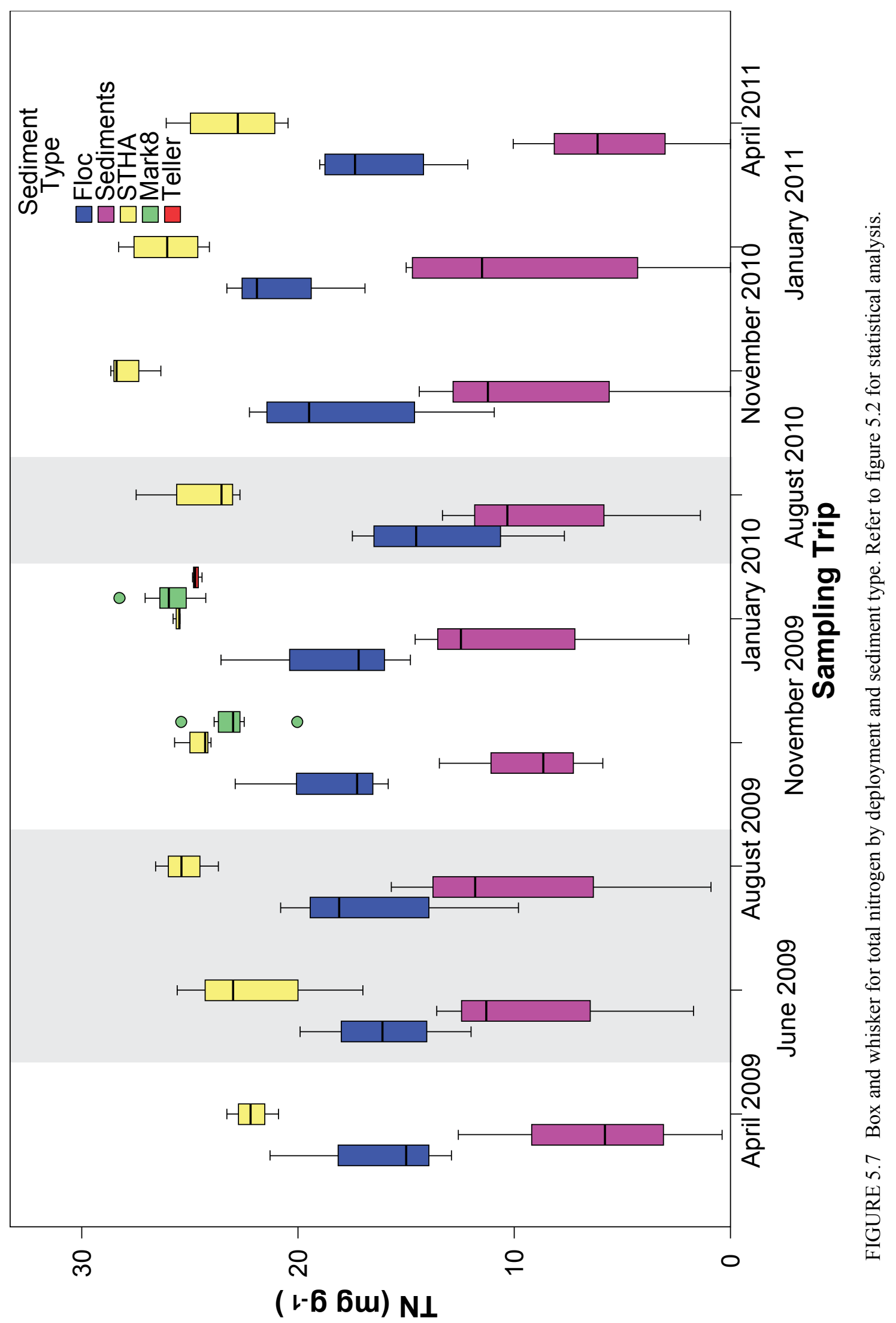




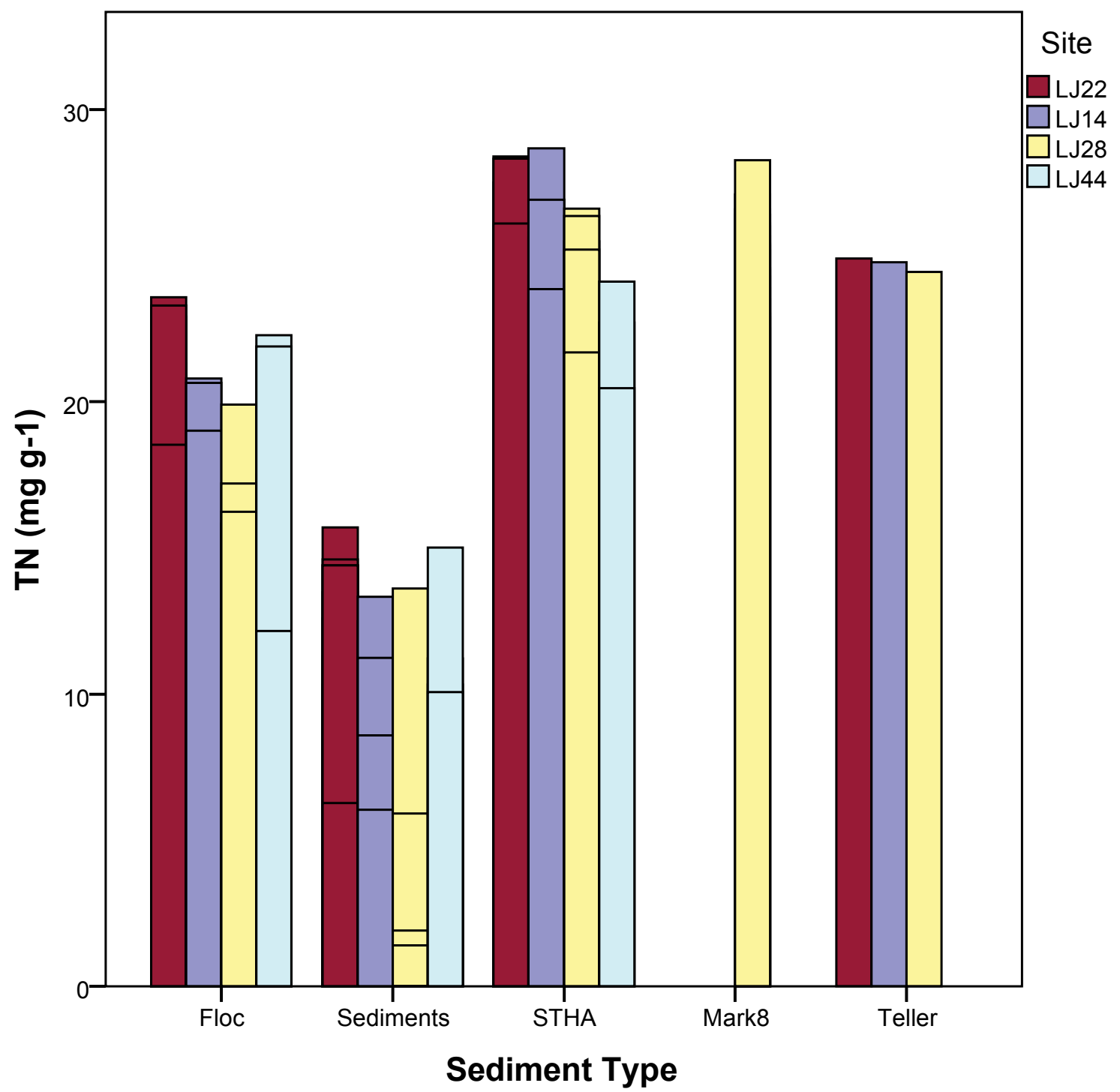

FIGURE 5.8 Variations for total nitrogen by sediment type. 


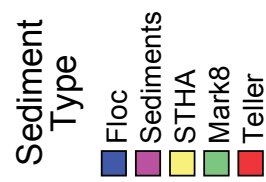

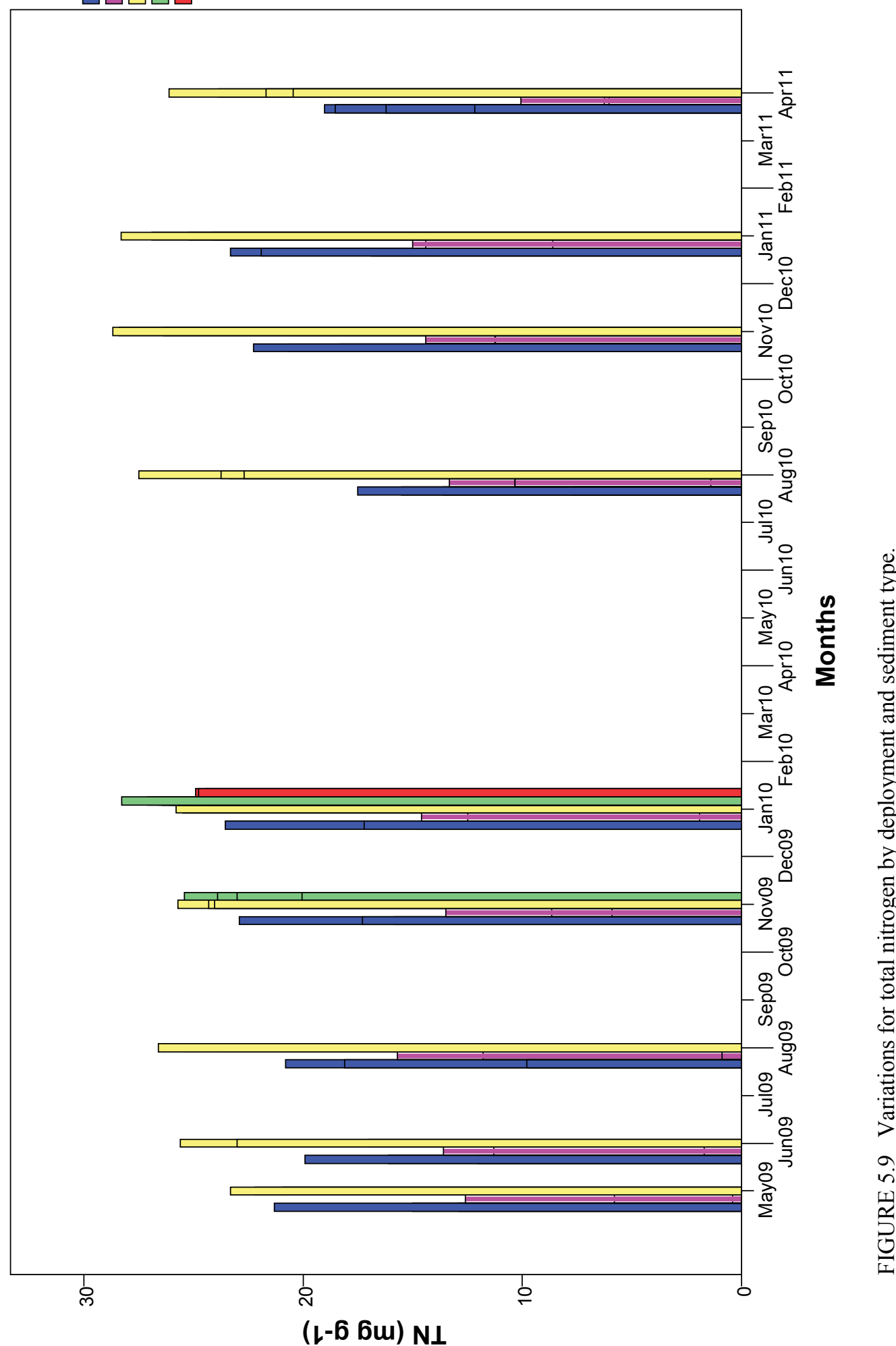




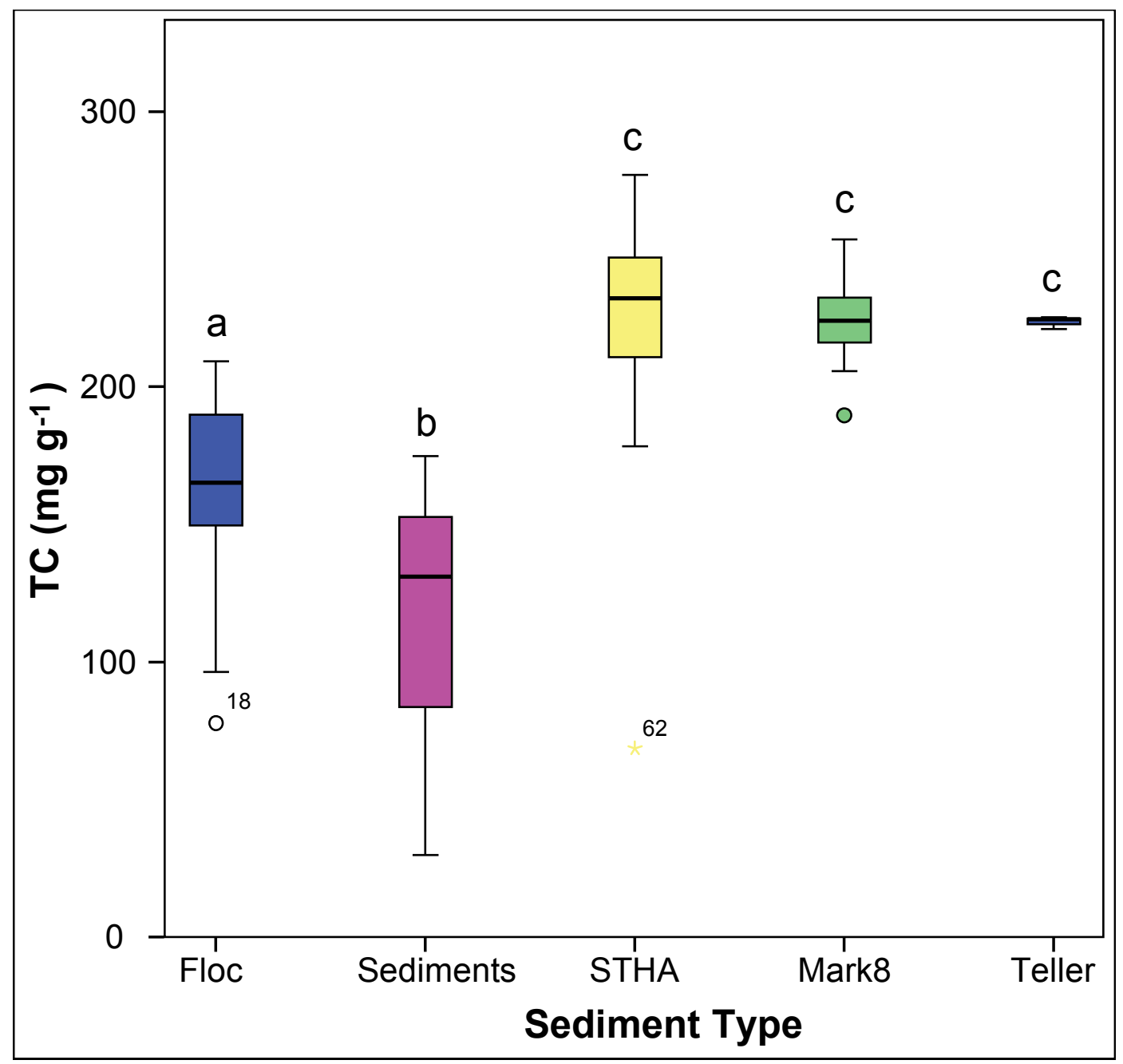

FIGURE 5.10 Box and whisker for total carbon by sediment type. Refer to figure 5.2 for statistical analysis.

TABLE 5.5 Mean, standard deviation and range of total carbon $\left(\mathrm{mg} \mathrm{L}^{-1}\right)$ by sediment type. Refer to figures 5.12 and 5.13 for additional graphs.

\begin{tabular}{|l|l|r|r|}
\hline Sediment Type & \multicolumn{1}{|c|}{ Mean +/- Std. Dev. } & Range & $\mathrm{n}$ \\
\hline Floc & $164.40+/-33.47$ & $77.80-209.24$ & 30 \\
Sediments & $118.73+/-43.29$ & $29.70-174.76$ & 31 \\
STHA & $225.98+/-36.61$ & $68.50-277.06$ & 31 \\
Mark8 & $224.18+/-15.03$ & $189.65-253.62$ & 20 \\
Teller & $223.53+/-2.32$ & $220.88-225.21$ & 3 \\
All Sediments & $181.33+/-56.52$ & $29.70-277.06$ & 117 \\
\hline
\end{tabular}




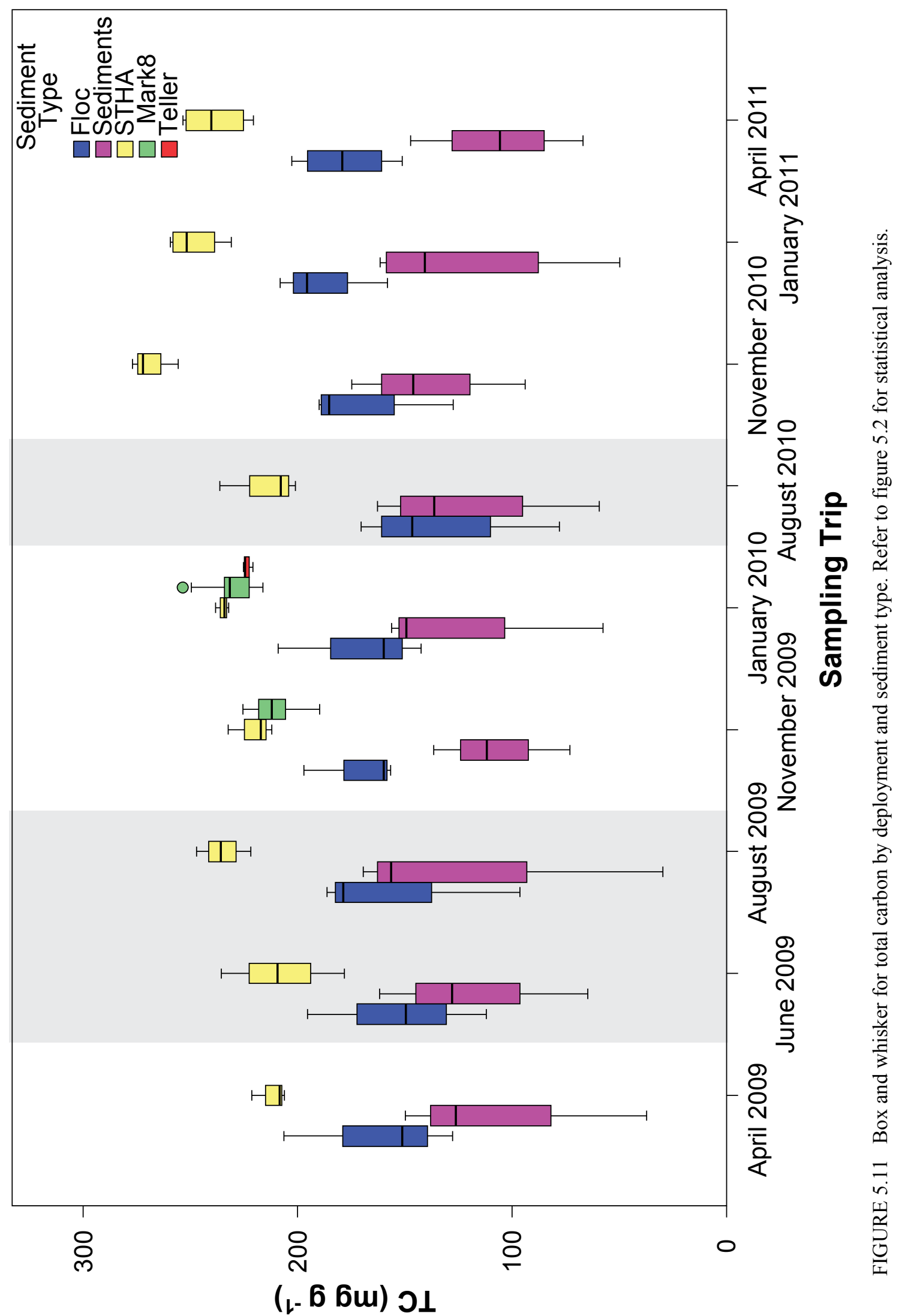




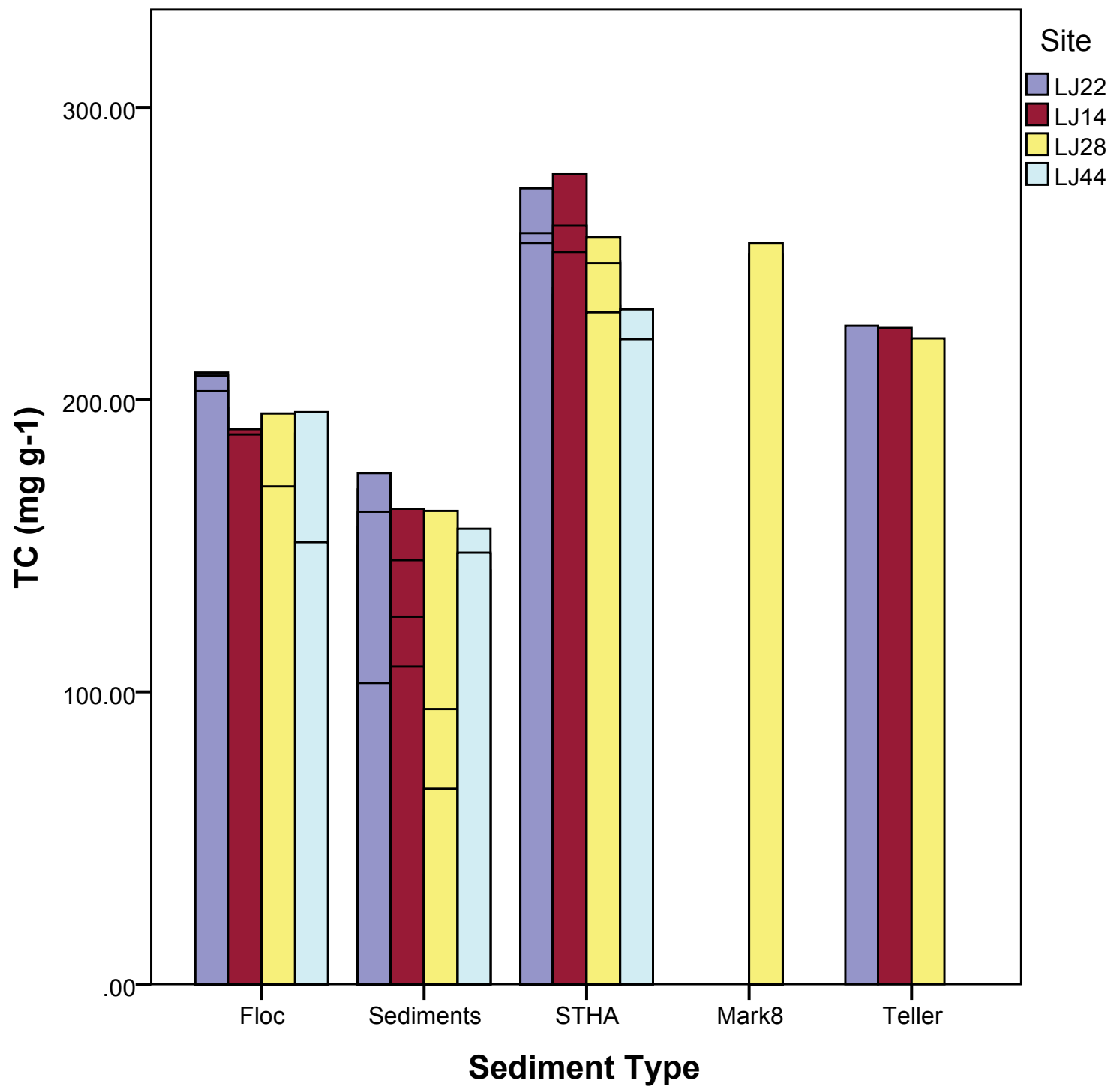

FIGURE 5.12 Variations for total carbon by sediment type. 

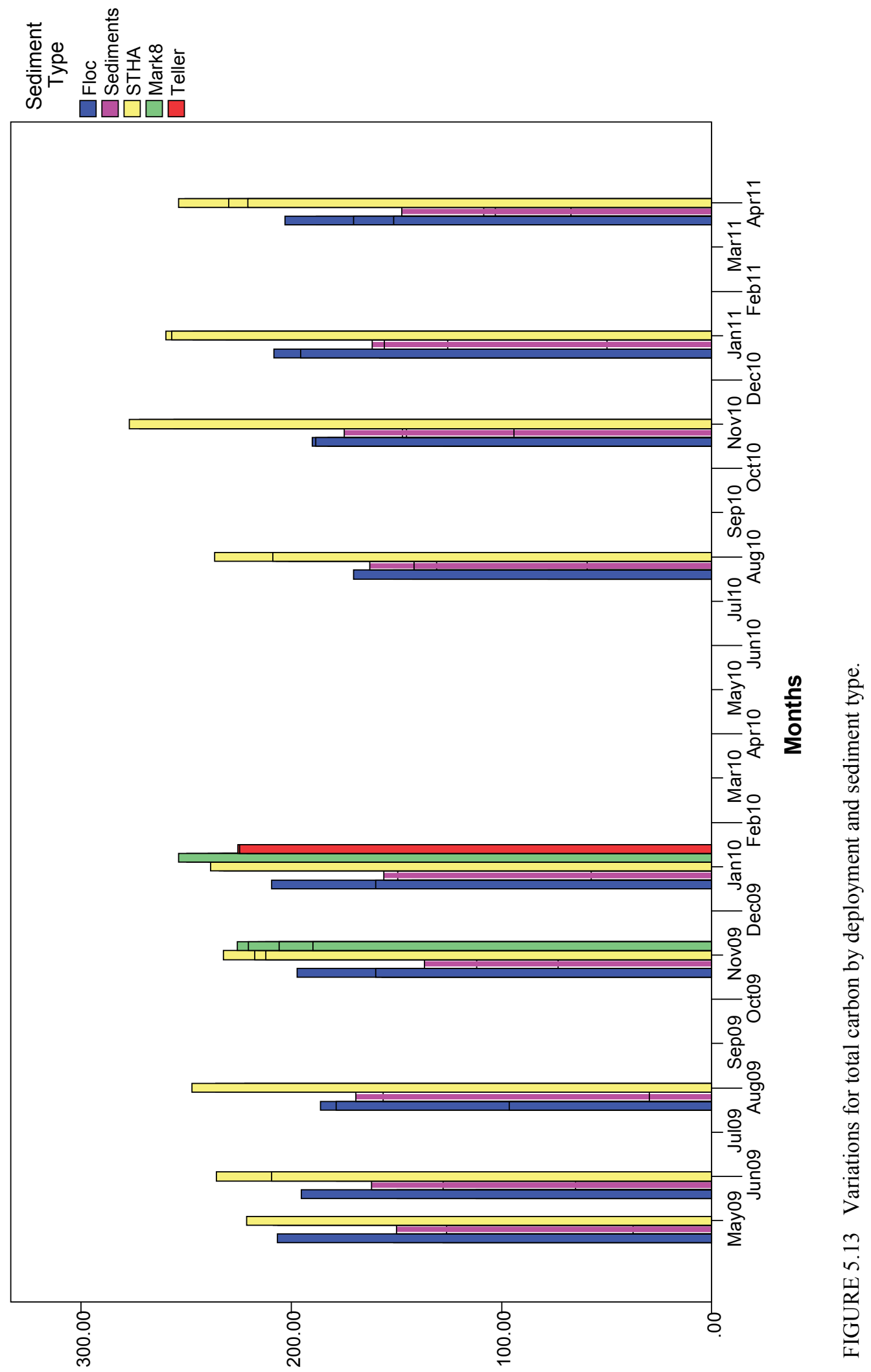

( 


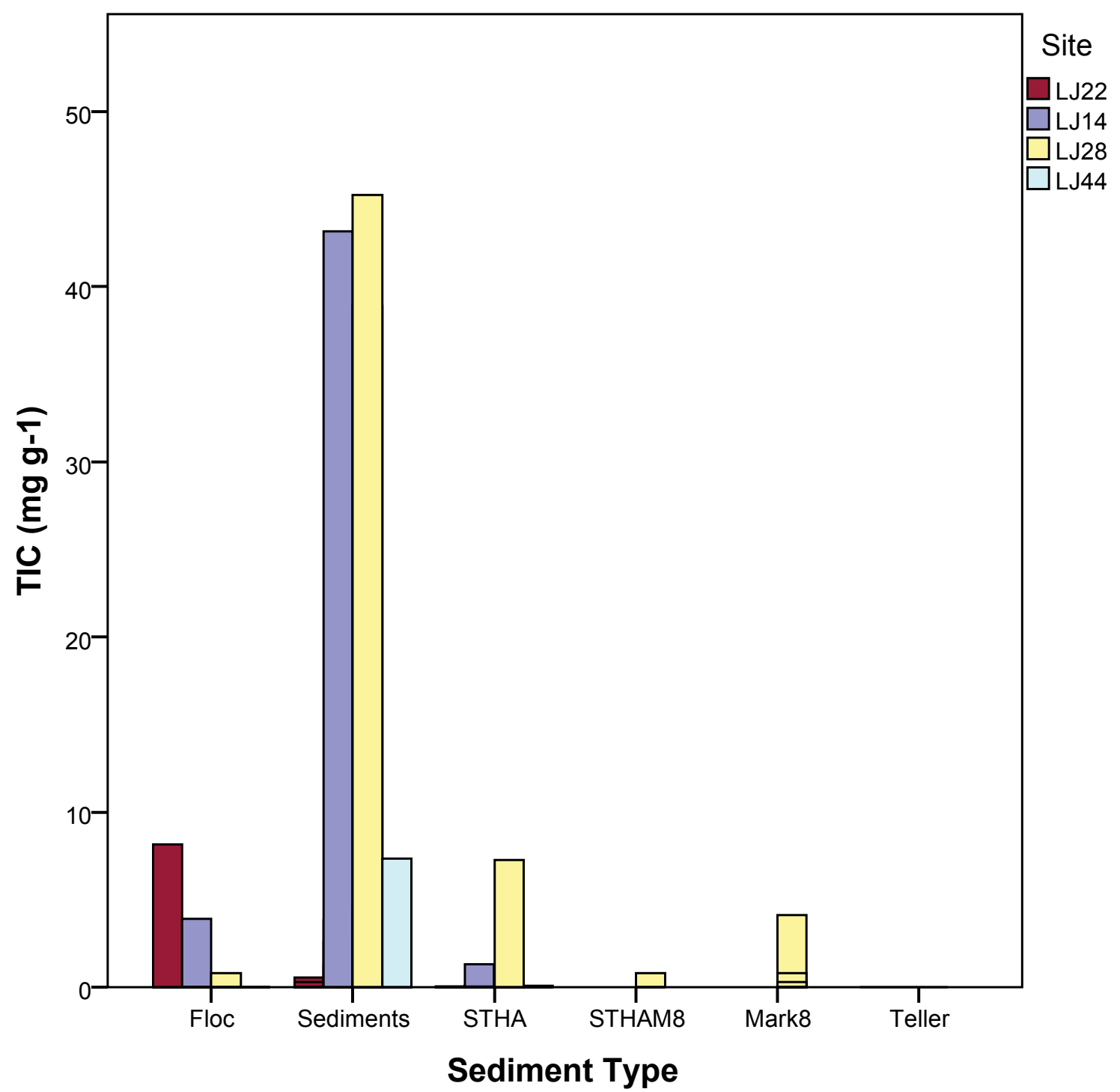

FIGURE 5.14 Variations for total inorganic carbon by type for each site. 


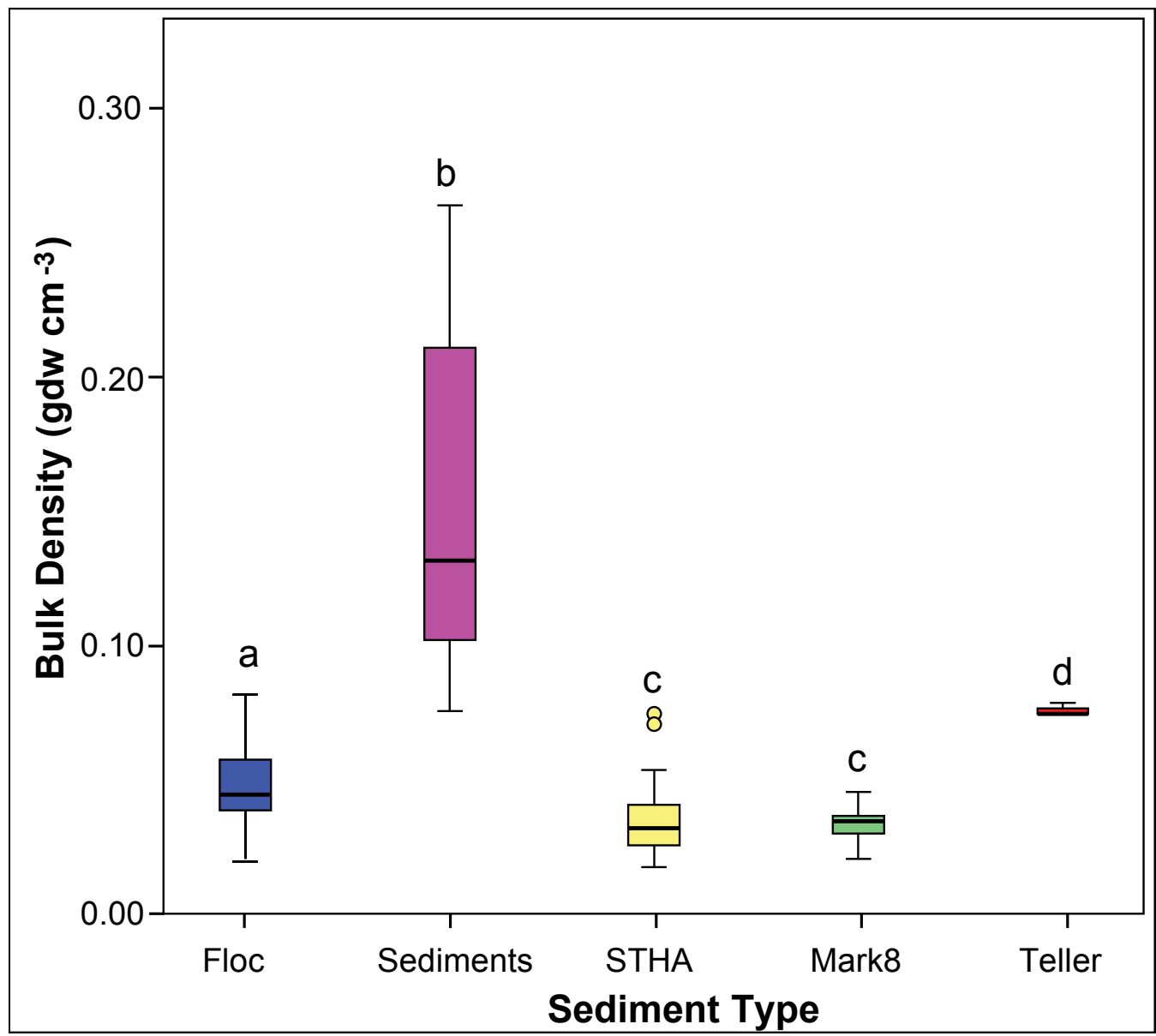

FIGURE 5.15 Box and whisker for bulk density by sediment type, seven outliers for sediments were removed (six from LJ28 and one from LJ22). Refer to figure 5.2 for statistical analysis.

TABLE 5.6 Mean, standard deviation and range of bulk density ( $\mathrm{g} \mathrm{dw}$ $\mathrm{cm}^{-3}$ ) by sediment type. Refer to figures 5.17 and 5.18 for additional graphs

\begin{tabular}{|l|l|c|r|}
\hline Sediment Type & Mean +/- Std. Dev. & Range & \multicolumn{1}{c|}{$\mathrm{n}$} \\
\hline Floc & $0.049+/-0.015$ & $0.021-0.082$ & 30 \\
Sediments & $0.232+/-0.211$ & $0.076-0.707$ & 31 \\
STHA & $0.035+/-0.013$ & $0.018-0.075$ & 42 \\
Mark8 & $0.034+/-0.006$ & $0.021-0.046$ & 20 \\
Teller & $0.076+/-0.002$ & $0.075-0.079$ & 3 \\
All Sediments & $0.087+/-0.132$ & $0.018-0.707$ & 128 \\
\hline
\end{tabular}




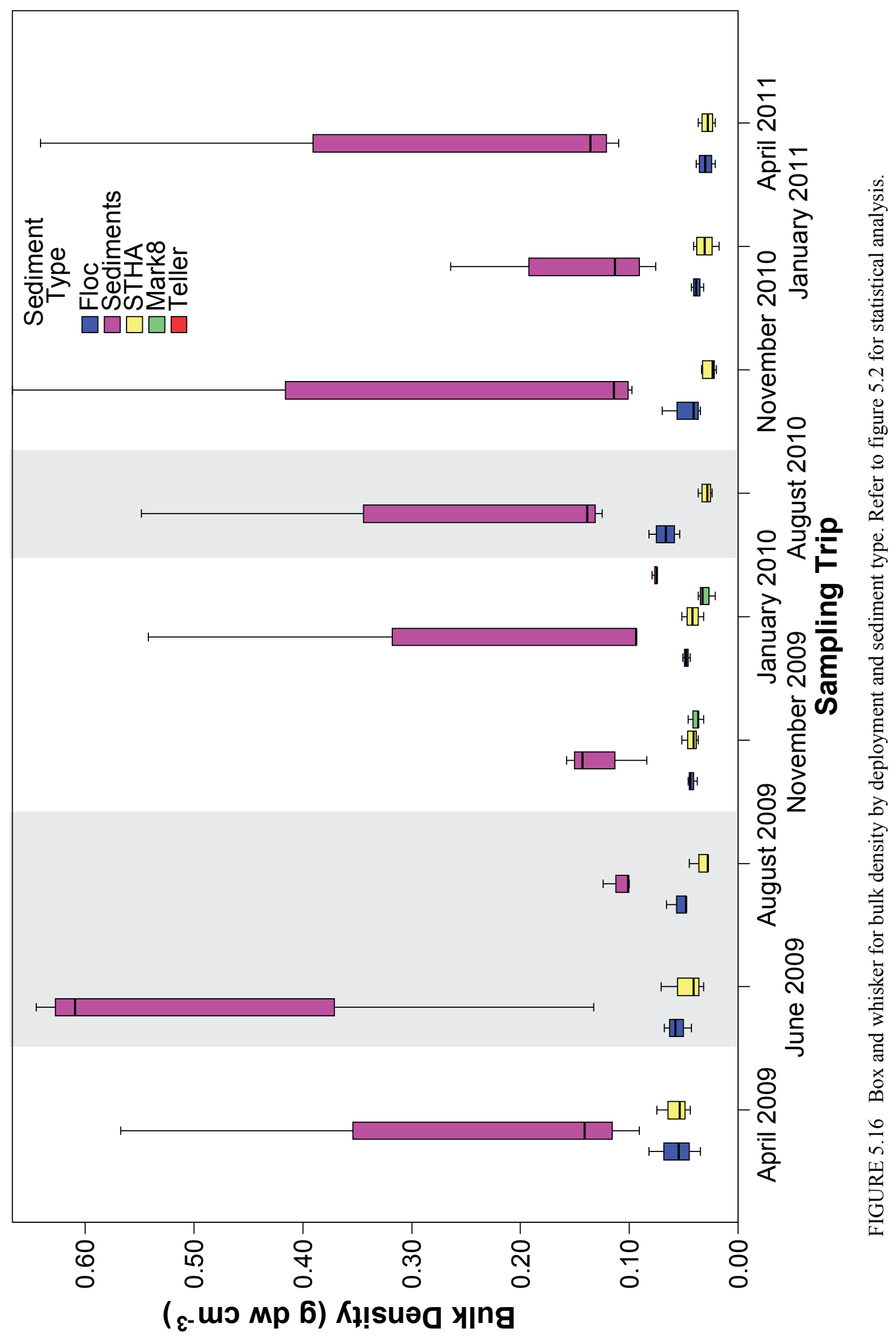




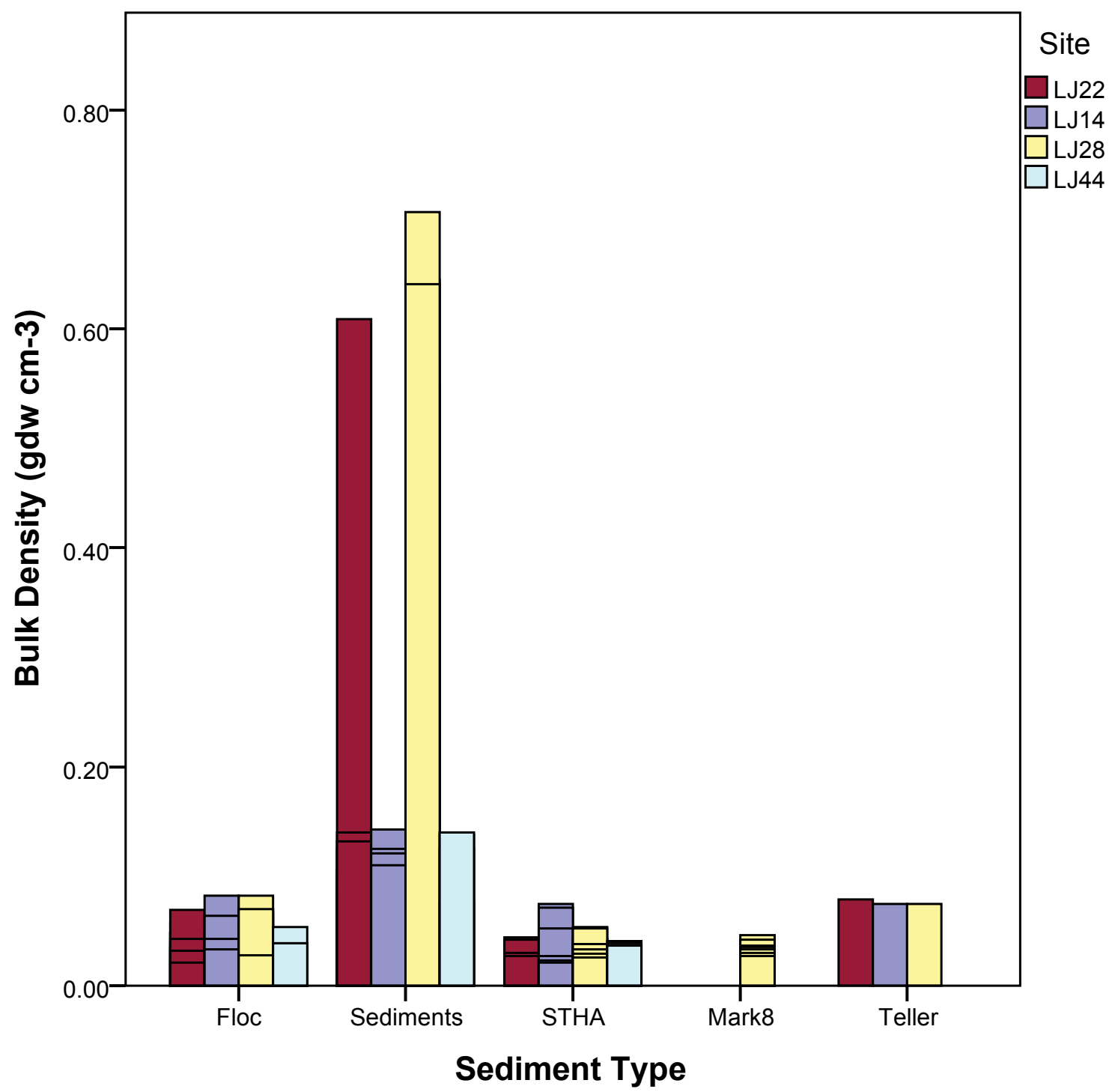

FIGURE 5.17 Variations for bulk density by sediment type for each site. 

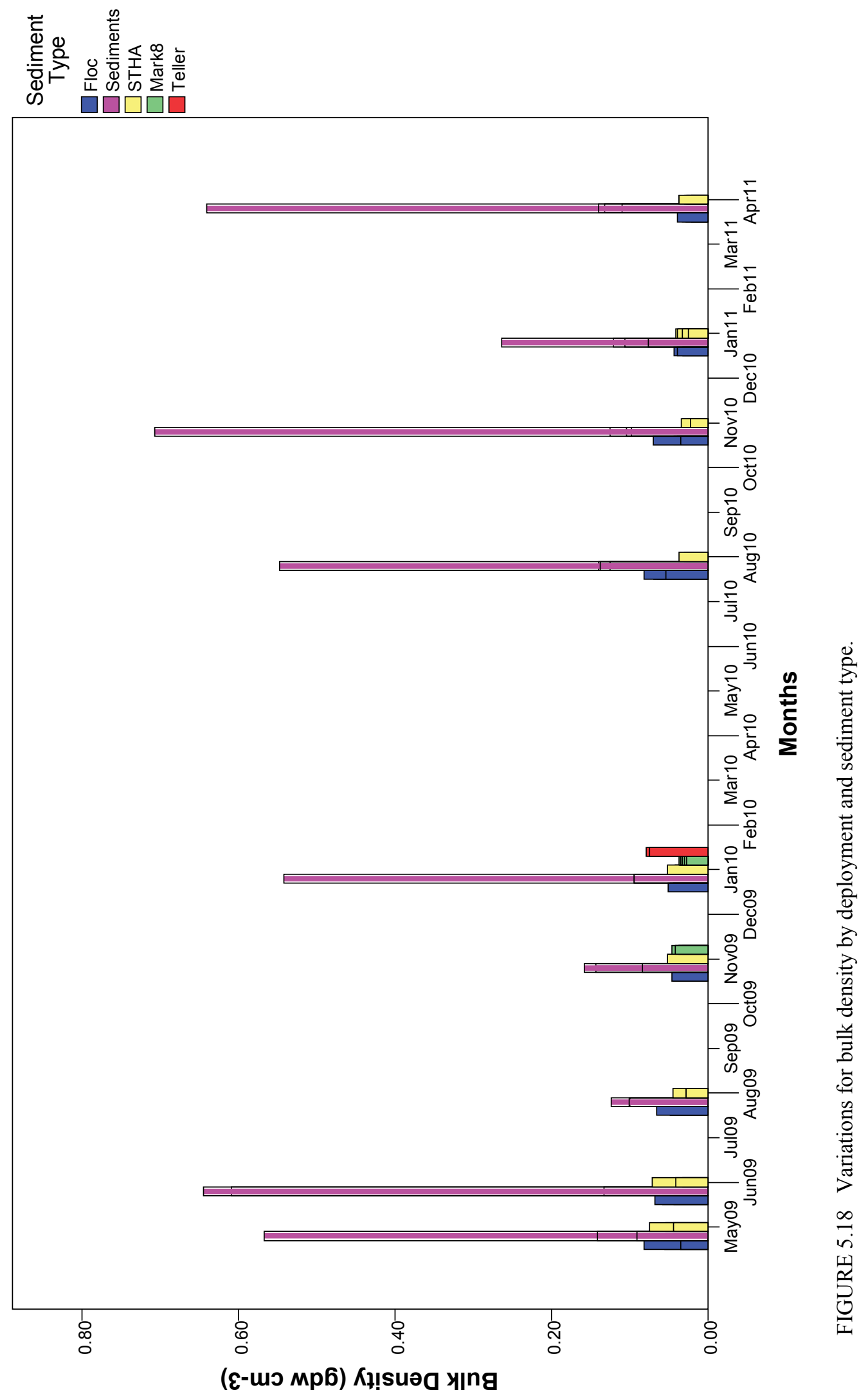


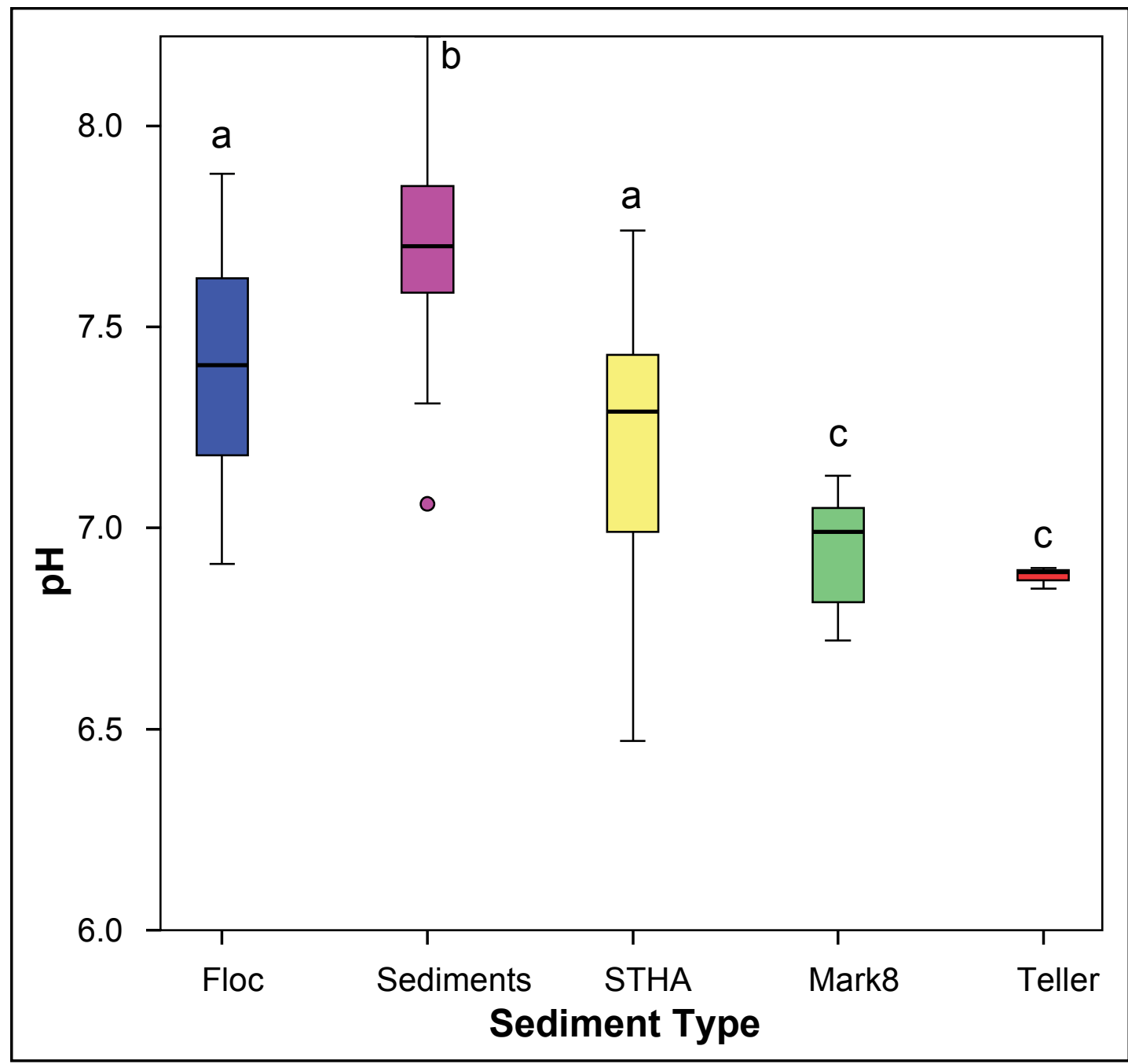

FIGURE 5.19 Box and whisker for total in $\mathrm{pH}$ by sediment type. Refer to figure 5.2 for statistical analysis. 


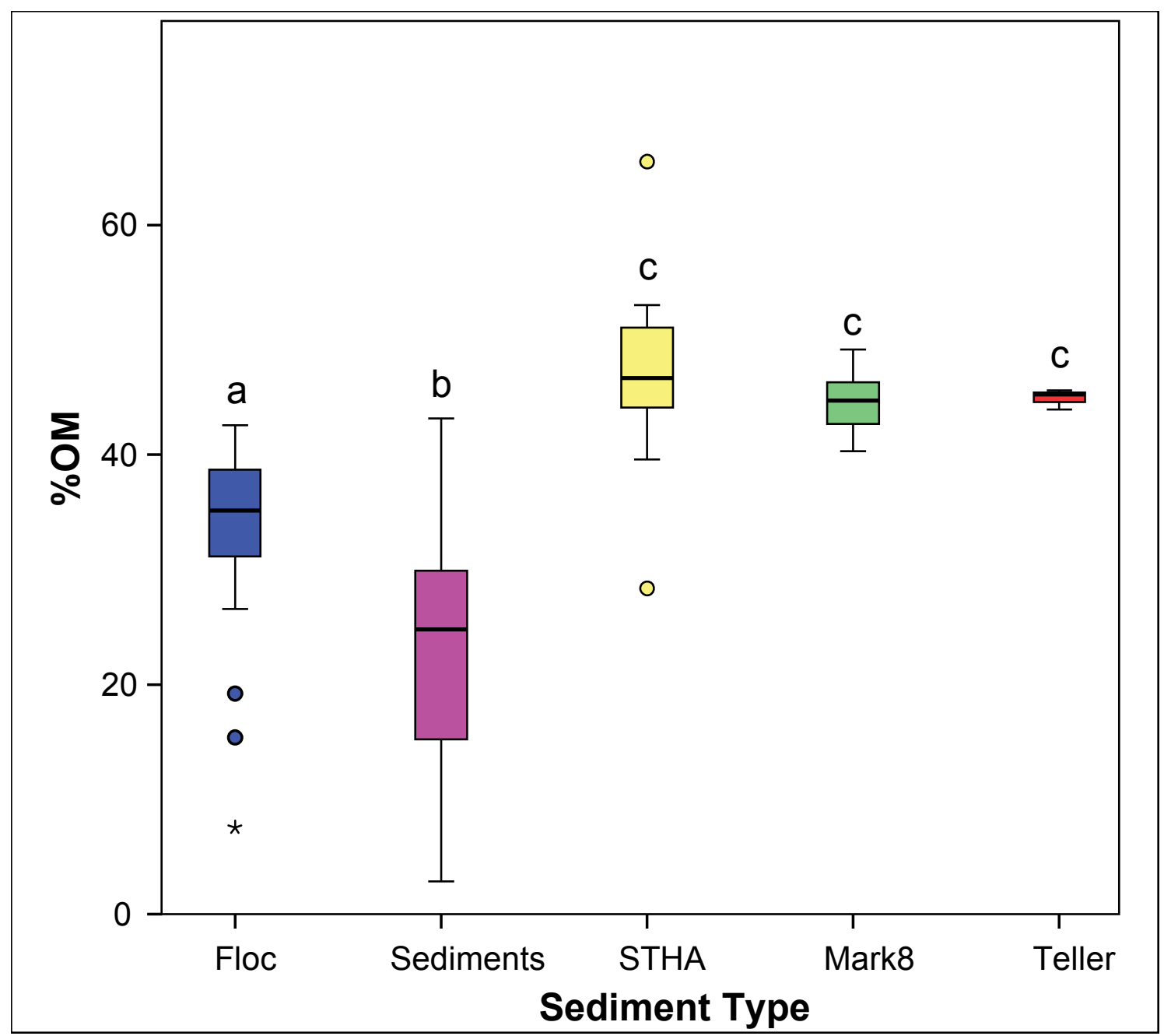

FIGURE 5.20 Box and whisker for percent organic matter by sediment type. Refer to figure 5.2 for statistical analysis.

TABLE 5.7 Mean, standard deviation and range of percent organic matter by sediment type. Refer to figures 5.21 to 5.22 for additional graphs.

\begin{tabular}{|l|c|r|r|}
\hline Sediment Type & Mean +/- Std. Dev. & \multicolumn{1}{|c|}{ Range } & \multicolumn{1}{c|}{$\mathrm{n}$} \\
\hline Floc & $33.28+/-7.96$ & $7.57-42.59$ & 30 \\
Sediments & $21.73+/-10.67$ & $2.86-43.17$ & 31 \\
STHA & $47.16+/-6.22$ & $28.38-65.51$ & 31 \\
Mark8 & $44.65+/-2.38$ & $40.34-49.17$ & 20 \\
Teller & $44.94+/-0.86$ & $43.97-45.62$ & 3 \\
All Sediments & $36.34+/-12.74$ & $2.86-65.51$ & 117 \\
\hline
\end{tabular}




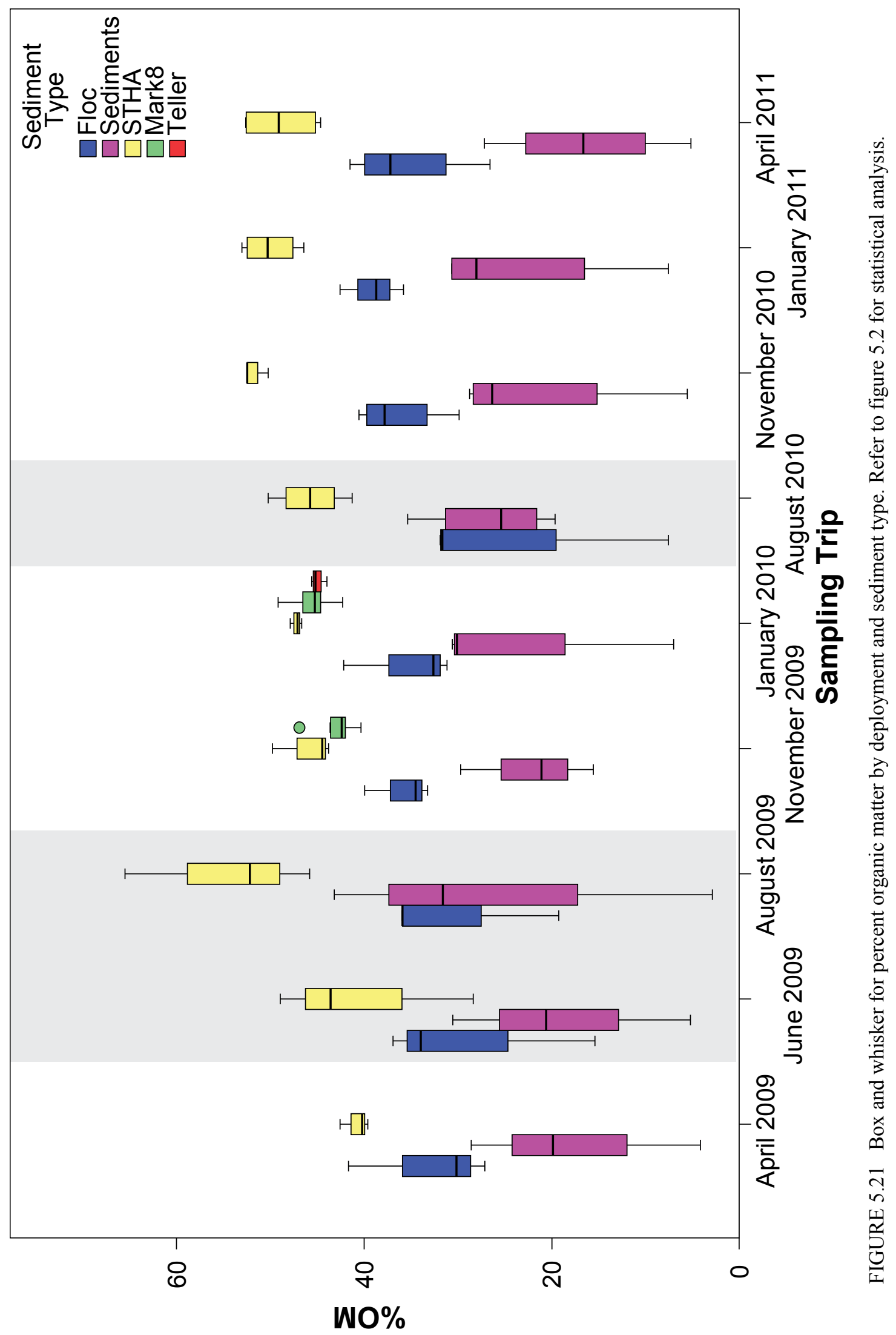




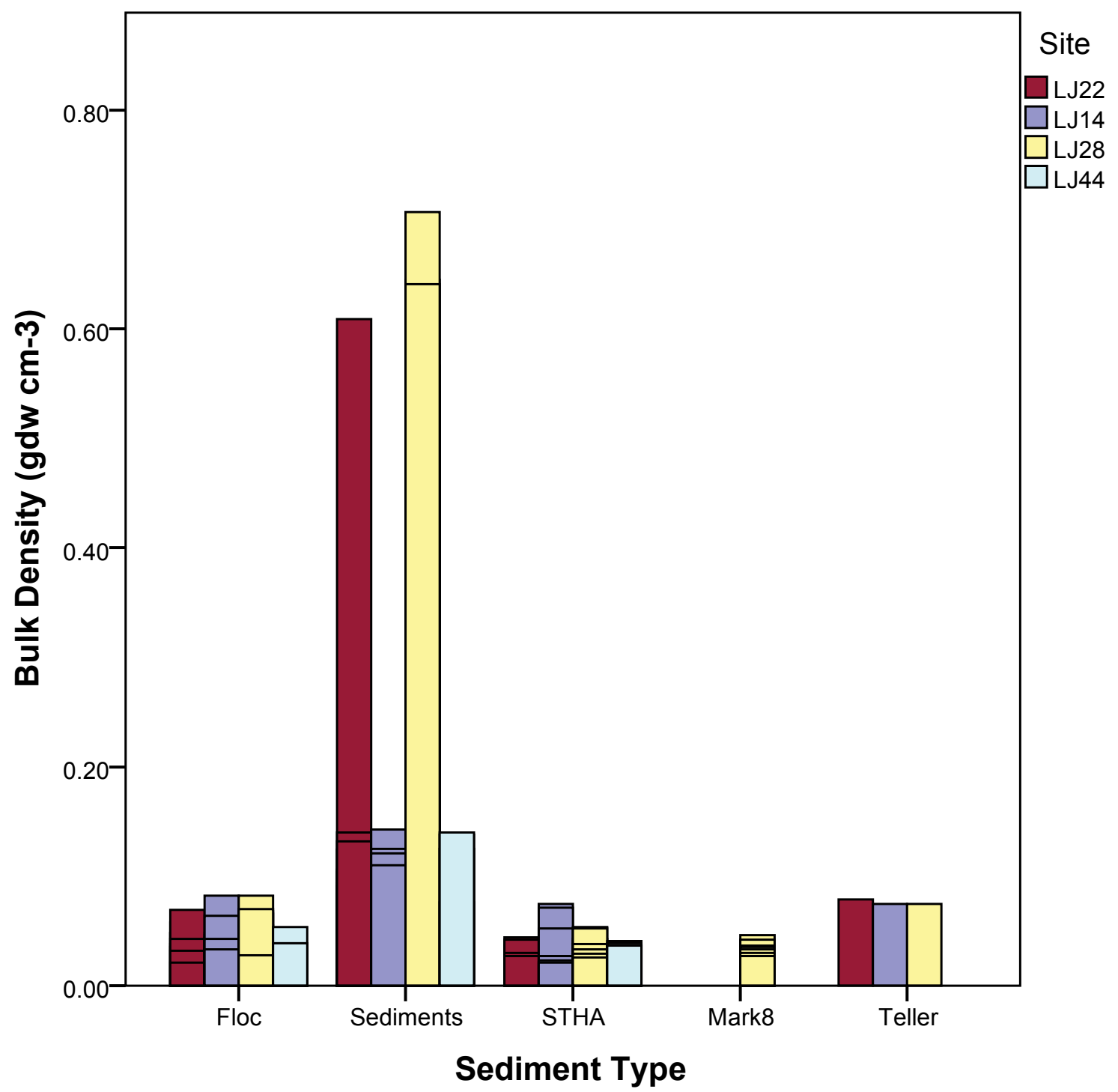

FIGURE 5.22 Variations for percent organic matter by sediment type. 

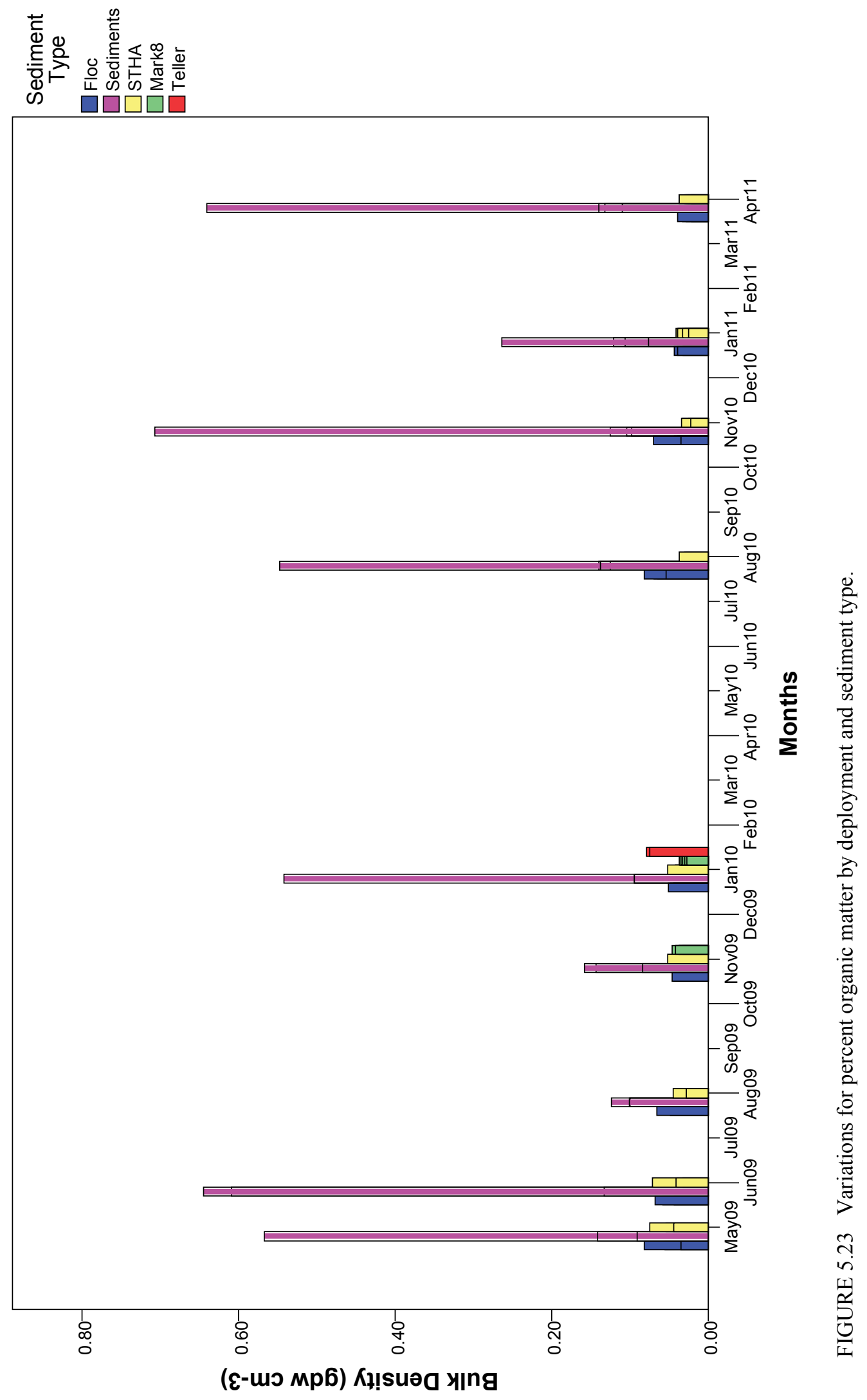


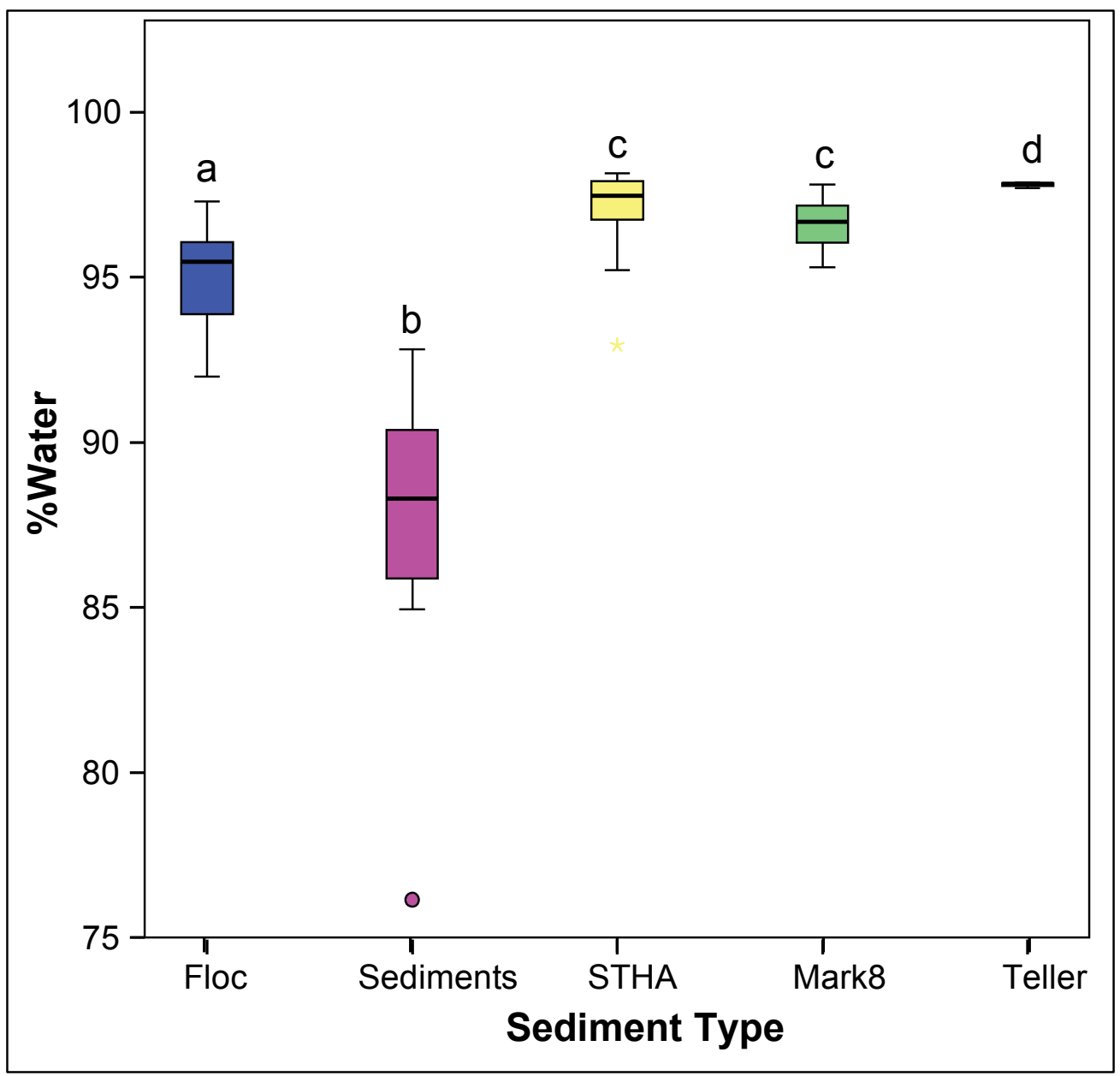

FIGURE 5.24 Box plots for percent water content by sediment type, 6 outliers were removed all from L28. Refer to figure 5.2 for statistical analysis.

TABLE 5.8 Mean, standard deviation and range of percent water content by sediment type.

\begin{tabular}{|l|c|c|r|}
\hline Type & Mean +/- Std. Dev. & Range & \multicolumn{1}{c|}{$\mathrm{n}$} \\
\hline Floc & $95.03+/-1.46$ & $92.02-97.32$ & 30 \\
Sediments & $82.00+/-14.30$ & $47.89-92.83$ & 31 \\
STHA & $97.20+/-1.02$ & $92.97-98.15$ & 42 \\
Mark8 & $96.68+/-0.67$ & $95.31-97.82$ & 20 \\
Teller & $97.81+/-0.08$ & $97.72-97.88$ & 3 \\
All Seds & $92.95+/-9.41$ & $47.89-98.17$ & 128 \\
\hline
\end{tabular}




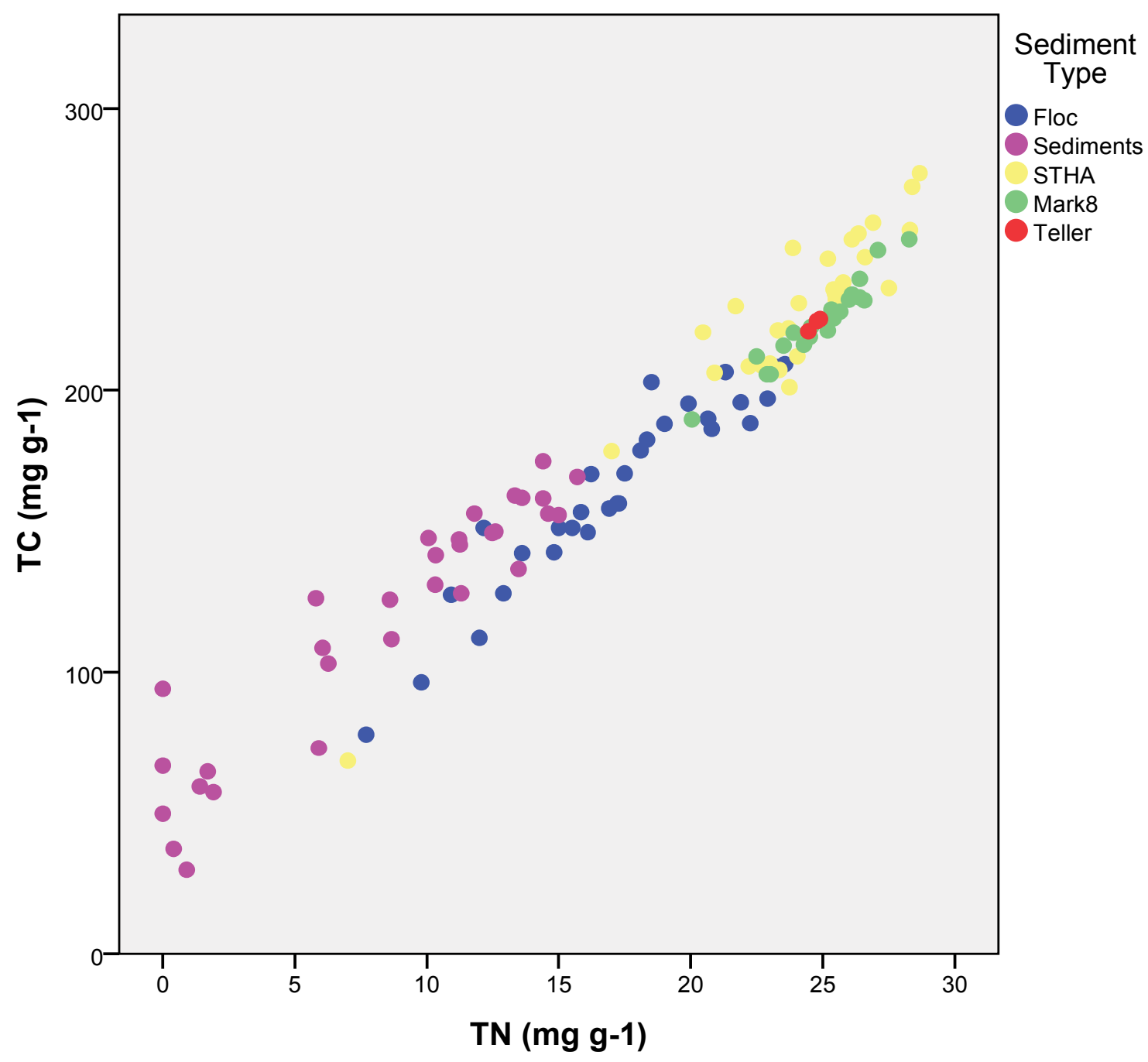

FIGURE 5.25 Total carbon vs. total nitrogen for all sediments. 


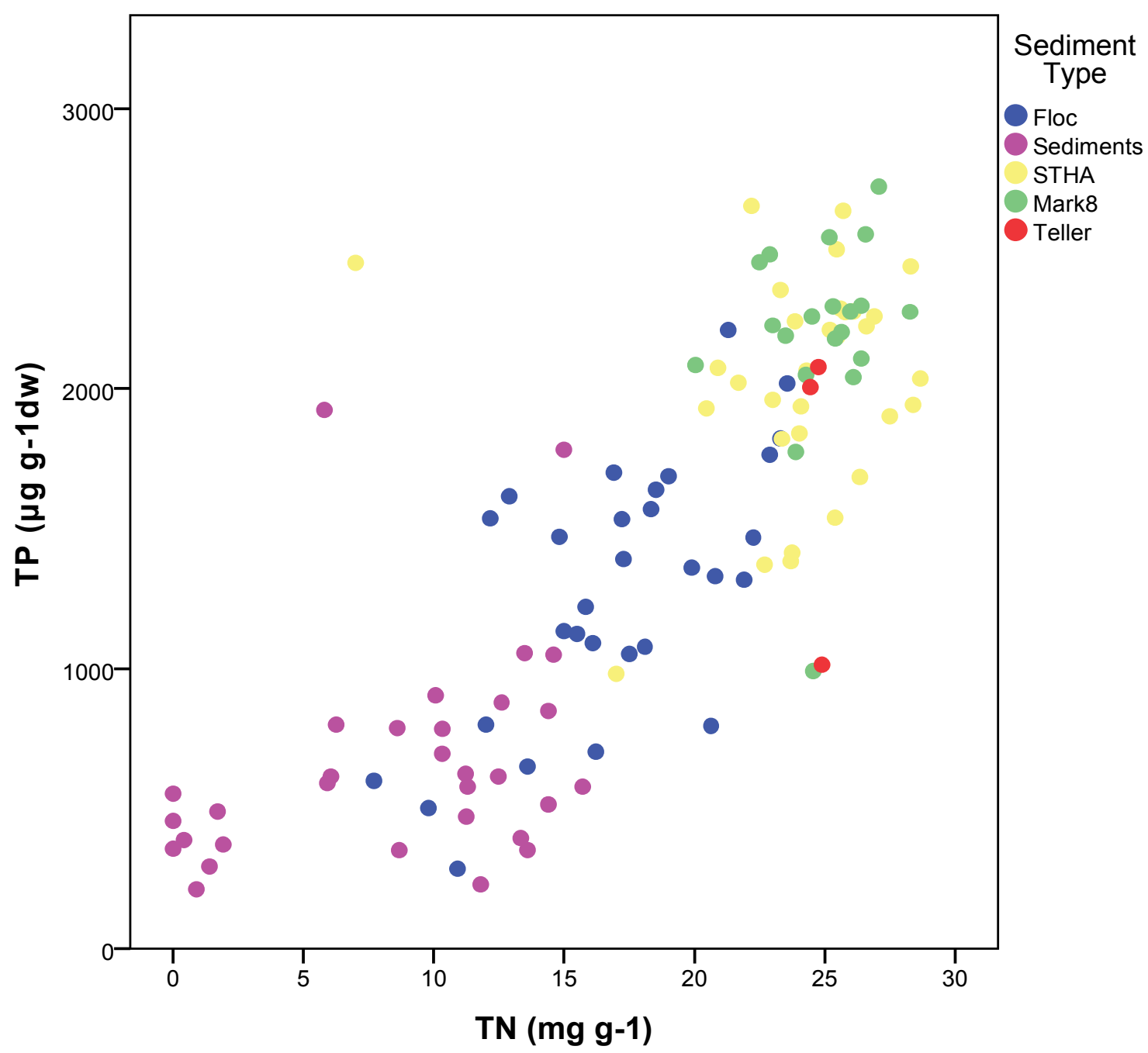

FIGURE 5.26 Total phosphorus vs. total nitrogen for all sediments. 


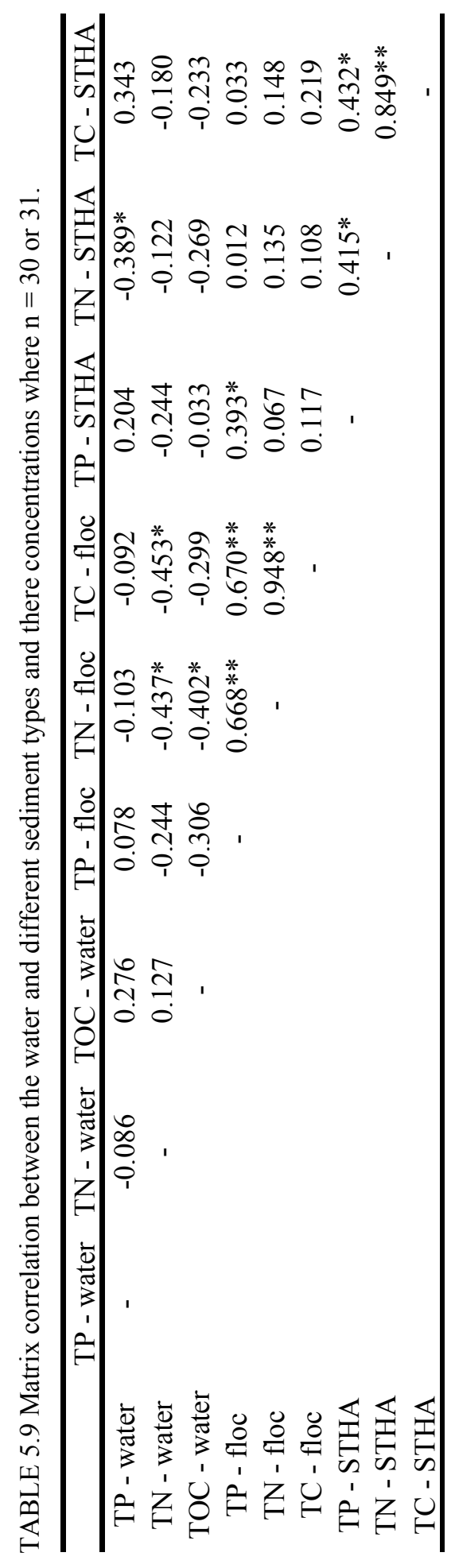




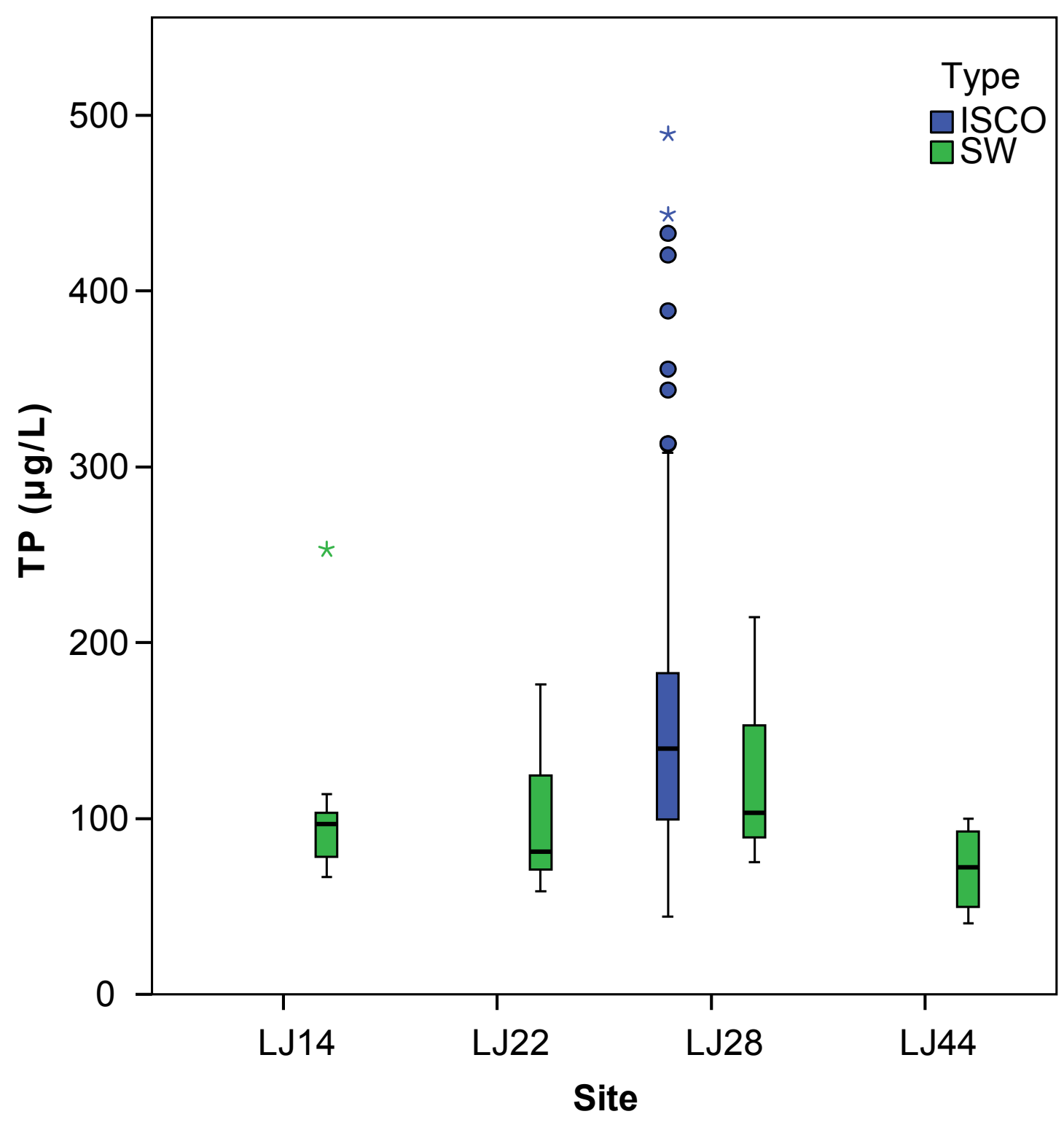

FIGURE 5.27 Box and whisker for total phosphorus in the water column by site location. Refer to figure 5.2 for statistical analysis.

TABLE 5.10 Water nutrient correlation matrix for ISCO water samples where $\mathrm{n}=$ 73 (except for TP, $\mathrm{n}=72$ ). $* *=$ significant at $\mathrm{p}<0.01$.

\begin{tabular}{ccccc}
\hline & TP & TN & TOC & TSS \\
\hline TP & - & -0.004 & -0.008 & $0.636^{* *}$ \\
TN & & - & $0.318^{* *}$ & 0.052 \\
TOC & & & - & 0.155 \\
TSS & & & & - \\
\hline
\end{tabular}


Table 5.11 Mean, standard deviation and range for total phosphorus, nitrogen, organic carbon and chlorophyll-a by site location and sampling type. Refer to figures 5.29 to 5.31 for additional graphs.

\begin{tabular}{|c|c|c|c|c|c|c|}
\hline \multicolumn{3}{|c|}{ Sample Type Site } & $\begin{array}{c}\mathrm{TP} \\
(\mu \mathrm{g} / \mathrm{L})\end{array}$ & $\begin{array}{c}\mathrm{TN} \\
(\mu \mathrm{g} / \mathrm{L})\end{array}$ & $\begin{array}{l}\text { TOC } \\
(\mu \mathrm{g} / \mathrm{L})\end{array}$ & $\begin{array}{l}\text { Chlr-a } \\
(\mu g / L)\end{array}$ \\
\hline \multirow{5}{*}{\multicolumn{2}{|c|}{ ISCO 28}} & Mean & 169 & 1713 & 17234 & \\
\hline & & Std. Dev. & 102 & 1015 & 4716 & \\
\hline & & Minimum & 44 & 496 & 11710 & \\
\hline & & Maximum & 489 & 7670 & 39528 & \\
\hline & & $\mathrm{N}$ & 72 & 72 & 72 & \\
\hline \multirow{5}{*}{\multicolumn{2}{|c|}{ SW 14}} & Mean & 107 & 1442 & 15248 & 45.6 \\
\hline & & Std. Dev. & 57 & 546 & 2348 & 24.7 \\
\hline & & Minimum & 66 & 623 & 10620 & 7.4 \\
\hline & & Maximum & 253 & 2374 & 18390 & 79.0 \\
\hline & & $\mathrm{N}$ & 9 & 9 & 9 & 9 \\
\hline \multirow{5}{*}{\multicolumn{2}{|c|}{22}} & Mean & 99 & 1108 & 14419 & 50.3 \\
\hline & & Std. Dev. & 40 & 387 & 2501 & 31.4 \\
\hline & & Minimum & 59 & 558 & 10340 & 6.9 \\
\hline & & Maximum & 176 & 1765 & 17200 & 103.6 \\
\hline & & $\mathrm{N}$ & 9 & 9 & 9 & 9 \\
\hline & 28 & Mean & 124 & 1811 & 15961 & 56.4 \\
\hline & & Std. Dev. & 49 & 1831 & 2705 & 41.7 \\
\hline & & Minimum & 75 & 648 & 10960 & 8.6 \\
\hline & & Maximum & 215 & 6851 & 20020 & 138.3 \\
\hline & & $\mathrm{N}$ & 10 & 10 & 10 & 10 \\
\hline & 44 & Mean & 71 & 1847 & 13729 & 35.1 \\
\hline & & Std. Dev. & 27 & 523 & 4096 & 19.4 \\
\hline & & Minimum & 40 & 1191 & 9601 & 8.2 \\
\hline & & Maximum & 100 & 2363 & 18188 & 51.3 \\
\hline & & $\mathrm{N}$ & 4 & 4 & 4 & 4 \\
\hline
\end{tabular}




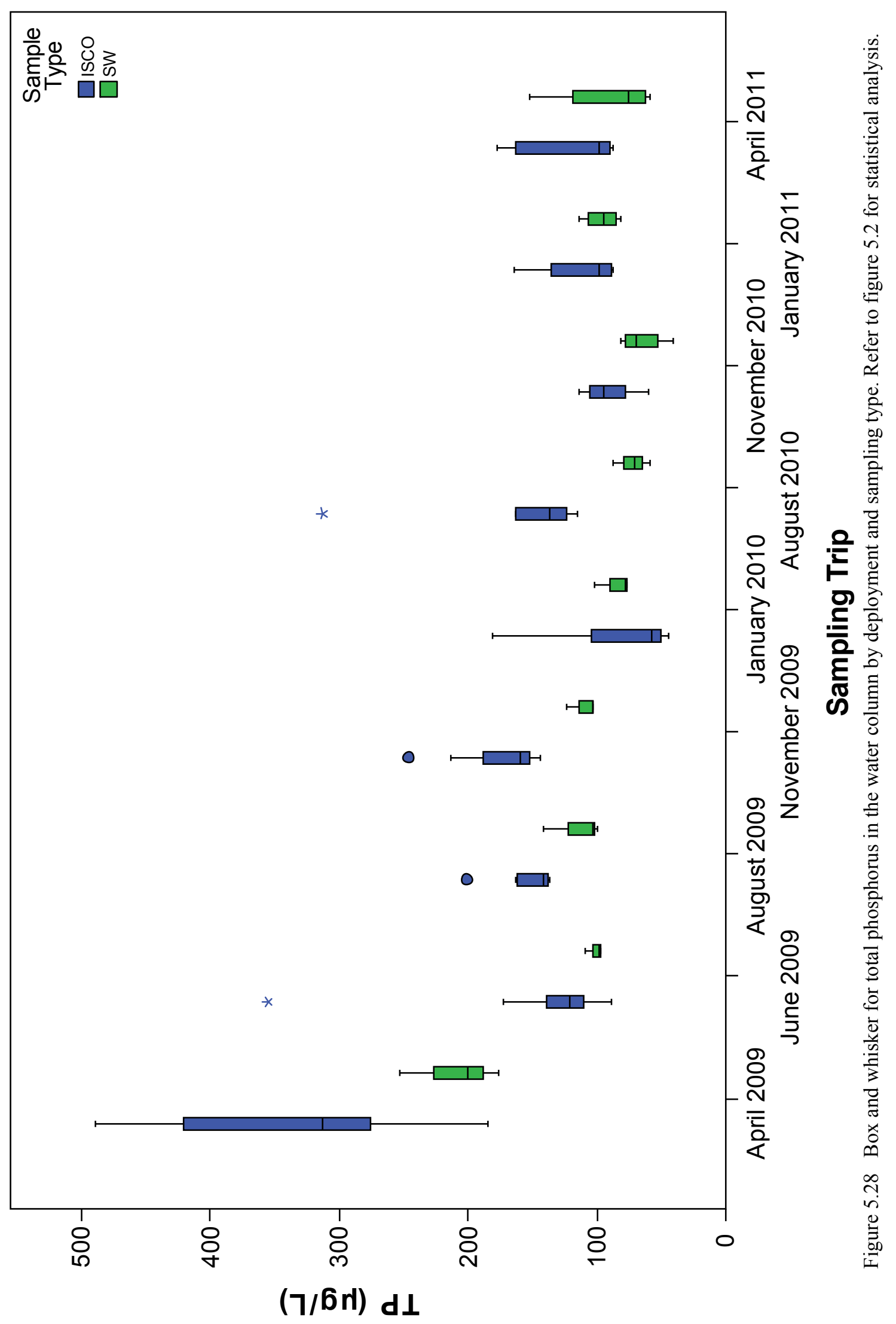




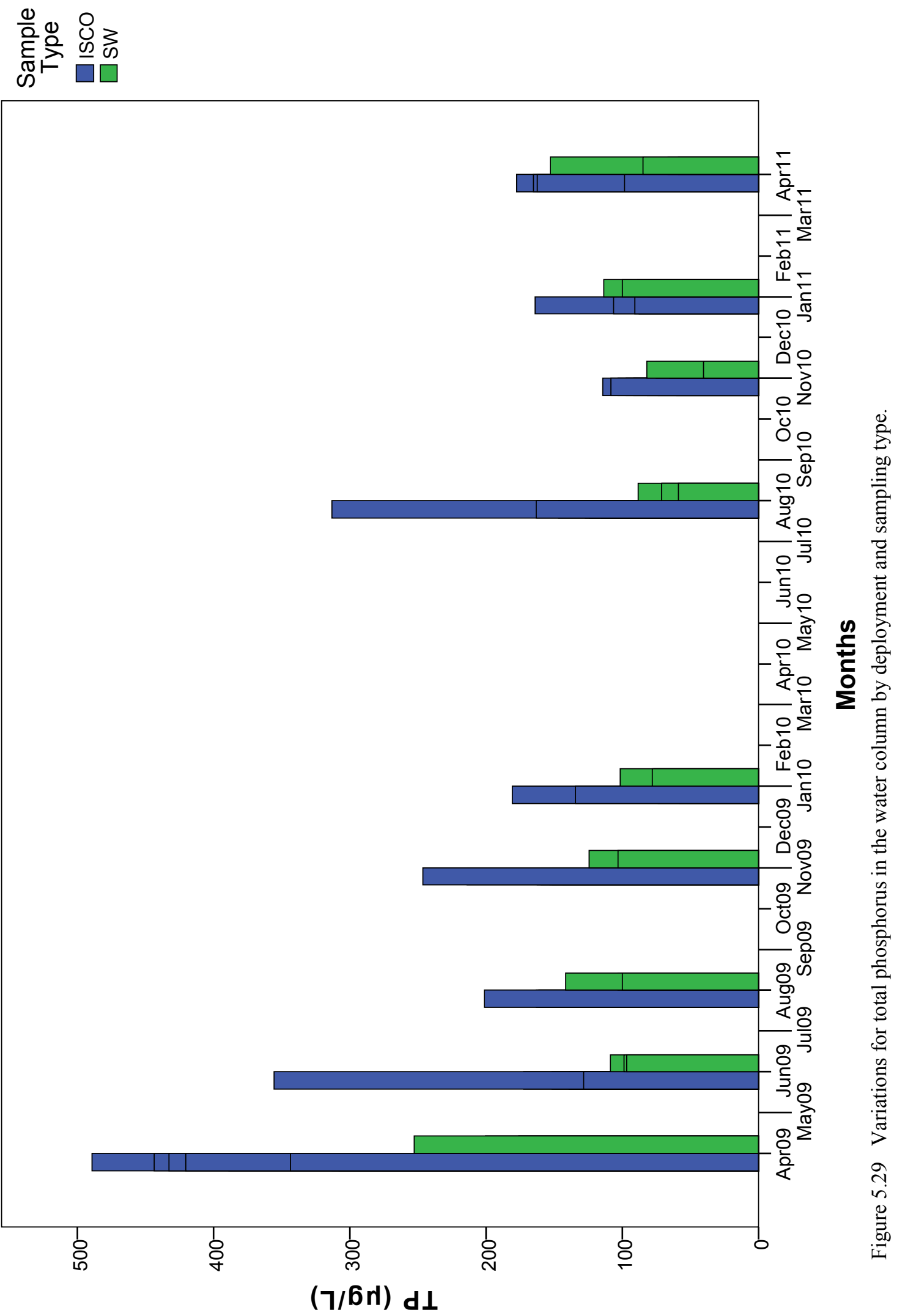




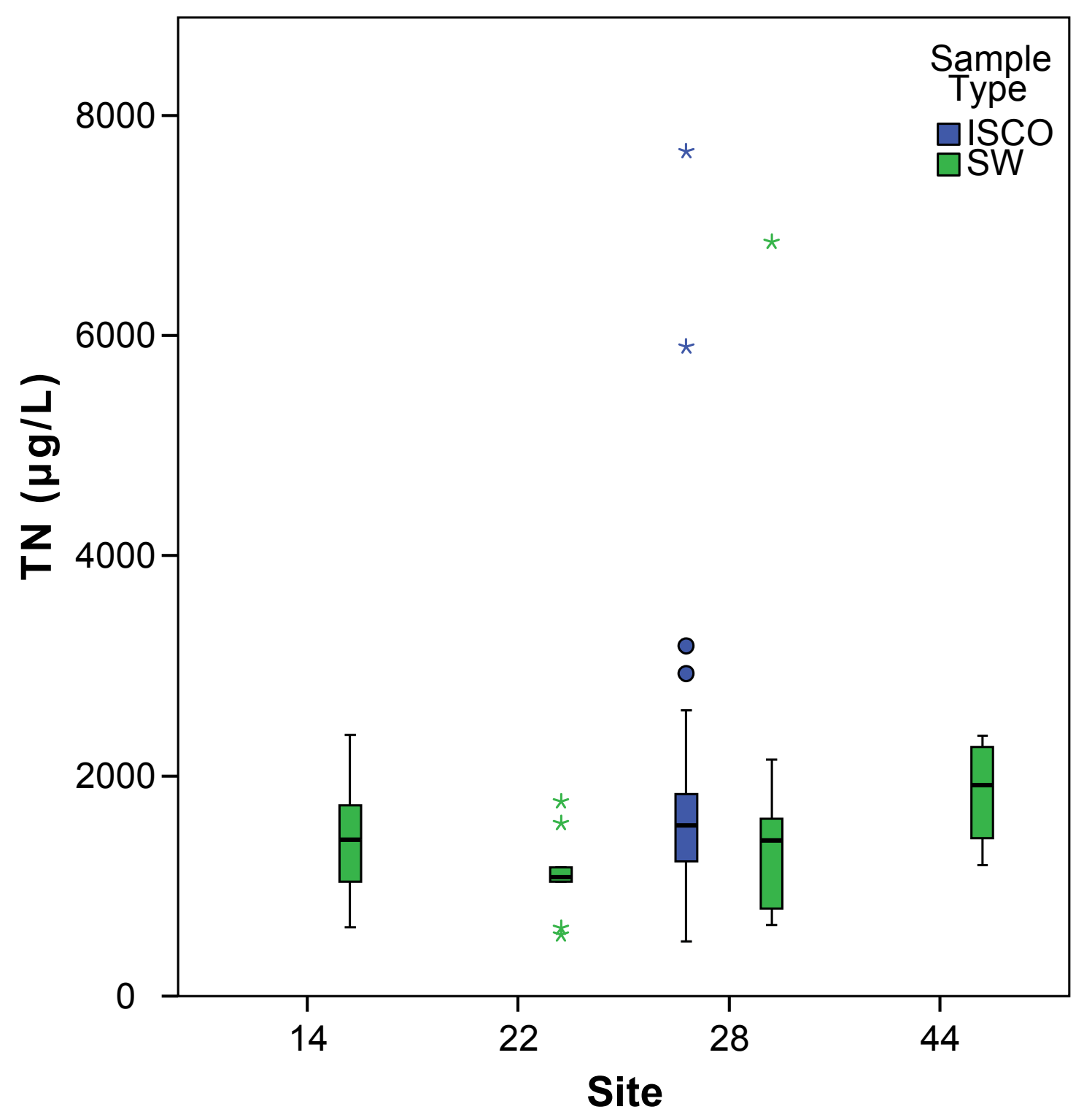

FIGURE 5.30 Box and whisker for total nitrogen in the water column by site location. Refer to figure 5.2 for statistical analysis. 


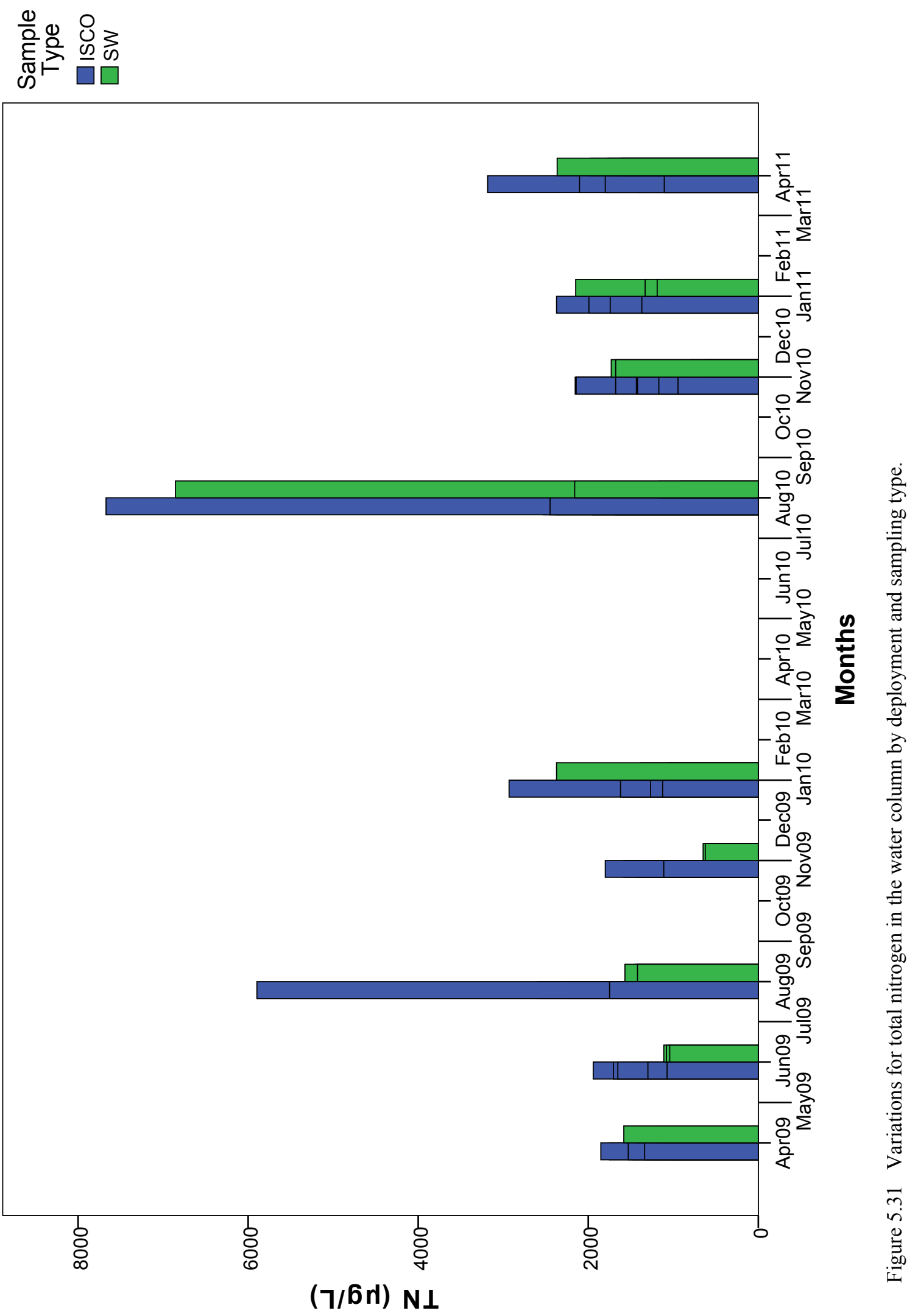




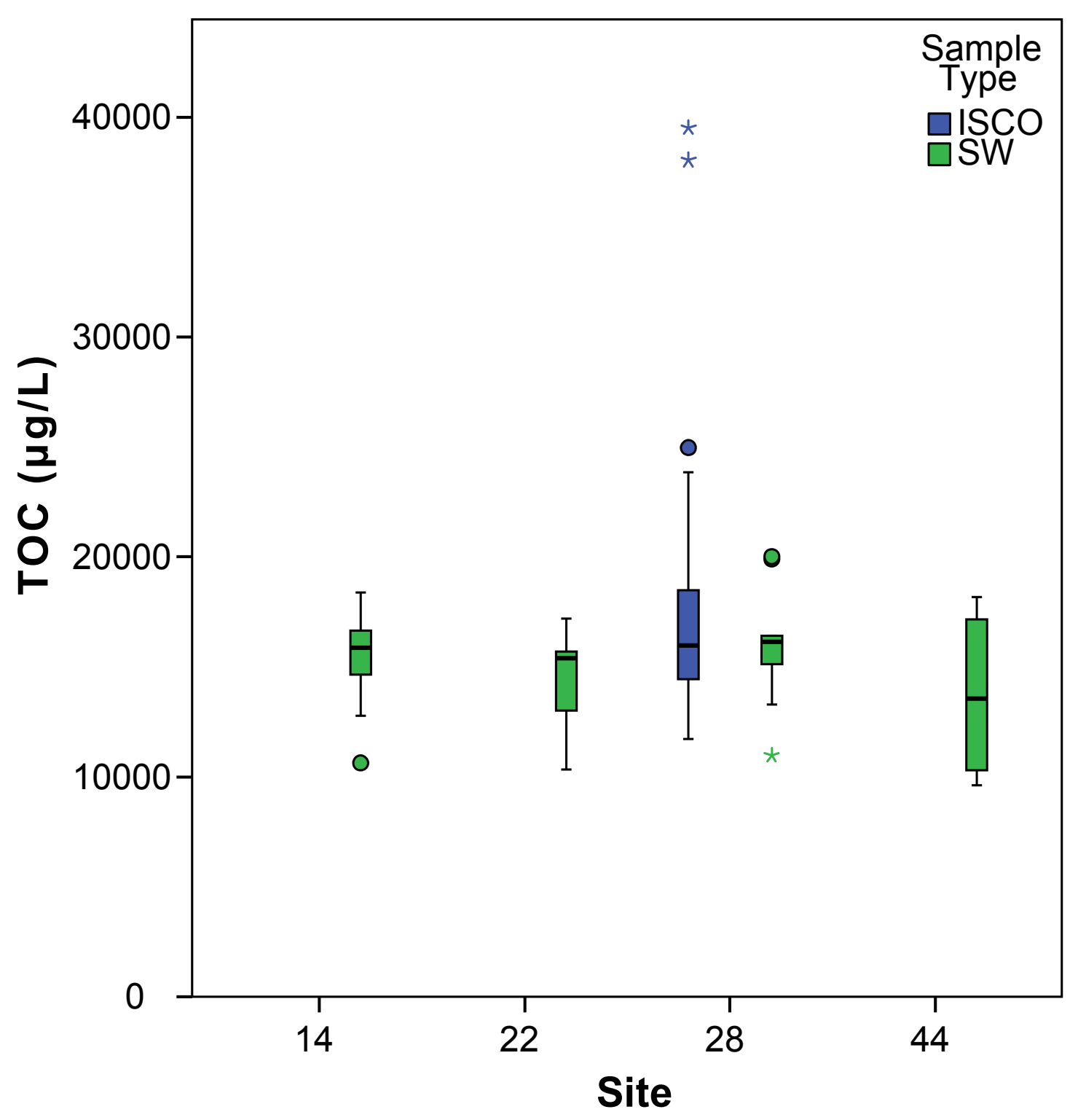

FIGURE 5.32 Box and whisker for total organic carbon in the water column by site location. Refer to figure 5.2 for statistical analysis. 


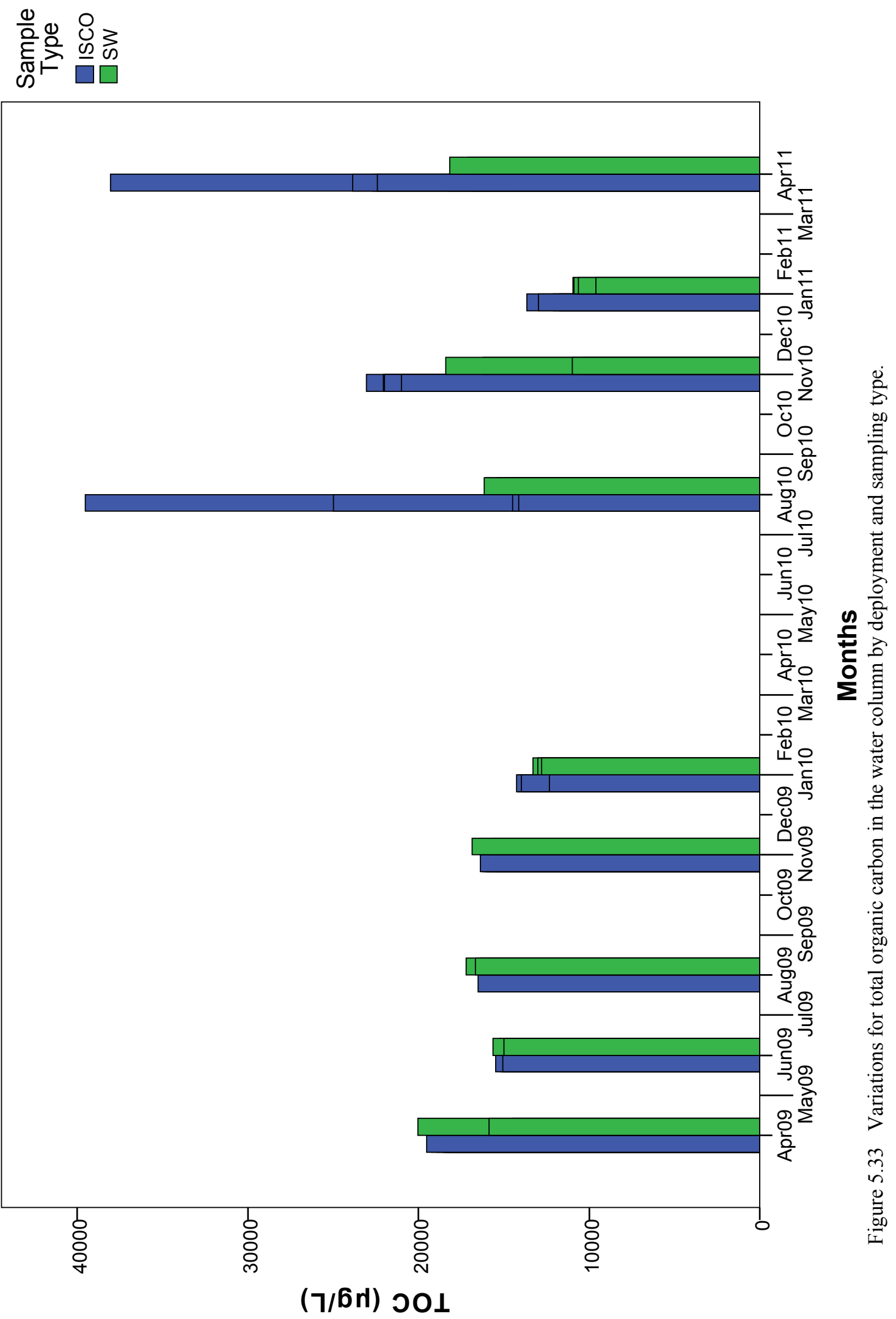




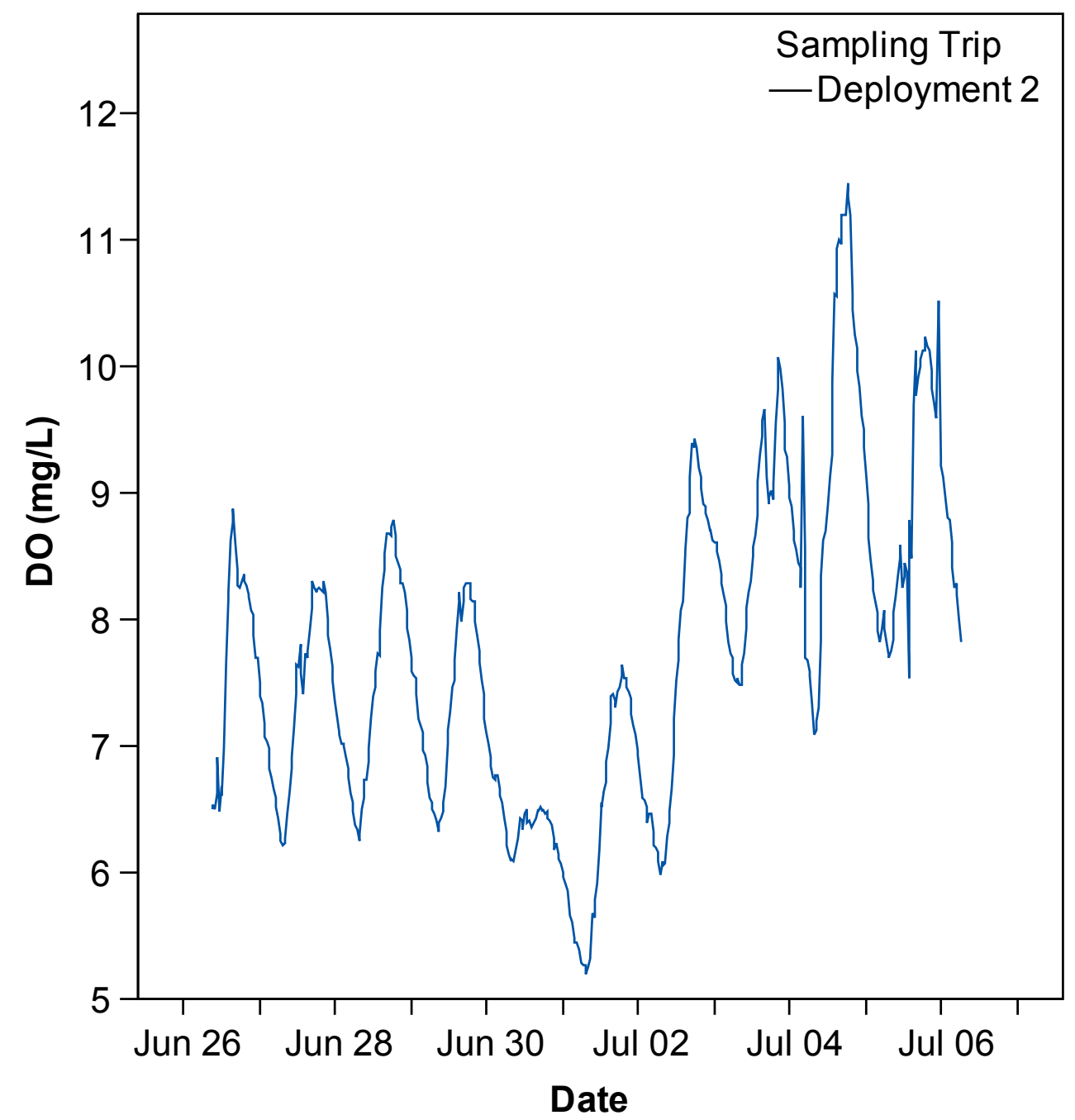

FIGURE 5.34 Time series analysis for dissolved oxygen during deployment 2 within the water column at 0.5 meter depth.

TABLE 5.12 Mean, standard deviation and range of dissolved oxygen in the surface water (depth around $0.5 \mathrm{~m}$ ) by deployment.

\begin{tabular}{|c|c|r|r|r|r|}
\hline Sampling Trip & Mean & Std. Deviation & Minimum & Maximum & \multicolumn{1}{c|}{$\mathrm{N}$} \\
\hline June 2009 & 7.7349 & 1.26030 & 5.21 & 11.45 & 475 \\
August 2009 & 1.2157 & .61888 & .67 & 8.42 & 334 \\
Nov. 2009 & 9.4118 & .67456 & 7.87 & 10.51 & 78 \\
Jan. 2010 & 16.4992 & 1.86692 & 13.01 & 20.62 & 334 \\
\hline
\end{tabular}




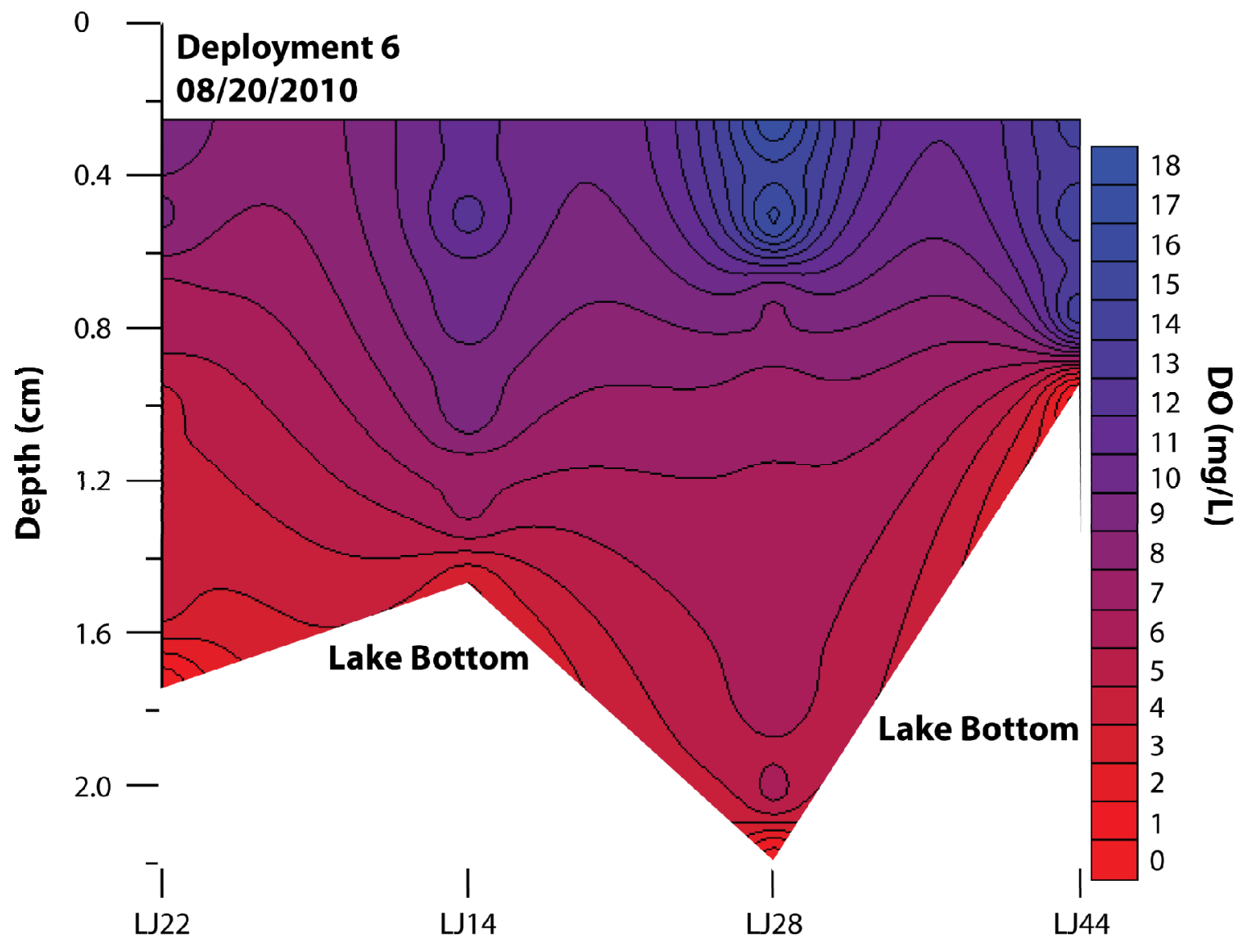

FIGURE 5.35 Lake wide profile for dissolved oxygen. LJ22 does not have nearly as much oxygen available then LJ28. Grouping occurs because profile was made from 4 locations. 


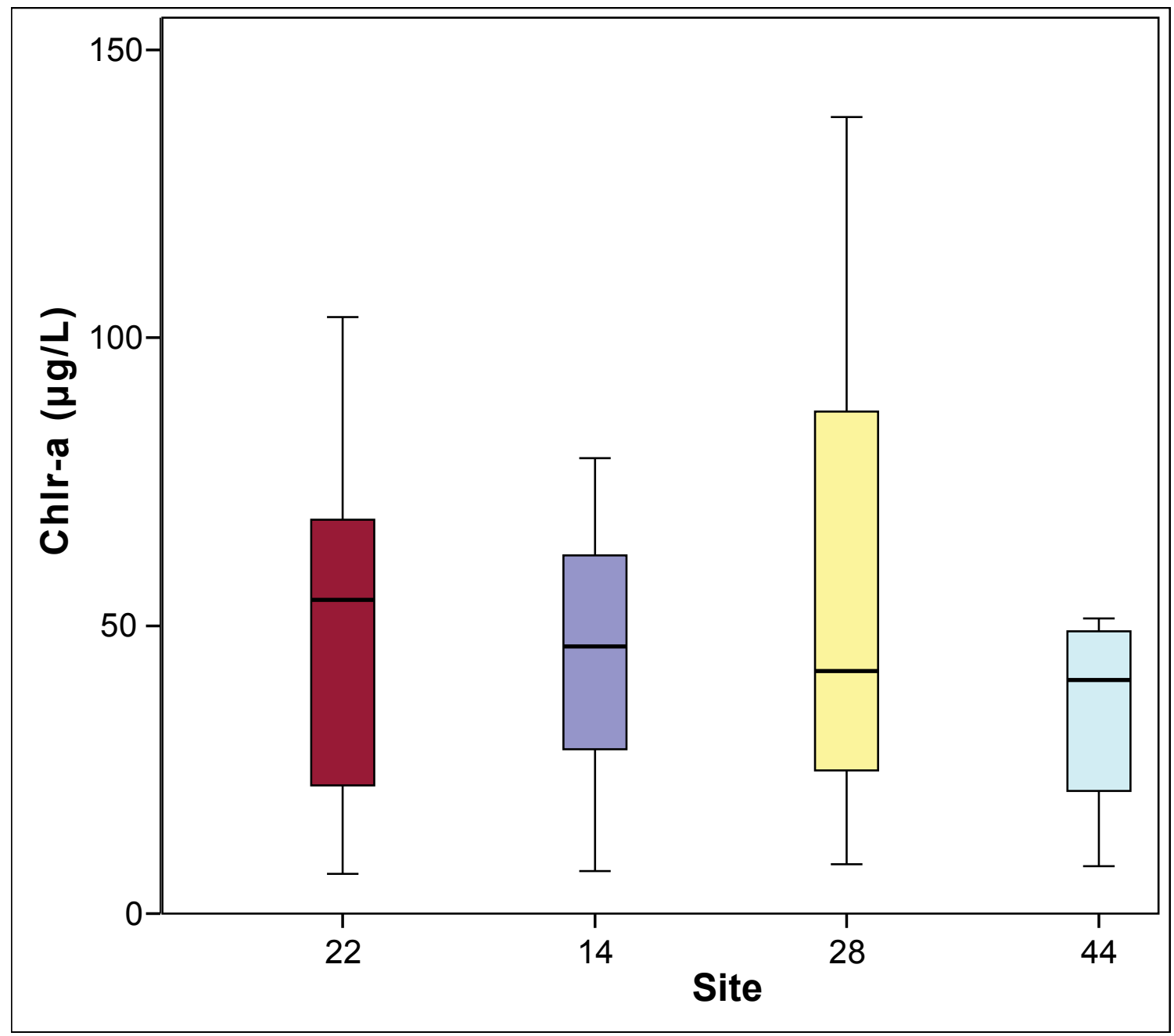

FIGURE 5.36 Box and whisker for chlorophyll-a in the water column by site location. Refer to figure 5.2 for statistical analysis. 


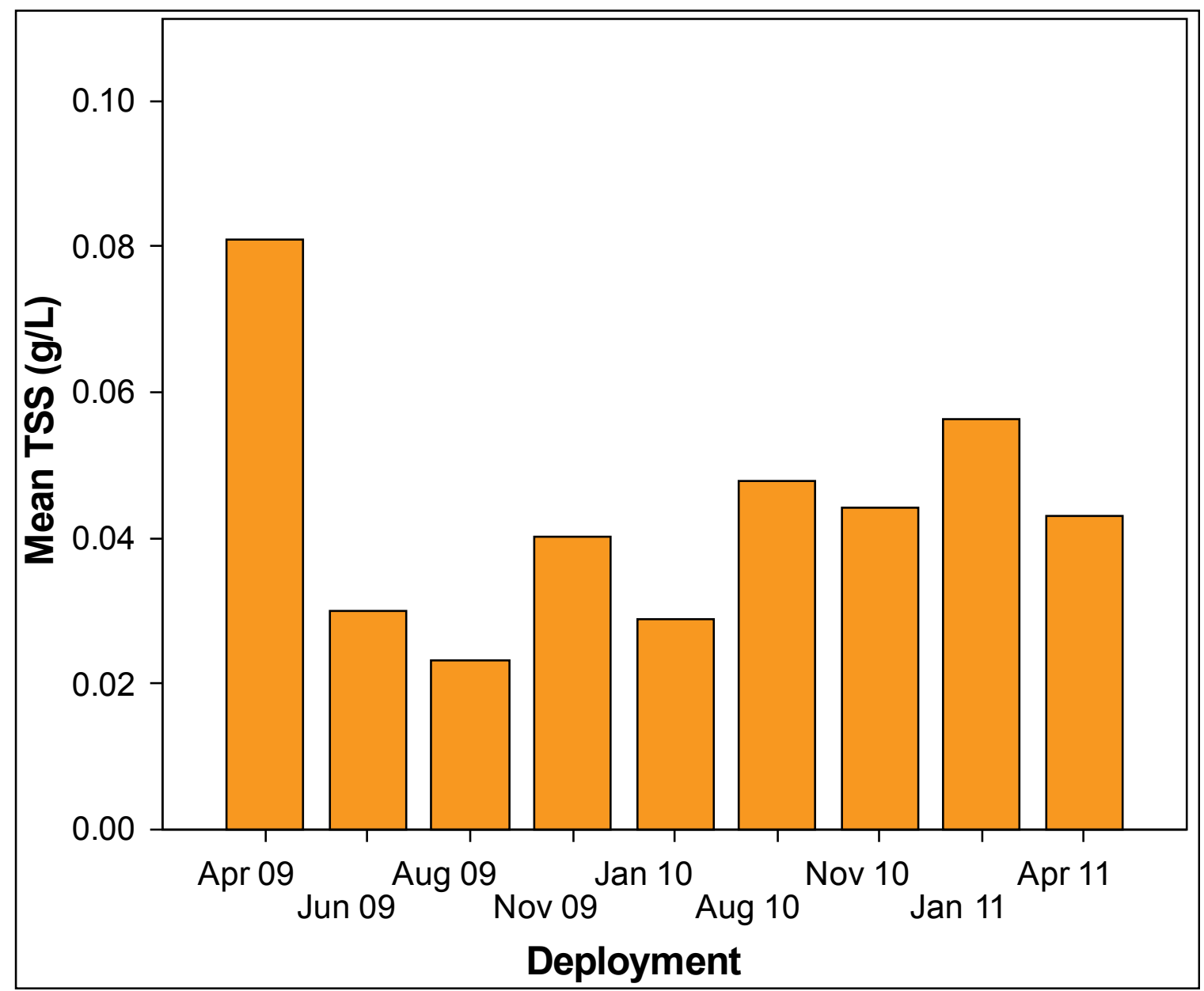

FIGURE 5.37 Bar graph of total suspended solids within the water column at a depth around 0.5 meters.

TABLE 5.13 Mean, standard deviation and range of the total suspended solids $(\mathrm{g} / \mathrm{L})$ within the water column (depth around $0.5 \mathrm{~m}$ ) by deployment.

\begin{tabular}{|c|c|c|c|c|c|}
\hline Deployment & Mean & Std. Deviation & Minimum & Maximum & $\mathrm{N}$ \\
\hline April 2009 & 0.08 & 0.02 & 0.05 & 0.11 & 13 \\
June 2009 & 0.03 & 0.01 & 0.02 & 0.05 & 13 \\
August 2009 & 0.02 & 0.01 & 0.01 & 0.04 & 7 \\
Nov. 2009 & 0.04 & 0.02 & 0.01 & 0.05 & 7 \\
Jan. 2010 & 0.03 & 0.01 & 0.02 & 0.04 & 7 \\
August 2010 & 0.05 & 0.01 & 0.03 & 0.07 & 7 \\
Nov. 2010 & 0.04 & 0.01 & 0.03 & 0.06 & 8 \\
Jan. 2011 & 0.06 & 0.03 & 0.03 & 0.08 & 4 \\
April 2011 & 0.04 & 0.02 & 0.02 & 0.06 & 7 \\
\hline
\end{tabular}




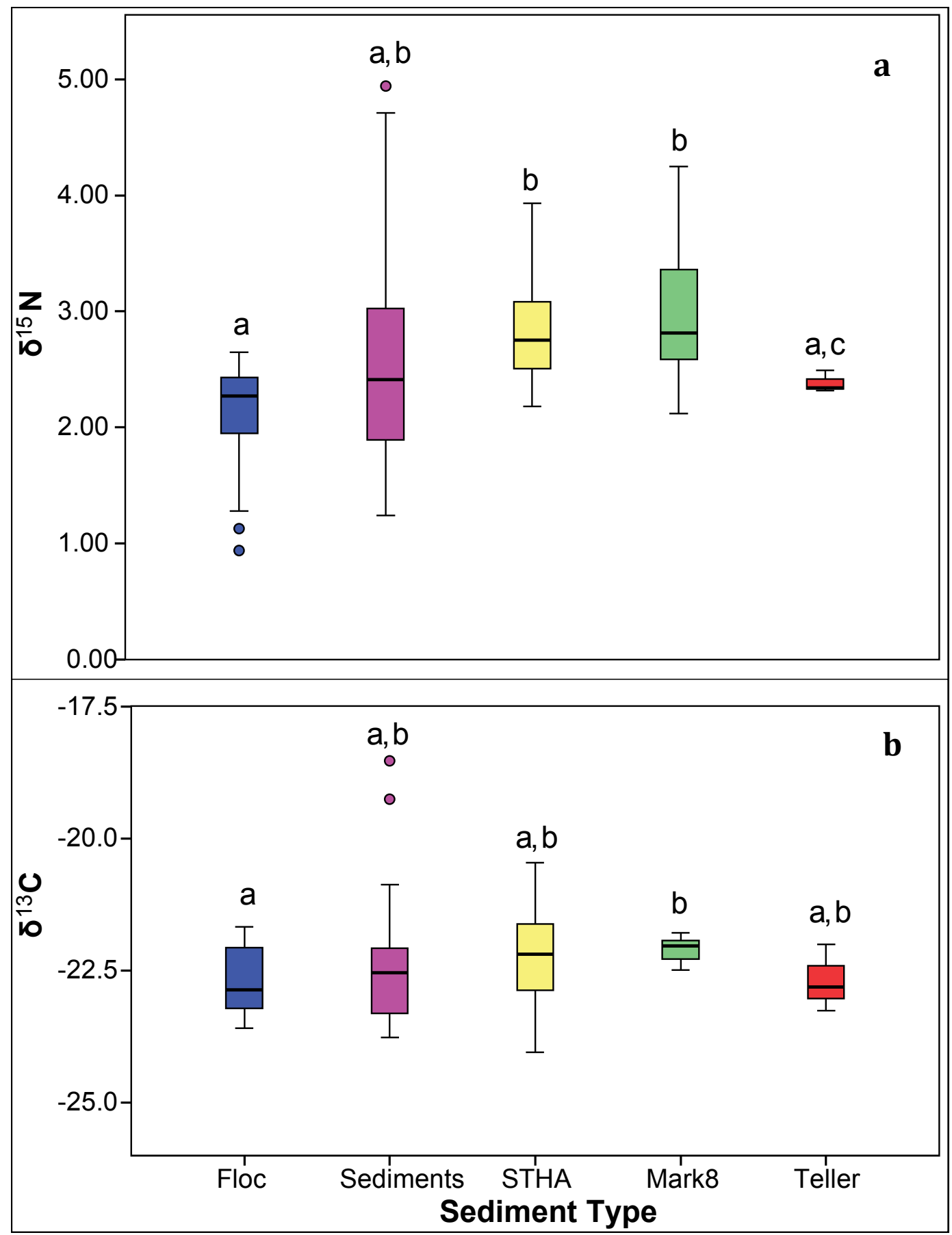

FIGURE 5.38 Box and whisker of stable isotopes, $\delta^{15} \mathrm{~N}(\mathrm{a})$ and $\delta^{13} \mathrm{C}(\mathrm{b})$ within the bottom sediments of Lake Jesup by sediment type. Refer to figure 5.2 for statistical analysis. 
TABLE 5.14 Mean, standard deviation and range of stable isotopes, $\delta^{15} \mathrm{~N}$ and $\delta^{13} \mathrm{C}(\mathrm{ppm})$ within the sediments by sediment type.

\begin{tabular}{|c|c|c|c|}
\hline \multicolumn{2}{|c|}{ Sediment Type } & $\delta 15 \mathrm{~N}$ & $\delta^{13} \mathrm{C}$ \\
\hline \multirow{3}{*}{ Floc } & Mean +/- Std. Dev. & $2.11+/-0.45$ & $-22.70+/-0.60$ \\
\hline & Range & 0.94 to 2.65 & -23.59 to -21.67 \\
\hline & $\mathrm{n}$ & 30 & 30 \\
\hline \multirow{3}{*}{ Sediment } & Mean +/- Std. Dev. & $2.67+/-1.03$ & $-22.40+/-1.20$ \\
\hline & Range & 1.24 to 4.94 & -23.77 to -18.53 \\
\hline & $\mathrm{n}$ & 31 & 31 \\
\hline \multirow{3}{*}{ STHA } & Mean +/- Std. Dev. & $2.82+/-0.43$ & $-22.40+/-1.20$ \\
\hline & Range & 2.18 to 3.93 & -23.77 to -18.53 \\
\hline & $\mathrm{n}$ & 31 & 31 \\
\hline \multirow{3}{*}{ Mark8 } & Mean +/- Std. Dev. & $2.94+/-0.57$ & $-22.09+/-0.21$ \\
\hline & Range & 2.12 to 4.25 & -22.49 to -21.79 \\
\hline & $\mathrm{n}$ & 20 & 20 \\
\hline \multirow{3}{*}{ Teller } & Mean +/- Std. Dev. & $2.38+/-0.09$ & $-22.69+/-0.64$ \\
\hline & Range & 2.32 to 2.49 & -23.26 to -22.00 \\
\hline & $\mathrm{n}$ & 3 & 3 \\
\hline
\end{tabular}




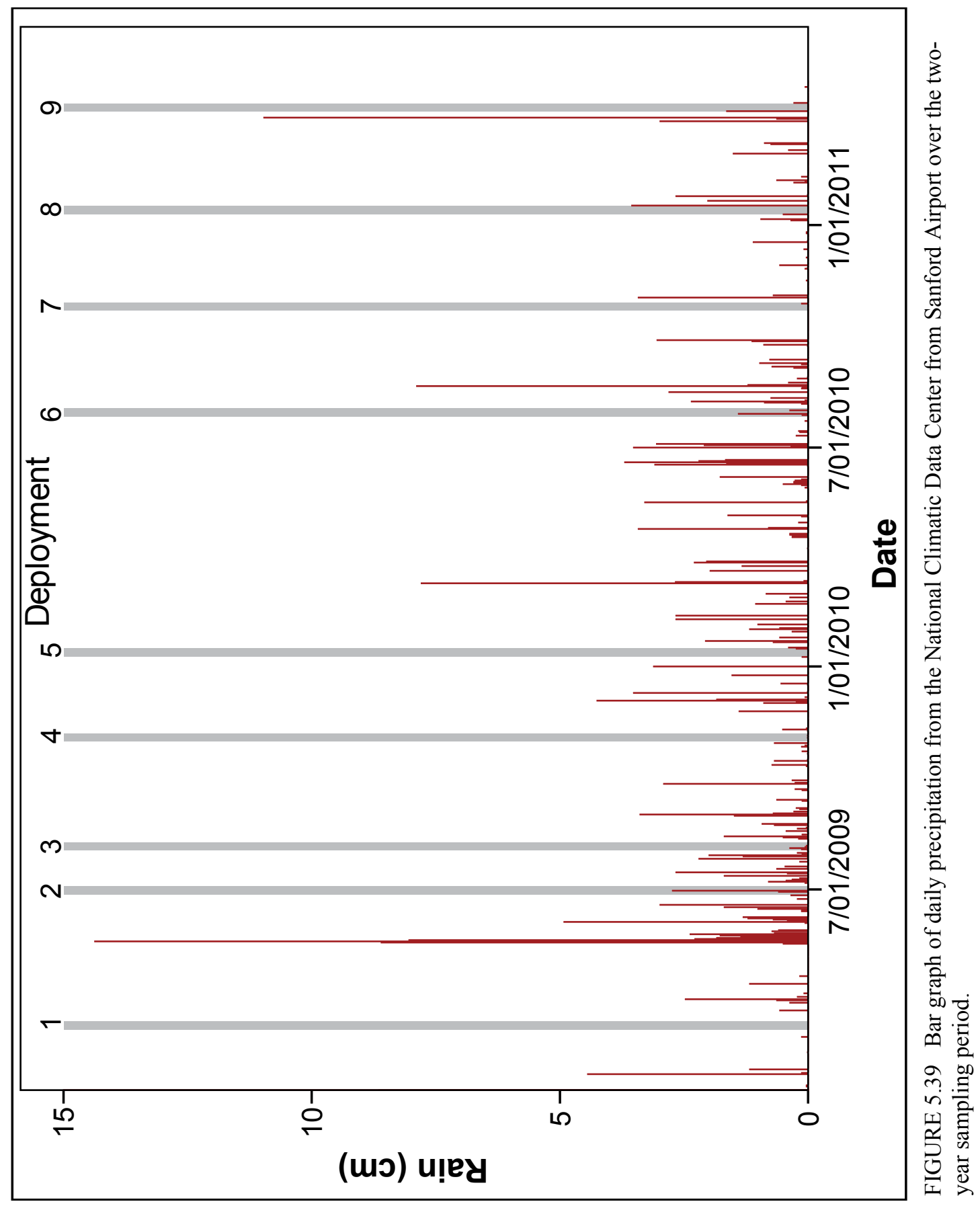




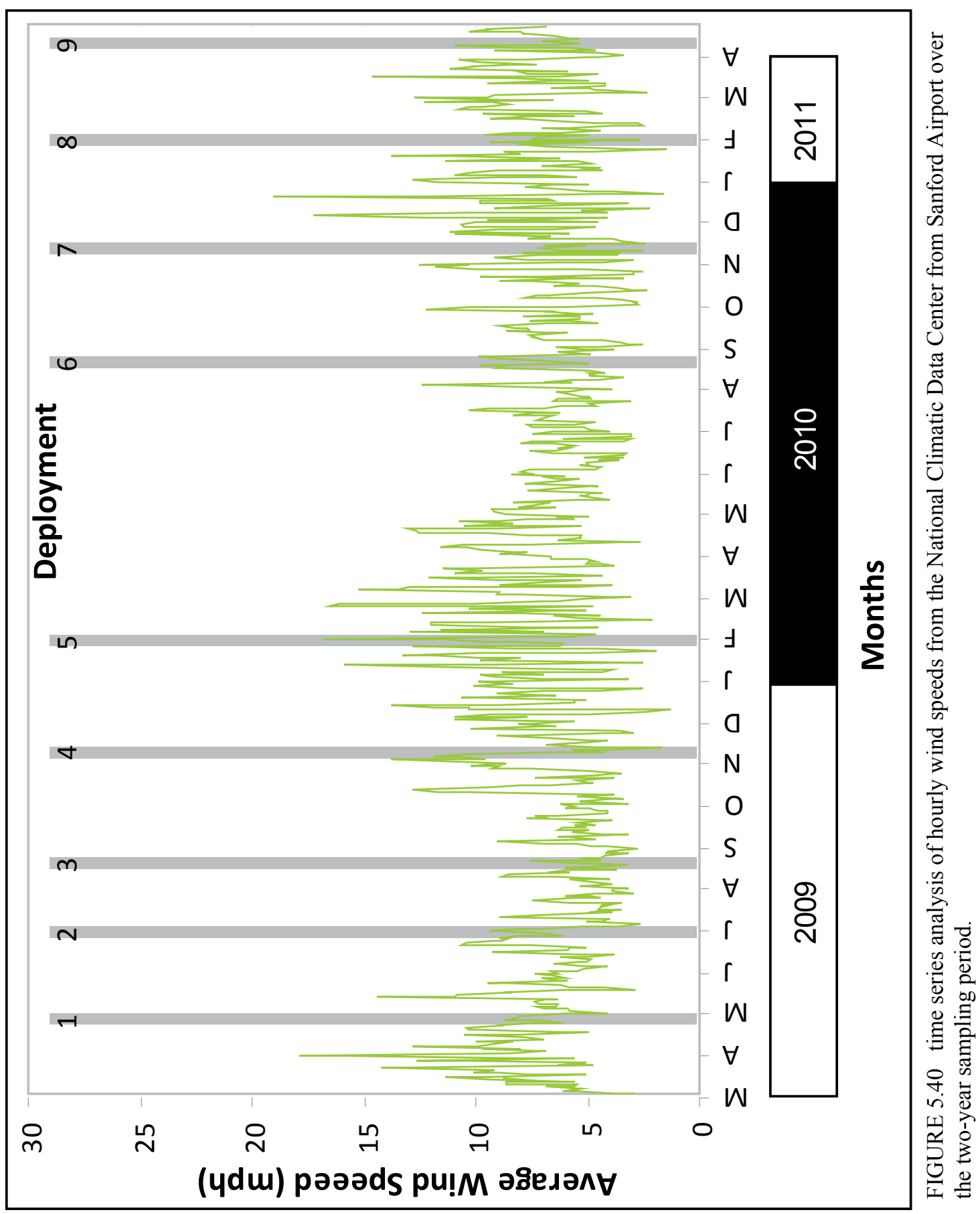




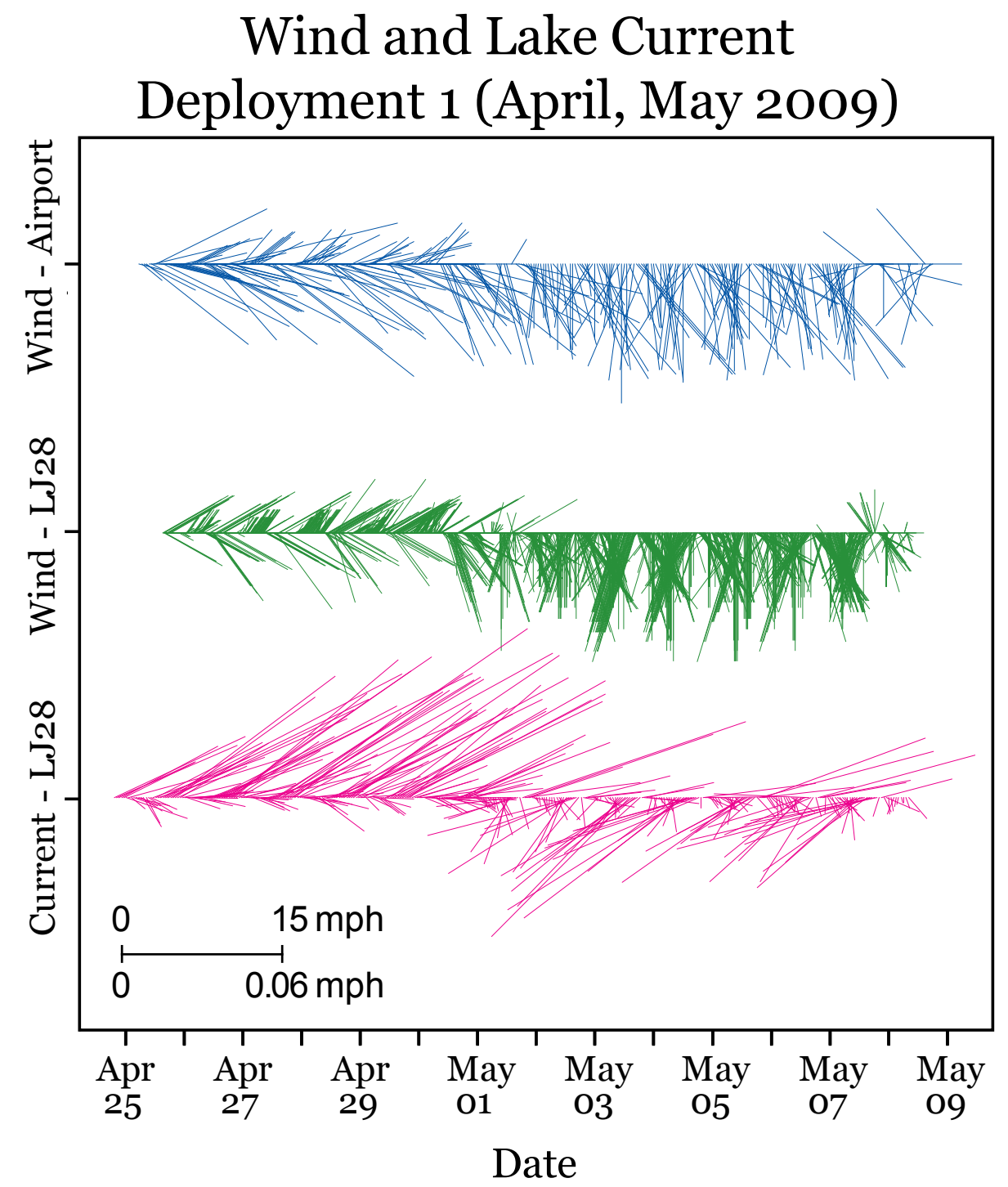

FIGURE 5.41 Stick plots for deployment 1, the top plot is weather data from Sanford Airport, middle plot is from the weather stations on the lake, and the bottom plot is current measured on the lake over time. 


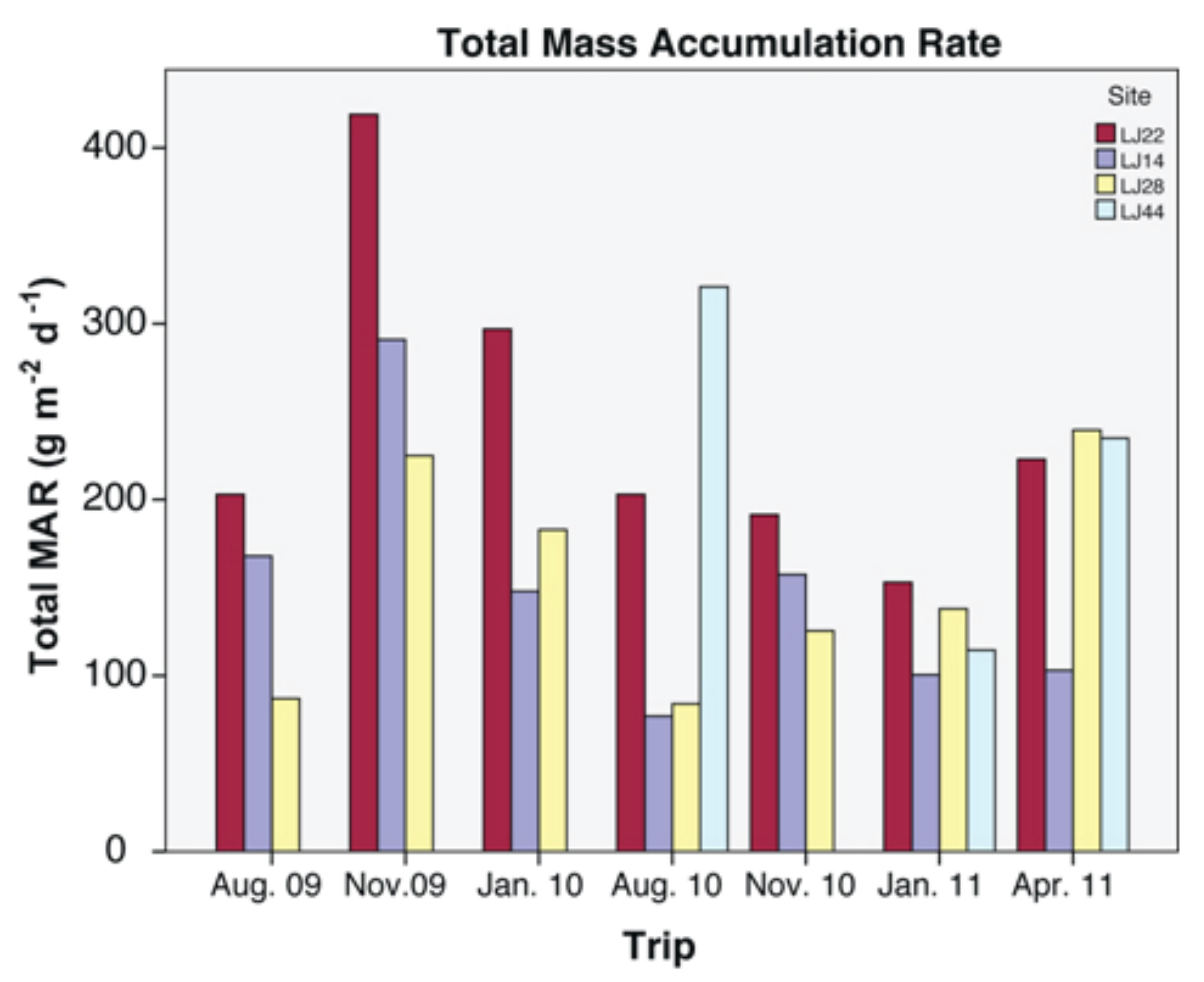

FIGURE 5.43 Variations in mass accumulation rate (MAR) for TC from deployments 3 to 9 . 


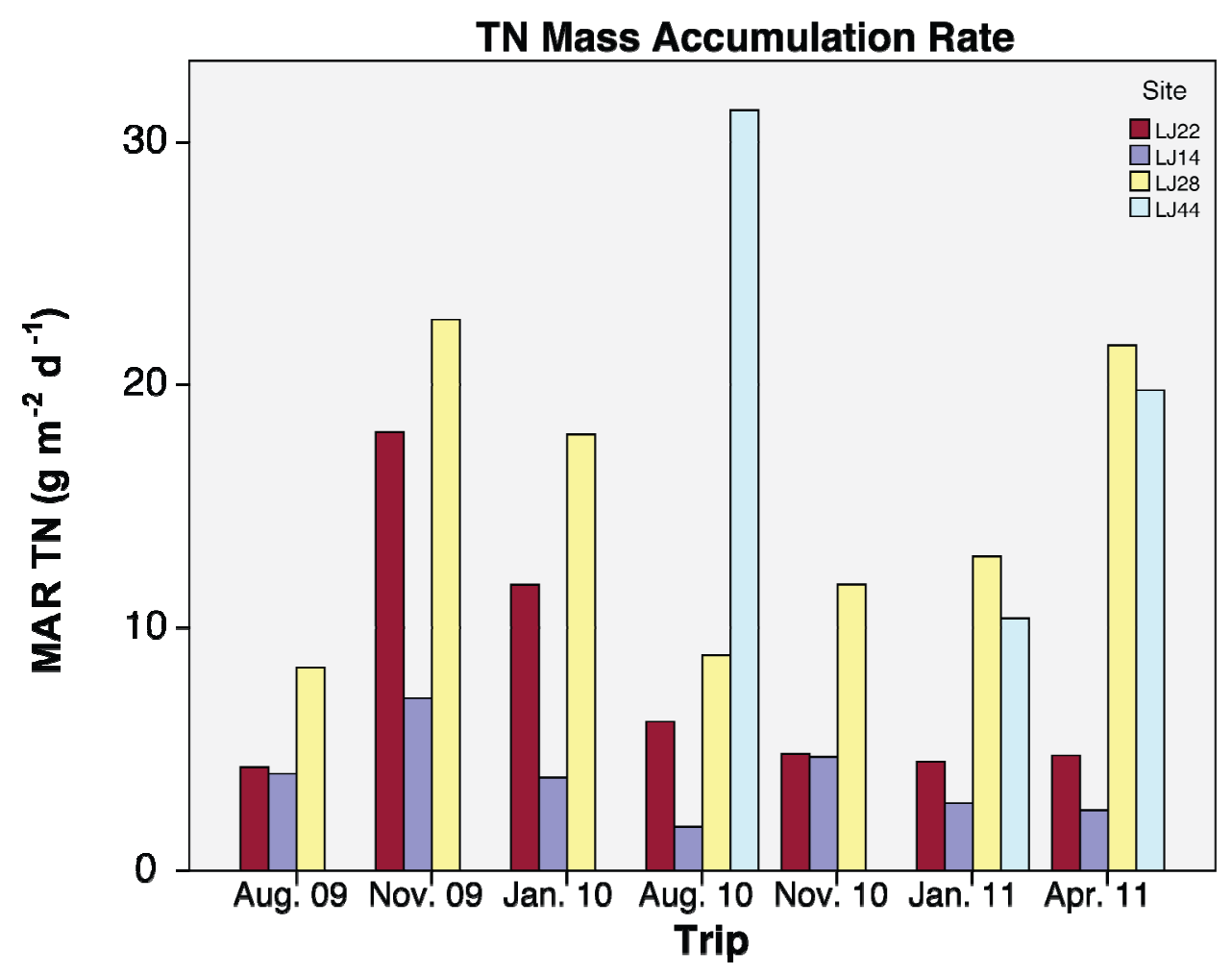

FIGURE 5.44 Variations in mass accumulation rate (MAR) for TN from deployments 3 to 9 . 


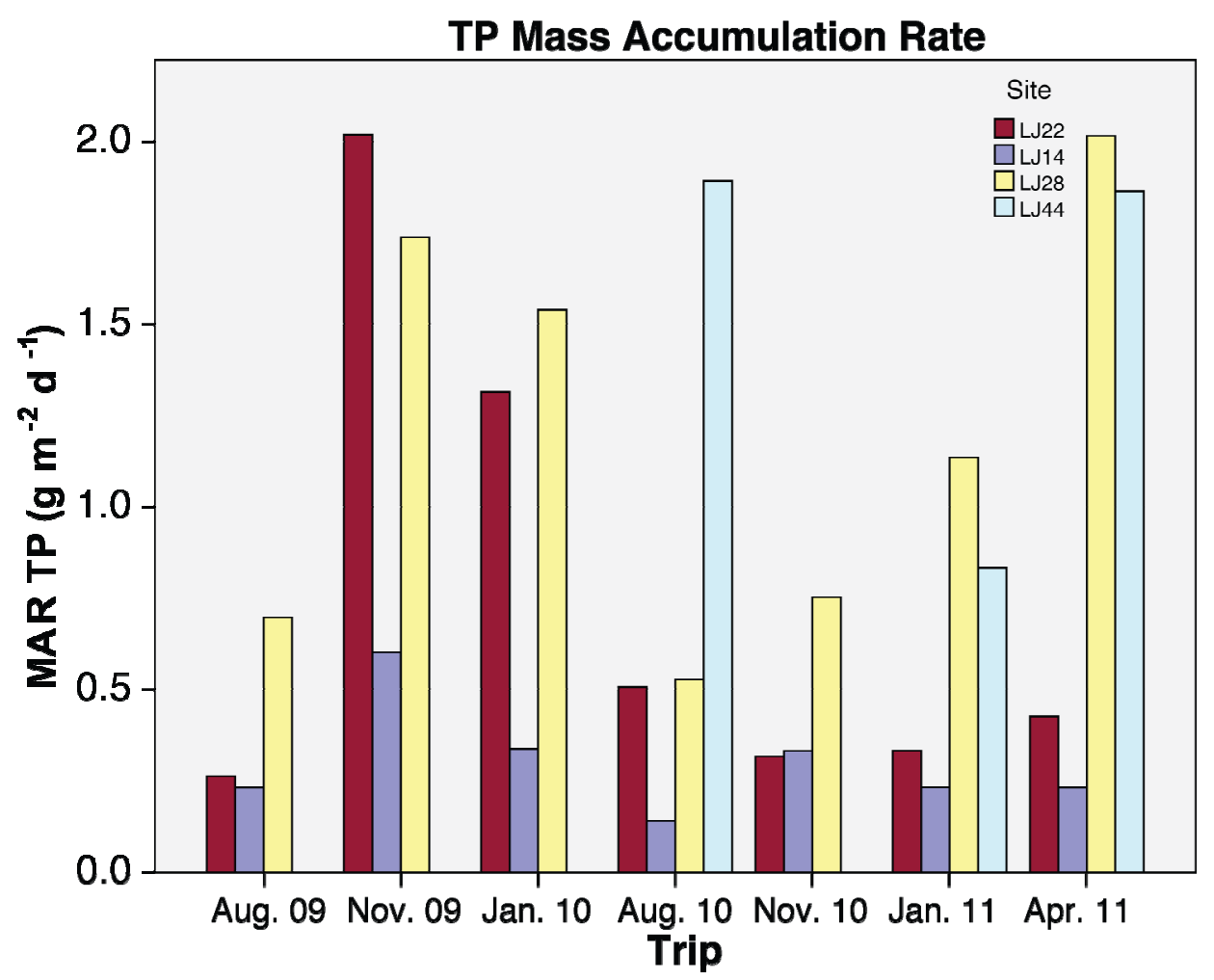

FIGURE 5.45 Variations in mass accumulation rate (MAR) for TP from deployments 3 to 9 . 
TABLE 5.15 Mean, standard deviation and range of wind velocity, direction temperature and rain by deployment from weather stations 1 and 2 (wind direction).

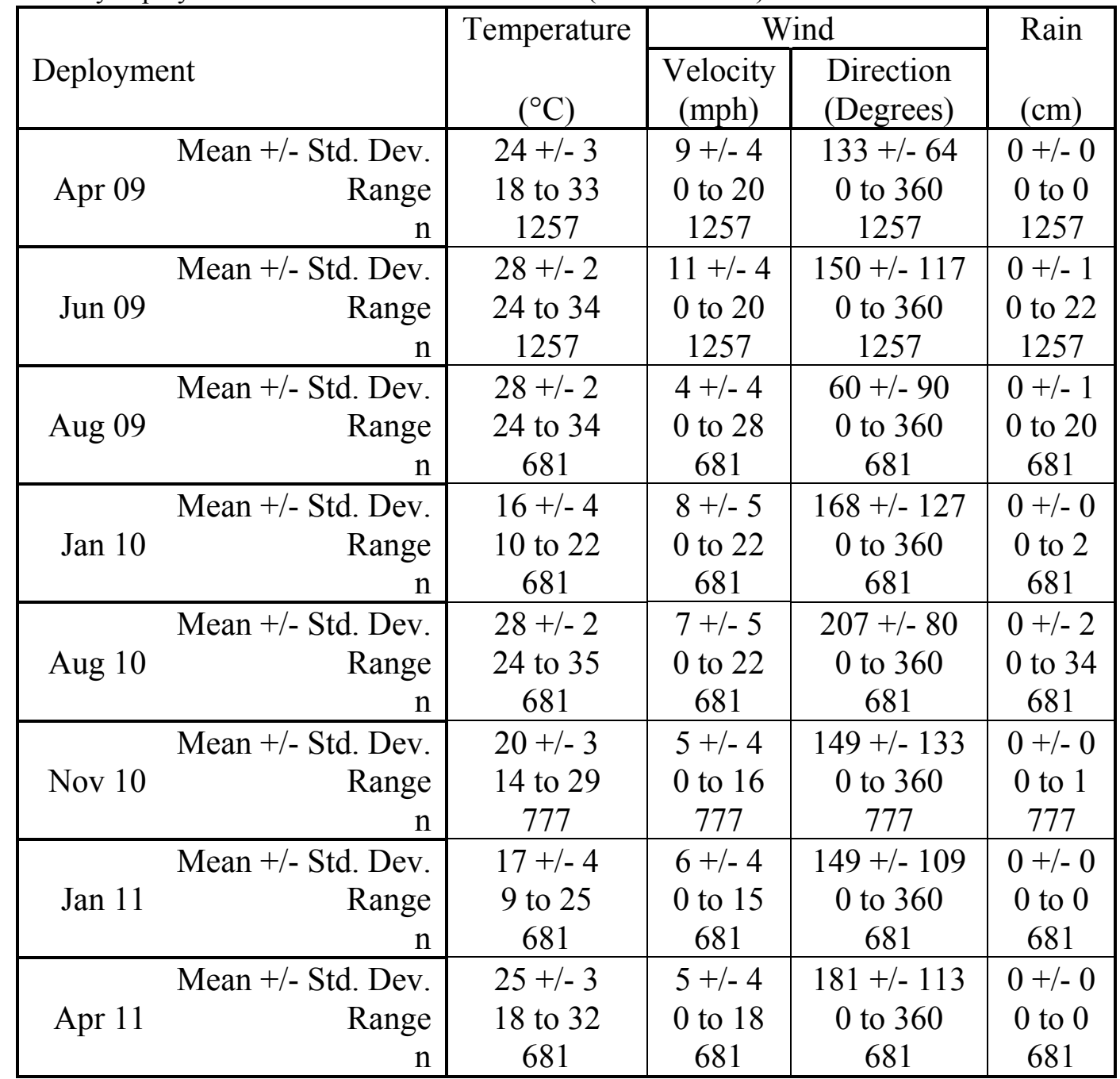


TABLE 5.16 Mean, standard deviation and range of lake current velocity and direction by deployment.

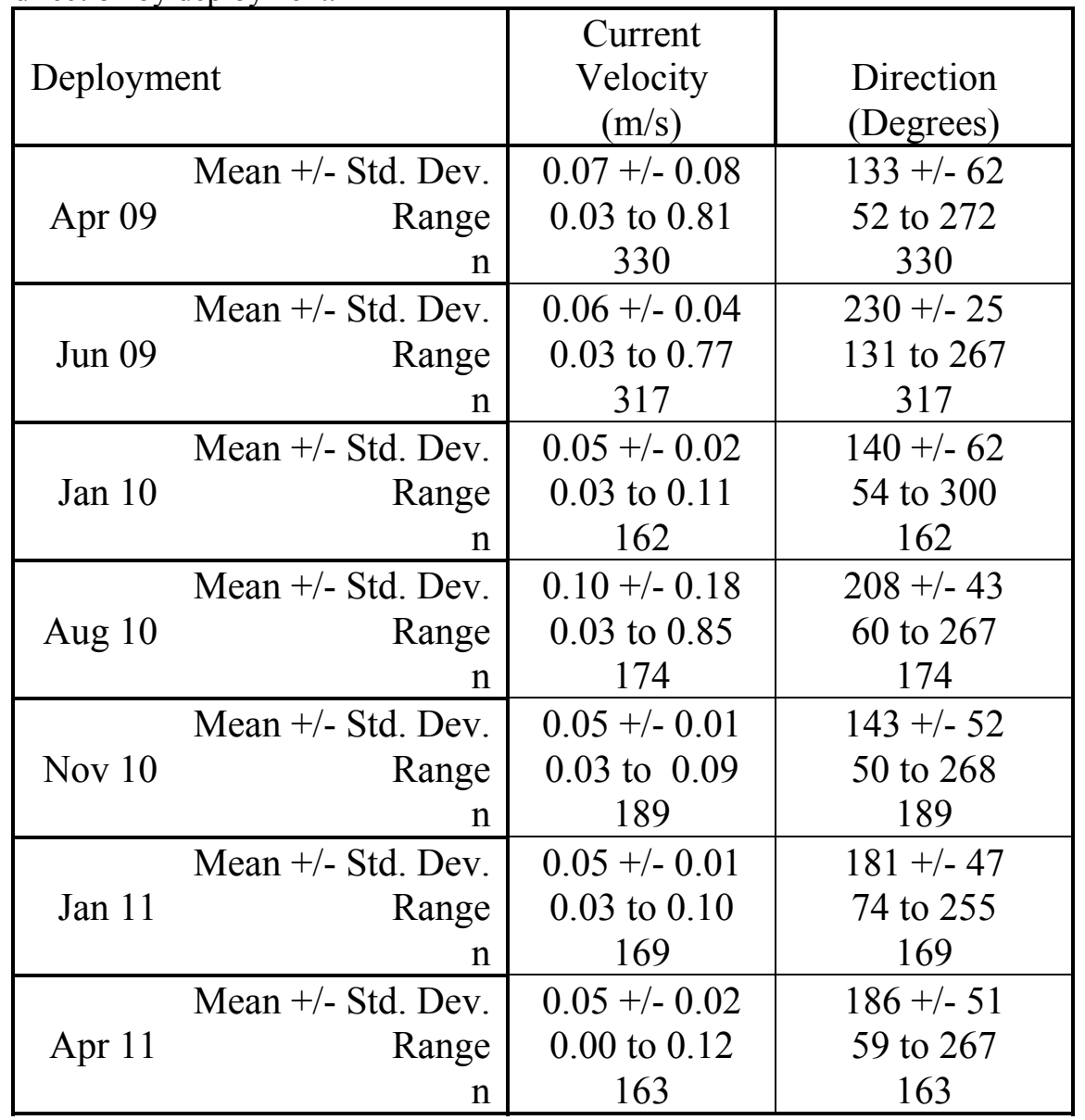




\section{DISCUSSION}

Understanding sediment resuspension in a lake environment is an important internal process, because it further enhances our understanding of nutrient cycling and it's affects on the aquatic environment (Bloesch 1994). Evans (1994) categorized two zones for sediment resuspension: the main zone or shallow areas of resuspension and deeper portions of the lake as episodic areas of resuspension. Shallow lake environments fall into the first category where continuous mixing occurs over the entire volume of the lake (Bloesch 1995). Mixing of a shallow lake is caused by mechanisms involving turbulence within the water column that applies enough shear stress to bottom sediments for suspension to occur (Lund-Hansen et al. 1999). In shallow lakes, the dominant mechanisms for sediment resuspension are waves and currents.

\subsection{Sediment and Water Chemistry}

From this two-year study, sediment concentrations were quantified for time series analysis. The sediment traps, floc, sediments, ISCO water samples and grab water samples showed variations by deployment for each nutrient ( $\mathrm{TN}, \mathrm{TP}$ and $\mathrm{TC}$ ). Interactions between the floc layer with the water column were observed through correlation analysis.

Nutrient concentrations within the sediment were correlated resulting in sediments that are influenced by OM. Water chemistry was also analyzed for total suspended solids (TSS), which correlated with TP water concentrations. This is significant in that TSS concentrations influences the TP concentrations within the water column due to resuspension of sediments, similar to Kristensen et al.'s (1992) results on 
Lake Arreso in Denmark, although, a higher frequency of sampling would improve the resolution of these findings. Most likely there is a lag between the suspension of particles and the release of nutrients from the particles into the water column, however in this study sampling took place once per day, therefore a lag time could not be established (Brezonik et al. 1976).

Correlations between the water column nutrients and sediments (floc, grab sediments and STHA traps) were analyzed. Significant inverse correlations were found between $\mathrm{TN}$ water concentrations and floc concentrations for $\mathrm{TN}(\mathrm{r}=-0.437, \mathrm{p}<0.05, \mathrm{n}$ $=30)$ and $\mathrm{TC}(\mathrm{r}=-0.453, \mathrm{p}<0.05, \mathrm{n}=30)$ and TOC water concentrations with floc TN concentrations $(\mathrm{r}=-0.403, \mathrm{p}<0.05, \mathrm{n}=30)$. These correlations determined that $\mathrm{TN}$ and TOC water nutrients increase as TN within the floc decreases and TOC water nutrients increase as TN of the floc decrease. TP correlations did not reflect interactions between the water and floc layer, perhaps there is another mechanism controlling TP particles. Further more there is a positive correlation between TP floc and TP STHA, representing a mechanism that was not tested during this study. Indicators that organic matter influences sediments are the stable isotope analysis of $\delta^{15} \mathrm{~N}$ and $\delta^{13} \mathrm{C}$ (Fig. 6.1). When $\delta^{13} \mathrm{C}$ and $\mathrm{C} / \mathrm{N}$ ratios are plotted against a Meyers plot the sediments are shifted up and to the right, suggesting this lake is highly productive (Meyers and Lallier-Vergès 1999)

Bulk density of the floc inversely correlates very high with TSS $(r=-0.938, p<$ $0.01, \mathrm{n}=8$ ), suggesting that there is an inverse relationship between floc and TSS. Lastly, TP for STHA and OM for STHA show a correlation, which suggests that TP concentrations for traps are mostly made of OM, possibly another indicator that TP from 
STHA traps are receiving additional OM from the water column not from resuspension by another source.

\subsection{Sediment Resuspension}

Sediment resuspension in shallow lakes is a whole lake process, but not necessarily uniform (Evans 1994). One area of a lake could be more affected by dominant wind directions resulting in more sediment that resuspends. Lateral movement of bottom sediments is another interest when examining resuspension. Cable et al. (1997) describes that Lake Jesup has thick flocculent layers in the southern part of the lake then in other areas. They further explain that the dominant wind direction is to the south. Weather data from weather stations 1 and 2 on Lake Jesup agree with these observations. Furthermore, Lake currents within Lake Jesup are predominantly towards the south, which can produce a build up of unconsolidated sediments in the southern region of the lake based on observations by Cable et al. (1997). For Lake Jesup this influences the nutrients that become suspended by current shear stress (CSS). TN water concentrations within the lake correlate with CSS that moves towards the south $(\mathrm{r}=0.754, \mathrm{p}<0.01, \mathrm{n}=$ 43), where CSS towards the north inversely correlates with TP $(r=-0.689, p<0.05$, $\mathrm{n}=11)$. Comparing TN and TP with CSS disregarding direction TP $(r=0.275, \mathrm{p}<0.05$, $\mathrm{r}=54)$ and $\mathrm{TN}(\mathrm{r}=0.733, \mathrm{p}<0.01, \mathrm{n}=54)$ show a less correlation (Table 6.1). It was hypothesized that sediment resuspension is caused predominantly by storms by creating higher wind and wave events, but there were no significant storm events during the two year sampling period. A storm even could have caused an increase in sediment resuspension and particles that collect in the traps. 
Sediment resuspension correlates with the process by which sediments resuspend (Qin 2004), meaning that sediment resuspension will correlate with the mechanism that causes the resuspension. By assuming TSS will directly correlate with a resuspension processes; correlations were made for TSS versus lake level, lake currents and wave heights. Wave analysis for each deployment (deployments 6 and 8 were unavailable) was supplied by Florida Gulf Coast University, where they used the weather data from weather stations 1 and 2 located at Lake Jesup using the Shore Protection Manual Shallow Wave Growth Model (SPMSWG) in Matlab. Through out the deployments wave height correlates with current velocities (Table 6.2). However, more data may be needed to determine if TSS correlates with high wind and current velocities.

Mentioned previously, TSS and TP water concentrations correlate for the entire two-year lake analysis. Alternatively, comparing the TSS and TP and current shear stress shows that regardless of the lack of samples there does appear to be a relationship. TSS inversely correlates well with lake level $(\mathrm{r}=-0.718, \mathrm{p}<0.01, \mathrm{n}=73)$, suggesting that bottom sediments are more easily disturbed by lower lake level coupled with winds or currents.

Depositional environments can be categorized using particle grain size and current velocities from the Hjulstrom Curve model. Hujulstrom (1935) created a model based on particle grain size and stream flow velocity. He then categorized three environments acting on the bottom sediments: erosional, depositional and transitional (Fig. 6.2). Cable et al. (1997) described the grain sizes through out lake Jesup as having 5.0\% sand, $76.6 \%$ silt and $18.4 \%$ clay. Figure 6.7 illustrates where Lake Jesup sediments are categorized. Radiochemical tracers of $\mathrm{Pb}-210, \mathrm{Cs}-137$ and $\mathrm{Br}-7$ were analyzed to 
evaluate the depositional, erosional and transport of sediments by East Carolina University (deployments 6, 7, 8 and 9). The results are comparable to the Hjulstrom model, where Deployment 7 had the slowest maximum velocity, which resulted in a depositional a phase for one of the stations (LJ14). LJ22 and LJ28 resulted in sediments that were constantly being transported for (deployments 7 through 9; Fig. 6.8).

\subsection{Yearly Nutrient Budget of Cycling Material}

A nutrient budget was developed from the STHA trap data for the two-year sampling period. Ultimately, a nutrient budget will express the amount of nutrients loading into the lake system from sediment resuspension. Deployments 1 and 2 were removed when developing the budget, because of a trap redesign. Initially, traps were deployed by sticking a PVC pipe in the soft sediment and left for the duration of the deployment; this was found to have flaws and was redesigned.

To develop a nutrient budget, traps were deployed at 3 or 4 sites through out the lake. Using previous work by Cable et al. (1997), zones were modified to encompass 1 trap per zone (Figs. 6.4 and 6.5). Flux was calculated for each deployment at each site. The area for each zone was established using ArcGIS and calculations were tallied to create the yearly flux for total sediment, TP, TN and TC. Total sediment flux for Lake Jesup is 2,033,882 mt/yr for August 2009 to August 2010 (Table 6.3). For August 2009 to 2010 the floc resuspended 47 times per year and from April 2010 to April 201138 times per year based on an average floc thickness (around $3 \mathrm{~cm}$ ).

Ultimately, sediment is constantly being resuspended within the water column and is affected by wind/waves, currents and lake level. The top most layer of sediment is 
being resuspended, but based on STHA samples, new material is also being collected on the basis of TP, TN, TC concentrations and \%OM having higher amounts in the traps then the floc layer also ${ }^{7} \mathrm{Be}$ (per comm. Dr. Corbett from ECU) was found in the traps and the floc, which has a half life of 53 days. Nutrients, particularly TP, increase in the water column when sediments resuspend, but nutrients within the water column recover if the current and wind/wave velocities decrease or lake level increases. Large storms most likely have an affect on the lake, but none were observed during the two-year period. 


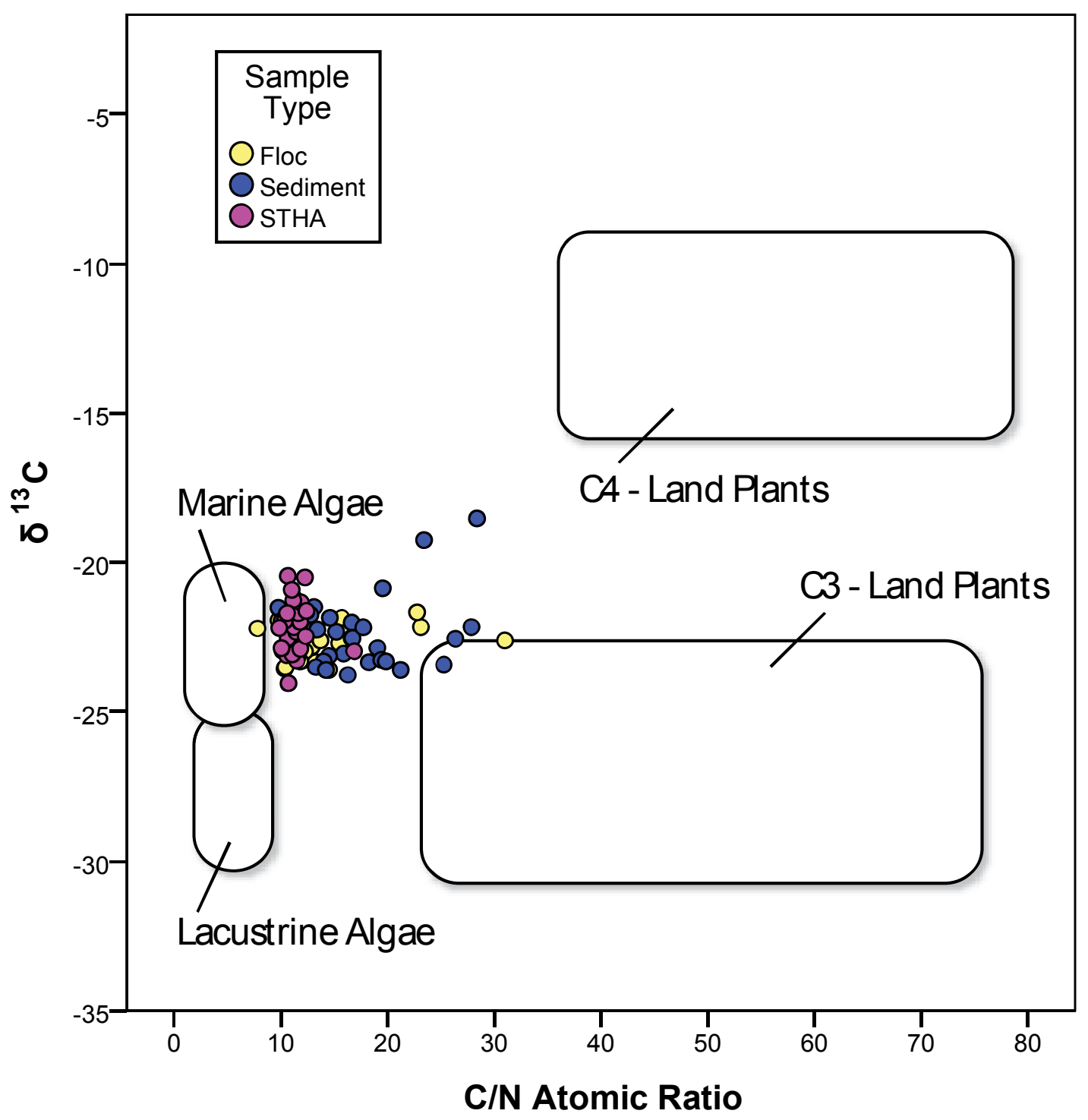

FIGURE $6.1 \delta^{13} \mathrm{C}$ vs. $\mathrm{C} / \mathrm{N}$ ratio for all sediments. Points plot slightly higher and to the right due to the high productivity within the lake (from Meyers and Lallier-Verges 1999). 


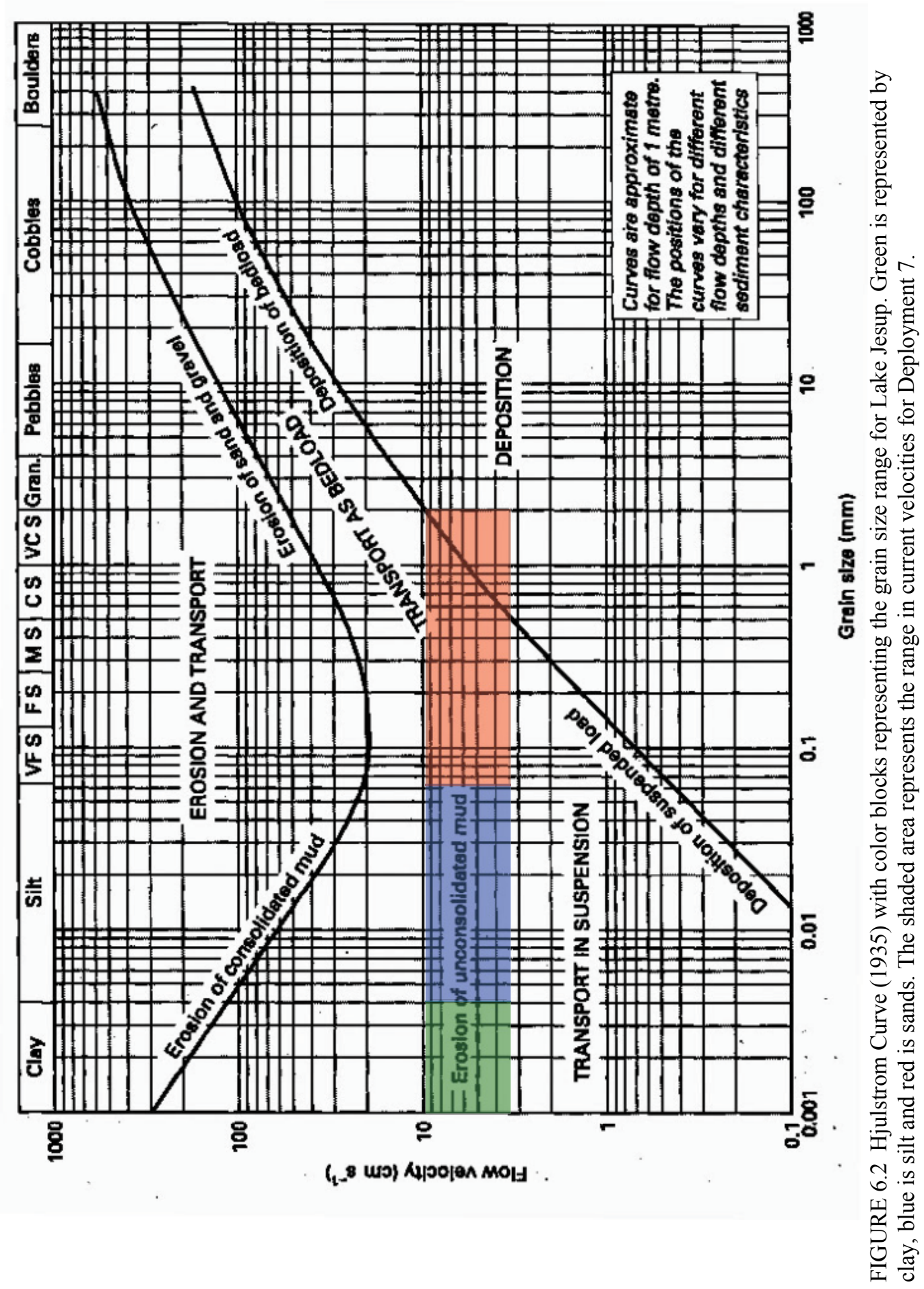



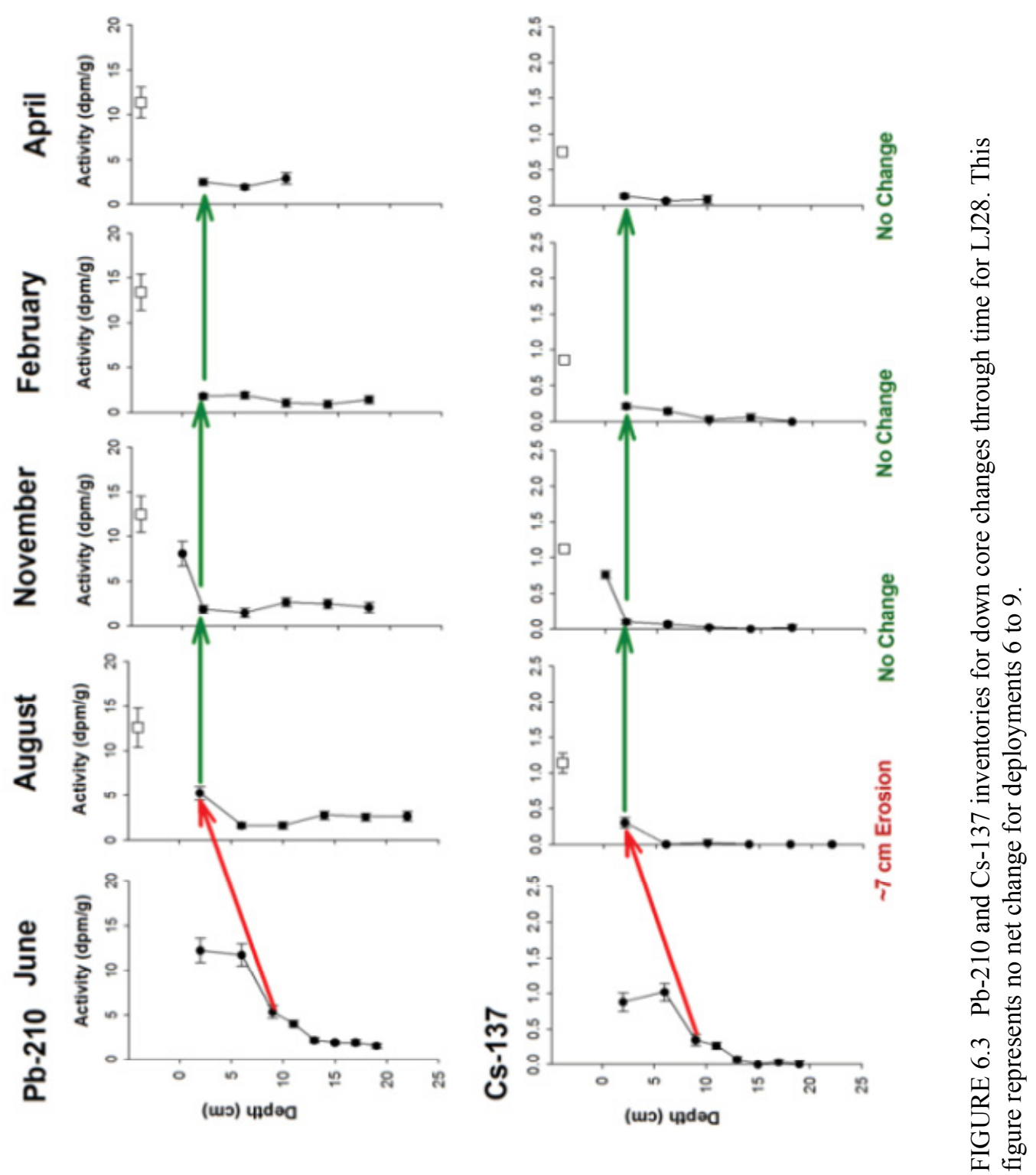


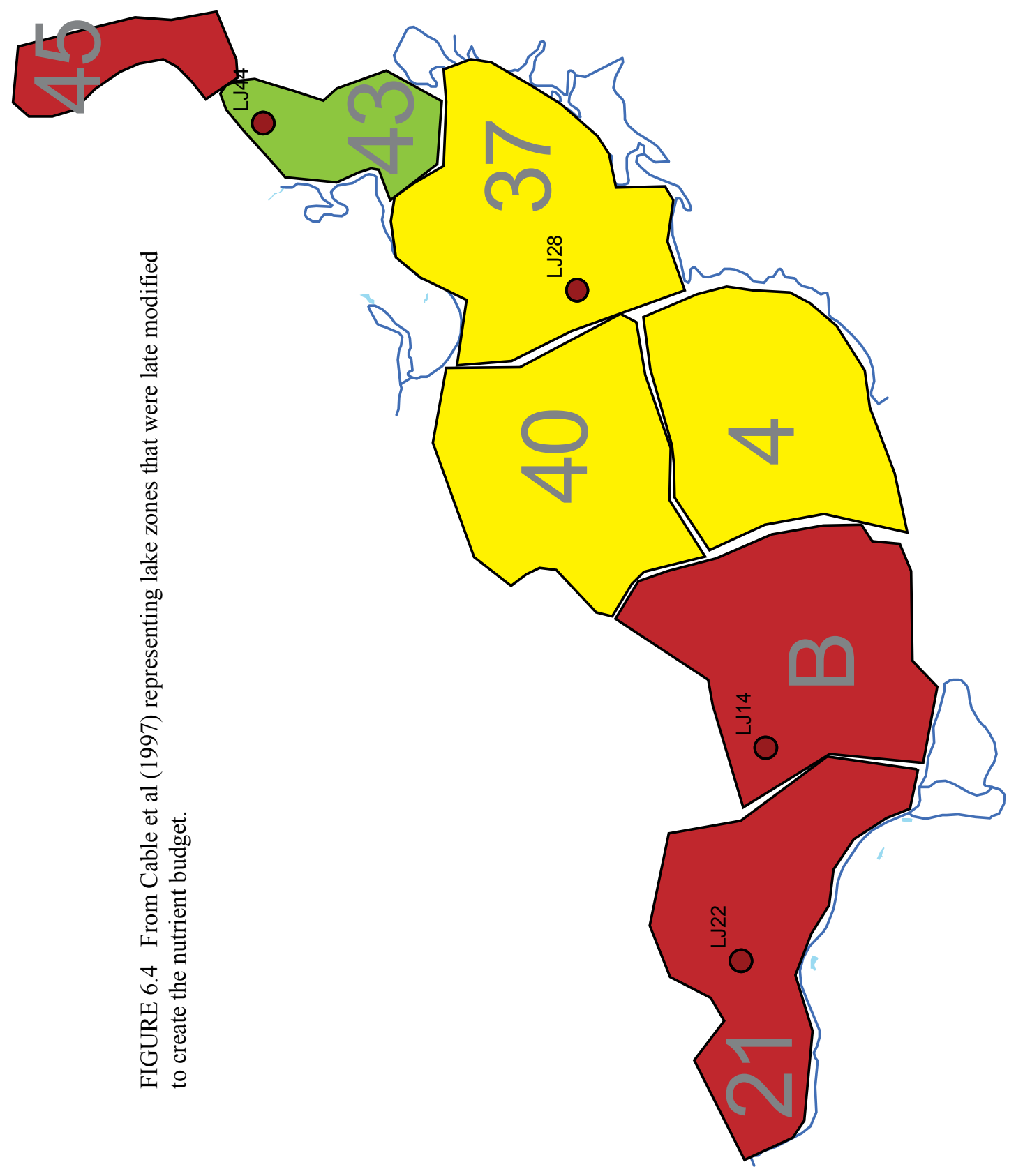


FIGURE 6.5 Zoning areas for the nutrient budget. a) represents the zoning when data is not available for LJ44, b) is the zooming with all four locations.

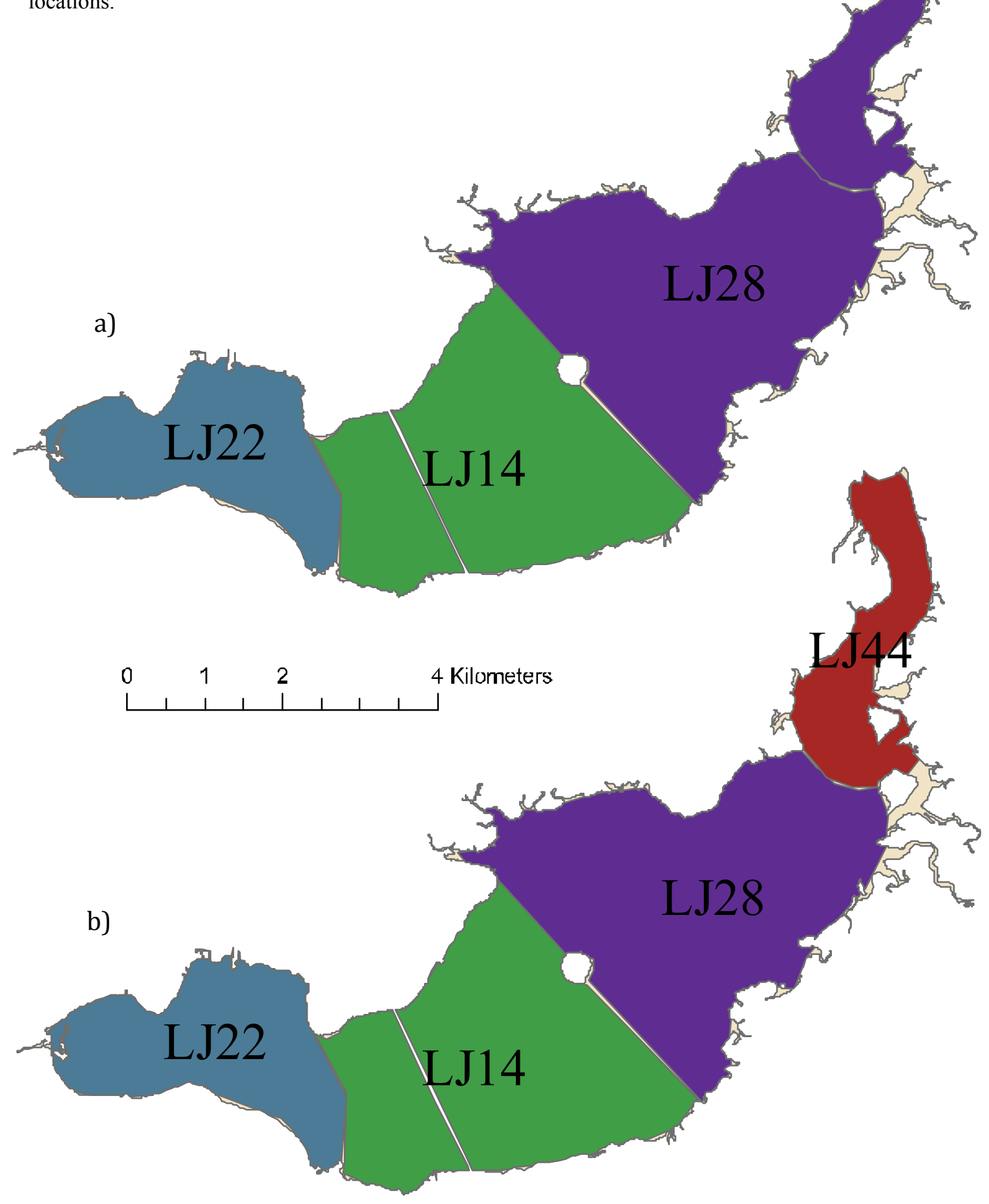




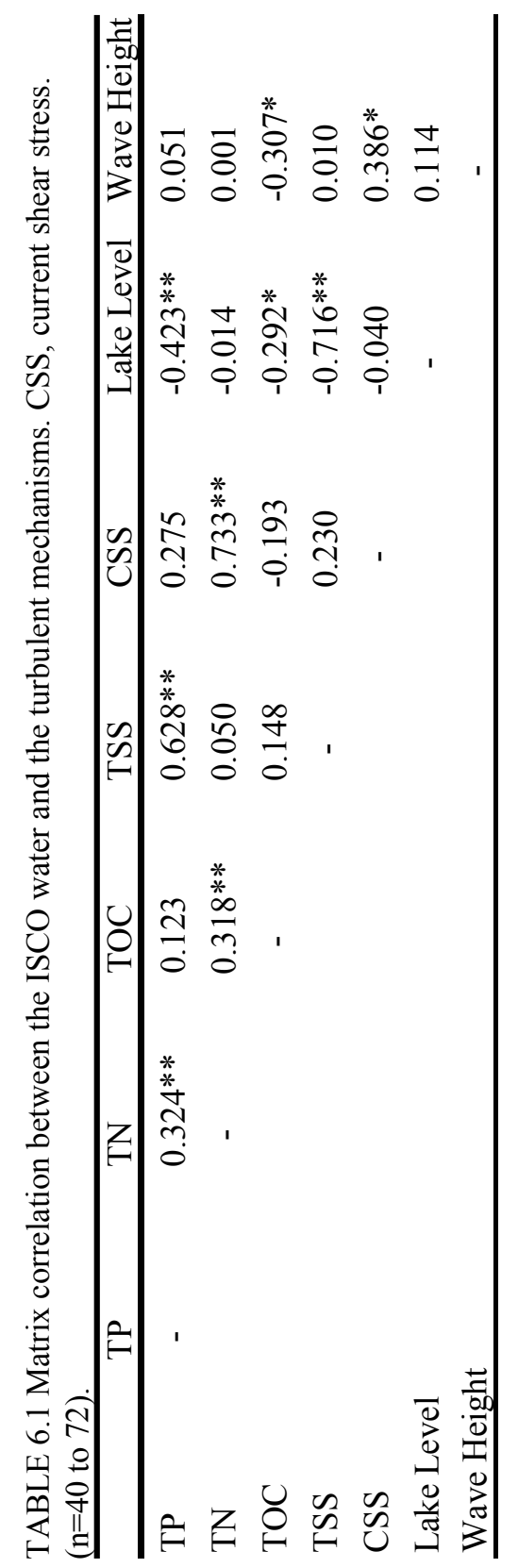




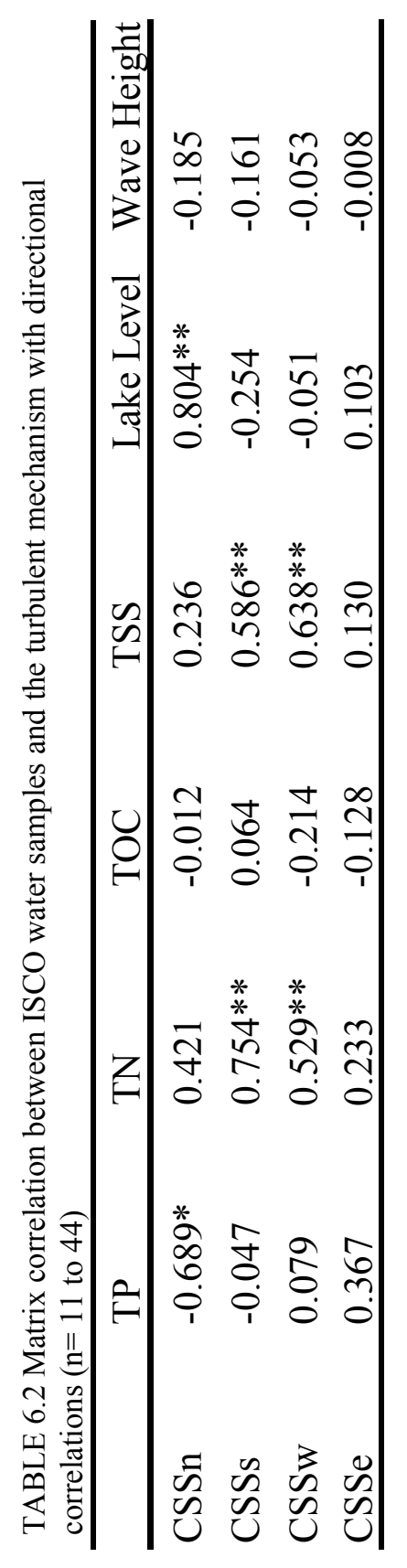


TABLE 6.3 Nutrient budget results for Lake Jesup.

\begin{tabular}{c|cc}
\hline & August 2009 to & April 2010 to \\
& $\mathbf{2 0 1 0}$ & $\mathbf{2 0 1 1}$ \\
\hline Total Flux (mt/yr) & $2,033,882$ & $1,609,672$ \\
TP (mt/yr) & 23 & 22 \\
TN (mt/yr) & 284 & 287 \\
TC (mt/yr) & 2,549 & 2,676 \\
\hline
\end{tabular}

\section{CONCLUSION}

Sediment nutrient concentrations and analysis of the internal processes that affect Lake Jesup were performed to better understand the relationship between sediment resuspension and lake water nutrients. Sediments were found to be nearly constantly in suspension throughout the nine separate deployments. Similar trends are seen in many lakes surrounding the MSJRB.

Sediments in Lake Jesup are continuously being resuspended, because the bottom sediments are in constant interaction with the overlying water column. As indicated by the Hjulstrom curve diagrams, sediments are constantly undergoing erosion, transportation and deposition. An inverse correlation between bulk density of the floc layer and TSS suggests that the floc layer is slightly denser when TSS is low; meaning when TSS is high, floc thickness is relatively lower. Lake level has a direct effect on sediment resuspension and TSS. This means that when lake level is relatively high, currents, wind and waves have a slightly reduced affect on the system. Conversely when lake levels are low, TSS are often found to be high. 
Currents within the Lake Jesup are typically moving along the longest axis of the lake (longest length) as interpreted by the current stick plots and analysis given by Florida Gulf Coast University, Dr. Fugate pers. comm. Dr. Fugates analysis determined that a wind speed at $2.24 \mathrm{~m} \mathrm{~s}-1(5 \mathrm{mph})$ is the lowest sustainable velocity, in order to resuspend sediment. This is significant, because the average wind speed for all deployments is $3.2 \mathrm{~m} \mathrm{~s}^{-1}$ (7.1 mph) from wind data collected by weather station 1 . Prevailing winds that move in the north or south direction are most dominant in sediment transport (Dr. Fugate (FGCU).

Directional shifts in the lake bottom currents may change how the sediment nutrient concentrations are distributed in to the overlying water column. Current directions influence the nutrient concentrations with TP concentrations lower when currents move northward and TN concentrations higher when current moves southward by current shear stress. This connection between current direction and nutrient concentrations suggests that nutrients within the lake sediments are not uniform and may play an important role in the distribution of the nutrients. These spatial differences are also seen in the DO profiles of the water column.

This study concentrated on creating a nutrient budget to understand sediment resuspension. The nutrient budget calculated from the sediment traps was extremely high; roughly two billion kg per year was collected in the sediment traps. This mass is an extremely high amount of sediment, because of this mass amount of sediment It is much more logical to assume that sediment is being resuspended, other was the lake would fill in within years. 


\subsection{Future Work}

This work revealed many interesting relationships such as, TP versus TSS, bulk density of the floc versus TSS and directional current shear stress versus nutrient water concentrations; however, an increase in frequency of sampling would help to improve our understanding of these relationships within the water column. Perhaps a model can be analyzed for bulk density of the floc and TSS, by sampling at a high resolution, predicting the amount of sediment that is being resuspended.

Further more, analysis of the end members for the nutrients within the sediment, floc and traps would be vital in creating a mixing curve for Lake Jesup. Sampling the inputs from rivers for terrestrial inputs and algal production would be essential in developing the mixing line and ultimately and improved nutrient budget.

Another interesting aspect of Lake Jesup is it's possible influence from tidal variations. These tidal influences may have a large effect on the current direction and velocities that ultimately would have an effect on sediment resuspension and the transport of nutrients within Lake Jesup. It is hypothesized that Lake Jesup's internal flushing of the entire lake could be due to higher then normal tides that pull water out of the lake and down the St. Johns River. Tides could be another mechanism controlling Lake Jesup's complex lake current structure, however diurnal wind variations could mimic tidal variations. 


\section{REFERENCES}

Ali, A. and Alam, M.K. 1996. Nutrient levels at the sediment-water interface in Lake Jesup, Florida. Florida Science. 50(1): 20-29.

Anderson, W.T., Gaiser, E.E., and Scinto, L.J. 2006. Lake Harney sediment accumulation and past water quality - Final Report. St. Johns River Water Management District (SH45213), 132p.

Anderson, W.T., Scinto, L.J., Gaiser, E.E., Carroll, B., Quillen, A. and Haberer, J. 2004. Lake Monroe sediment accumulation and past water quality - Final Report. St. Johns River Water Management District (SG452AA), 196p.

Appleby, P.G. and Oldfield, F. 1983. The assessment of ${ }^{210} \mathrm{~Pb}$ data from sites with varying accumulation rates. Hydrobiologia. 103: 29-35.

Bachmann, R.W., Hoyer, M.V., Vinzon, S.B. and Canfield Jr., D.E. 2005. The oridgin of the fluid mud layer in Lake Apopka, Florida. Limnol. Oceanogr. 50(2): 629-635.

Bachmann, R.W., Hoyer, M.V. and Canfield Jr., D.E. 2000. The potential for wave disturbance in shallow Florida lakes. Lake and Res. Manage. 16(4): 281-291.

Bloesch, J. 1994. Editorial: Sediment resuspension in lakes. Hydrobiologia 284: 1-3

Bloesch, J. 1995. Mechanisms, measurement and the importance of sediment resuspension in lakes. Mar. Freshwater Res. 46: 295-304

Bloesch, J. and Burns, N.M. 1979. A critical review of sediment trap technique. Swiss Journ. Of Hydrobiol. 42: 15-55.

Brezonik, P.L. and Engstrom, D.R. 1998. Modern and historic accumulation rates of phosphorus in Lake Okeechobee, Florida. J. Paleolim. 20: 31-46.

Brezonik, P.L., Fox, J.L. Carriker, N.E., Hand, J.G. Nisson, J.D. and Belanger, T.V. 1976. Analysis of eutrophication and water quality factors in the middle St. Johns River Basin. Report for Department of Environmental Engineering Sciences, University of Florida, Gainsville, FL.

Brooks. H.K. 1981. Guide to the physiographic division of Florida. Institute of Food and Agriculture Sciences. Gainesville, Florida.: University of Florida.

Brooks. H.K. 1981. Guide to the physiographic division of Florida (map). Institute of Food and Agriculture Sciences. Gainesville, Florida.: University of Florida. 
Brooks, H.K., 1968, The Plio-Pleistocene of Florida with special reference to the strata outcropping on the Caloosahatchee River., in Perkins, R.D., ed., Late Cenozoic stratigraphy of south Florida: Miami, Miami Geological Society, p. 3-42.

Cable, J.E., Schelske, C.L., Hansen, P.S., Kenney, W.F. and Whitmore, T.J. 1997. Sediment and nutrient deposition in Lake Jesup, Florida (USA) - Final Report. Department of Fisheries and Aquatic Sciences. Univ. of Florida.

Carpenter, S.R., Caraco, N.F., Correll, D.L., Howarth, R.W., Sharply, A.N. and Smith, V.H. 1998. Nonpoint pollution of surface waters with phosphorus and nitrogen. Issues in Ecology No. 3.

Carper, G.L. and Bachmann, R.W. 1984. Wind resuspension of sediments in a prairie lake. Canadian Journal of Fisheries and Aquatic Sciences. 41:1763-1767.

Carrick, H.J., Aldridge, F.J. and Schelske, C.L. 1993. Wind influences phytoplankton biomass and composition in a shallow productive lake. Limnol. Oceanogr. 38:1179-1192.

Dail, M.D., Corbett, D.R., Walsh, J.P., 2007. Assessing the Importance of a Major Hurricane on Continental Margin Sedimentation in the Mississippi Delta Region. Continental Shelf Research, 27, 1857-1874.

Durham, R.W. and Joshi, S.R. 1980. Recent sedimentation rates, ${ }^{210} \mathrm{~Pb}$ fluxes and particle settling velocities in Lake Huron, Laurentian Great Lakes. Chem. Geol. 31: 53-66.

Evans, R.D. 1994. Emperical evidence of sediment resuspension in lakes. Hydrobiologia 317:5-12.

Flower, R.J. 1991. Field calibration and performance of sediment traps in a eutrophic holomictic lake. J. Paleolimnology 5:157-188.

Fugate, D.C., and Friedrichs, C.T., 2002. Determining concentration and fall velocity of estuarine particle populations using ADV, OBS and LISST. Continental Shelf Research, 22: $1867-1886$.

Gao, X. 1996. Nutrient and Unionized Ammonia TMDLs for Lake Jesup. Division of Water Resource Management, Bureau of Watershed Management. Florida Department of Environmental Protection.

Goldberg, E.D. 1963. Geochronology with Pb-210. In radioactive dating. Internat. Energy Agency. 121-131.

Guildford, S.J. and Hecky, R.E. 2000. Total nitrogen, total phosphorus, and nutrient limitation in lakes and oceans: Is there a common relationship?. Limnology and Oceanography, 45(6): 1213-1223 
Henderson-Sellers, B. and Markland H.R. 1987. Decaying lakes: the origins and control of cultural eutrophication. Chichester [West Sussex] ; New York : Wiley.

Hjulstrom, F. (1935). "The Morphological Activity of Rivers as Illustrated by River Fyris," Bulletin of the Geological Institute, Uppsala, vol. 25, ch. 3.

Horppila, J. and Nurminen, L. 2005. Effects of calculation procedure and sampling site on trap method estimates of sediment resuspension in a shallow lake. Sedimentology 52: 903-913.

Keesecker, D.H. 1992. Lake Jessup restoration, diagnostic evaluation, water budget and nutrient budget. Water and air research, inc. Gainesville, FL.

Kenney, W.F., Waters, M.N., Schelske, C.L. and Brenner, M. 2002. Sediment records of phosphorus-driven shifts to phytoplankton dominance in shallow Florida lakes. Journal of Paleolimnology. 27: 367-377.

Kozerski, H.P. 2003. More about plate sediment trap measurements - Reply to comment of Sukhodolov er el. Water Research. 37: 2796-2801.

Kozerski, H.P and Leuschner, K. 2000. A plate sediment trap: design and first experiences. Verh. Intern. Verein. Limnol. 27: 242-245.

Kozerski, H.P., Behrendt, H. and Kohler, J. 1999. The N and P budget of the shallow, flushed lake Muggelsee retention, external and internal load. Hydrobiologia. 408/409: 159-166.

Kozerski, H.P and Leuschner, K. 1999. Plate sediment traps for slow moving waters. Water Res. 33(13): 2913-2922.

Krishnaswami, S., Lal, D. Martin, J.M. and Meybeck, M. 1971. Geochronology of lake sediments. Earth Planate. Sci. Letters. 11: 407-414.

Kristensen, P., Sondergaard, M. and Jeppesen, E. 1992. Resuspension in shallow eutrophic lakes. Hydrobiologia. 228: 101-109.

Lee, G.F. 1970. Factors affecting the transfer of materials between water and sediments. Univ. of Wisconsin. Eutrophication Information Program, Literature Review No. 1 Madison, Wisconsin.

Lijklema, L., Aalderink, R.H., Blom, G. and VanDuin, E.H.S. 1994. Sediment transport in shallow lakes - two case studies related to eutrophication. P. 235-280. In: J.V. 
DePinto, W. Lick, and J.F. Paul. (eds.) Transport and transformation of contaminants near the sediment-water interface. Lewis Publ. Boca Raton, FL.

Luettich, R.A., Harlman, D.R.F., Sonlyody, L. 1990. Dynamic behavior of suspended sediment concentrations in a shallow lake perturbed by episodic wind events. Limnol. Oceanogr. 35: 1050-1067.

Lund-Hansen, L.C., Peterson, M. and Nurjaya, W. 1999. Vertical sediment fluxes and wave-induced sediment resuspension in a shallow-water coastal lagoon. Estuaries. 22(1): $39-46$.

Meyers, P.A and Lallier-Vergès, E. 1999. Lacustrine sedimentary organic matter records of Late Quaternary paleoclimates. Journal of Palelimnology. 21: 345-372.

Nelson, D.W. and Sommers, L.E., 1996. Total carbon, organic carbon, and organic matter. In: Methods of Soil Analysis, Part 2, 2nd ed., A.L. Page et al., Ed. Agronomy. 9:961-1010. Am. Soc. of Agron., Inc. Madison, WI.

Newman, S. and Reddy, K.R. 1992. Sediment resuspension effects on alkaline phosphate activity. Hydrobiologia 245:75-86.

Qin, B., Hu, W., Gao, G., Luo, L. and Zhang, J. 2004. Dynamics of sediment resuspension and the conceptual schema of nutrient release in the large shallow Lake Taihu, China. Chinese Science Bulletin. 49(1): 54-64.

Schindler, D.W., Hesslein, R., and Kipphur, G. 1977. Interactions between sediments and overlying waters in an experimentally eutrophied Precambrian Shield Lake. In: H.L. Golterman (ed.), Interactions between sediments and freshwater. Dr. W. Junk, The Hague: 235-243.

Seminole County. 1991. Sanitary Sewer Element. Seminole County 1991 Comprehensive Plan. Seminole County Planning Office, Sanford, Florida.

Solorzano, L and Sharp, J.H., 1980. Determination of Total Dissolved Phosphorus and Particulate Phosphorus in Natural Waters. Limnology and Oceanography, 25(4): 754758.

Sternberg, R.W. 1972. Predicting initial motion and bedload transport of sediment particles in the shallow marine environments, p. 61-82. In Swift, D.J.P. and Pikey, O.H. (eds), Shelf Sediment Transport: Process and Pattern. Dowden, Huchinson and Ross, Stroudsberg, PA.

Tassenow, U., 1972 Losungs-, Diffusions- und sorption-sprozesse in der Oberschicht von Seesedimenten. 1. Ein Langzeitexperiment unter aeroben end anaeroben Bedingungen in Fleibgleichgewicht. Arch. Hydrobiol. Suppl. 38: 353-398. 
Wetzel, R.G. 2001. Limnology: Lake and River Ecosystems, $3^{\text {rd }}$ ed. Academic Press. San Diego, CA. p.2

White, W.A., 1970, The Geomorphology of the Florida Peninsula: Tallahassee, Bureau of Geology, p. 147.

Winn, E. rev. 2003. Early History of the St. Johns River. Winn's Books, Maitland, Florida. 


\section{APPENDICES}

TABLE A1 List of sediment nutrient analysis.

\begin{tabular}{ccccccc}
\hline $\begin{array}{c}\text { Sample } \\
\text { Type }\end{array}$ & Sample ID & Site & Deployment & $\begin{array}{c}\text { Collection } \\
\text { Date }\end{array}$ & $\begin{array}{c}\text { UTM } \\
\text { North }\end{array}$ & $\begin{array}{c}\text { UTM } \\
\text { East }\end{array}$ \\
\hline \hline & & & & & & \\
SF & LJ280508SF & 28 & 1 & $5 / 8 / 2009$ & 480334 & 3178274 \\
SF & LJ140514SF & 14 & 1 & $5 / 14 / 2009$ & 475800 & 3176405 \\
SF & LJ220514SF & 22 & 1 & $5 / 14 / 2009$ & 473685 & 3176656 \\
SF & LJ140626SF & 14 & 2 & $6 / 26 / 2009$ & 475800 & 3176405 \\
SF & LJ220626SF & 22 & 2 & $6 / 26 / 2009$ & 473685 & 3176656 \\
SF & LJ280626SF & 28 & 2 & $6 / 26 / 2009$ & 480334 & 3178274 \\
SF & LJ140821SF & 14 & 3 & $8 / 21 / 2009$ & 475800 & 3176405 \\
SF & LJ220821SF & 22 & 3 & $8 / 21 / 2009$ & 473685 & 3176656 \\
SF & LJ280821SF & 28 & 3 & $8 / 21 / 2009$ & 480334 & 3178274 \\
SF & LJ221106SF & 22 & 4 & $11 / 6 / 2009$ & 473685 & 3176656 \\
SF & LJ281106SF & 28 & 4 & $11 / 6 / 2009$ & 480334 & 3178274 \\
SF & LJ141106SF & 14 & 4 & $11 / 6 / 2009$ & 475800 & 3176405 \\
SF & LJ140129SF & 14 & 5 & $1 / 29 / 2010$ & 475800 & 3176405 \\
SF & LJ220129SF & 22 & 5 & $1 / 29 / 2010$ & 473685 & 3176656 \\
SF & LJ280129SF & 28 & 5 & $1 / 29 / 2010$ & 480334 & 3178274 \\
SF & LJ140820SF & 14 & 6 & $8 / 20 / 2010$ & 475800 & 3176405 \\
SF & LJ220820SF & 22 & 6 & $8 / 20 / 2010$ & 473685 & 3176656 \\
SF & LJ280820SF & 28 & 6 & $8 / 20 / 2010$ & 480334 & 3178274 \\
SF & LJ440820SF & 44 & 6 & $8 / 20 / 2010$ & 481994 & 3181379 \\
SF & LJ221111SF & 22 & 7 & $11 / 11 / 2010$ & 473685 & 3176656 \\
SF & LJ141111SF & 14 & 7 & $11 / 11 / 2010$ & 475800 & 3176405 \\
SF & LJ281111SF & 28 & 7 & $11 / 11 / 2010$ & 480334 & 3178274 \\
SF & LJ441111SF & 44 & 7 & $11 / 11 / 2010$ & 481994 & 3181379 \\
SF & LJ140128 SF & 14 & 8 & $1 / 28 / 2011$ & 475800 & 3176405 \\
SF & LJ220128 SF & 22 & 8 & $1 / 28 / 2011$ & 473685 & 3176656 \\
SF & LJ440128 SF & 44 & 8 & $1 / 28 / 2011$ & 481994 & 3181379 \\
SF & LJ140408 SF & 14 & 9 & $4 / 8 / 2011$ & 475800 & 3176405 \\
SF & LJ220408 SF & 22 & 9 & $4 / 8 / 2011$ & 473685 & 3176656 \\
SF & LJ280408 SF & 28 & 9 & $4 / 8 / 2011$ & 480334 & 3178274 \\
SF & LJ440408 SF & 44 & 9 & $4 / 8 / 2011$ & 481994 & 3181379 \\
& & & & &
\end{tabular}




\begin{tabular}{|c|c|c|c|c|c|c|}
\hline $\begin{array}{c}\text { Sample } \\
\text { Type }\end{array}$ & Sample ID & Site & Deployment & $\begin{array}{c}\text { Collection } \\
\text { Date } \\
\end{array}$ & $\begin{array}{l}\text { UTM } \\
\text { North } \\
\end{array}$ & $\begin{array}{l}\text { UTM } \\
\text { East } \\
\end{array}$ \\
\hline $\mathrm{SS}$ & LJ280508SS & 28 & 1 & $5 / 8 / 2009$ & 480334 & 3178274 \\
\hline $\mathrm{SS}$ & LJ140514SS & 14 & 1 & $5 / 14 / 2009$ & 475800 & 3176405 \\
\hline SS & LJ220514SS & 22 & 1 & $5 / 14 / 2009$ & 473685 & 3176656 \\
\hline SS & LJ140626SS & 14 & 2 & $6 / 26 / 2009$ & 475800 & 3176405 \\
\hline $\mathrm{SS}$ & LJ220626SS & 22 & 2 & $6 / 26 / 2009$ & 473685 & 3176656 \\
\hline SS & LJ280626SS & 28 & 2 & $6 / 26 / 2009$ & 480334 & 3178274 \\
\hline SS & LJ140821SS & 14 & 3 & $8 / 21 / 2009$ & 475800 & 3176405 \\
\hline SS & LJ220821SS & 22 & 3 & $8 / 21 / 2009$ & 473685 & 3176656 \\
\hline SS & LJ280821SS & 28 & 3 & $8 / 21 / 2009$ & 480334 & 3178274 \\
\hline $\mathrm{SS}$ & LJ141106SS & 14 & 4 & $11 / 6 / 2009$ & 475800 & 3176405 \\
\hline $\mathrm{SS}$ & LJ281106SS & 28 & 4 & $11 / 6 / 2009$ & 480334 & 3178274 \\
\hline SS & LJ221106SS & 22 & 4 & $11 / 6 / 2009$ & 473685 & 3176656 \\
\hline SS & LJ280129SS & 28 & 5 & $1 / 29 / 2010$ & 480334 & 3178274 \\
\hline SS & LJ140129SS & 14 & 5 & $1 / 29 / 2010$ & 475800 & 3176405 \\
\hline SS & LJ220129SS & 22 & 5 & $1 / 29 / 2010$ & 473685 & 3176656 \\
\hline SS & LJ140820SS & 14 & 6 & $8 / 20 / 2010$ & 475800 & 3176405 \\
\hline SS & LJ220820SS & 22 & 6 & $8 / 20 / 2010$ & 473685 & 3176656 \\
\hline $\mathrm{SS}$ & LJ280820SS & 28 & 6 & $8 / 20 / 2010$ & 480334 & 3178274 \\
\hline $\mathrm{SS}$ & LJ440820SS & 44 & 6 & $8 / 20 / 2010$ & 481994 & 3181379 \\
\hline SS & LJ441111SS & 44 & 7 & $11 / 11 / 2010$ & 481994 & 3181379 \\
\hline SS & LJ141111SS & 14 & 7 & $11 / 11 / 2010$ & 475800 & 3176405 \\
\hline $\mathrm{SS}$ & LJ221111SS & 22 & 7 & $11 / 11 / 2010$ & 473685 & 3176656 \\
\hline SS & LJ281111SS & 28 & 7 & $11 / 11 / 2010$ & 480334 & 3178274 \\
\hline SS & LJ140128 SS & 14 & 8 & $1 / 28 / 2011$ & 475800 & 3176405 \\
\hline $\mathrm{SS}$ & LJ220128 SS & 22 & 8 & $1 / 28 / 2011$ & 473685 & 3176656 \\
\hline $\mathrm{SS}$ & LJ280128 SS & 28 & 8 & $1 / 28 / 2011$ & 480334 & 3178274 \\
\hline SS & LJ440128 SS & 44 & 8 & $1 / 28 / 2011$ & 481994 & 3181379 \\
\hline $\mathrm{SS}$ & LJ140408 SS & 14 & 9 & 4/8/2011 & 475800 & 3176405 \\
\hline $\mathrm{SS}$ & LJ220408 SS & 22 & 9 & $4 / 8 / 2011$ & 473685 & 3176656 \\
\hline SS & LJ280408 SS & 28 & 9 & 4/8/2011 & 480334 & 3178274 \\
\hline SS & LJ440408 SS & 44 & 9 & $4 / 8 / 2011$ & 481994 & 3181379 \\
\hline
\end{tabular}


TABLE A1 cont. List of sediment nutrient analysis.

\begin{tabular}{|c|c|c|c|c|c|c|}
\hline $\begin{array}{c}\text { Sample } \\
\text { Type }\end{array}$ & Sample ID & Site & Deployment & $\begin{array}{c}\text { Collection } \\
\text { Date }\end{array}$ & $\begin{array}{l}\text { UTM } \\
\text { North }\end{array}$ & $\begin{array}{l}\text { UTM } \\
\text { East }\end{array}$ \\
\hline STHA & LJ280329STHA & 28 & 0 & $3 / 29 / 2009$ & 480334 & 3178274 \\
\hline STHA & LJ280425 STHA & 28 & 1 & $4 / 25 / 2009$ & 480334 & 3178274 \\
\hline STHA & LJ140514STHA & 14 & 1 & $5 / 14 / 2009$ & 475800 & 3176405 \\
\hline STHA & LJ220514STHA & 22 & 1 & $5 / 14 / 2009$ & 473685 & 3176656 \\
\hline STHA & LJ140709STHA & 14 & 2 & 7/9/2009 & 475800 & 3176405 \\
\hline STHA & LJ220709STHA & 22 & 2 & 7/9/2009 & 473685 & 3176656 \\
\hline STHA & LJ280709STHA & 28 & 2 & 7/9/2009 & 480334 & 3178274 \\
\hline STHA & LJ140828STHA & 14 & 3 & $8 / 28 / 2009$ & 475800 & 3176405 \\
\hline STHA & LJ220828STHA & 22 & 3 & $8 / 28 / 2009$ & 473685 & 3176656 \\
\hline STHA & LJ280828STHA & 28 & 3 & $8 / 28 / 2009$ & 480334 & 3178274 \\
\hline STHA & LJ221113STHA & 22 & 4 & $11 / 13 / 2009$ & 473685 & 3176656 \\
\hline STHA & LJ141113STHA & 14 & 4 & $11 / 13 / 2009$ & 475800 & 3176405 \\
\hline STHA & LJ281113STHA & 28 & 4 & $11 / 13 / 2009$ & 480334 & 3178274 \\
\hline STHA & LJ280205STHA & 28 & 5 & $2 / 5 / 2010$ & 480334 & 3178274 \\
\hline STHA & LJ220205STHA & 22 & 5 & $2 / 5 / 2010$ & 473685 & 3176656 \\
\hline STHA & LJ140205STHA & 14 & 5 & $2 / 5 / 2010$ & 475800 & 3176405 \\
\hline STHA & LJ140827STHA & 14 & 6 & $8 / 28 / 2010$ & 475800 & 3176405 \\
\hline STHA & LJ220827STHA & 22 & 6 & $8 / 28 / 2010$ & 473685 & 3176656 \\
\hline STHA & LJ280827STHA & 28 & 6 & $8 / 28 / 2010$ & 480334 & 3178274 \\
\hline STHA & LJ440827STHA & 44 & 6 & $8 / 28 / 2010$ & 481994 & 3181379 \\
\hline STHA & LJ22B1119STHA & 22 & 7 & $11 / 19 / 2010$ & 473685 & 3176656 \\
\hline STHA & LJ28B1119STHA & 28 & 7 & $11 / 19 / 2010$ & 480334 & 3178274 \\
\hline STHA & LJ22A1119STHA & 22 & 7 & $11 / 19 / 2010$ & 473685 & 3176656 \\
\hline STHA & LJ28A1119STHA & 28 & 7 & $11 / 19 / 2010$ & 480334 & 3178274 \\
\hline STHA & LJ14B1119STHA & 14 & 7 & $11 / 19 / 2010$ & 475800 & 3176405 \\
\hline STHA & LJ14A1119STHA & 14 & 7 & $11 / 19 / 2010$ & 475800 & 3176405 \\
\hline
\end{tabular}


TABLE A1 cont. List of sediment nutrient analysis.

\begin{tabular}{|c|c|c|c|c|c|c|}
\hline $\begin{array}{c}\text { Sample } \\
\text { Type } \\
\end{array}$ & Sample ID & Site & Deployment & $\begin{array}{c}\text { Collection } \\
\text { Date } \\
\end{array}$ & $\begin{array}{l}\text { UTM } \\
\text { North } \\
\end{array}$ & $\begin{array}{l}\text { UTM } \\
\text { East } \\
\end{array}$ \\
\hline STHA & $\begin{array}{l}\text { LJ44B0204 } \\
\text { STHA } \\
\text { LJ28B0204 }\end{array}$ & 44 & 8 & $2 / 4 / 2011$ & 481994 & 3181379 \\
\hline STHA & $\begin{array}{l}\text { STHA } \\
\text { LJ44A0204 }\end{array}$ & 28 & 8 & $2 / 4 / 2011$ & 480334 & 3178274 \\
\hline STHA & $\begin{array}{l}\text { STHA } \\
\text { LJ22B0204 }\end{array}$ & 44 & 8 & $2 / 4 / 2011$ & 481994 & 3181379 \\
\hline STHA & $\begin{array}{l}\text { STHA } \\
\text { LJ14B0204 }\end{array}$ & 22 & 8 & $2 / 4 / 2011$ & 473685 & 3176656 \\
\hline STHA & $\begin{array}{l}\text { STHA } \\
\text { LJ28A0204 }\end{array}$ & 14 & 8 & $2 / 4 / 2011$ & 475800 & 3176405 \\
\hline STHA & $\begin{array}{l}\text { STHA } \\
\text { LJ14A0204 }\end{array}$ & 28 & 8 & $2 / 4 / 2011$ & 480334 & 3178274 \\
\hline STHA & $\begin{array}{l}\text { STHA } \\
\text { LJ22A0204 }\end{array}$ & 14 & 8 & $2 / 4 / 2011$ & 475800 & 3176405 \\
\hline STHA & $\begin{array}{l}\text { STHA } \\
\text { LJ14A0415 }\end{array}$ & 22 & 8 & $2 / 4 / 2011$ & 473685 & 3176656 \\
\hline STHA & $\begin{array}{l}\text { STHA } \\
\text { LJ14B0415 }\end{array}$ & 14 & 9 & $4 / 15 / 2011$ & 475800 & 3176405 \\
\hline STHA & $\begin{array}{l}\text { STHA } \\
\text { LJ22A0415 }\end{array}$ & 14 & 9 & $4 / 15 / 2011$ & 475800 & 3176405 \\
\hline STHA & $\begin{array}{l}\text { STHA } \\
\text { LJ22B0415 }\end{array}$ & 22 & 9 & $4 / 15 / 2011$ & 473685 & 3176656 \\
\hline STHA & $\begin{array}{l}\text { STHA } \\
\text { LJ28A0415 }\end{array}$ & 22 & 9 & $4 / 15 / 2011$ & 473685 & 3176656 \\
\hline STHA & $\begin{array}{l}\text { STHA } \\
\text { LJ28B0415 }\end{array}$ & 28 & 9 & $4 / 15 / 2011$ & 480334 & 3178274 \\
\hline STHA & $\begin{array}{l}\text { STHA } \\
\text { LJ44A0415 }\end{array}$ & 28 & 9 & $4 / 15 / 2011$ & 480334 & 3178274 \\
\hline STHA & $\begin{array}{l}\text { STHA } \\
\text { LJ44B0415 }\end{array}$ & 44 & 9 & $4 / 15 / 2011$ & 481994 & 3181379 \\
\hline STHA & STHA & 44 & 9 & $4 / 15 / 2011$ & 481994 & 3181379 \\
\hline
\end{tabular}


TABLE A1 cont. List of sediment nutrient analysis.

\begin{tabular}{|c|c|c|c|c|c|c|}
\hline $\begin{array}{c}\text { Sample } \\
\text { Type }\end{array}$ & Sample ID & Site & $\begin{array}{c}\text { Deploymen } \\
\mathbf{t}\end{array}$ & $\begin{array}{c}\text { Collection } \\
\text { Date }\end{array}$ & $\begin{array}{l}\text { UTM } \\
\text { North }\end{array}$ & $\begin{array}{l}\text { UTM } \\
\text { East } \\
\end{array}$ \\
\hline STM8 & LJ281107STM8 & 28 & 4 & $11 / 7 / 2009$ & 480334 & 3178274 \\
\hline STM8 & LJ281108STM8 & 28 & 4 & $11 / 8 / 2009$ & 480334 & 3178274 \\
\hline STM8 & LJ281109STM8 & 28 & 4 & $11 / 9 / 2009$ & 480334 & 3178274 \\
\hline STM8 & LJ281110STM8 & 28 & 4 & $11 / 10 / 2009$ & 480334 & 3178274 \\
\hline STM8 & LJ281111STM8 & 28 & 4 & $11 / 11 / 2009$ & 480334 & 3178274 \\
\hline STM8 & LJ281112STM8 & 28 & 4 & $11 / 12 / 2009$ & 480334 & 3178274 \\
\hline STM8 & LJ281113STM8 & 28 & 4 & $11 / 13 / 2009$ & 480334 & 3178274 \\
\hline STM8 & LJ280205STM8 & 28 & 5 & $2 / 5 / 2010$ & 480334 & 3178274 \\
\hline STM8 & LJ280204bSTM8 & 28 & 5 & $2 / 4 / 2010$ & 480334 & 3178274 \\
\hline STM8 & LJ280204aSTM8 & 28 & 5 & $2 / 4 / 2010$ & 480334 & 3178274 \\
\hline STM8 & LJ280203bSTM8 & 28 & 5 & $2 / 3 / 2010$ & 480334 & 3178274 \\
\hline STM8 & LJ280203aSTM8 & 28 & 5 & $2 / 3 / 2010$ & 480334 & 3178274 \\
\hline STM8 & LJ280202bSTM8 & 28 & 5 & $2 / 2 / 2010$ & 480334 & 3178274 \\
\hline STM8 & LJ280202aSTM8 & 28 & 5 & $2 / 2 / 2010$ & 480334 & 3178274 \\
\hline STM8 & LJ280201bSTM8 & 28 & 5 & $2 / 1 / 2010$ & 480334 & 3178274 \\
\hline STM8 & LJ280201aSTM8 & 28 & 5 & $2 / 1 / 2010$ & 480334 & 3178274 \\
\hline STM8 & LJ280131bSTM8 & 28 & 5 & $1 / 31 / 2010$ & 480334 & 3178274 \\
\hline STM8 & LJ280131aSTM8 & 28 & 5 & $1 / 31 / 2010$ & 480334 & 3178274 \\
\hline STM8 & LJ280130bSTM8 & 28 & 5 & $1 / 30 / 2010$ & 480334 & 3178274 \\
\hline STM8 & LJ280130aSTM8 & 28 & 5 & $1 / 30 / 2010$ & 480334 & 3178274 \\
\hline STT & LJ280508STT & 28 & 1 & $5 / 8 / 2009$ & 480334 & 3178274 \\
\hline STT & LJ220514STT & 22 & 1 & $5 / 14 / 2009$ & 473685 & 3176656 \\
\hline STT & LJ140828STT & 14 & 3 & $8 / 28 / 2009$ & 480334 & 3178274 \\
\hline STT & LJ220828STT & 22 & 3 & $8 / 28 / 2009$ & 480334 & 3178274 \\
\hline STT & LJ280828STT & 28 & 3 & $8 / 28 / 2009$ & 480334 & 3178274 \\
\hline STT & LJ141113STT & 14 & 4 & $11 / 13 / 2010$ & 475800 & 3176405 \\
\hline STT & LJ280205STT & 28 & 5 & $2 / 5 / 2010$ & 480334 & 3178274 \\
\hline STT & LJ220205STT & 22 & 5 & $2 / 5 / 2010$ & 473685 & 3176656 \\
\hline STT & LJ140205STT & 14 & 5 & $2 / 5 / 2010$ & 475800 & 3176405 \\
\hline
\end{tabular}

TABLE A1 cont. List of sediment nutrient analysis. 


\begin{tabular}{lcccccc}
\hline & & & & & & \\
Sample ID & BD $^{\mathbf{2}}$ & $\mathbf{p H}$ & $\mathbf{D r y}$ & $\mathbf{H}_{\mathbf{2}} \mathbf{O}$ & $\mathbf{\text { OM }}$ & $\mathbf{\text { Ash }}$ \\
& gdw cm $^{-3}$ & & $\mathbf{\%}$ & $\mathbf{\%}$ & $\mathbf{\%}$ & $\mathbf{\%}$ \\
\hline \hline LJ280508SF & 0.055 & 7.64 & 5.47 & 94.53 & 27.13 & 72.87 \\
LJ140514SF & 0.082 & 7.48 & 7.73 & 92.27 & 30.13 & 69.87 \\
LJ220514SF & 0.035 & 7.30 & 3.44 & 96.56 & 41.69 & 58.31 \\
LJ140626SF & 0.043 & 7.14 & 4.27 & 95.73 & 15.38 & 84.62 \\
LJ220626SF & 0.058 & 6.91 & 5.54 & 94.46 & 33.94 & 66.06 \\
LJ280626SF & 0.068 & 7.21 & 7.12 & 92.88 & 36.94 & 63.06 \\
LJ140821SF & 0.048 & 6.96 & 4.68 & 95.32 & 35.89 & 64.11 \\
LJ220821SF & 0.048 & 7.01 & 4.97 & 95.03 & 36.00 & 64.00 \\
LJ280821SF & 0.066 & 7.15 & 6.80 & 93.20 & 19.22 & 80.78 \\
LJ221106SF & 0.038 & 7.03 & 3.84 & 96.16 & 39.92 & 60.08 \\
LJ281106SF & 0.044 & 7.18 & 4.24 & 95.76 & 33.24 & 66.76 \\
LJ141106SF & 0.046 & 7.04 & 4.55 & 95.45 & 34.50 & 65.50 \\
LJ140129SF & 0.044 & 7.73 & 4.77 & 95.23 & 32.60 & 67.40 \\
LJ220129SF & 0.048 & 7.72 & 4.39 & 95.61 & 42.20 & 57.80 \\
LJ280129SF & 0.051 & 7.57 & 5.30 & 94.70 & 31.15 & 68.85 \\
LJ140820SF & 0.064 & 7.41 & 7.69 & 92.31 & 31.90 & 68.10 \\
LJ220820SF & 0.069 & 7.38 & 6.54 & 93.46 & 31.52 & 68.48 \\
LJ280820SF & 0.082 & 7.40 & 7.98 & 92.02 & 7.57 & 92.43 \\
LJ440820SF & 0.054 & 7.36 & 6.51 & 93.49 & 31.78 & 68.22 \\
LJ221111SF & 0.043 & 7.35 & 4.14 & 95.86 & 36.72 & 63.28 \\
LJ141111SF & 0.039 & 7.45 & 3.92 & 96.08 & 38.91 & 61.09 \\
LJ281111SF & 0.070 & 7.50 & 6.10 & 93.90 & 29.89 & 70.11 \\
LJ441111SF & 0.035 & 7.33 & 3.60 & 96.40 & 40.54 & 59.46 \\
LJ140128 SF & 0.043 & 7.54 & 4.46 & 95.54 & 35.79 & 64.21 \\
LJ220128 SF & 0.032 & 7.62 & 3.20 & 96.80 & 42.59 & 57.41 \\
LJ440128 SF & 0.039 & 7.53 & 3.94 & 96.06 & 38.70 & 61.30 \\
LJ140408 SF & 0.033 & 7.78 & 3.80 & 96.20 & 38.42 & 61.58 \\
LJ220408 SF & 0.021 & 7.77 & 2.68 & 97.32 & 41.49 & 58.51 \\
LJ280408 SF & 0.028 & 7.88 & 3.39 & 96.61 & 26.57 & 73.43 \\
LJ440408 SF & 0.039 & 7.67 & 4.18 & 95.82 & 36.02 & 63.98 \\
& & & & & &
\end{tabular}


TABLE A1 cont. List of sediment nutrient analysis.

\begin{tabular}{|c|c|c|c|c|c|c|}
\hline Sample ID & $\begin{array}{c}\mathbf{B D}^{\mathbf{2}} \\
\mathrm{gdw} \mathrm{cm}{ }^{-3} \\
\end{array}$ & pH & $\begin{array}{c}\text { Dry } \\
\% \\
\end{array}$ & $\begin{array}{c}\mathrm{H}_{2} \mathbf{O} \\
\% \\
\end{array}$ & $\begin{array}{c}\text { OM } \\
\% \\
\end{array}$ & $\begin{array}{c}\text { Ash } \\
\% \\
\end{array}$ \\
\hline LJ280508SS & 0.567 & 8.23 & 43.55 & 56.45 & 4.13 & 95.87 \\
\hline LJ140514SS & 0.141 & 7.38 & 13.15 & 86.85 & 19.86 & 80.14 \\
\hline LJ220514SS & 0.091 & 7.44 & 9.56 & 90.44 & 28.60 & 71.40 \\
\hline LJ140626SS & 0.133 & 7.82 & 10.45 & 89.55 & 5.19 & 94.81 \\
\hline LJ220626SS & 0.609 & 7.83 & 12.11 & 87.89 & 20.61 & 79.39 \\
\hline LJ280626SS & 0.645 & 7.98 & 44.52 & 55.48 & 30.56 & 69.44 \\
\hline LJ140821SS & 0.100 & 7.31 & 9.03 & 90.97 & 31.61 & 68.39 \\
\hline LJ220821SS & 0.124 & 7.63 & 11.67 & 88.33 & 43.17 & 56.83 \\
\hline LJ280821SS & 0.101 & 7.56 & 9.11 & 90.89 & 2.86 & 97.14 \\
\hline LJ141106SS & 0.143 & 7.41 & 11.55 & 88.45 & 21.10 & 78.90 \\
\hline LJ281106SS & 0.158 & 7.52 & 15.03 & 84.97 & 15.54 & 84.46 \\
\hline LJ221106SS & 0.084 & 7.06 & 8.21 & 91.79 & 29.71 & 70.29 \\
\hline LJ280129SS & 0.542 & 8.03 & 39.83 & 60.17 & 6.98 & 93.02 \\
\hline LJ140129SS & 0.094 & 7.85 & 9.43 & 90.57 & 30.12 & 69.88 \\
\hline LJ220129SS & 0.094 & 7.89 & 8.59 & 91.41 & 30.61 & 69.39 \\
\hline LJ140820SS & 0.125 & 7.56 & 10.55 & 89.45 & 23.51 & 76.49 \\
\hline LJ220820SS & 0.140 & 7.65 & 11.93 & 88.07 & 35.37 & 64.63 \\
\hline LJ280820SS & 0.548 & 7.61 & 52.11 & 47.89 & 19.65 & 80.35 \\
\hline LJ440820SS & 0.138 & 7.67 & 12.89 & 87.11 & 27.33 & 72.67 \\
\hline LJ441111SS & 0.125 & 7.69 & 12.03 & 87.97 & 24.80 & 75.20 \\
\hline LJ141111SS & 0.098 & 7.73 & 9.54 & 90.46 & 28.77 & 71.23 \\
\hline LJ221111SS & 0.104 & 7.67 & 10.04 & 89.96 & 27.95 & 72.05 \\
\hline LJ281111SS & 0.707 & 7.99 & 49.02 & 50.98 & 5.56 & 94.44 \\
\hline LJ140128 SS & 0.121 & 7.71 & 11.56 & 88.40 & 25.53 & 74.47 \\
\hline LJ220128 SS & 0.106 & 7.78 & 9.66 & 90.34 & 30.68 & 69.32 \\
\hline LJ280128 SS & 0.264 & 7.86 & 23.81 & 76.19 & 7.54 & 92.46 \\
\hline LJ440128 SS & 0.076 & 7.70 & 7.17 & 92.83 & 30.59 & 69.41 \\
\hline LJ140408 SS & 0.110 & 7.85 & 10.87 & 89.13 & 14.86 & 85.14 \\
\hline LJ220408 SS & 0.132 & 7.85 & 12.36 & 87.64 & 18.41 & 81.59 \\
\hline LJ280408 SS & 0.641 & 8.01 & 46.54 & 53.46 & 5.14 & 94.86 \\
\hline LJ440408 SS & 0.140 & 7.69 & 12.06 & 87.94 & 27.19 & 72.81 \\
\hline
\end{tabular}


TABLE A1 cont. List of sediment nutrient analysis.

\begin{tabular}{|c|c|c|c|c|c|c|}
\hline Sample ID & $\begin{array}{c}\text { Trap Days } \\
\text { Collecting } \\
\text { days } \\
\end{array}$ & $\begin{array}{c}\text { STHA } \\
\text { height } \\
\text { cm } \\
\end{array}$ & $\begin{array}{c}\begin{array}{c}\text { Volume } \\
\mathbf{c m}^{3}\end{array} \\
\end{array}$ & $\begin{array}{c}\mathbf{B D}^{\mathbf{1}} \\
\mathrm{gdw} \mathrm{cm}^{-3} \\
\end{array}$ & $\begin{array}{c}\text { Dry } \\
\text { Weight } \\
\text { g } \\
\end{array}$ & $\begin{array}{c}\text { MAR } \\
\mathrm{g} \mathrm{m}^{-2} \mathrm{~d}^{-1} \\
\end{array}$ \\
\hline LJ280329STHA & 16 & 11 & 235.59 & 0.043 & 10.100 & 295 \\
\hline LJ280425 STHA & 14 & 28.5 & 610.39 & 0.054 & 32.660 & 1089 \\
\hline LJ140514STHA & 18 & 13 & 278.42 & 0.075 & 20.791 & 539 \\
\hline LJ220514STHA & 18 & 47.5 & 1017.32 & 0.044 & 44.826 & 1163 \\
\hline LJ140709STHA & 13 & 55 & 1177.95 & 0.071 & 83.730 & 3007 \\
\hline LJ220709STHA & 13 & 10 & 214.17 & 0.032 & 6.942 & 249 \\
\hline LJ280709STHA & 13 & 10 & 214.17 & 0.041 & 8.833 & 317 \\
\hline LJ140828STHA & 7 & 2.6 & 55.68 & 0.045 & 2.511 & 168 \\
\hline LJ220828STHA & 7 & 5 & 107.09 & 0.028 & 3.037 & 203 \\
\hline LJ280828STHA & 7 & 2.2 & 47.12 & 0.028 & 1.298 & 87 \\
\hline LJ221113STHA & 7 & 8 & 171.34 & 0.037 & 6.275 & 419 \\
\hline LJ141113STHA & 7 & 5 & 107.09 & 0.041 & 4.370 & 291 \\
\hline LJ281113STHA & 7 & 3 & 64.25 & 0.052 & 3.368 & 225 \\
\hline LJ280205STHA & 7 & 4 & 85.67 & 0.032 & 2.741 & 183 \\
\hline LJ220205STHA & 7 & 5 & 107.09 & 0.042 & 4.450 & 297 \\
\hline LJ140205STHA & 7 & 2 & 42.83 & 0.052 & 2.222 & 148 \\
\hline LJ140827STHA & 7 & 2 & 42.83 & 0.027 & 1.156 & 77 \\
\hline LJ220827STHA & 7 & 6 & 128.50 & 0.024 & 3.040 & 203 \\
\hline LJ280827STHA & 7 & 2 & 42.83 & 0.030 & 1.264 & 84 \\
\hline LJ440827STHA & 7 & 6 & 128.50 & 0.037 & 4.812 & 321 \\
\hline LJ22B1119STHA & 8 & 7 & 149.92 & 0.022 & 3.319 & 194 \\
\hline LJ28B1119STHA & 8 & 3 & 64.25 & 0.033 & 2.131 & 124 \\
\hline LJ22A1119STHA & 8 & 6 & 128.50 & 0.025 & 3.234 & 189 \\
\hline LJ28A1119STHA & 8 & 3 & 64.25 & 0.034 & 2.171 & 127 \\
\hline LJ14B1119STHA & 8 & 6 & 128.50 & 0.020 & 2.601 & 152 \\
\hline LJ14A1119STHA & 8 & 6 & 128.50 & 0.022 & 2.788 & 163 \\
\hline
\end{tabular}


TABLE A1 cont. List of sediment nutrient analysis.

\begin{tabular}{|c|c|c|c|c|c|c|}
\hline Sample ID & $\begin{array}{c}\text { Trap } \\
\text { Days } \\
\text { Collecti } \\
\text { ng } \\
\text { days } \\
\end{array}$ & $\begin{array}{c}\text { STHA } \\
\text { height } \\
\mathrm{cm} \\
\end{array}$ & $\begin{array}{c}\text { Volume } \\
\mathrm{cm}^{3} \\
\end{array}$ & $\begin{array}{c}\mathbf{B D}^{\mathbf{1}} \\
\mathrm{gdw} \mathrm{cm}^{-3}\end{array}$ & $\begin{array}{c}\text { Dry } \\
\text { Weight } \\
\text { g } \\
\end{array}$ & $\begin{array}{c}\text { MAR } \\
\mathrm{g} \mathrm{m}^{-2} \mathrm{~d}^{-1}\end{array}$ \\
\hline LJ44B0204 & & & & & & \\
\hline $\begin{array}{l}\text { STHA } \\
\text { LJ28B0204 }\end{array}$ & 7 & 2 & 42.83 & 0.041 & 1.771 & 118 \\
\hline $\begin{array}{l}\text { STHA } \\
\text { LJ44A0204 }\end{array}$ & 7 & 2.5 & 53.54 & 0.038 & 2.020 & 135 \\
\hline $\begin{array}{l}\text { STHA } \\
\text { LJ22B0204 }\end{array}$ & 7 & 2 & 42.83 & 0.039 & 1.659 & 111 \\
\hline $\begin{array}{l}\text { STHA } \\
\text { LJ14B0204 }\end{array}$ & 7 & 3.5 & 74.96 & 0.029 & 2.173 & 145 \\
\hline $\begin{array}{l}\text { STHA } \\
\text { LJ28A0204 }\end{array}$ & 7 & 3 & 64.25 & 0.023 & 1.462 & 98 \\
\hline $\begin{array}{l}\text { STHA } \\
\text { LJ14A0204 }\end{array}$ & 7 & 3 & 64.25 & 0.033 & 2.108 & 141 \\
\hline $\begin{array}{l}\text { STHA } \\
\text { LJ22A0204 }\end{array}$ & 7 & 4 & 85.67 & 0.018 & 1.542 & 103 \\
\hline $\begin{array}{l}\text { STHA } \\
\text { LJ14A0415 }\end{array}$ & 7 & 4.5 & 96.38 & 0.025 & 2.419 & 161 \\
\hline $\begin{array}{l}\text { STHA } \\
\text { LJ14B0415 }\end{array}$ & 7 & 3.5 & 74.96 & 0.021 & 1.550 & 103 \\
\hline $\begin{array}{l}\text { STHA } \\
\text { LJ22A0415 }\end{array}$ & 7 & 3.5 & 74.96 & 0.021 & 1.543 & 103 \\
\hline $\begin{array}{l}\text { STHA } \\
\text { LJ22B0415 }\end{array}$ & 7 & 5 & 107.09 & 0.030 & 3.229 & 215 \\
\hline $\begin{array}{l}\text { STHA } \\
\text { LJ28A0415 }\end{array}$ & 7 & 6 & 128.50 & 0.027 & 3.458 & 231 \\
\hline $\begin{array}{l}\text { STHA } \\
\text { LJ28B0415 }\end{array}$ & 7 & 6 & 128.50 & 0.029 & 3.790 & 253 \\
\hline $\begin{array}{l}\text { STHA } \\
\text { LJ44A0415 }\end{array}$ & 7 & 6 & 128.50 & 0.026 & 3.395 & 226 \\
\hline $\begin{array}{l}\text { STHA } \\
\text { LJ44B0415 }\end{array}$ & 7 & 4.5 & 96.38 & 0.037 & 3.518 & 235 \\
\hline STHA & 7 & 4.5 & 96.38 & 0.037 & 3.525 & 235 \\
\hline
\end{tabular}

TABLE A1 cont. List of sediment nutrient analysis. 


\begin{tabular}{|c|c|c|c|c|c|c|}
\hline Sample ID & $\begin{array}{c}\text { Trap Days } \\
\text { Collecting } \\
\text { days } \\
\end{array}$ & $\begin{array}{c}\begin{array}{c}\text { Volume } \\
\mathbf{c m}^{3}\end{array} \\
\end{array}$ & $\begin{array}{c}\mathbf{B D}^{\mathbf{2}} \\
\mathrm{gdw} \mathrm{cm}{ }^{-3}\end{array}$ & $\begin{array}{c}\text { Dry } \\
\text { Weight } \\
\text { g } \\
\end{array}$ & $\begin{array}{c}\text { MAR } \\
\mathrm{g} \mathrm{m}^{-2} \mathrm{~d}^{-1} \\
\end{array}$ & pH \\
\hline LJ281107STM8 & 1 & 285 & 0.032 & 9.210 & 37 & 6.81 \\
\hline LJ281108STM8 & 1 & 245 & 0.041 & 10.139 & 41 & 6.72 \\
\hline LJ281109STM8 & 1 & 260 & 0.037 & 9.694 & 39 & 6.77 \\
\hline LJ281110STM8 & 1 & 290 & 0.037 & 10.588 & 42 & 6.82 \\
\hline LJ281111STM8 & 1 & 275 & 0.037 & 10.201 & 41 & 6.84 \\
\hline LJ281112STM8 & 1 & 250 & 0.046 & 11.614 & 46 & 6.81 \\
\hline LJ281113STM8 & 1 & 145 & 0.042 & 6.106 & 24 & 7.05 \\
\hline LJ280205STM8 & 0.5 & 200 & 0.035 & 6.979 & 56 & 7.11 \\
\hline LJ280204bSTM8 & 0.5 & 180 & 0.036 & 6.481 & 52 & 7.13 \\
\hline LJ280204aSTM8 & 0.5 & 210 & 0.035 & 7.346 & 59 & 7.13 \\
\hline LJ280203bSTM8 & 0.5 & 140 & 0.036 & 5.026 & 40 & 7.13 \\
\hline LJ280203aSTM8 & 0.5 & 190 & 0.037 & 7.072 & 57 & 7.02 \\
\hline LJ280202bSTM8 & 0.5 & 95 & 0.021 & 1.983 & 16 & 7.05 \\
\hline LJ280202aSTM8 & 0.5 & 160 & 0.027 & 4.261 & 34 & 7.00 \\
\hline LJ280201bSTM8 & 0.5 & 180 & 0.035 & 6.225 & 50 & 6.99 \\
\hline LJ280201aSTM8 & 0.5 & 210 & 0.031 & 6.465 & 52 & 6.99 \\
\hline LJ280131bSTM8 & 0.5 & 75 & 0.027 & 2.036 & 16 & 6.99 \\
\hline LJ280131aSTM8 & 0.5 & 115 & 0.033 & 3.807 & 30 & 6.96 \\
\hline LJ280130bSTM8 & 0.5 & 145 & 0.030 & 4.394 & 35 & 6.91 \\
\hline LJ280130aSTM8 & 0.5 & 160 & 0.027 & 4.275 & 34 & 6.78 \\
\hline LJ280508STT & & & \multirow{5}{*}{$\mathrm{NO}$} & \multirow{5}{*}{ DATA } & & \\
\hline LJ220514STT & & & & & & \\
\hline LJ140828STT & 7 & & & & & \\
\hline LJ220828STT & 7 & & & & & \\
\hline LJ280828STT & 7 & & & & & \\
\hline LJ141113STT & 7 & 10 & 0.742 & 7.422 & 638 & -- \\
\hline LJ280205STT & 7 & 150 & 0.075 & 11.229 & 965 & 6.90 \\
\hline LJ220205STT & 7 & 128 & 0.079 & 10.142 & 872 & 6.89 \\
\hline LJ140205STT & 7 & 130 & 0.075 & 9.811 & 843 & 6.85 \\
\hline
\end{tabular}

TABLE A1 cont. List of sediment nutrient analysis. 


\begin{tabular}{|c|c|c|c|c|c|c|}
\hline Sample ID & $\begin{array}{c}T P^{a} \\
\mu g^{-1} d w\end{array}$ & $\begin{array}{c}\text { TP } \\
\text { mg g-1 }\end{array}$ & $\begin{array}{c}\mathbf{T N}^{\mathrm{a}} \\
\mathrm{mg} \mathrm{g}^{-1}\end{array}$ & $\begin{array}{c}\mathrm{TN}^{\mathrm{a}} \\
\% \\
\end{array}$ & $\begin{array}{c}\text { TC } \\
\mathrm{mg} \mathrm{g}^{-1} \\
\end{array}$ & $\begin{array}{c}\text { TIC } \\
\text { mg g }^{-1}\end{array}$ \\
\hline LJ280508SF & 1615.26 & 1.62 & 12.90 & 1.29 & 127.80 & 0.00 \\
\hline LJ140514SF & 1132.98 & 1.13 & 15.00 & 1.50 & 151.20 & 0.00 \\
\hline LJ220514SF & 2208.75 & 2.21 & 21.30 & 2.13 & 206.50 & 0.00 \\
\hline LJ140626SF & 799.22 & 0.80 & 12.00 & 1.20 & 112.00 & 0.03 \\
\hline LJ220626SF & 1091.74 & 1.09 & 16.10 & 1.61 & 149.50 & 0.00 \\
\hline LJ280626SF & 1359.77 & 1.36 & 19.90 & 1.99 & 195.30 & 0.00 \\
\hline LJ140821SF & 1329.11 & 1.33 & 20.80 & 2.08 & 186.20 & 0.00 \\
\hline LJ220821SF & 1077.22 & 1.08 & 18.10 & 1.81 & 178.60 & 0.00 \\
\hline LJ280821SF & 501.90 & 0.50 & 9.80 & 0.98 & 96.20 & 0.00 \\
\hline LJ221106SF & 1764.14 & 1.76 & 22.90 & 2.29 & 197.03 & 0.48 \\
\hline LJ281106SF & 1220.00 & 1.22 & 15.83 & 1.58 & 156.75 & 0.00 \\
\hline LJ141106SF & 1390.68 & 1.39 & 17.28 & 1.73 & 159.81 & 3.90 \\
\hline LJ140129SF & 1471.26 & 1.47 & 14.81 & 1.48 & 142.52 & 0.00 \\
\hline LJ220129SF & 2018.73 & 2.02 & 23.56 & 2.36 & 209.24 & 0.00 \\
\hline LJ280129SF & 1533.59 & 1.53 & 17.21 & 1.72 & 159.77 & 0.80 \\
\hline LJ140820SF & 650.59 & 0.65 & 13.6 & 1.36 & 142.1 & 0.00 \\
\hline LJ220820SF & 1123.84 & 1.12 & 15.5 & 1.55 & 151.2 & 0.00 \\
\hline LJ280820SF & 599.34 & 0.60 & 7.7 & 0.77 & 77.8 & 0.00 \\
\hline LJ440820SF & 1051.52 & 1.05 & 17.5 & 1.75 & 170.4 & 0.00 \\
\hline LJ221111SF & 1569.38 & 1.57 & 18.33 & 1.83 & 182.39 & 0.00 \\
\hline LJ141111SF & 796.08 & 0.80 & 20.64 & 2.06 & 189.92 & 0.00 \\
\hline LJ281111SF & 285.06 & 0.29 & 10.92 & 1.09 & 127.39 & 0.00 \\
\hline LJ441111SF & 1468.42 & 1.47 & 22.26 & 2.23 & 188.22 & 0.00 \\
\hline LJ140128 SF & 1700.59 & 1.70 & 16.90 & 2.33 & 158.00 & 0.00 \\
\hline LJ220128 SF & 1903.33 & 1.90 & 23.30 & 2.19 & 208.20 & 0.00 \\
\hline LJ440128 SF & 1316.26 & 1.32 & 21.90 & 1.69 & 195.60 & 0.00 \\
\hline LJ140408 SF & 1687.09 & 1.69 & 19.01 & 1.90 & 188.02 & 0.00 \\
\hline LJ220408 SF & 1639.07 & 1.64 & 18.52 & 1.85 & 202.86 & 8.14 \\
\hline LJ280408 SF & 702.42 & 0.70 & 16.22 & 1.62 & 170.25 & 0.00 \\
\hline LJ440408 SF & 1535.76 & 1.54 & 12.16 & 1.22 & 151.22 & 0.00 \\
\hline
\end{tabular}

TABLE A1 cont. List of sediment nutrient analysis. 


\begin{tabular}{|c|c|c|c|c|c|c|}
\hline Sample ID & $\begin{array}{c}\mathbf{T P} \\
\mu \mathbf{g}^{-1} \mathbf{d w} \\
\end{array}$ & $\begin{array}{c}\text { TP } \\
\text { mg g-1 } \\
\end{array}$ & $\begin{array}{c}\mathbf{T N}^{\mathrm{a}} \\
\mathbf{m g ~ g}^{-1} \\
\end{array}$ & $\begin{array}{c}\mathbf{T N}^{\mathrm{a}} \\
\% \\
\end{array}$ & $\begin{array}{c}\mathrm{TC} \\
\mathrm{mg} \mathrm{g}^{-1} \\
\end{array}$ & $\begin{array}{c}\text { TIC } \\
\text { mg g }^{-1} \\
\end{array}$ \\
\hline LJ280508SS & 387.80 & 0.39 & 0.40 & 0.04 & 37.30 & 2.72 \\
\hline LJ140514SS & 1923.24 & 1.92 & 5.80 & 0.58 & 126.20 & 3.81 \\
\hline LJ220514SS & 878.54 & 0.88 & 12.60 & 1.26 & 149.80 & 0.54 \\
\hline LJ140626SS & 489.85 & 0.49 & 1.70 & 0.17 & 64.70 & 2.58 \\
\hline LJ220626SS & 577.79 & 0.58 & 11.30 & 1.13 & 127.90 & 0.02 \\
\hline LJ280626SS & 351.99 & 0.35 & 13.60 & 1.36 & 161.70 & 0.01 \\
\hline LJ140821SS & 229.06 & 0.23 & 11.80 & 1.18 & 156.30 & 0.00 \\
\hline LJ220821SS & 577.62 & 0.58 & 15.70 & 1.57 & 169.30 & 0.00 \\
\hline LJ280821SS & 211.71 & 0.21 & 0.90 & 0.09 & 29.70 & 0.00 \\
\hline LJ141106SS & 351.33 & 0.35 & 8.67 & 0.87 & 111.68 & 1.21 \\
\hline LJ281106SS & 590.00 & 0.59 & 5.90 & 0.59 & 73.00 & 1.09 \\
\hline LJ221106SS & 1055.51 & 1.06 & 13.48 & 1.35 & 136.51 & 0.16 \\
\hline LJ280129SS & 371.07 & 0.37 & 1.92 & 0.19 & 57.43 & 38.90 \\
\hline LJ140129SS & 614.73 & 0.61 & 12.48 & 1.25 & 149.29 & 0.00 \\
\hline LJ220129SS & 1049.00 & 1.05 & 14.59 & 1.46 & 156.11 & 0.00 \\
\hline LJ140820SS & 393.72 & 0.39 & 13.33 & 1.33 & 162.69 & 0.00 \\
\hline LJ220820SS & 696.33 & 0.70 & 10.32 & 1.03 & 130.89 & 0.30 \\
\hline LJ280820SS & 294.17 & 0.29 & 1.40 & 0.14 & 59.37 & 4.33 \\
\hline LJ440820SS & 784.13 & 0.78 & 10.33 & 1.03 & 141.49 & 0.34 \\
\hline LJ441111SS & 623.60 & 0.62 & 11.22 & 1.12 & 147.10 & 0.00 \\
\hline LJ141111SS & 470.69 & 0.47 & 11.25 & 1.13 & 145.12 & 0.06 \\
\hline LJ221111SS & 514.69 & 0.51 & 14.40 & 1.44 & 174.76 & 0.00 \\
\hline LJ281111SS & 552.97 & 0.55 & 0.00 & 0.00 & 93.95 & 4.58 \\
\hline LJ140128 SS & 787.60 & 0.79 & 8.60 & 1.50 & 125.70 & 0.00 \\
\hline LJ220128 SS & 849.16 & 0.85 & 14.40 & 0.86 & 161.60 & 0.00 \\
\hline LJ280128 SS & 456.01 & 0.46 & 0.00 & 0.00 & 49.70 & 1.84 \\
\hline LJ440128 SS & 1781.58 & 1.78 & 15.00 & 1.44 & 155.70 & 0.00 \\
\hline LJ140408 SS & 614.44 & 0.61 & 6.05 & 0.61 & 108.48 & 43.14 \\
\hline LJ220408 SS & 800.00 & 0.80 & 6.26 & 0.63 & 103.00 & 0.00 \\
\hline LJ280408 SS & 355.84 & 0.36 & 0.00 & 0.00 & 66.84 & 45.24 \\
\hline LJ440408 SS & 904.27 & 0.90 & 10.06 & 1.01 & 147.43 & 7.36 \\
\hline
\end{tabular}

TABLE A1 cont. List of sediment nutrient analysis. 


\begin{tabular}{lccccc}
\hline & & & & & \\
\multicolumn{1}{c}{ Sample ID } & $\mathbf{p H}$ & $\begin{array}{c}\text { Dry } \\
\text { \% }\end{array}$ & $\begin{array}{c}\mathbf{H}_{\mathbf{2}} \mathbf{0} \\
\mathbf{\%}\end{array}$ & $\begin{array}{c}\text { OM } \\
\text { \% }\end{array}$ & $\begin{array}{c}\text { Ash } \\
\text { \% }\end{array}$ \\
\hline \hline LJ280329STHA & 6.99 & 4.28 & 95.72 & 41.23 & 58.77 \\
LJ280425 STHA & 6.82 & 4.77 & 95.23 & 40.25 & 59.75 \\
LJ140514STHA & 7.00 & 4.68 & 95.32 & 39.59 & 60.41 \\
LJ220514STHA & 7.17 & 4.16 & 95.84 & 42.55 & 57.45 \\
LJ140709STHA & 7.05 & 7.03 & 92.97 & 48.97 & 51.03 \\
LJ220709STHA & 7.08 & 3.24 & 96.76 & 28.38 & 71.62 \\
LJ280709STHA & -- & 3.74 & 96.26 & 43.57 & 56.43 \\
LJ140828STHA & 6.55 & 3.02 & 96.98 & 45.84 & 54.16 \\
LJ220828STHA & 6.47 & 2.97 & 97.03 & 65.51 & 34.49 \\
LJ280828STHA & 6.88 & 2.71 & 97.29 & 52.19 & 47.81 \\
LJ221113STHA & 6.57 & 3.25 & 96.75 & 49.81 & 50.19 \\
LJ141113STHA & 6.59 & 3.29 & 96.71 & 43.83 & 56.17 \\
LJ281113STHA & 6.75 & 3.30 & 96.70 & 44.46 & 55.54 \\
LJ280205STHA & 6.64 & 2.22 & 97.78 & 46.67 & 53.33 \\
LJ220205STHA & 6.71 & 2.26 & 97.74 & 47.09 & 52.91 \\
LJ140205STHA & 6.71 & 1.92 & 98.08 & 47.90 & 52.10 \\
LJ140827STHA & 7.67 & 2.19 & 97.81 & 46.42 & 53.58 \\
LJ220827STHA & 7.16 & 2.44 & 97.56 & 50.22 & 49.78 \\
LJ280827STHA & 7.60 & 2.67 & 97.33 & 45.12 & 54.88 \\
LJ440827STHA & 7.49 & 3.68 & 96.32 & 41.31 & 58.69 \\
LJ22B1119STHA & 7.14 & 2.06 & 97.94 & & \\
LJ28B1119STHA & 7.43 & 2.11 & 97.89 & & \\
LJ22A1119STHA & 7.33 & 2.06 & 97.94 & 52.49 & 47.51 \\
LJ28A1119STHA & 7.39 & 2.29 & 97.71 & 50.25 & 49.75 \\
LJ14B1119STHA & 7.09 & 1.91 & 98.09 & & \\
LJ14A1119STHA & 6.99 & 1.86 & 98.14 & 52.49 & 47.51 \\
& & & & & \\
& & & & \\
\hline
\end{tabular}

TABLE A1 cont. List of sediment nutrient analysis. 


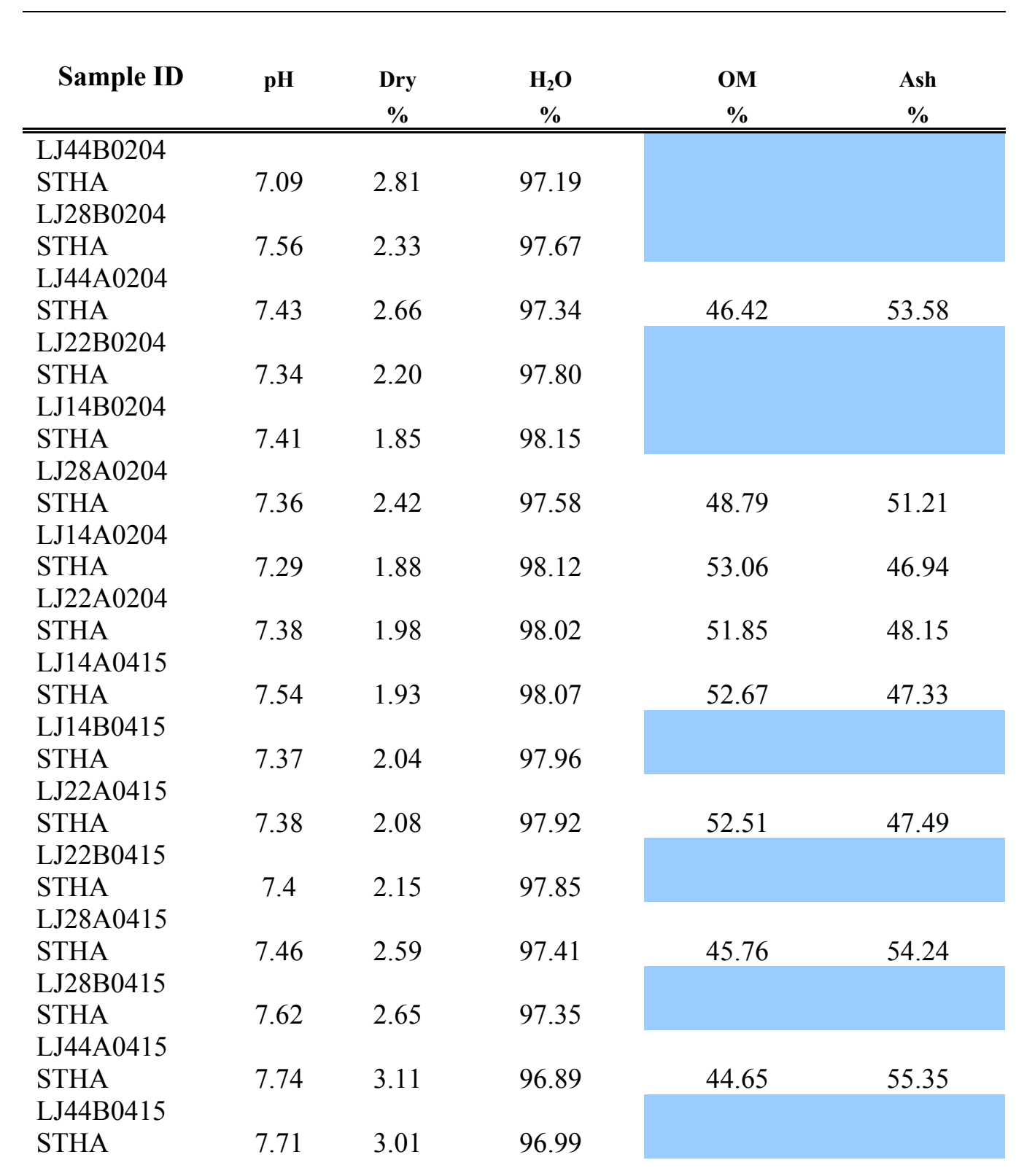

TABLE A1 cont. List of sediment nutrient analysis.

$\begin{array}{llllll}\text { Sample ID } & \text { Dry } & \mathrm{H}_{2} \mathrm{O} & \text { OM } & \text { Ash } & \text { TP }^{\mathrm{a}}\end{array}$




\begin{tabular}{|c|c|c|c|c|c|}
\hline & $\%$ & $\%$ & $\%$ & $\%$ & $\mu \mathrm{g} \mathrm{g}^{-1} \mathrm{dw}$ \\
\hline LJ281107STM8 & 3.38 & 96.62 & 43.65 & 56.35 & 2178.51 \\
\hline LJ281108STM8 & 3.85 & 96.15 & 46.91 & 53.09 & 2188.99 \\
\hline LJ281109STM8 & 4.03 & 95.97 & 41.69 & 58.31 & 2450.71 \\
\hline LJ281110STM8 & 4.04 & 95.96 & 43.54 & 56.46 & 1773.69 \\
\hline LJ281111STM8 & 4.04 & 95.96 & 42.31 & 57.69 & 2478.79 \\
\hline LJ281112STM8 & 4.69 & 95.31 & 42.39 & 57.61 & 2225.92 \\
\hline LJ281113STM8 & 4.23 & 95.77 & 40.34 & 59.66 & 2083.69 \\
\hline LJ280205STM8 & 3.40 & 96.60 & 45.26 & 54.74 & 2551.02 \\
\hline LJ280204bSTM8 & 3.21 & 96.79 & 44.73 & 55.27 & 2540.63 \\
\hline LJ280204aSTM8 & 3.46 & 96.54 & 44.66 & 55.34 & 2202.34 \\
\hline LJ280203bSTM8 & 3.28 & 96.72 & 43.03 & 56.97 & 991.09 \\
\hline LJ280203aSTM8 & 3.33 & 96.67 & 44.78 & 55.22 & 2293.63 \\
\hline LJ280202bSTM8 & 2.18 & 97.82 & 47.74 & 52.26 & 2040.42 \\
\hline LJ280202aSTM8 & 2.53 & 97.47 & 48.57 & 51.43 & 2720.90 \\
\hline LJ280201bSTM8 & 3.06 & 96.94 & 46.07 & 53.93 & 2274.78 \\
\hline LJ280201aSTM8 & 2.94 & 97.06 & 45.82 & 54.18 & 2107.15 \\
\hline LJ280131bSTM8 & 2.56 & 97.44 & 43.60 & 56.40 & 2049.38 \\
\hline LJ280131aSTM8 & 3.22 & 96.78 & 42.27 & 57.73 & 2256.73 \\
\hline LJ280130bSTM8 & 2.71 & 97.29 & 46.53 & 53.47 & 2295.82 \\
\hline LJ280130aSTM8 & 2.37 & 97.63 & 49.17 & 50.83 & 2274.38 \\
\hline LJ280508STT & 2.86 & 97.14 & & & \\
\hline LJ220514STT & 1.96 & 98.04 & & & \\
\hline LJ140828STT & 27.85 & 72.15 & & & \\
\hline LJ220828STT & 19.95 & 80.05 & & & \\
\hline LJ280828STT & 13.17 & 86.83 & & & \\
\hline LJ141113STT & 1.48 & 98.52 & 49.39 & 50.61 & 2103.48 \\
\hline LJ280205STT & 2.28 & 97.72 & 43.97 & 56.03 & 2004.63 \\
\hline LJ220205STT & 2.17 & 97.83 & 45.62 & 54.38 & 1013.78 \\
\hline LJ140205STT & 2.12 & 97.88 & 45.22 & 54.78 & 2077.85 \\
\hline
\end{tabular}

TABLE A1 cont. List of sediment nutrient analysis. 


\begin{tabular}{lcccc}
\hline & & & & \\
Sample ID & $\mathbf{\% N}$ & $\boldsymbol{\delta}^{\mathbf{1 5}} \mathbf{N}$ & $\mathbf{\% C}$ & $\begin{array}{c}\boldsymbol{\delta}^{\mathbf{1 3}} \mathbf{C} \\
\text { Decarbonated }\end{array}$ \\
\hline \hline LJ280508SF & 1.15 & 2.61 & 15.54 & -21.87 \\
LJ140514SF & 1.29 & 2.47 & 17.14 & -22.70 \\
LJ220514SF & 2.18 & 2.62 & 20.68 & -23.26 \\
LJ140626SF & 1.67 & 2.25 & 17.23 & -22.93 \\
LJ220626SF & 1.93 & 2.47 & 19.90 & -23.29 \\
LJ280626SF & 0.47 & 2.18 & 12.43 & -22.62 \\
LJ140821SF & 1.75 & 2.30 & 19.36 & -22.82 \\
LJ220821SF & 1.52 & 2.35 & 18.92 & -23.59 \\
LJ280821SF & 0.81 & 2.43 & 6.86 & -21.96 \\
LJ221106SF & 2.39 & 2.36 & 21.26 & -23.55 \\
LJ281106SF & 1.61 & 2.65 & 17.47 & -22.19 \\
LJ141106SF & 1.91 & 2.52 & 19.24 & -23.17 \\
LJ140129SF & 1.73 & 2.33 & 17.39 & -23.06 \\
LJ220129SF & 2.47 & 1.95 & 22.05 & -23.51 \\
LJ280129SF & 1.51 & 2.58 & 10.13 & -22.21 \\
LJ140820SF & 1.47 & 1.13 & 17.31 & -22.62 \\
LJ220820SF & 1.73 & 1.32 & 17.89 & -23.13 \\
LJ280820SF & 0.66 & 0.94 & 13.17 & -22.16 \\
LJ440820SF & 1.75 & 1.28 & 18.69 & -21.91 \\
LJ221111SF & 1.77 & 2.31 & 20.23 & -23.33 \\
LJ141111SF & 1.90 & 1.86 & 19.94 & -22.98 \\
LJ281111SF & 1.51 & 2.28 & 14.75 & -21.98 \\
LJ441111SF & 2.10 & 2.00 & 17.67 & -21.94 \\
LJ140128 SF & 1.98 & 1.77 & 19.12 & -22.95 \\
LJ220128 SF & 2.26 & 1.96 & 22.89 & -23.31 \\
LJ440128 SF & 2.13 & 1.79 & 20.14 & -21.97 \\
LJ140408 SF & 2.09 & 2.08 & 20.85 & -22.91 \\
LJ220408 SF & 2.27 & 2.26 & 22.38 & -23.22 \\
LJ280408 SF & 0.83 & 2.06 & 16.20 & -21.67 \\
LJ440408 SF & 2.06 & 2.28 & 19.02 & -22.07 \\
& & & & \\
\hline
\end{tabular}

TABLE A1 cont. List of sediment nutrient analysis. 


\begin{tabular}{|c|c|c|c|c|}
\hline \multirow[t]{2}{*}{ Sample ID } & \multirow[t]{2}{*}{$\% \mathbf{N}$} & \multirow[t]{2}{*}{$\delta^{15} \mathbf{N}$} & $\% \mathrm{C}$ & $\delta^{13} \mathrm{C}$ \\
\hline & & & \multicolumn{2}{|c|}{ Decarbonated } \\
\hline LJ280508SS & 0.21 & 4.03 & 1.77 & -21.52 \\
\hline LJ140514SS & 0.68 & 1.78 & 11.17 & -22.86 \\
\hline LJ220514SS & 1.20 & 2.30 & 14.49 & -23.52 \\
\hline LJ140626SS & 1.26 & 1.55 & 17.21 & -23.05 \\
\hline LJ220626SS & 0.82 & 1.93 & 12.87 & -23.35 \\
\hline LJ280626SS & 0.18 & 4.15 & 1.62 & -22.13 \\
\hline LJ140821SS & 1.47 & 2.09 & 16.61 & -22.24 \\
\hline LJ220821SS & 1.21 & 2.50 & 16.92 & -23.77 \\
\hline LJ280821SS & 0.11 & 2.92 & 1.26 & -22.25 \\
\hline LJ141106SS & 0.99 & 1.50 & 16.47 & -23.27 \\
\hline LJ281106SS & 0.50 & 2.52 & 5.64 & -21.50 \\
\hline LJ221106SS & 1.48 & 2.57 & 18.38 & -23.14 \\
\hline LJ280129SS & 0.24 & 4.07 & 4.01 & -20.87 \\
\hline LJ140129SS & 1.34 & 1.77 & 12.85 & -22.50 \\
\hline LJ220129SS & 1.51 & 2.68 & 18.14 & -23.31 \\
\hline LJ140820SS & 1.33 & 1.24 & 17.35 & -22.32 \\
\hline LJ220820SS & 0.99 & 1.61 & 16.85 & -23.32 \\
\hline LJ280820SS & 0.20 & 4.06 & 4.88 & -18.53 \\
\hline LJ440820SS & 1.06 & 2.89 & 15.08 & -22.02 \\
\hline LJ441111SS & 1.11 & 3.03 & 15.74 & -22.54 \\
\hline LJ141111SS & 1.10 & 1.87 & 15.74 & -22.54 \\
\hline LJ221111SS & 1.36 & 1.92 & 15.48 & -23.51 \\
\hline LJ281111SS & 0.17 & 4.94 & 3.73 & -23.43 \\
\hline LJ140128 SS & 1.04 & 1.54 & 15.83 & -22.18 \\
\hline LJ220128 SS & 1.40 & 2.27 & 17.13 & -23.60 \\
\hline LJ280128 SS & 0.33 & 4.32 & 6.72 & -19.25 \\
\hline LJ440128 SS & 1.52 & 2.41 & 16.72 & -21.76 \\
\hline LJ140408 SS & 0.68 & 2.02 & 15.37 & -22.55 \\
\hline LJ220408 SS & 0.74 & 2.39 & 13.54 & -23.60 \\
\hline LJ280408 SS & 0.17 & 4.71 & 4.17 & -22.16 \\
\hline LJ440408 SS & 1.20 & 3.02 & 15.07 & -21.85 \\
\hline
\end{tabular}

TABLE A1 cont. List of sediment nutrient analysis. 


\begin{tabular}{|c|c|c|c|c|c|c|}
\hline Sample ID & $\begin{array}{c}\mathrm{TP}^{\mathrm{a}} \\
\mu \mathrm{g} \mathrm{g}^{-1} \mathrm{dw} \\
\end{array}$ & $\begin{array}{c}\text { TP } \\
\text { mg g-1 } \\
\end{array}$ & $\begin{array}{c}\mathrm{TN}^{\mathrm{a}} \\
\mathrm{mg} \mathrm{g}^{-1} \\
\end{array}$ & $\begin{array}{r}\mathrm{TN}^{\mathrm{a}} \\
\% \\
\end{array}$ & $\begin{array}{c}\mathrm{TC} \\
\mathrm{mg} \mathrm{g}^{-1} \\
\end{array}$ & $\begin{array}{r}\text { TIC } \\
\mathbf{m g} g\end{array}$ \\
\hline LJ280329STHA & 2449.12 & 2.45 & 7.0 & 0.70 & 68.5 & 0.27 \\
\hline LJ280425 STHA & 2652.36 & 2.65 & 22.20 & 2.22 & 208.50 & 0.00 \\
\hline LJ140514STHA & 2073.75 & 2.07 & 20.90 & 2.09 & 206.20 & 0.14 \\
\hline LJ220514STHA & 2352.57 & 2.35 & 23.30 & 2.33 & 221.30 & 0.00 \\
\hline LJ140709STHA & 2286.71 & 2.29 & 25.60 & 2.56 & 235.70 & 0.00 \\
\hline LJ220709STHA & 982.08 & 0.98 & 17.00 & 1.70 & 178.30 & 0.05 \\
\hline LJ280709STHA & 1960.84 & 1.96 & 23.00 & 2.30 & 209.40 & 0.00 \\
\hline LJ140828STHA & 1382.53 & 1.38 & 23.70 & 2.37 & 221.90 & 0.00 \\
\hline LJ220828STHA & 1537.94 & 1.54 & 25.40 & 2.54 & 235.80 & 0.00 \\
\hline LJ280828STHA & 2223.28 & 2.22 & 26.60 & 2.66 & 247.20 & 0.00 \\
\hline LJ221113STHA & 2635.00 & 2.64 & 25.72 & 2.57 & 232.33 & 0.04 \\
\hline LJ141113STHA & 2065.02 & 2.07 & 24.31 & 2.43 & 217.33 & 1.30 \\
\hline LJ281113STHA & 1840.16 & 1.84 & 24.03 & 2.40 & 212.09 & 0.00 \\
\hline LJ280205STHA & 2185.50 & 2.19 & 25.49 & 2.55 & 232.07 & 0.00 \\
\hline LJ220205STHA & 2496.41 & 2.50 & 25.46 & 2.55 & 234.20 & 0.00 \\
\hline LJ140205STHA & 2271.91 & 2.27 & 25.78 & 2.58 & 238.23 & 0.05 \\
\hline LJ140827STHA & 1820.73 & 1.82 & 23.35 & 2.34 & 207.19 & 0.00 \\
\hline LJ220827STHA & 1901.81 & 1.90 & 27.50 & 2.75 & 236.27 & 0.00 \\
\hline LJ280827STHA & 1414.00 & 1.41 & 23.74 & 2.37 & 201.06 & 0.00 \\
\hline LJ440827STHA & 1371.34 & 1.37 & 22.70 & 2.27 & 208.66 & 0.00 \\
\hline \multicolumn{7}{|l|}{ LJ22B1119STHA } \\
\hline LJ22A1119STHA & 1942.59 & 1.94 & 28.39 & 2.84 & 272.17 & 0.00 \\
\hline LJ28A1119STHA & 1684.05 & 1.68 & 26.35 & 2.63 & 255.70 & 0.00 \\
\hline \multicolumn{7}{|l|}{ LJ14B1119STHA } \\
\hline LJ14A1119STHA & 2035.06 & 2.04 & 28.67 & 2.87 & 277.06 & 0.00 \\
\hline
\end{tabular}

TABLE A1 cont. List of sediment nutrient analysis. 


\begin{tabular}{|c|c|c|c|c|c|c|}
\hline Sample ID & $\begin{array}{c}T P^{\mathrm{a}} \\
\mu \mathrm{g} \mathrm{g}^{-1} \mathrm{dw}\end{array}$ & $\begin{array}{c}\text { TP } \\
\text { mg g-1 } \\
\end{array}$ & $\begin{array}{c}\mathbf{T N}^{\mathrm{a}} \\
\mathrm{mg} \mathrm{g}^{-1} \\
\end{array}$ & $\begin{array}{c}\mathbf{T N}^{\mathrm{a}} \\
\% \\
\end{array}$ & $\begin{array}{c}\mathrm{TC} \\
\mathrm{mg} \mathrm{g}^{-1} \\
\end{array}$ & $\begin{array}{c}\text { TIC } \\
\text { mg g }^{-1}\end{array}$ \\
\hline $\begin{array}{l}\text { LJ44B0204 STHA } \\
\text { LJ28B0204 STHA }\end{array}$ & & & & & & \\
\hline LJ44A0204 STHA & 1935.67 & 1.94 & 24.10 & 2.41 & 231.00 & 0.07 \\
\hline $\begin{array}{l}\text { LJ22B0204 STHA } \\
\text { LJ14B0204 STHA }\end{array}$ & & & & & & \\
\hline LJ28A0204 STHA & 2210.28 & 2.21 & 25.20 & 2.52 & 246.60 & 0.31 \\
\hline LJ14A0204 STHA & 2258.40 & 2.26 & 26.90 & 2.69 & 259.50 & 0.00 \\
\hline LJ22A0204 STHA & 2436.25 & 2.44 & 28.30 & 2.83 & 256.80 & 0.00 \\
\hline LJ14A0415 STHA & 2241.17 & 2.24 & 23.86 & 2.39 & 250.46 & 0.00 \\
\hline LJ14B0415 STHA & & & & & & \\
\hline LJ22A0415 STHA & 2275.43 & 2.28 & 26.10 & 2.61 & 253.49 & 0.00 \\
\hline LJ22B0415 STHA & & & & & & \\
\hline LJ28A0415 STHA & 2021.20 & 2.02 & 21.69 & 2.17 & 229.84 & 7.27 \\
\hline LJ28B0415 STHA & & & & & & \\
\hline LJ44A0415 STHA & 1929.31 & 1.93 & 20.46 & 2.05 & 220.56 & 0.00 \\
\hline
\end{tabular}

TABLE A1 cont. List of sediment nutrient analysis. 


\begin{tabular}{|c|c|c|c|c|c|}
\hline Sample ID & $\begin{array}{c}\text { TP } \\
\text { mg g-1 }\end{array}$ & $\begin{array}{c}\mathrm{TN}^{\mathrm{a}} \\
\mathrm{mg} \mathrm{g}^{-1} \\
\end{array}$ & $\begin{array}{c}\mathrm{TN}^{\mathrm{a}} \\
\% \\
\end{array}$ & $\begin{array}{c}\mathrm{TC} \\
\mathrm{mg} \mathrm{g}^{-1} \\
\end{array}$ & $\begin{array}{c}\text { TIC } \\
\text { mg g }^{-1}\end{array}$ \\
\hline LJ281107STM8 & 2.18 & 25.41 & 2.54 & 225.52 & 0.22 \\
\hline LJ281108STM8 & 2.19 & 23.5 & 2.35 & 215.75 & 0.00 \\
\hline LJ281109STM8 & 2.45 & 22.49 & 2.25 & 212.00 & 0.02 \\
\hline LJ281110STM8 & 1.77 & 23.89 & 2.39 & 220.42 & 4.10 \\
\hline LJ281111STM8 & 2.48 & 22.89 & 2.29 & 205.64 & 0.80 \\
\hline LJ281112STM8 & 2.23 & 23.01 & 2.30 & 205.76 & 0.03 \\
\hline LJ281113STM8 & 2.08 & 20.04 & 2.00 & 189.65 & 0.31 \\
\hline LJ280205STM8 & 2.55 & 26.57 & 2.64 & 231.79 & 0.00 \\
\hline LJ280204bSTM8 & 2.54 & 25.18 & 2.83 & 221.08 & 0.00 \\
\hline LJ280204aSTM8 & 2.20 & 25.65 & 2.43 & 227.83 & 0.00 \\
\hline LJ280203bSTM8 & 0.99 & 24.56 & 2.45 & 222.57 & 0.00 \\
\hline LJ280203aSTM8 & 2.29 & 25.32 & 2.60 & 228.66 & 0.00 \\
\hline LJ280202bSTM8 & 2.04 & 26.10 & 2.64 & 234.02 & 0.00 \\
\hline LJ280202aSTM8 & 2.72 & 27.08 & 2.61 & 249.63 & 0.00 \\
\hline LJ280201bSTM8 & 2.27 & 25.99 & 2.71 & 232.16 & 0.00 \\
\hline LJ280201aSTM8 & 2.11 & 26.40 & 2.46 & 232.90 & 0.00 \\
\hline LJ280131bSTM8 & 2.05 & 24.28 & 2.53 & 216.22 & 0.00 \\
\hline LJ280131aSTM8 & 2.26 & 24.51 & 2.52 & 218.93 & 0.00 \\
\hline LJ280130bSTM8 & 2.30 & 26.40 & 2.56 & 239.51 & 0.00 \\
\hline LJ280130aSTM8 & 2.27 & 28.27 & 2.66 & 253.62 & 0.00 \\
\hline \multicolumn{6}{|l|}{ LJ280508STT } \\
\hline \multicolumn{6}{|l|}{ LJ220514STT } \\
\hline \multicolumn{6}{|l|}{ LJ140828STT } \\
\hline \multicolumn{6}{|l|}{ LJ220828STT } \\
\hline \multicolumn{6}{|l|}{ LJ280828STT } \\
\hline LJ141113STT & 2.10 & 24.40 & 2.45 & 221.28 & 0.00 \\
\hline LJ280205STT & 2.00 & 24.45 & 2.49 & 220.88 & 0.00 \\
\hline LJ220205STT & 1.01 & 24.89 & 2.48 & 225.21 & 0.00 \\
\hline LJ140205STT & 2.08 & 24.77 & 2.44 & 224.51 & 0.00 \\
\hline
\end{tabular}

TABLE A1 cont. List of sediment nutrient analysis. 


\begin{tabular}{lcccc}
\hline \multicolumn{1}{c}{ Sample ID } & \%N & $\boldsymbol{\delta}^{\mathbf{1 5}} \mathbf{N}$ & $\begin{array}{c}\text { \%C } \\
\text { Decarbonated }\end{array}$ \\
\hline \hline LJ280329STHA & 2.52 & 3.08 & 21.71 & -21.97 \\
LJ280425 STHA & 2.23 & 3.40 & 20.30 & -22.25 \\
LJ140514STHA & 2.19 & 3.08 & 21.08 & -22.73 \\
LJ220514STHA & 2.38 & 2.79 & 23.04 & -23.15 \\
LJ140709STHA & 1.23 & 2.59 & 17.85 & -22.97 \\
LJ220709STHA & 2.66 & 3.93 & 24.40 & -24.05 \\
LJ280709STHA & 2.42 & 3.39 & 22.22 & -22.52 \\
LJ140828STHA & 2.58 & 3.06 & 23.59 & -22.53 \\
LJ220828STHA & 2.98 & 3.58 & 25.83 & -22.95 \\
LJ280828STHA & 2.38 & 2.94 & 23.34 & -22.33 \\
LJ221113STHA & 2.58 & 3.20 & 25.40 & -23.30 \\
LJ141113STHA & 2.47 & 3.12 & 22.38 & -23.10 \\
LJ281113STHA & 2.47 & 2.92 & 23.79 & -22.16 \\
LJ280205STHA & 2.62 & 2.51 & 23.31 & -21.97 \\
LJ220205STHA & 2.63 & 2.75 & 25.01 & -23.08 \\
LJ140205STHA & 2.69 & 2.96 & 23.21 & -22.87 \\
LJ140827STHA & 2.26 & 2.20 & 22.91 & -22.89 \\
LJ220827STHA & 2.59 & 3.28 & 27.33 & -22.47 \\
LJ280827STHA & 2.32 & 2.18 & 22.66 & -21.55 \\
LJ440827STHA & 2.25 & 2.44 & 22.30 & -21.61 \\
LJ22B1119STHA & & & & \\
LJ28B1119STHA & & & & \\
LJ22A1119STHA & 2.75 & 2.36 & 27.89 & -21.99 \\
LJ28A1119STHA & 2.74 & 2.49 & 26.56 & -21.24 \\
LJ14B1119STHA & & & & \\
LJ14A1119STHA & 2.78 & 2.50 & 27.80 & -21.71 \\
& & & & \\
\hline
\end{tabular}

TABLE A1 cont. List of sediment nutrient analysis. 


\begin{tabular}{|c|c|c|c|c|}
\hline Sample ID & $\% \mathbf{N}$ & $\delta^{15} \mathbf{N}$ & Decarbonated & $\begin{array}{r}\delta^{13} \mathrm{C} \\
\text { nated }\end{array}$ \\
\hline $\begin{array}{l}\text { LJ44B0204 } \\
\text { STHA } \\
\text { LJ28B0204 } \\
\text { STHA }\end{array}$ & & & & \\
\hline $\begin{array}{l}\text { LJ44A0204 } \\
\text { STHA }\end{array}$ & 2.42 & 2.70 & 24.62 & -21.35 \\
\hline $\begin{array}{l}\text { LJ22B0204 } \\
\text { STHA } \\
\text { LJ14B0204 } \\
\text { STHA }\end{array}$ & & & & \\
\hline $\begin{array}{l}\text { LJ28A0204 } \\
\text { STHA } \\
\text { LJ14A0204 }\end{array}$ & 2.43 & 2.63 & 25.53 & -20.50 \\
\hline $\begin{array}{l}\text { STHA } \\
\text { LJ22A0204 }\end{array}$ & 2.65 & 2.54 & 28.14 & -21.63 \\
\hline $\begin{array}{l}\text { STHA } \\
\text { LJ14A0415 }\end{array}$ & 2.73 & 2.77 & 23.09 & -22.19 \\
\hline $\begin{array}{l}\text { STHA } \\
\text { LJ14B0415 } \\
\text { STHA }\end{array}$ & 2.76 & 2.22 & 26.41 & -21.27 \\
\hline $\begin{array}{l}\text { LJ22A0415 } \\
\text { STHA }\end{array}$ & 2.92 & 2.69 & 26.55 & -21.70 \\
\hline $\begin{array}{l}\text { LJ22B0415 } \\
\text { STHA }\end{array}$ & & & & \\
\hline $\begin{array}{l}\text { LJ28A0415 } \\
\text { STHA }\end{array}$ & 2.48 & 2.61 & 22.69 & -20.46 \\
\hline $\begin{array}{l}\text { LJ28B0415 } \\
\text { STHA }\end{array}$ & & & & \\
\hline $\begin{array}{l}\text { LJ44A0415 } \\
\text { STHA }\end{array}$ & 2.37 & 2.39 & 22.40 & -20.92 \\
\hline $\begin{array}{l}\text { LJ44B0415 } \\
\text { STHA }\end{array}$ & & & & \\
\hline
\end{tabular}


TABLE A1 cont. List of sediment nutrient analysis.

\begin{tabular}{|c|c|c|c|c|}
\hline \multirow[t]{2}{*}{ Sample ID } & \multirow[t]{2}{*}{$\% \mathbf{N}$} & \multirow[t]{2}{*}{$\delta^{15} \mathbf{N}$} & $\% \mathrm{C}$ & $\delta^{13} \mathrm{C}$ \\
\hline & & & \multicolumn{2}{|c|}{ Decarbonated } \\
\hline LJ281107STM8 & 2.58 & 3.44 & 22.67 & -22.29 \\
\hline LJ281108STM8 & 2.46 & 3.59 & 23.48 & -22.09 \\
\hline LJ281109STM8 & 2.22 & 3.61 & 22.75 & -22.49 \\
\hline LJ281110STM8 & 2.45 & 3.28 & 23.12 & -22.27 \\
\hline LJ281111STM8 & 2.37 & 4.25 & 22.54 & -22.43 \\
\hline LJ281112STM8 & 2.32 & 3.05 & 22.58 & -22.35 \\
\hline LJ281113STM8 & 2.17 & 3.86 & 22.02 & -22.29 \\
\hline LJ280205STM8 & 2.68 & 2.79 & 22.25 & -22.18 \\
\hline LJ280204bSTM8 & 2.67 & 2.76 & 23.34 & -22.02 \\
\hline LJ280204aSTM8 & 2.70 & 2.66 & 22.93 & -21.94 \\
\hline LJ280203bSTM8 & 2.69 & 2.87 & 22.56 & -22.01 \\
\hline LJ280203aSTM8 & 2.71 & 2.70 & 23.17 & -22.00 \\
\hline LJ280202bSTM8 & 2.75 & 2.47 & 23.84 & -21.82 \\
\hline LJ280202aSTM8 & 2.86 & 2.70 & 24.06 & -21.88 \\
\hline LJ280201bSTM8 & 2.75 & 2.51 & 23.54 & -21.83 \\
\hline LJ280201aSTM8 & 2.84 & 2.85 & 24.02 & -21.98 \\
\hline LJ280131bSTM8 & 2.57 & 2.21 & 21.93 & -22.17 \\
\hline LJ280131aSTM8 & 2.71 & 2.84 & 21.18 & -22.05 \\
\hline LJ280130bSTM8 & 2.79 & 2.23 & 23.82 & -21.79 \\
\hline LJ280130aSTM8 & 3.06 & 2.12 & 22.50 & -21.92 \\
\hline \multicolumn{5}{|l|}{ LJ280508STT } \\
\hline LJ220514STT & & & 20.20 & -22.76 \\
\hline \multicolumn{5}{|l|}{ LJ140828STT } \\
\hline \multicolumn{5}{|l|}{ LJ220828STT } \\
\hline \multicolumn{5}{|l|}{ LJ280828STT } \\
\hline LJ141113STT & 2.55 & 1.78 & 23.06 & -22.97 \\
\hline LJ280205STT & 2.52 & 2.32 & 21.60 & -22.00 \\
\hline LJ220205STT & 2.56 & 2.34 & 23.45 & -23.26 \\
\hline LJ140205STT & 2.56 & 2.49 & 22.88 & -22.81 \\
\hline
\end{tabular}




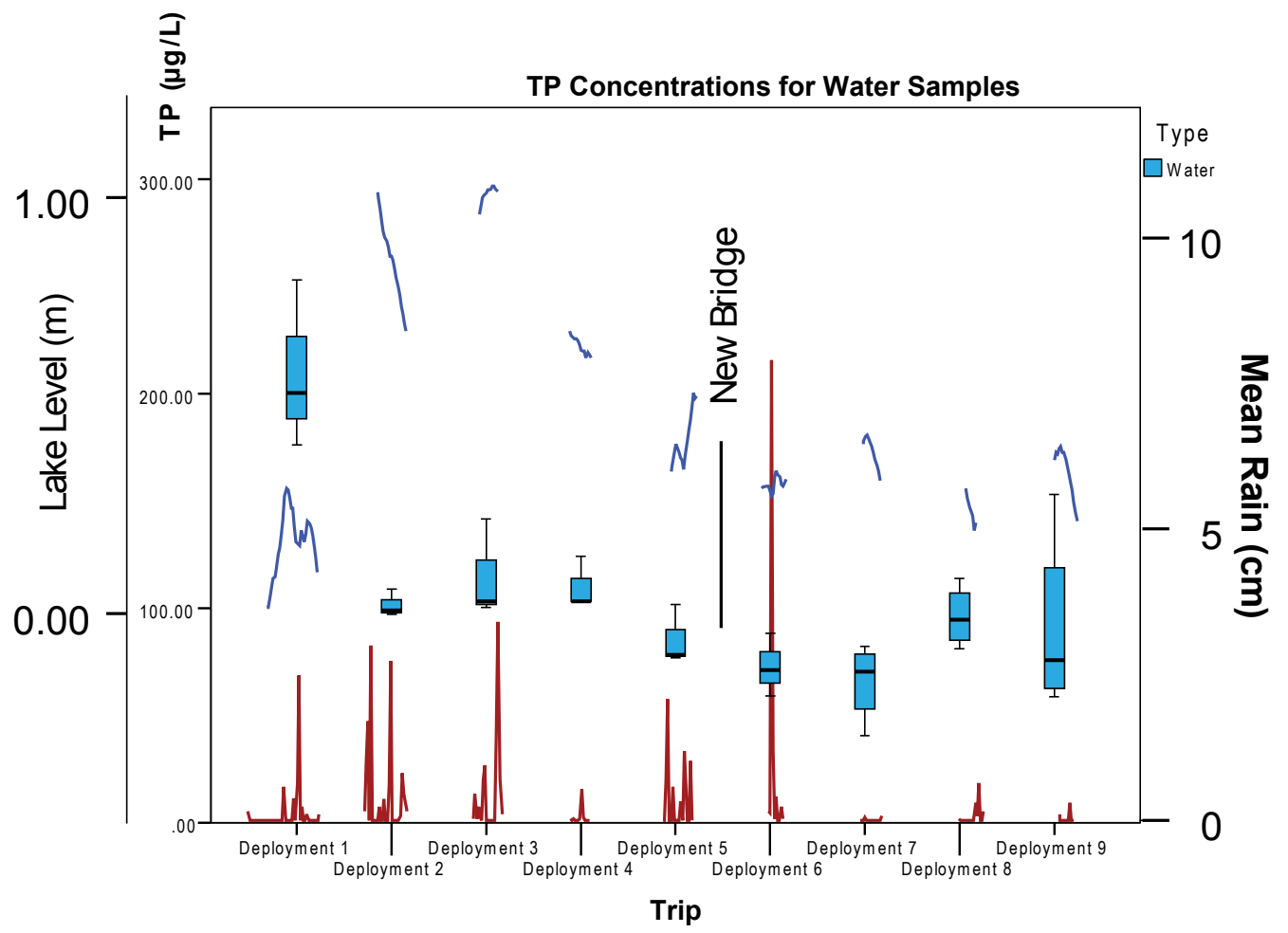

FIGURE A1. Precipitation, TP and Lake level for all 9 Deployments. 


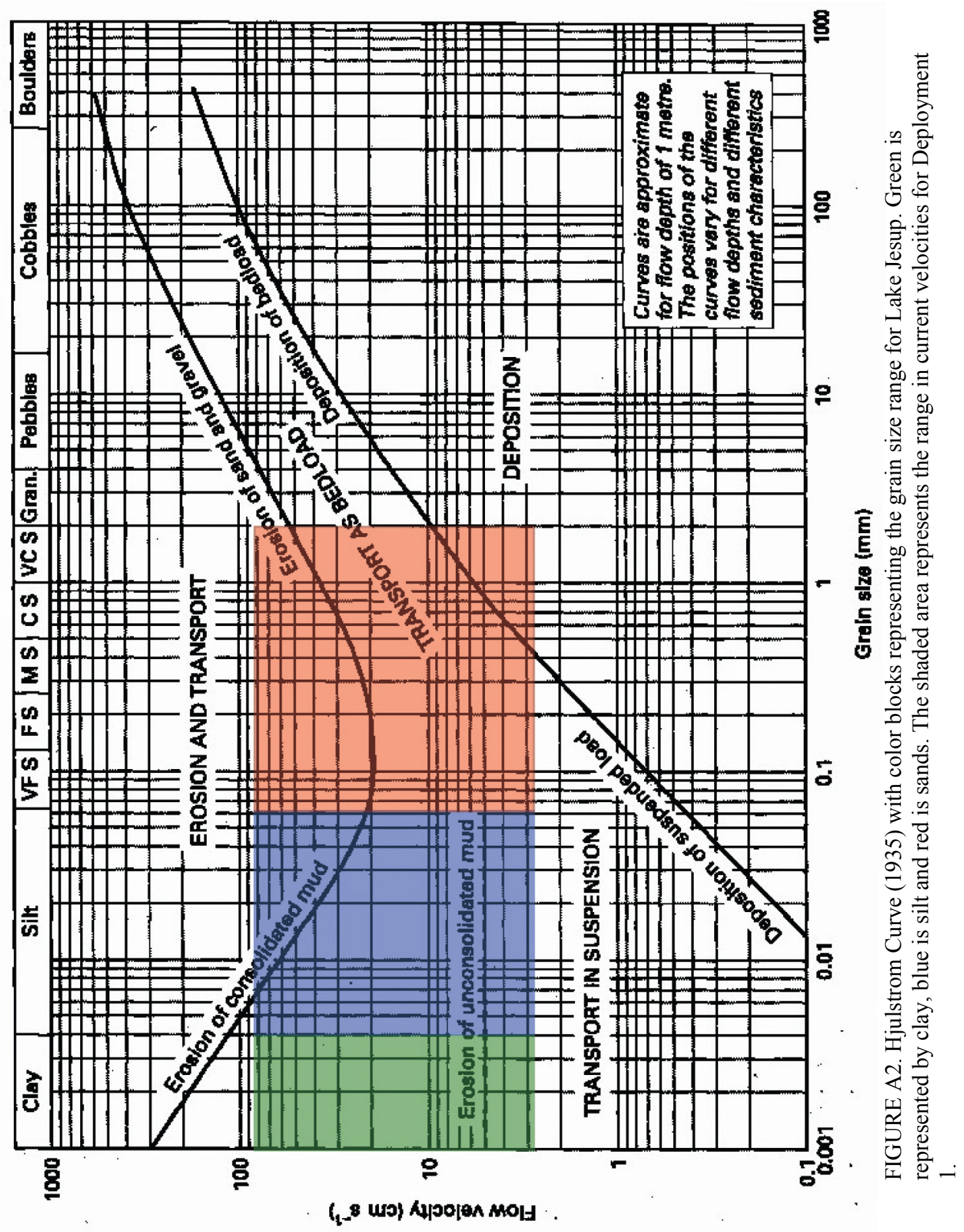




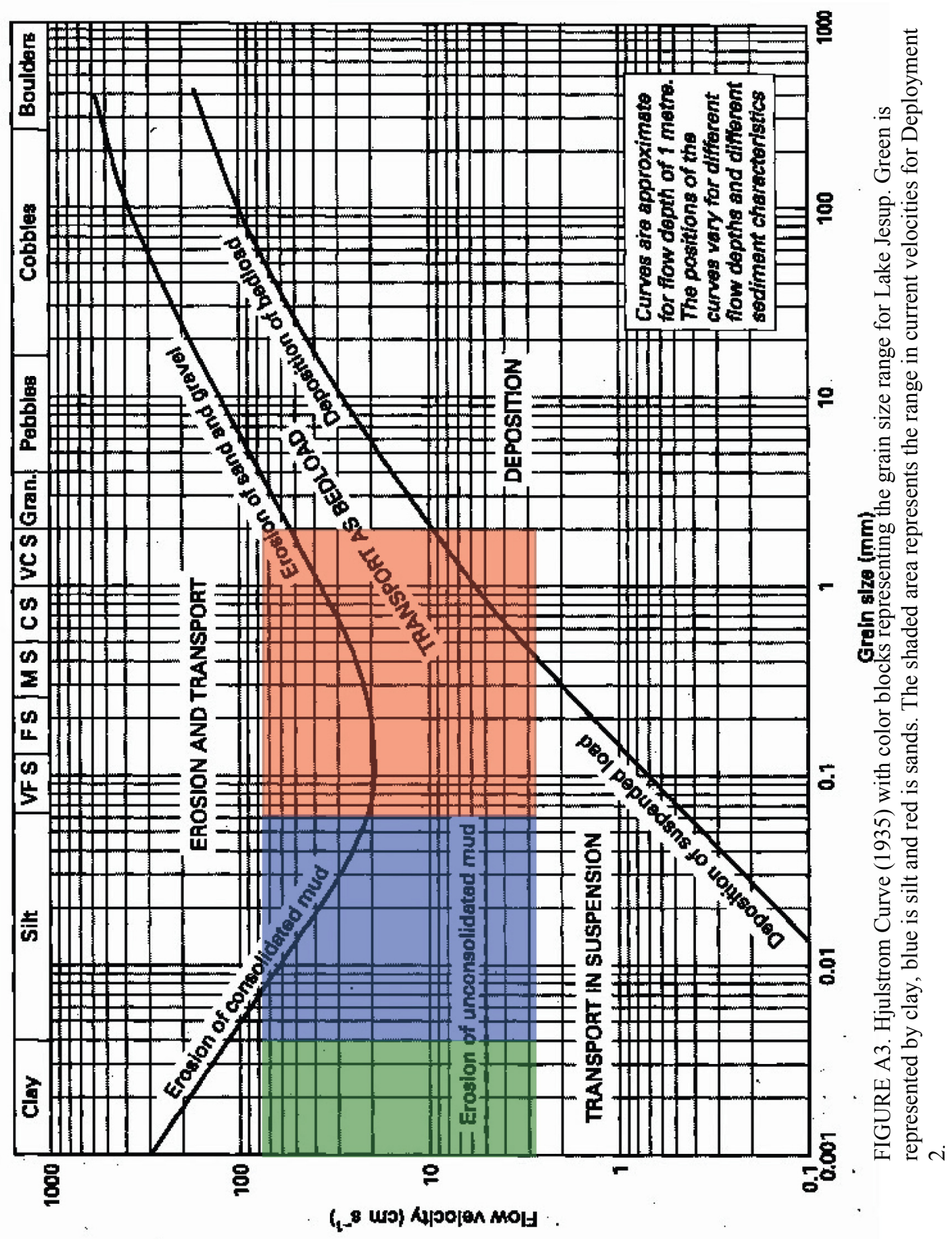




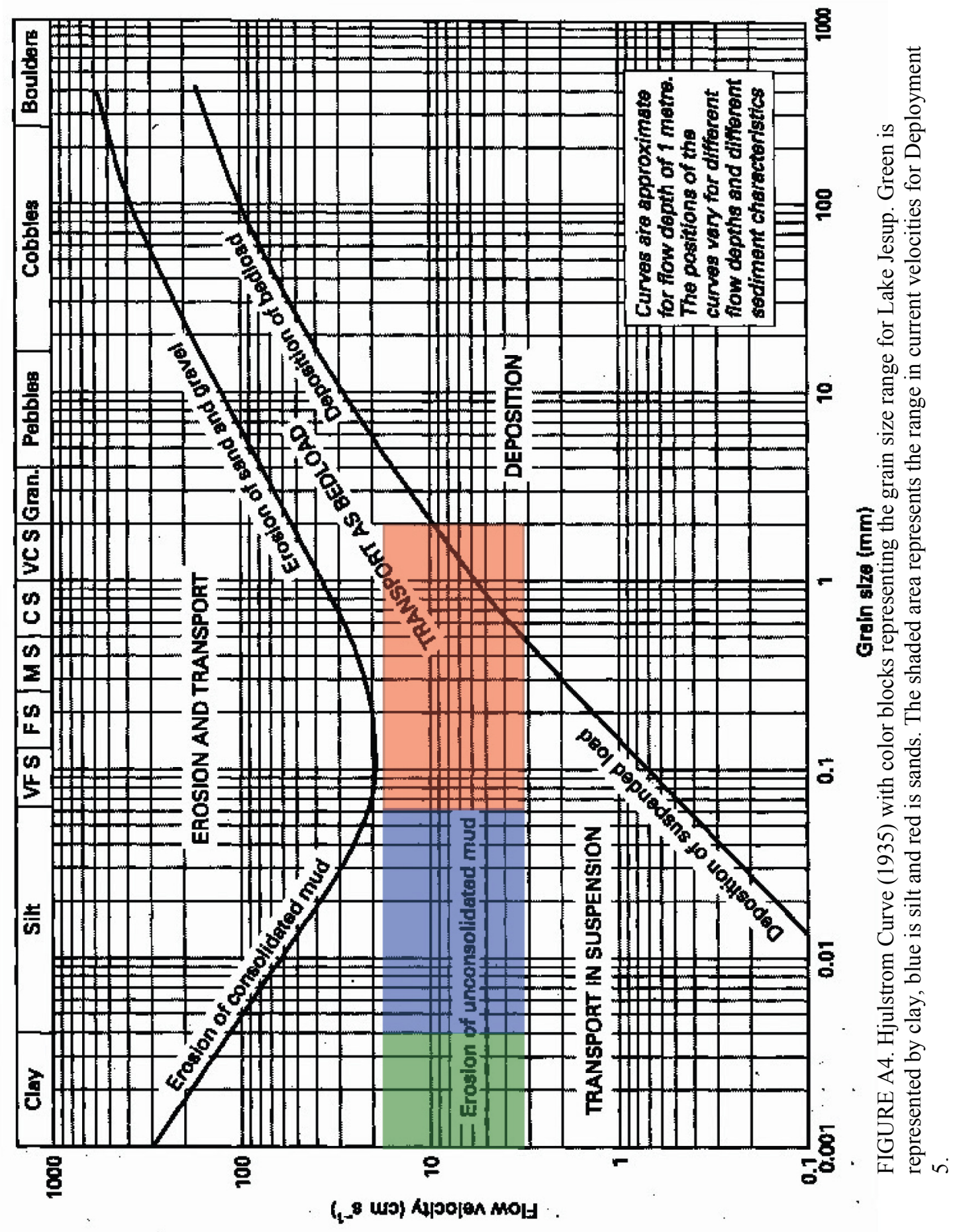




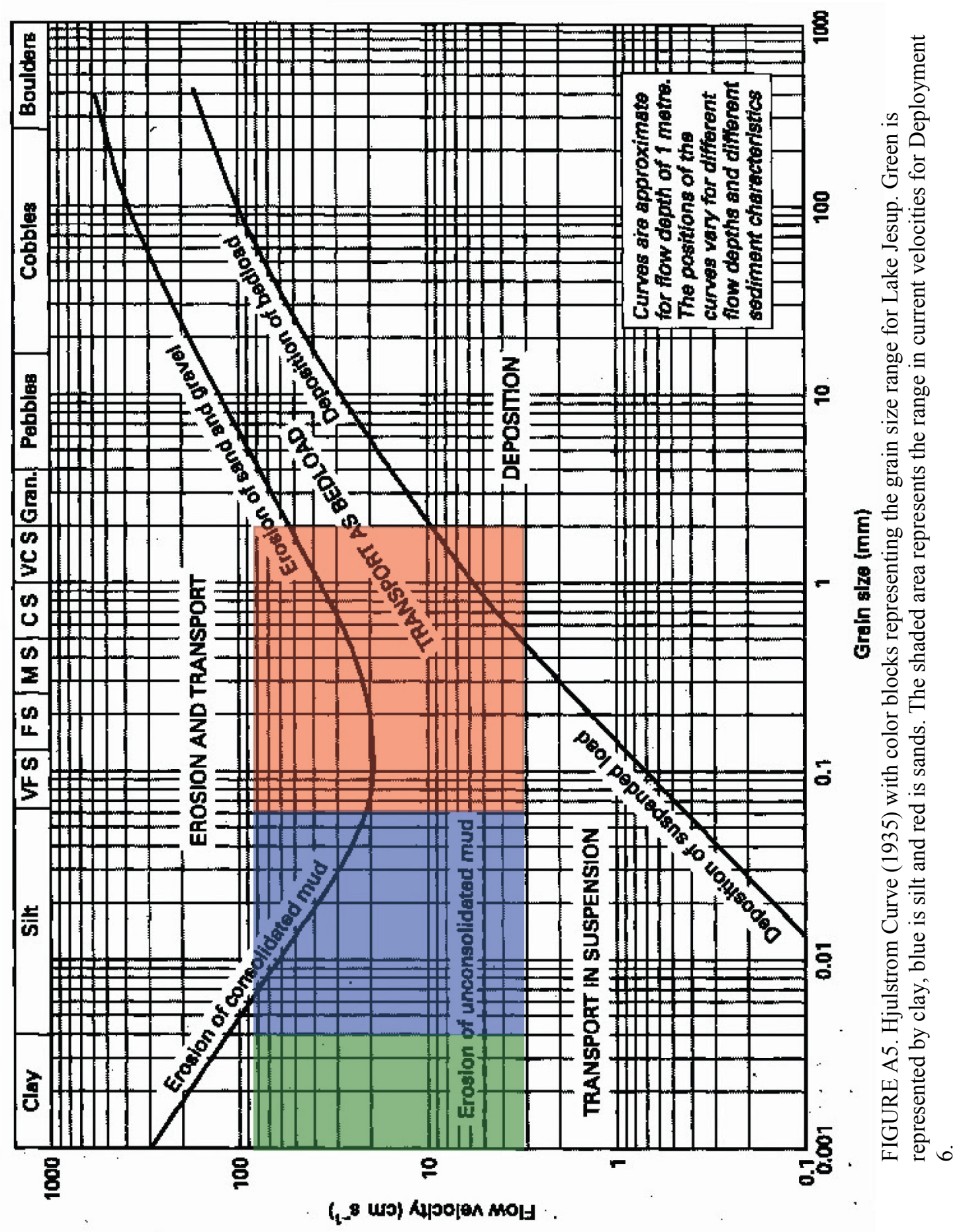




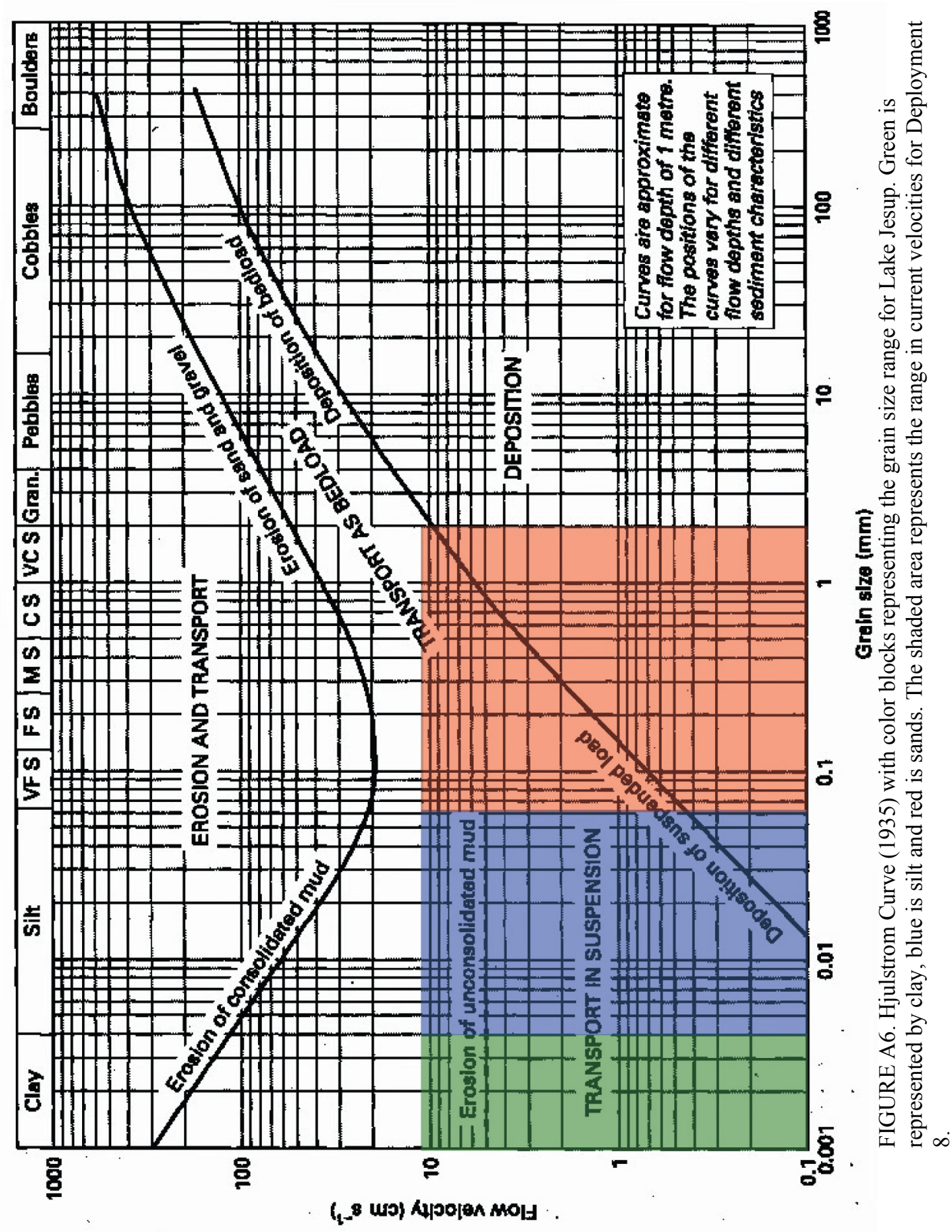




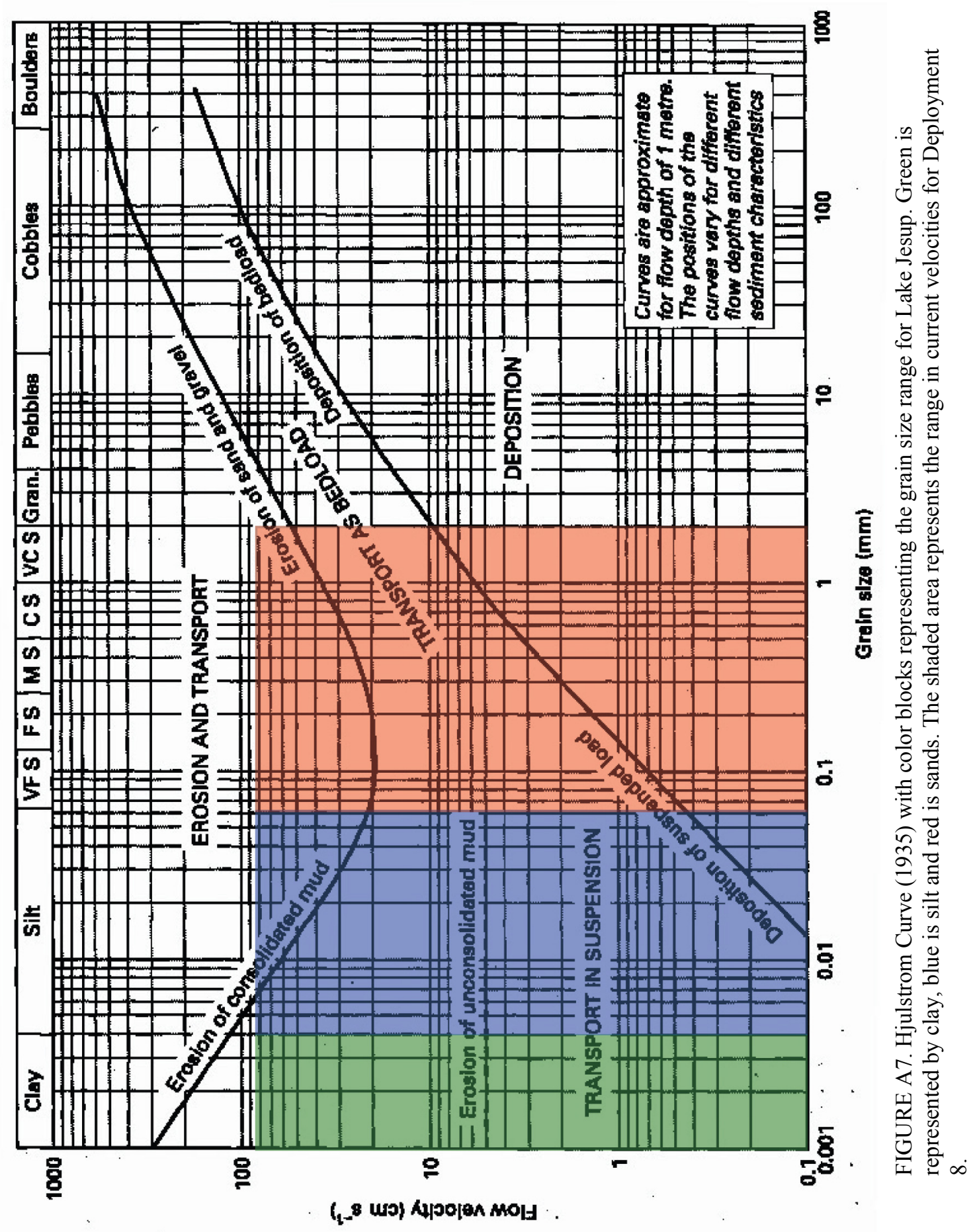




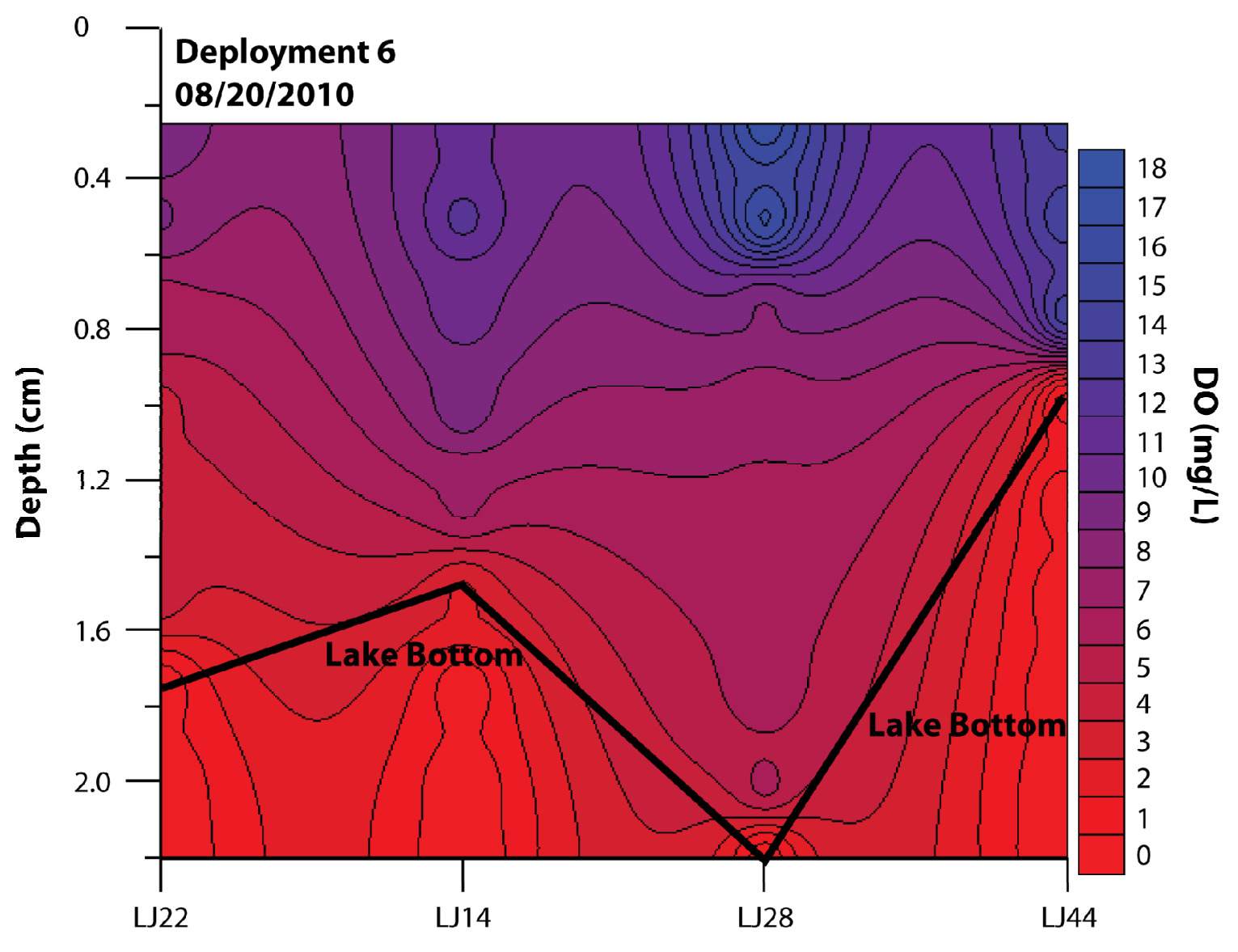

FIGURE A8. Lake wide DO profile for from West to East for Deployment 6. 


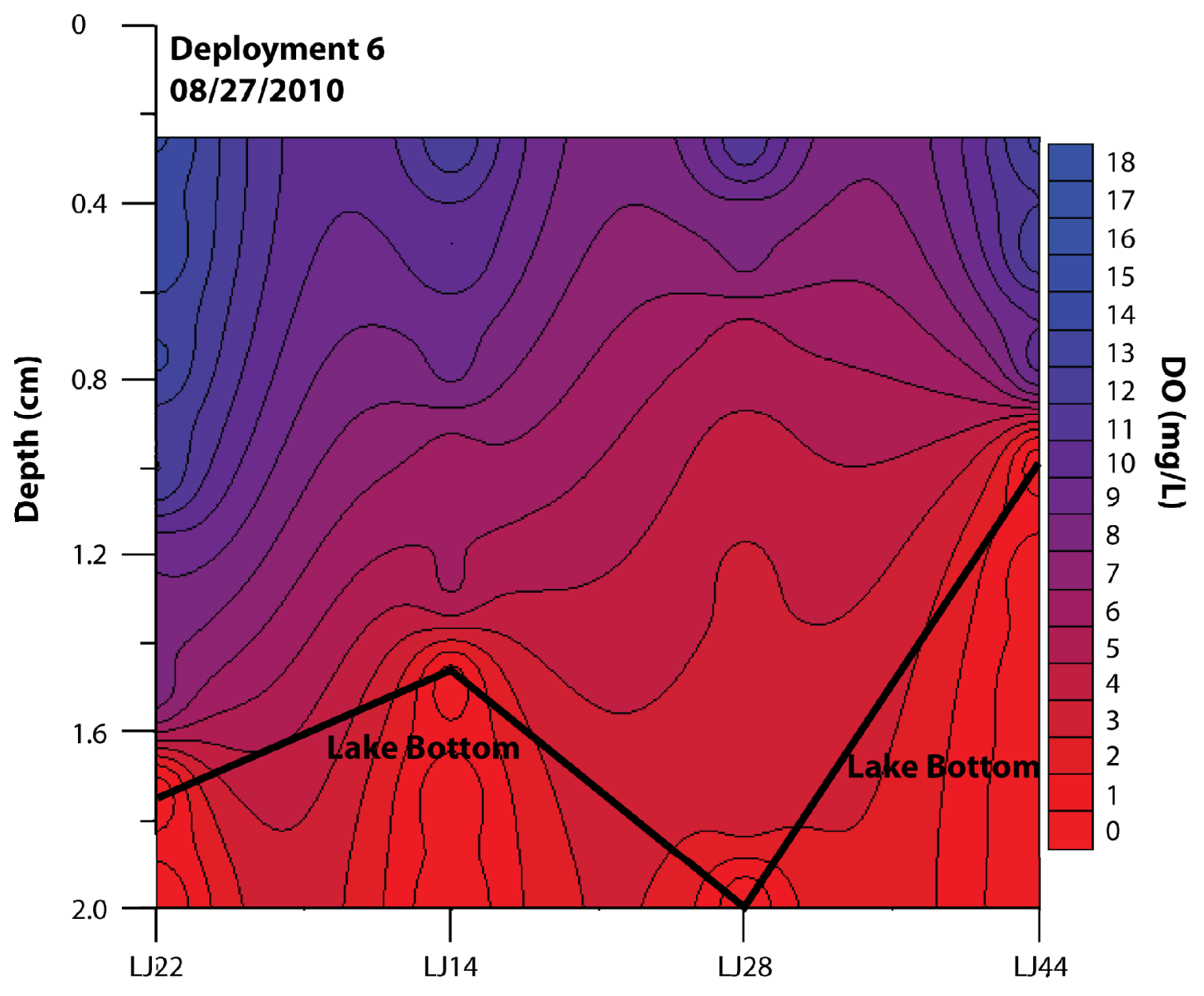

FIGURE A9. Lake wide DO profile for from West to East for Deployment 6. 


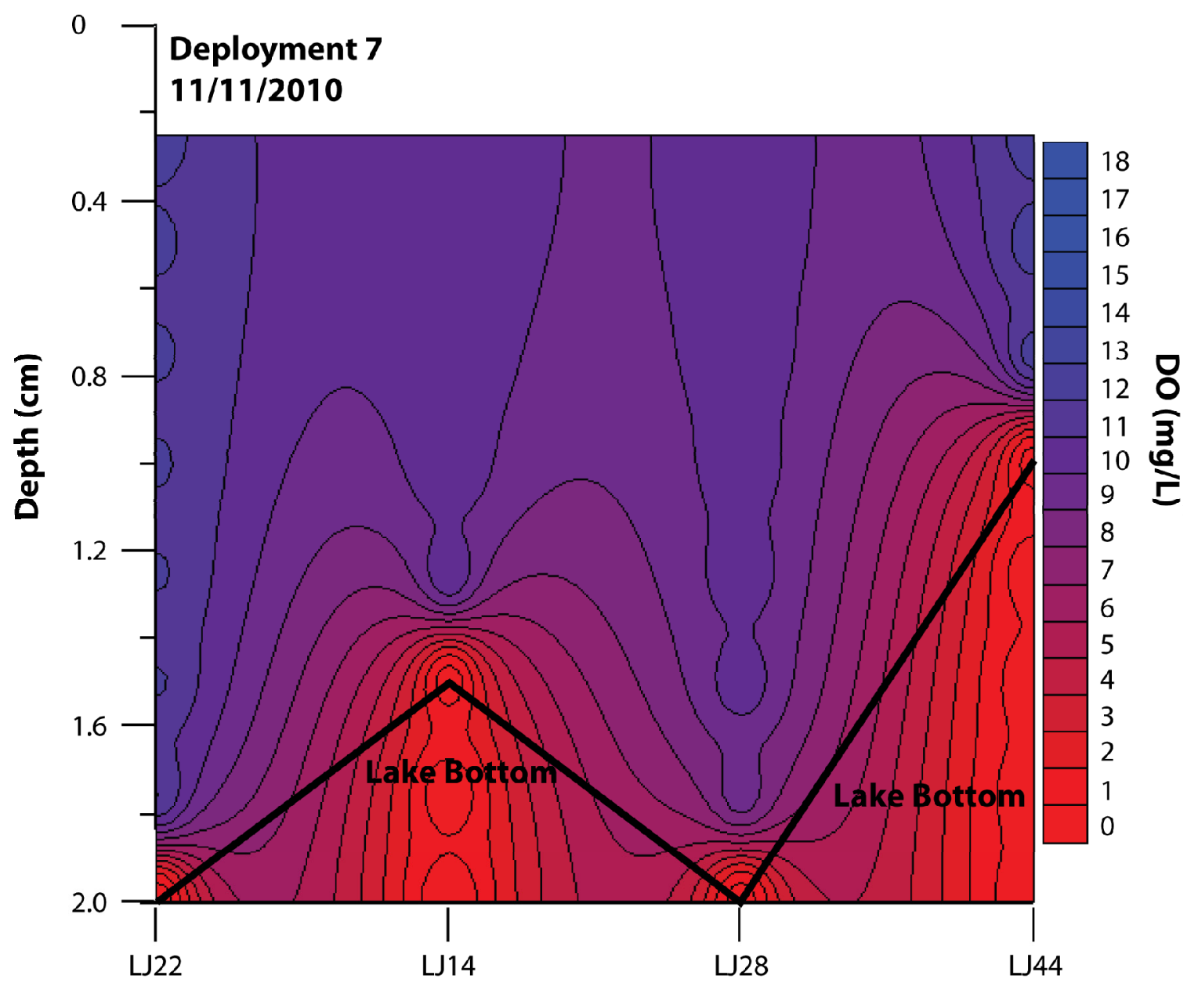

FIGURE A10. Lake wide DO profile for from West to East for Deployment 7. 


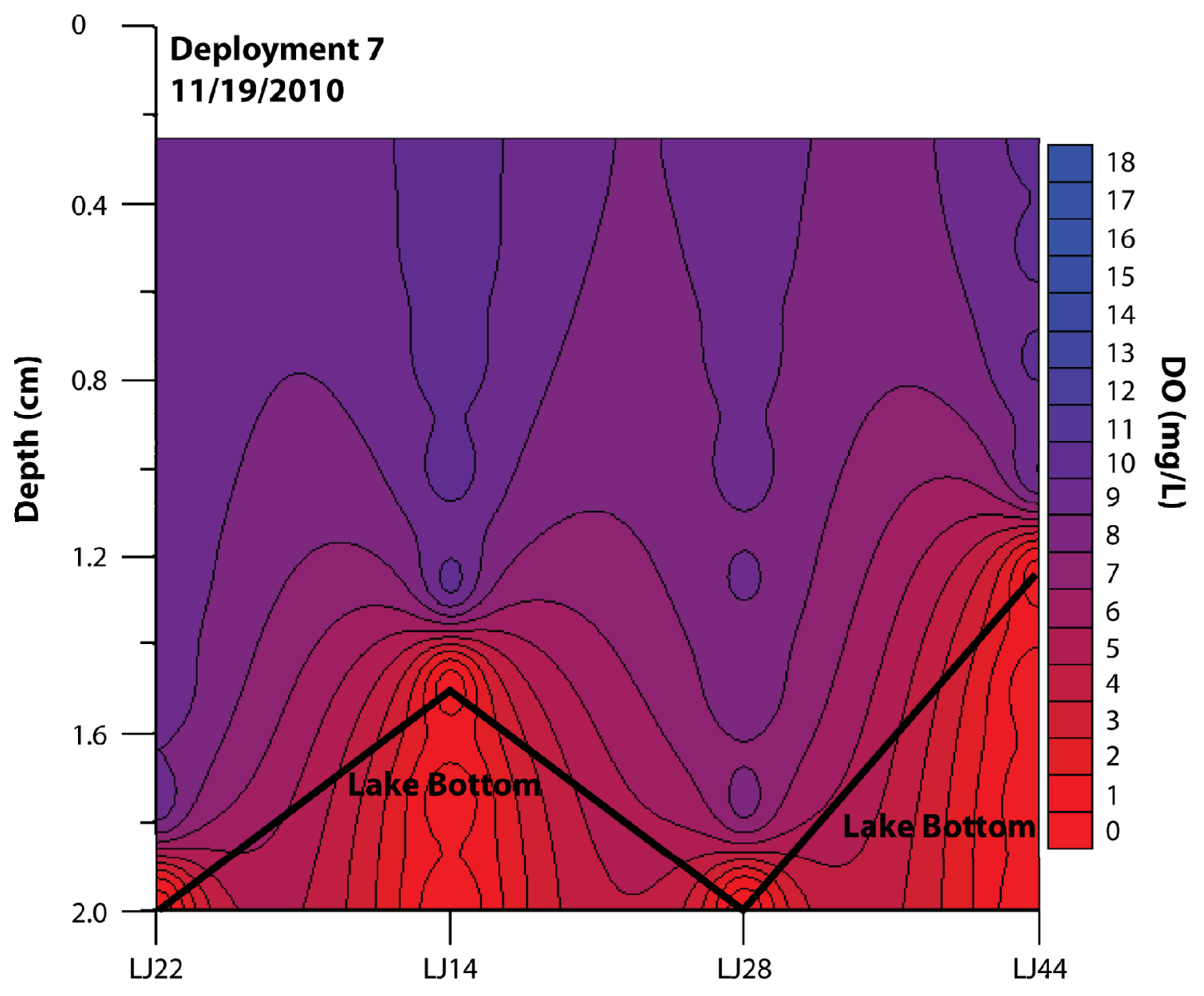

FIGURE A11. Lake wide DO profile for from West to East for Deployment 7. 


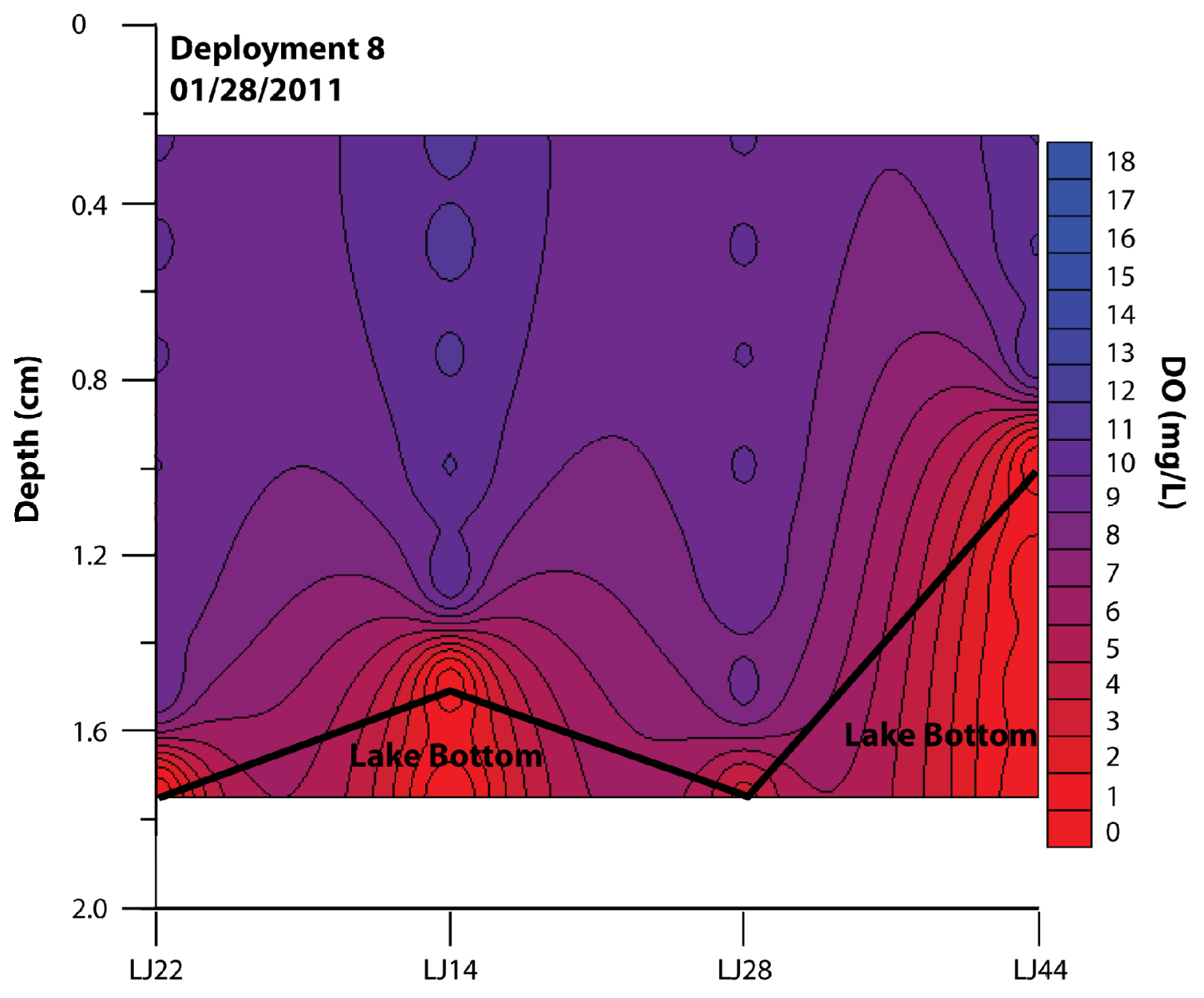

FIGURE A12. Lake wide DO profile for from West to East for Deployment 8. 


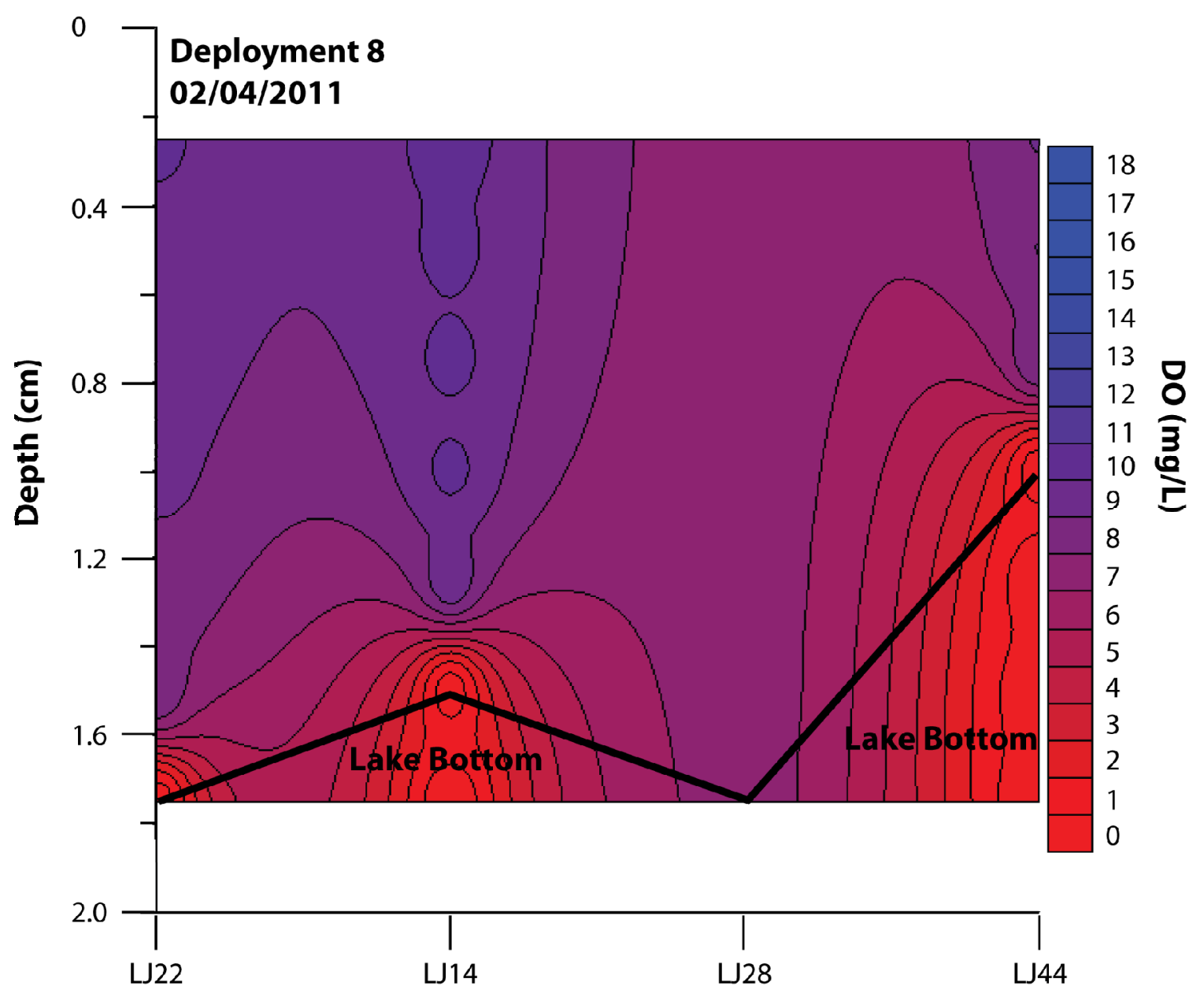

FIGURE A13. Lake wide DO profile for from West to East for Deployment 8. 


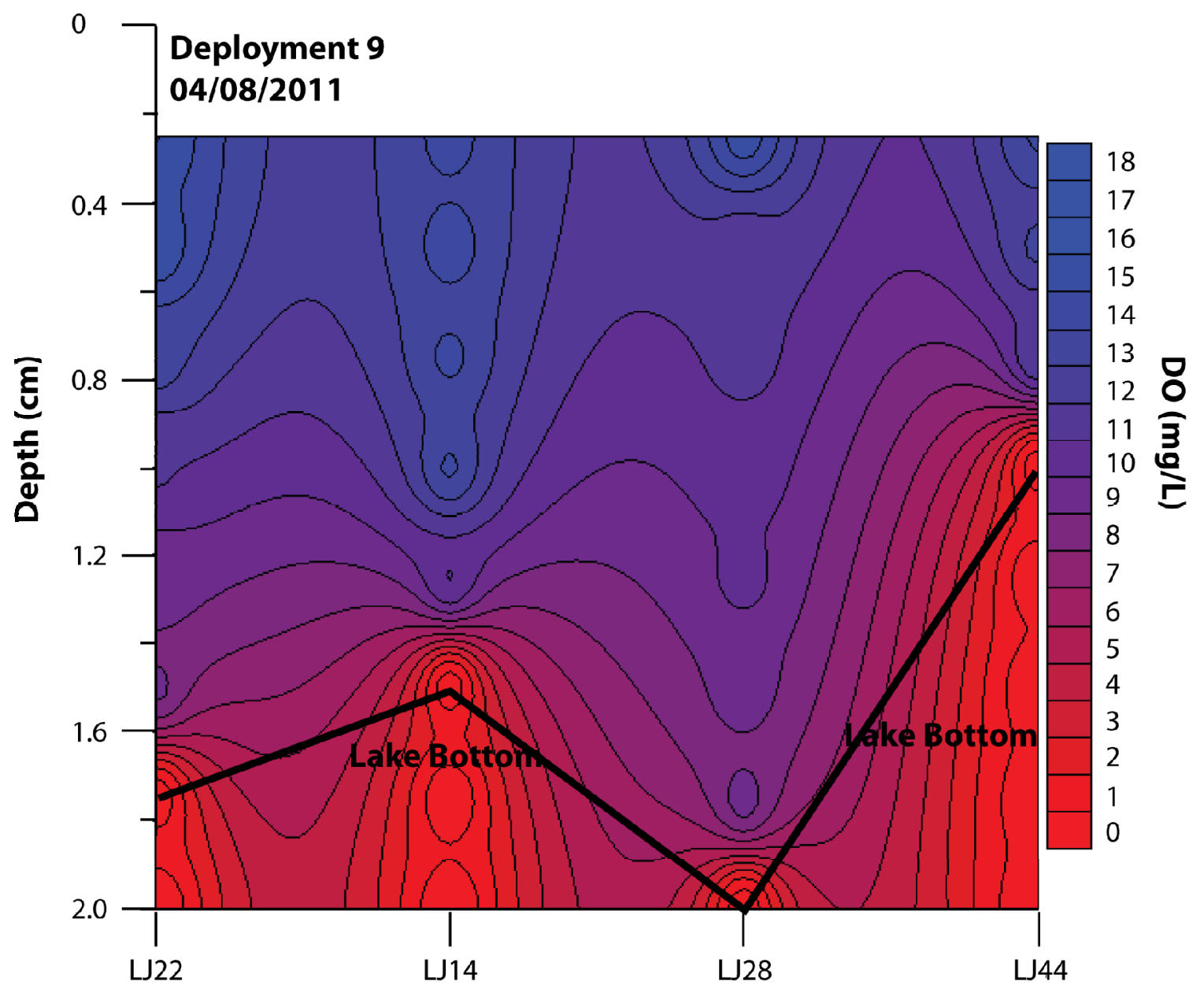

FIGURE A14. Lake wide DO profile for from West to East for Deployment 9. 


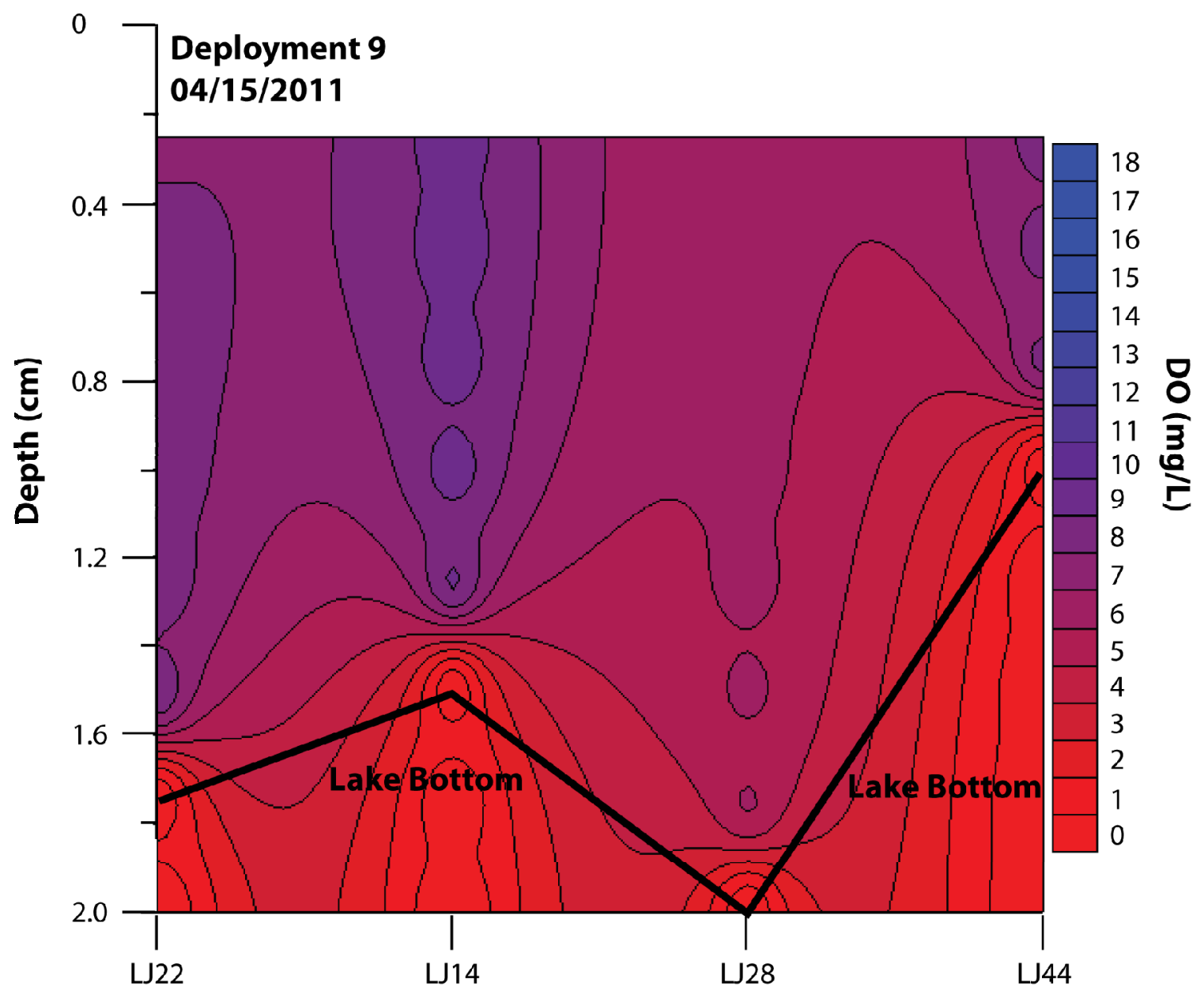

FIGURE A15. Lake wide DO profile for from West to East for Deployment 9 TP, TN and TC from ISCO Deployment 1 (April, May 2009)

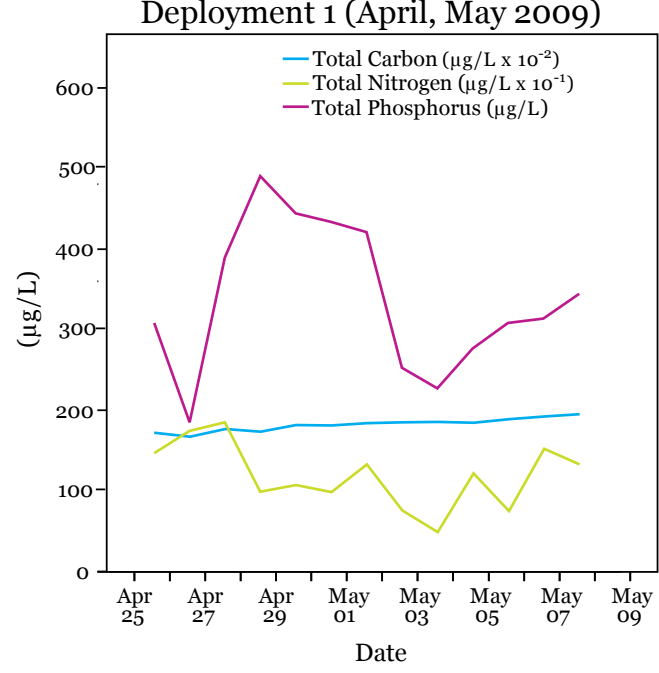

TP, TN and TC from ISCO

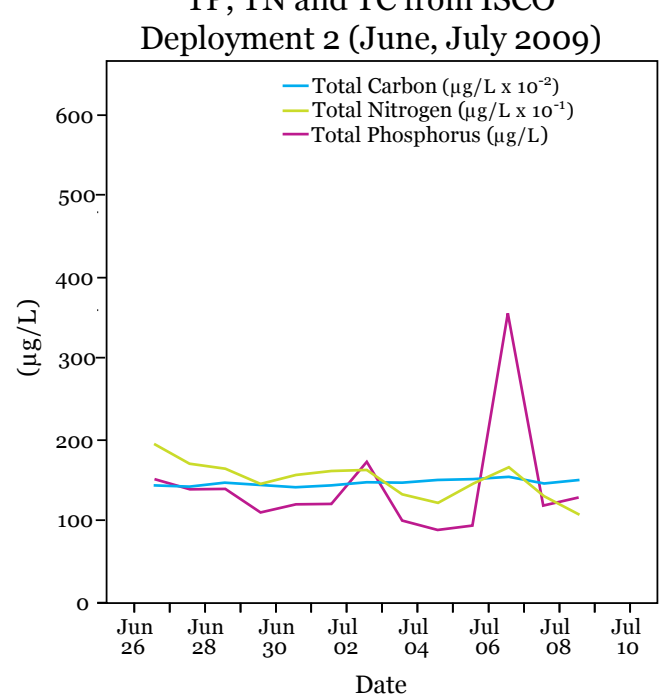


TP, TN and TC from ISCO

Deployment 3 (August, 2009)

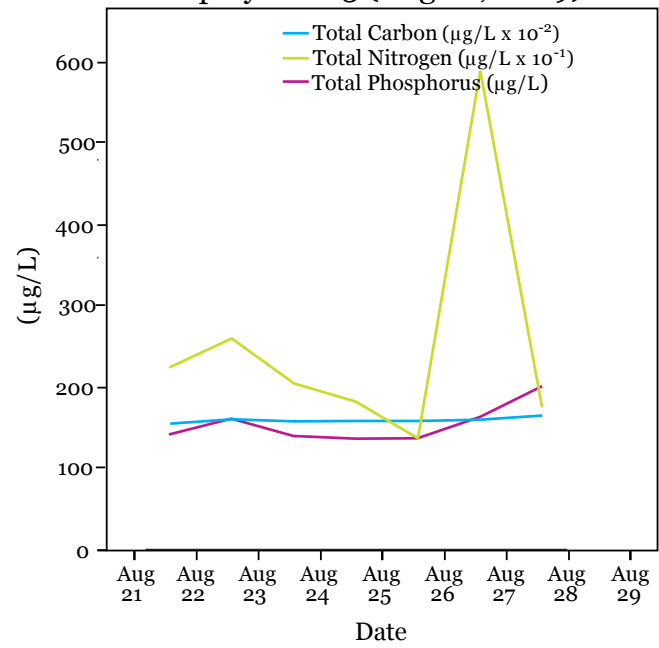

TP, TN and TC from ISCO Deployment 4 (November, 2009)

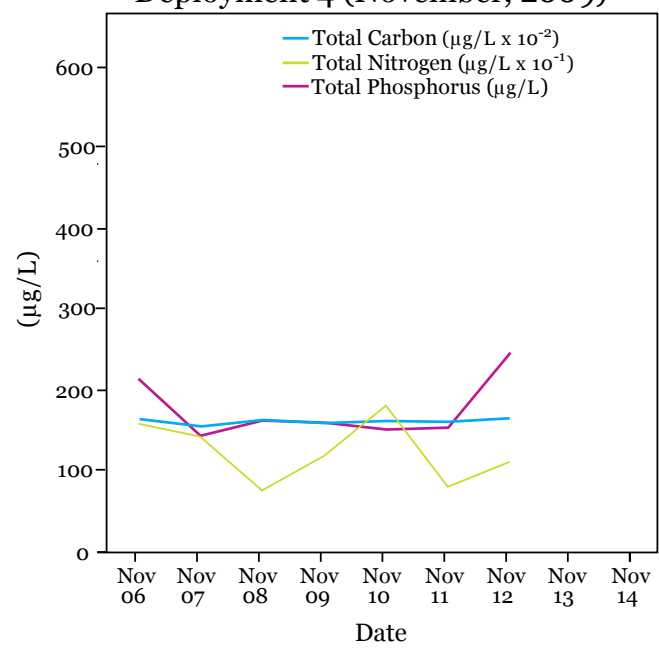


$\mathrm{TP}, \mathrm{TN}$ and $\mathrm{TC}$ from ISCO

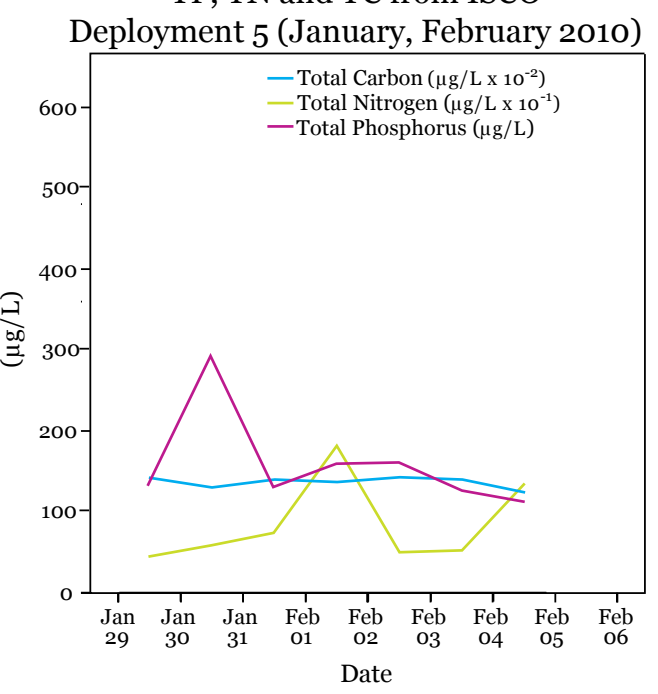

$\mathrm{TP}, \mathrm{TN}$ and TC from ISCO Deployment 7 (November, 2010)

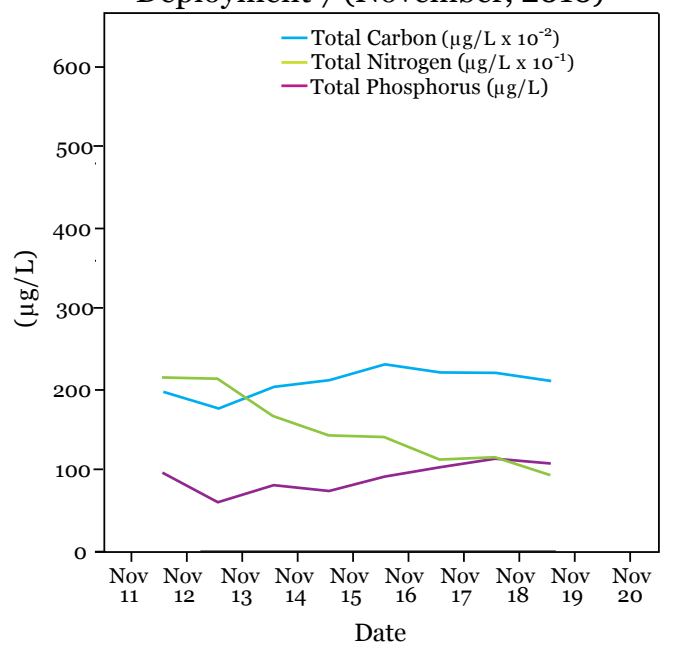

TP, TN and TC from ISCO Deployment 6 (August, 2010)

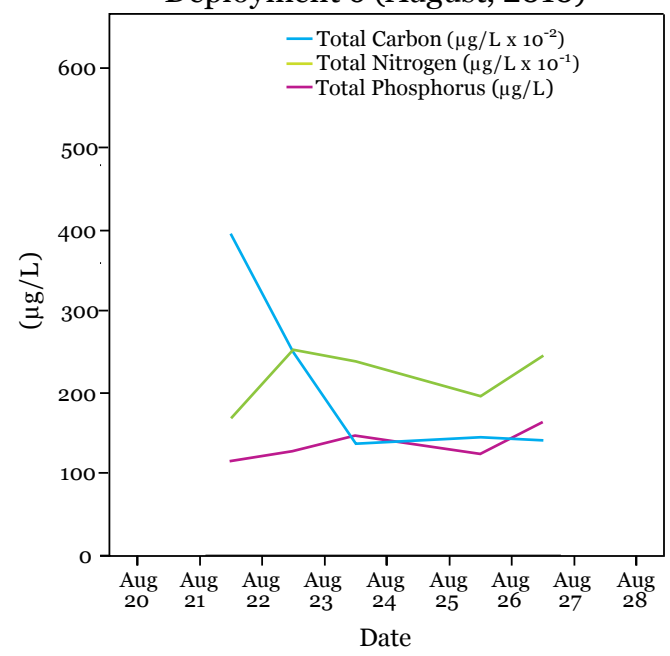

TP, TN and TC from ISCO

Deployment 8 (January, February 2011)

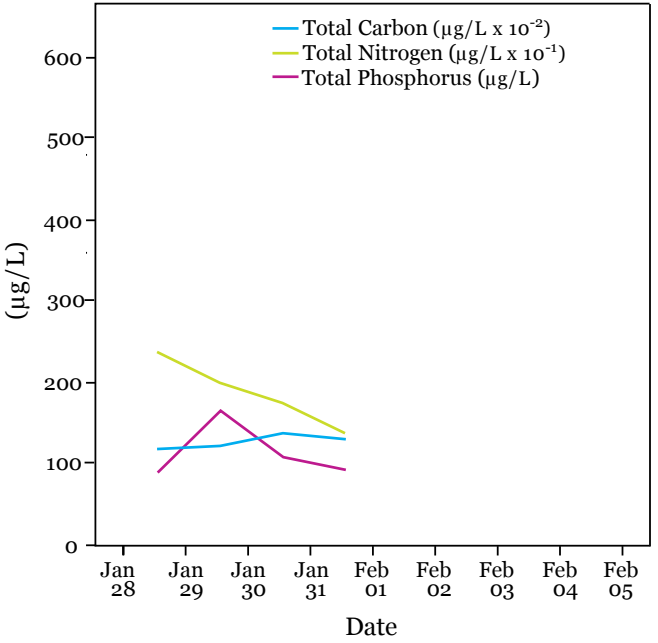

FIGURE A17. Daily nutrient concentrations for TP, TN and TOC for Deployments 5 to 8 
TP, TN and TC from ISCO Deployment 9 (April, 2011)

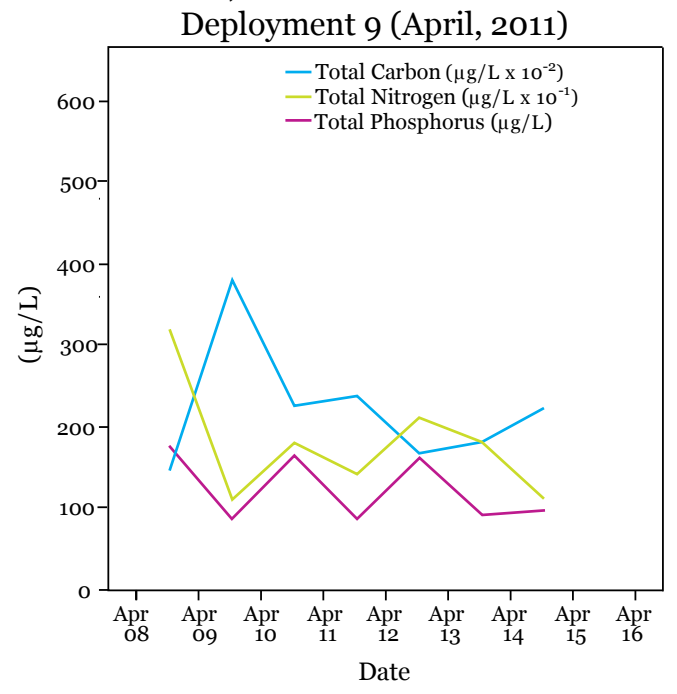

FIGURE A18. Daily nutrient

concentrations for TP, TN and TOC for Deployment 9. 
Floc Thickness

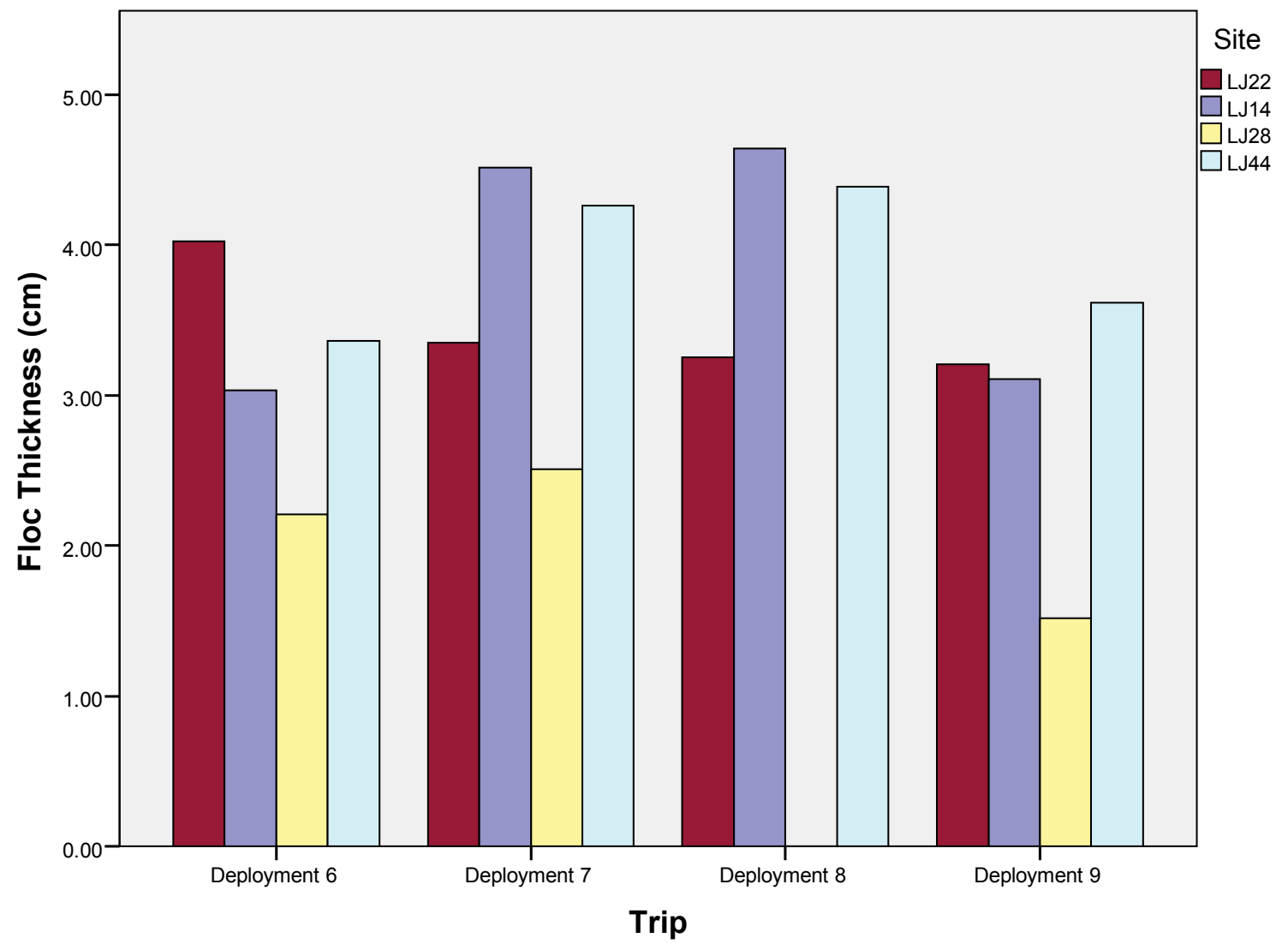

FIGURE A19. Floc thickness for deployments 6 to 9 . 


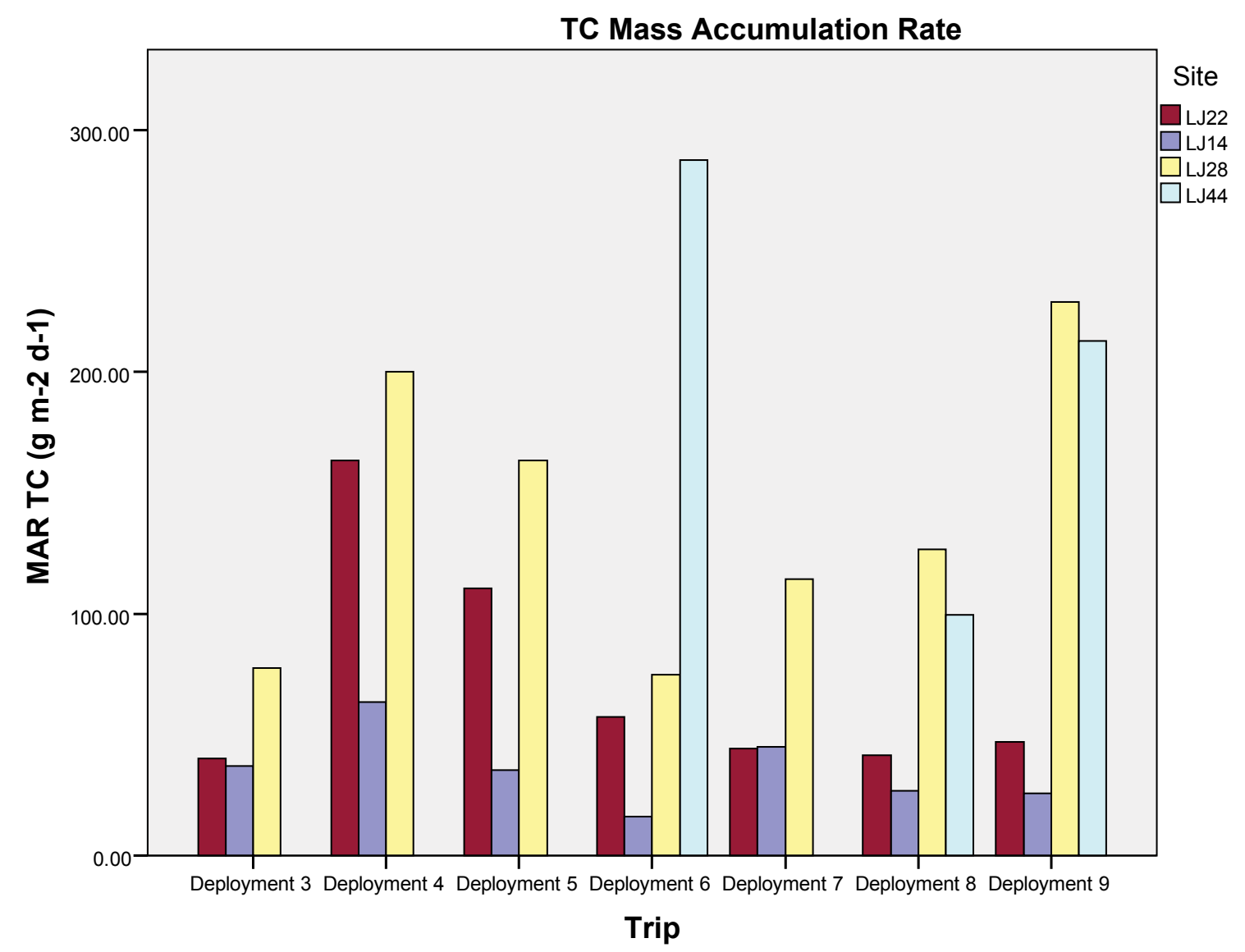

FIGURE A20. TC Mass accumulation rates for Deployments 3 to 9 . 


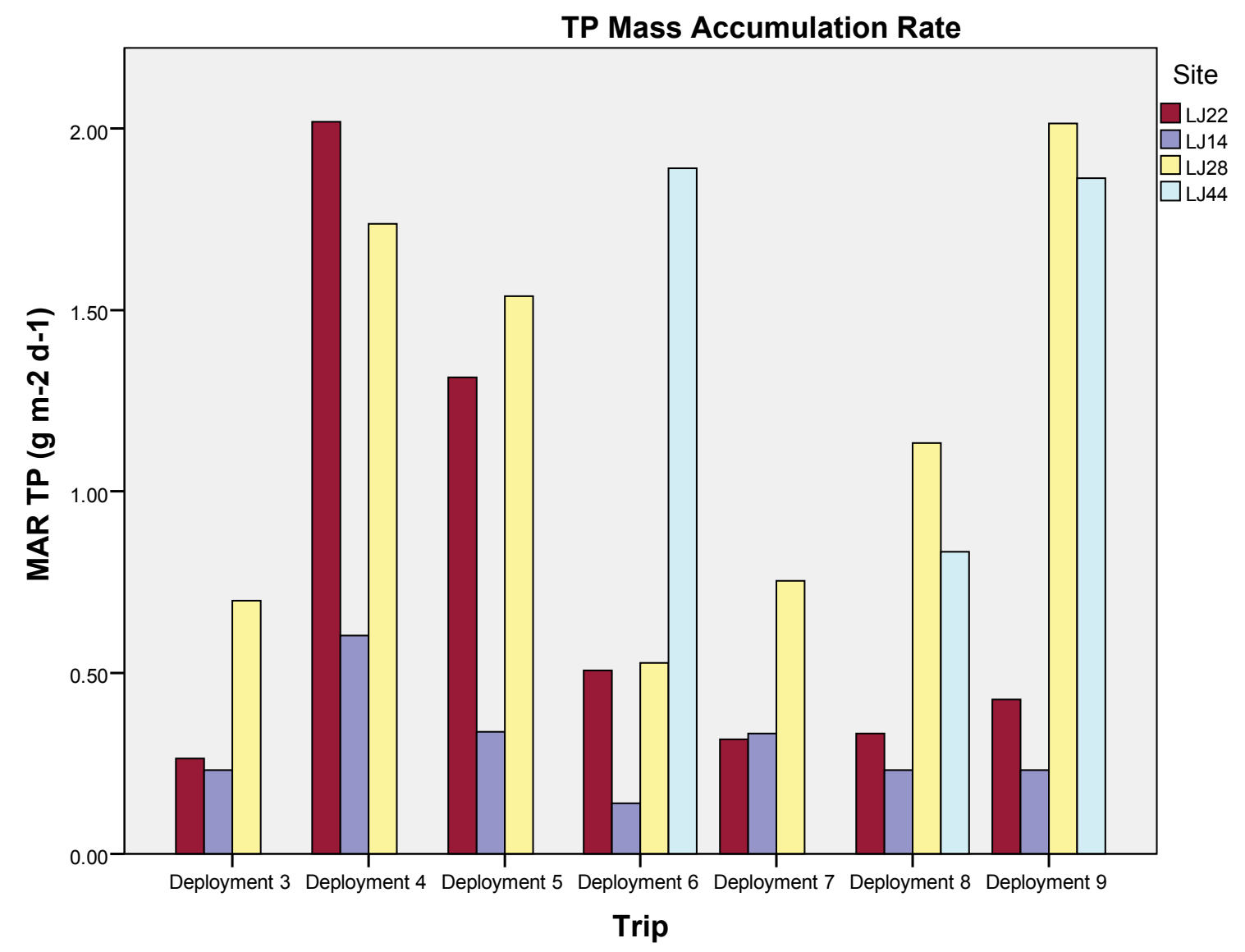

FIGURE A21. TP Mass accumulation rates for Deployments 3 to 9 . 


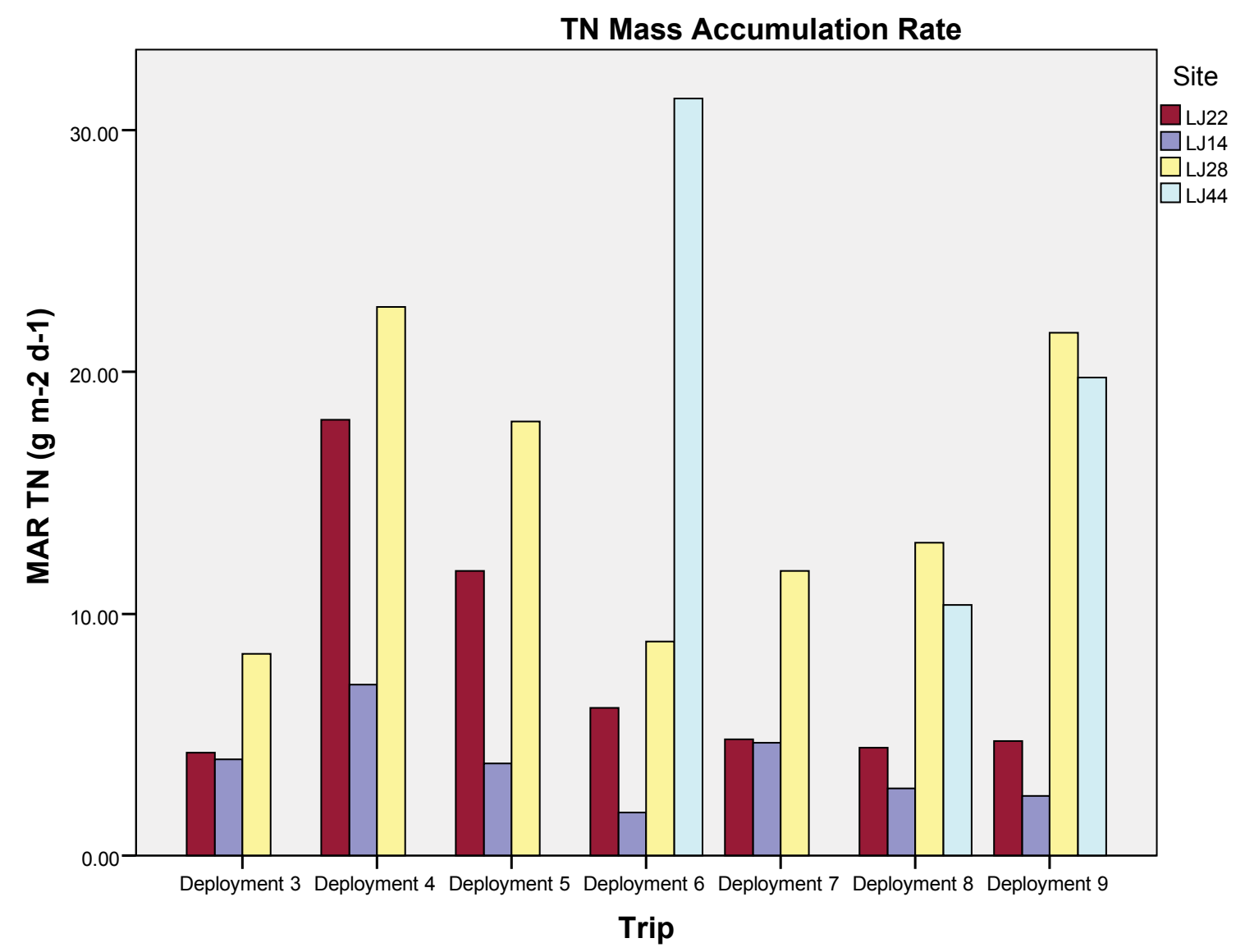

FIGURE A22. TN Mass accumulation rates for Deployments 3 to 9 . 


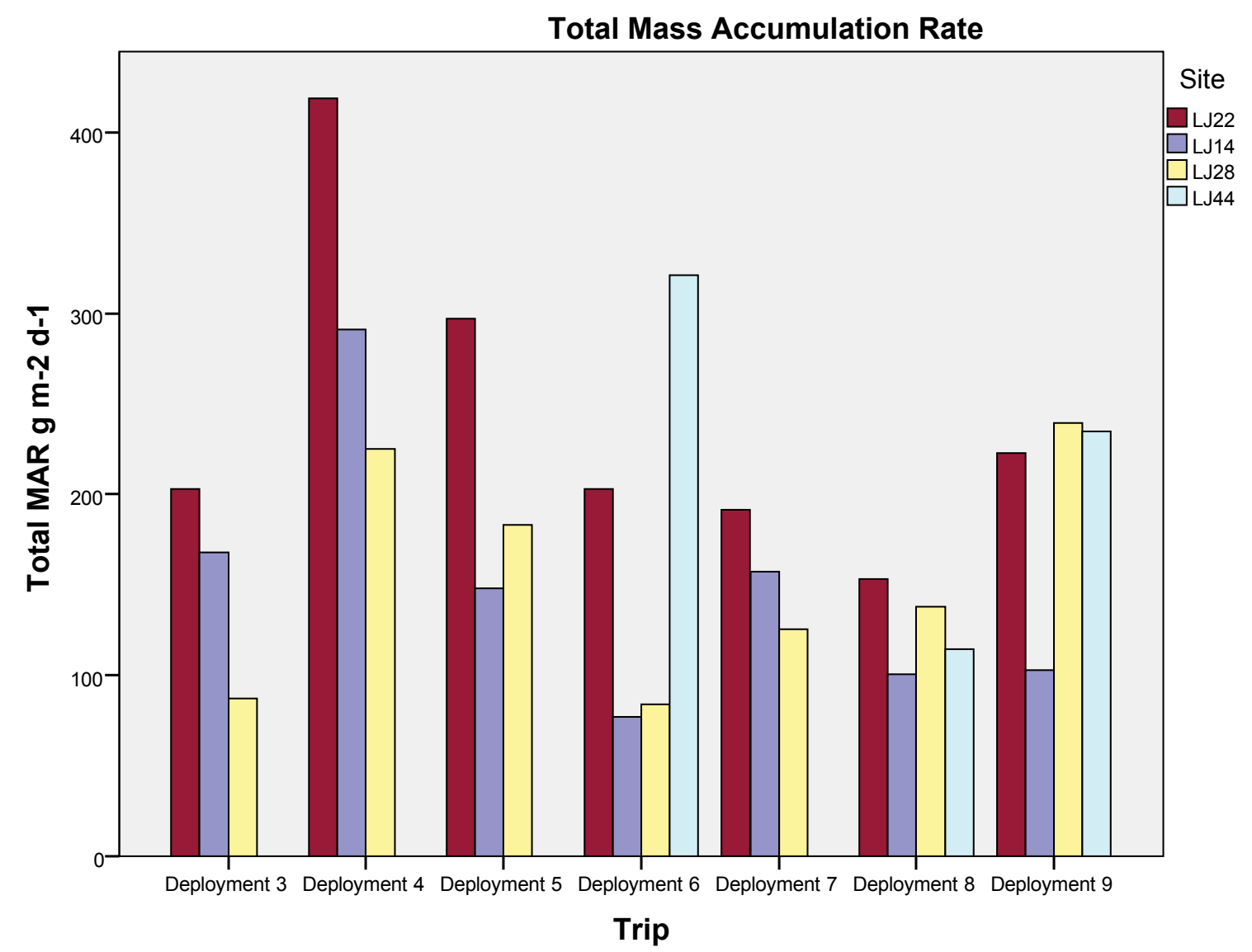

FIGURE A23. Total Mass accumulation rates for Deployments 3 to 9. 
Total Suspended Solids Deployment 1 (April, May 2009)

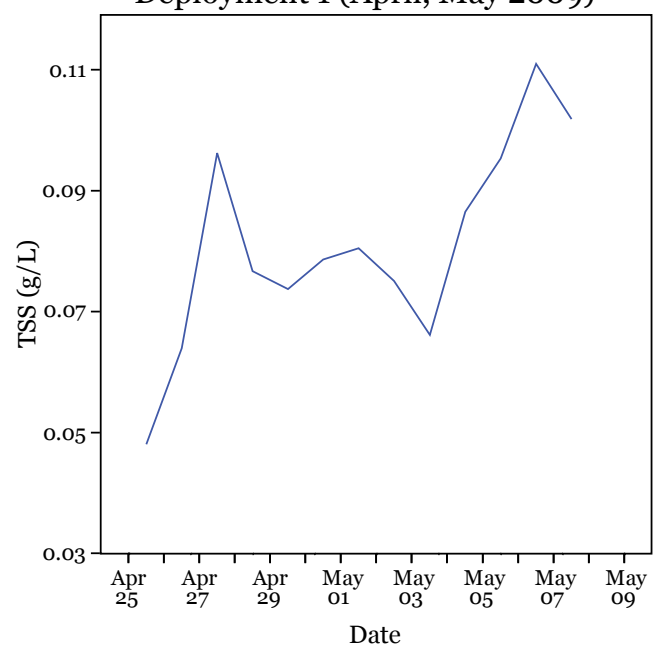

Total Suspended Solids

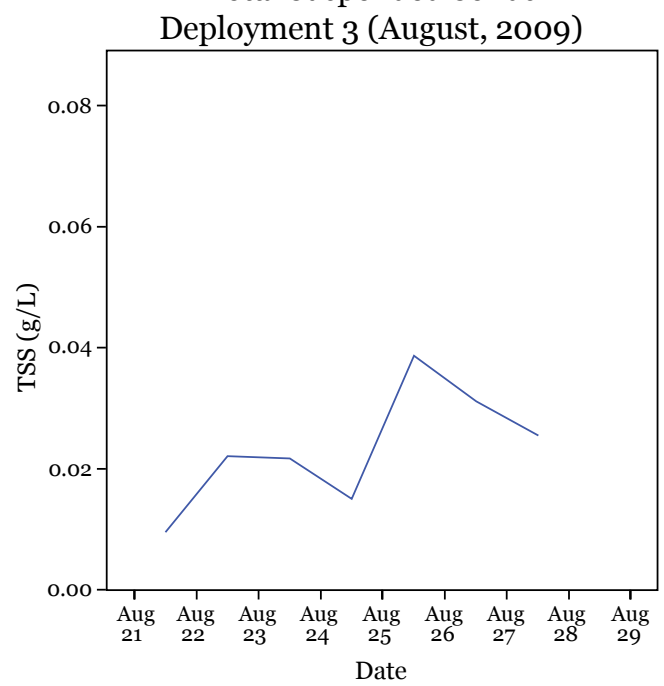

Total Suspended Solids

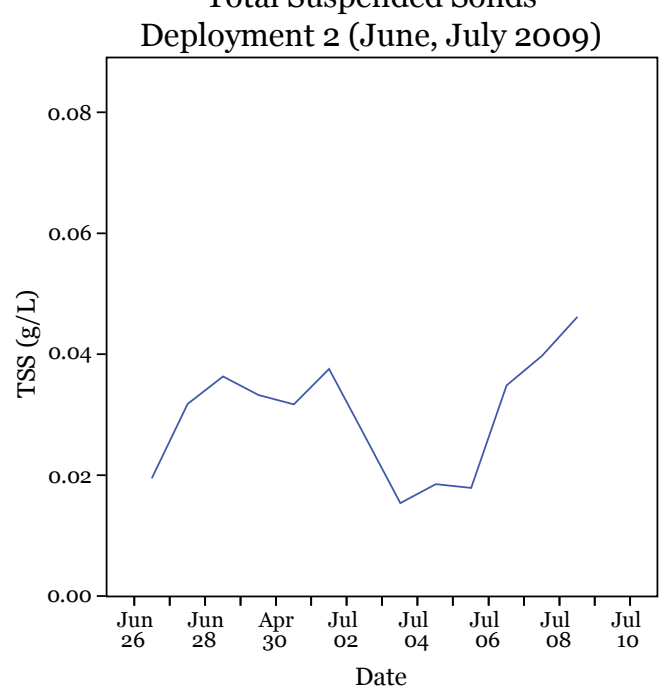

Total Suspended Solids

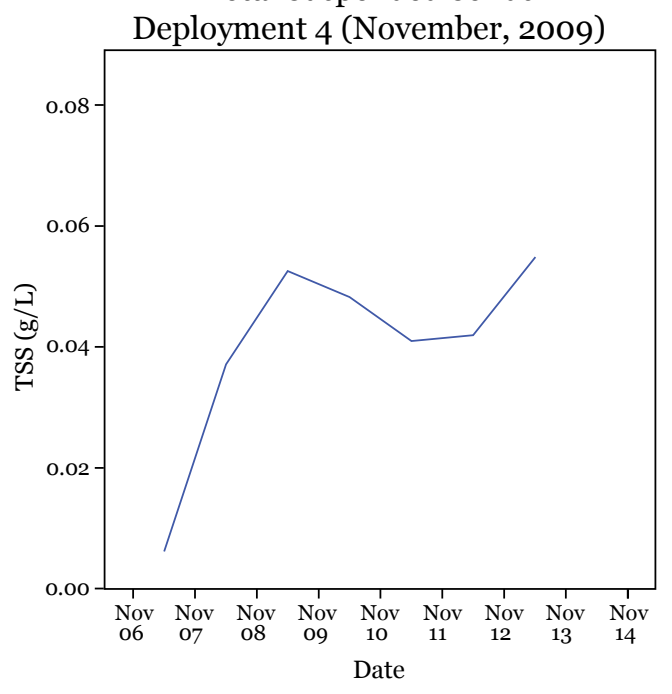

FIGURE A24. Total suspended solids for Deployments 1 to 4 . 
Total Suspended Solids

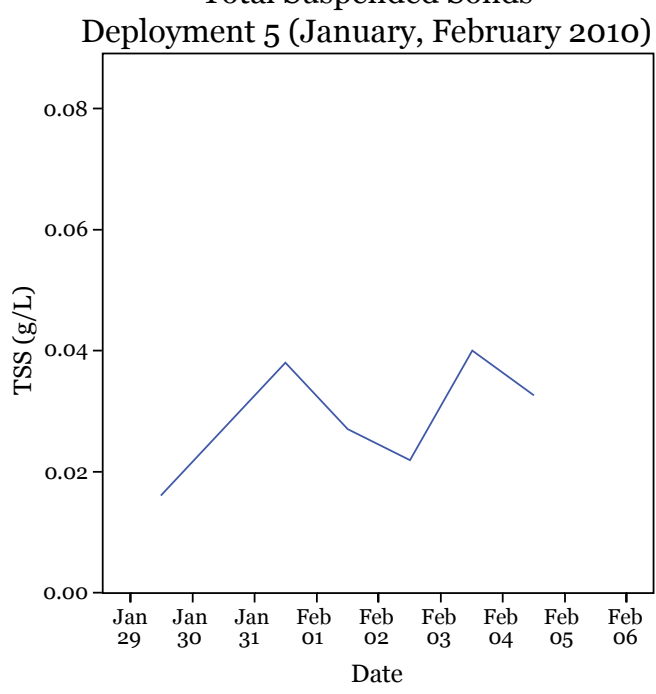

Total Suspended Solids Deployment 7 (November, 2010)

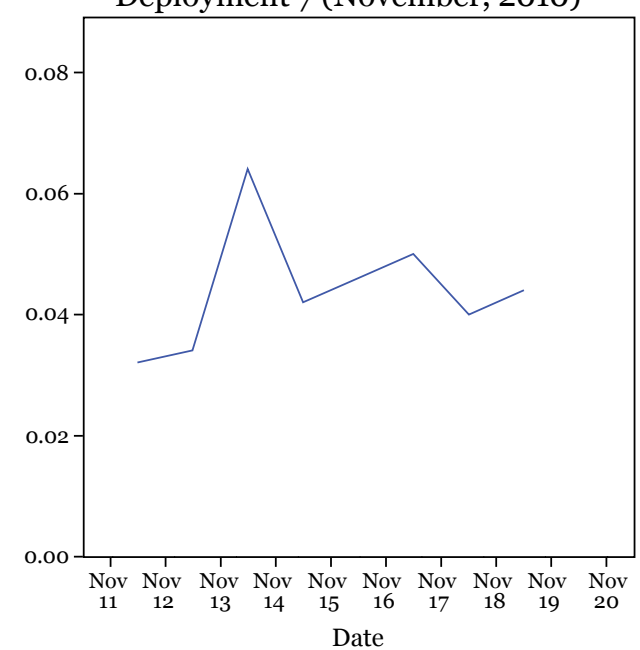

Total Suspended Solids Deployment 6 (August, 2010)

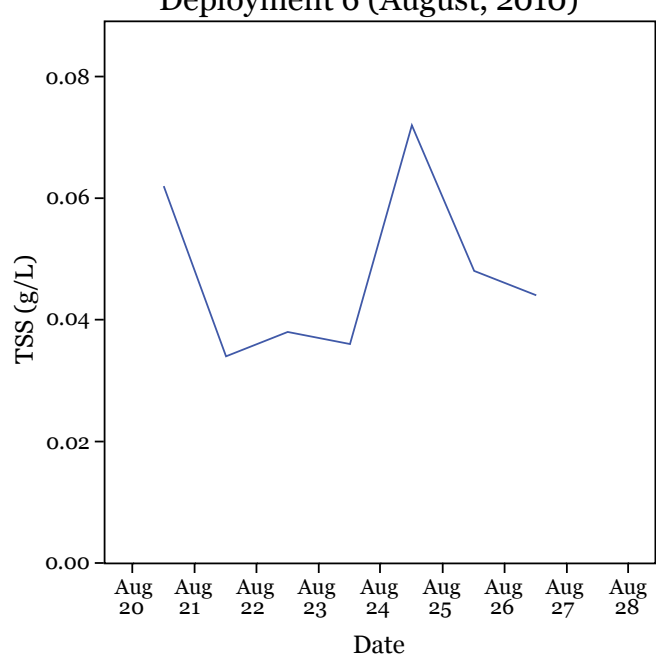

Total Suspended Solids Deployment 8 (January, February 2011)

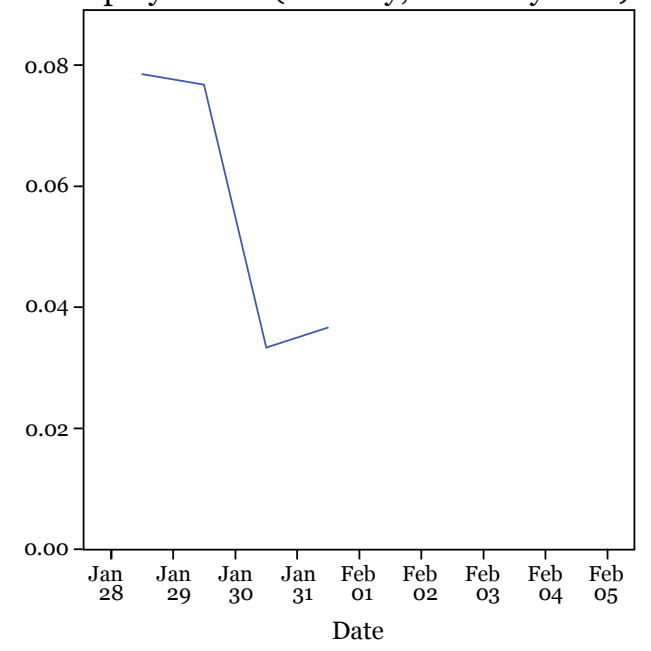

FIGURE A25. Total suspended solids for Deployments 5 to 6 . 
Total Suspended Solids Deployment 9 (April, 2011)

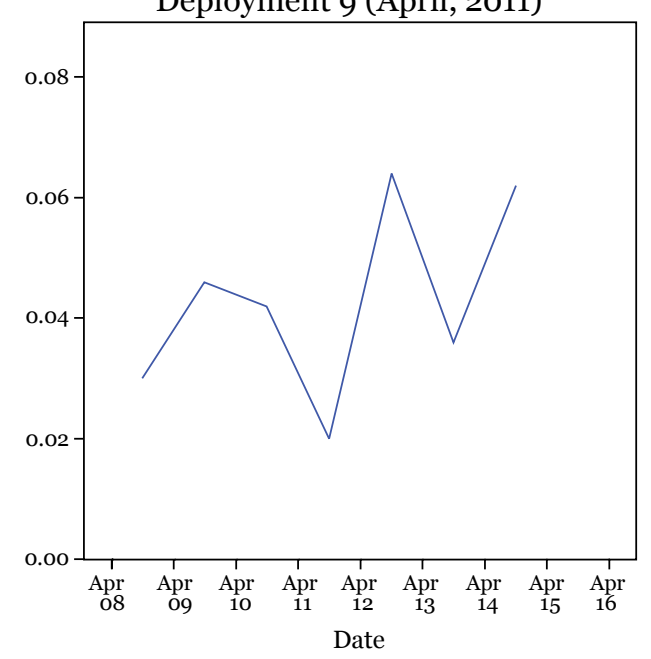

FIGURE A26. Total suspended solids for Deployment 9. 


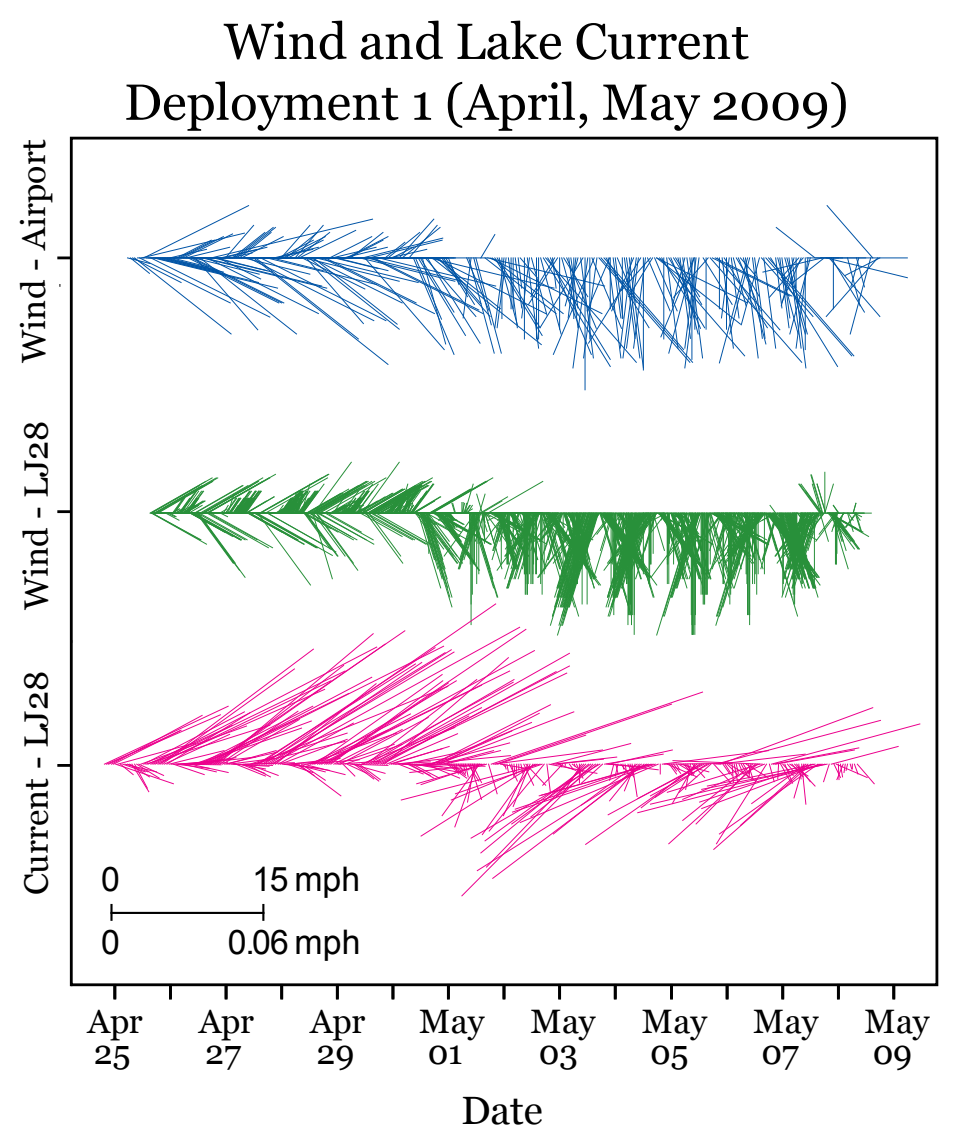

FIGURE A27. Stick plots of wind (LJ28 and Sanford Airport) and current for Deployment 1. 


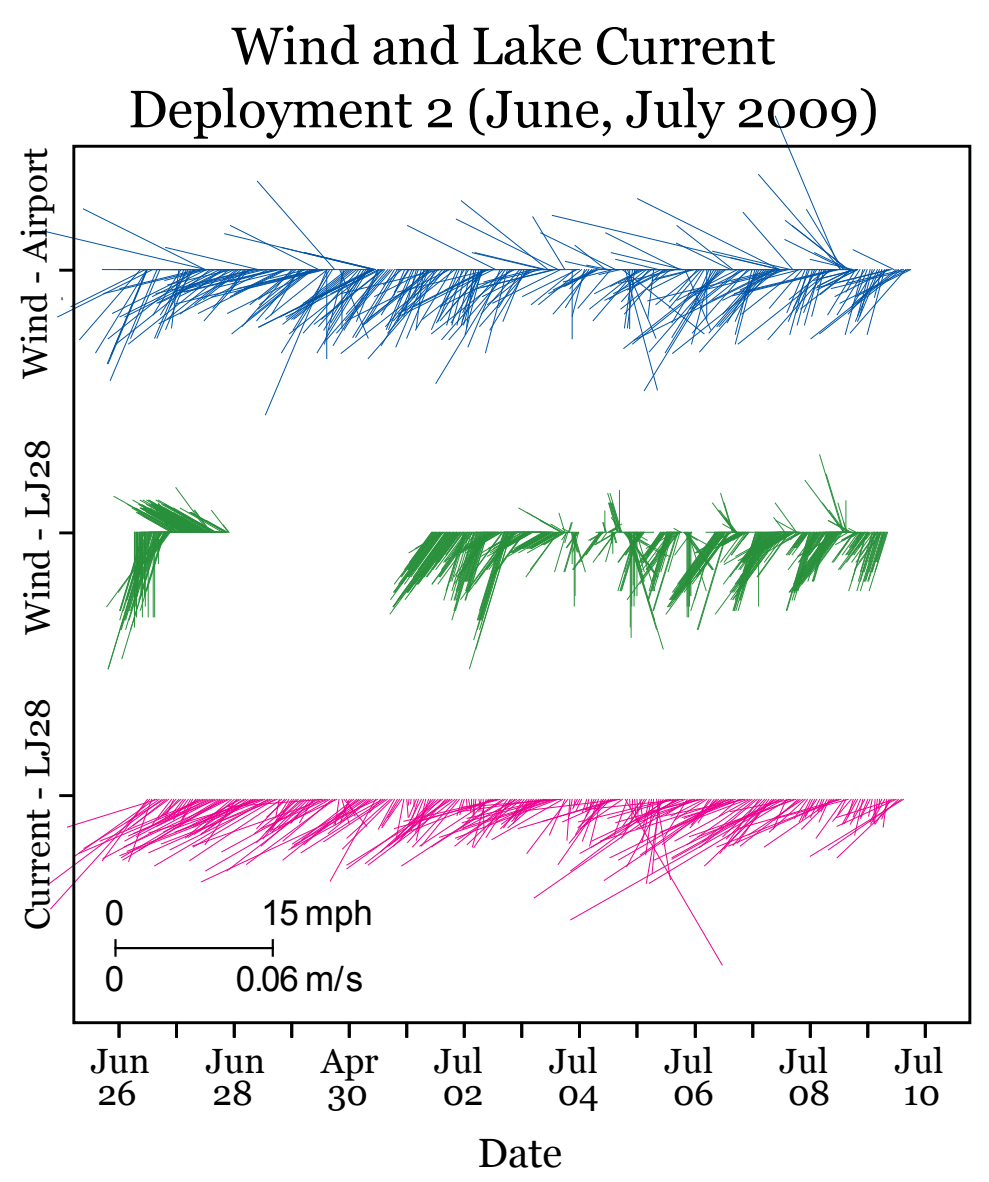

FIGURE A28. Stick plots of wind (LJ28 and Sanford Airport) and current for Deployment 2. 


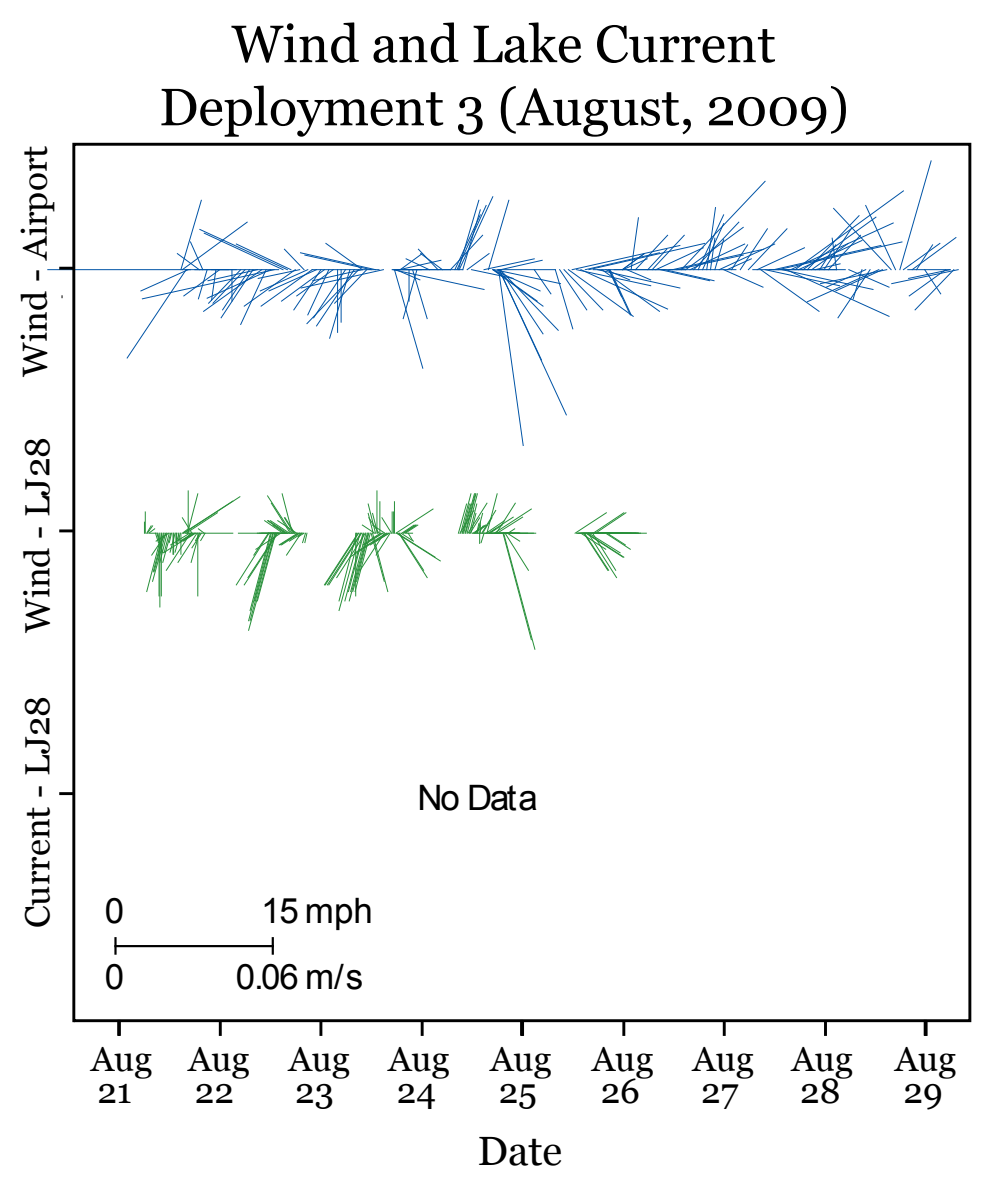

FIGURE A29. Stick plots of wind (LJ28 and Sanford Airport) for Deployment 3. 


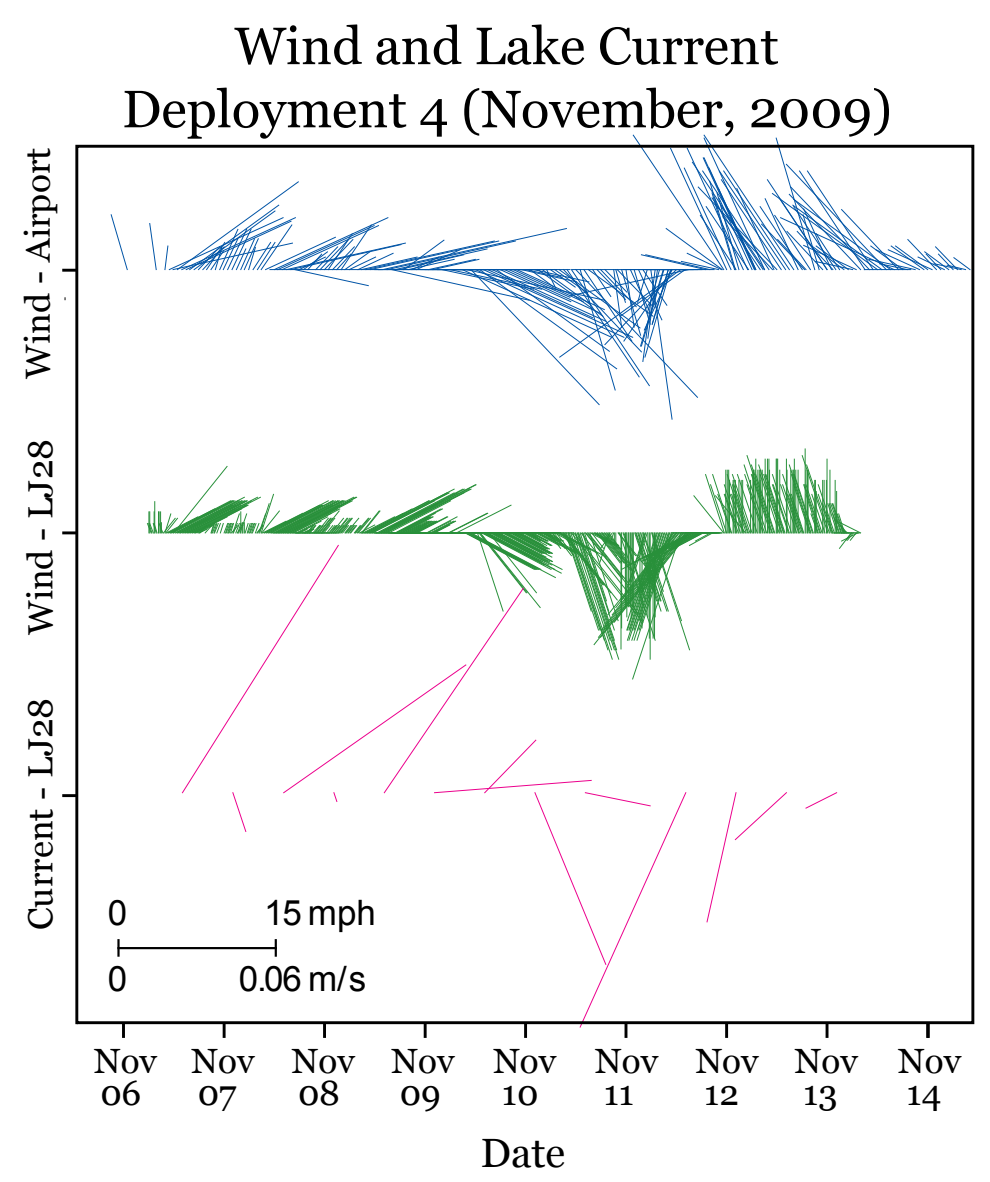

FIGURE A30. Stick plots for wind (LJ28 and Sanford Airport) and current for Deployment 4. 


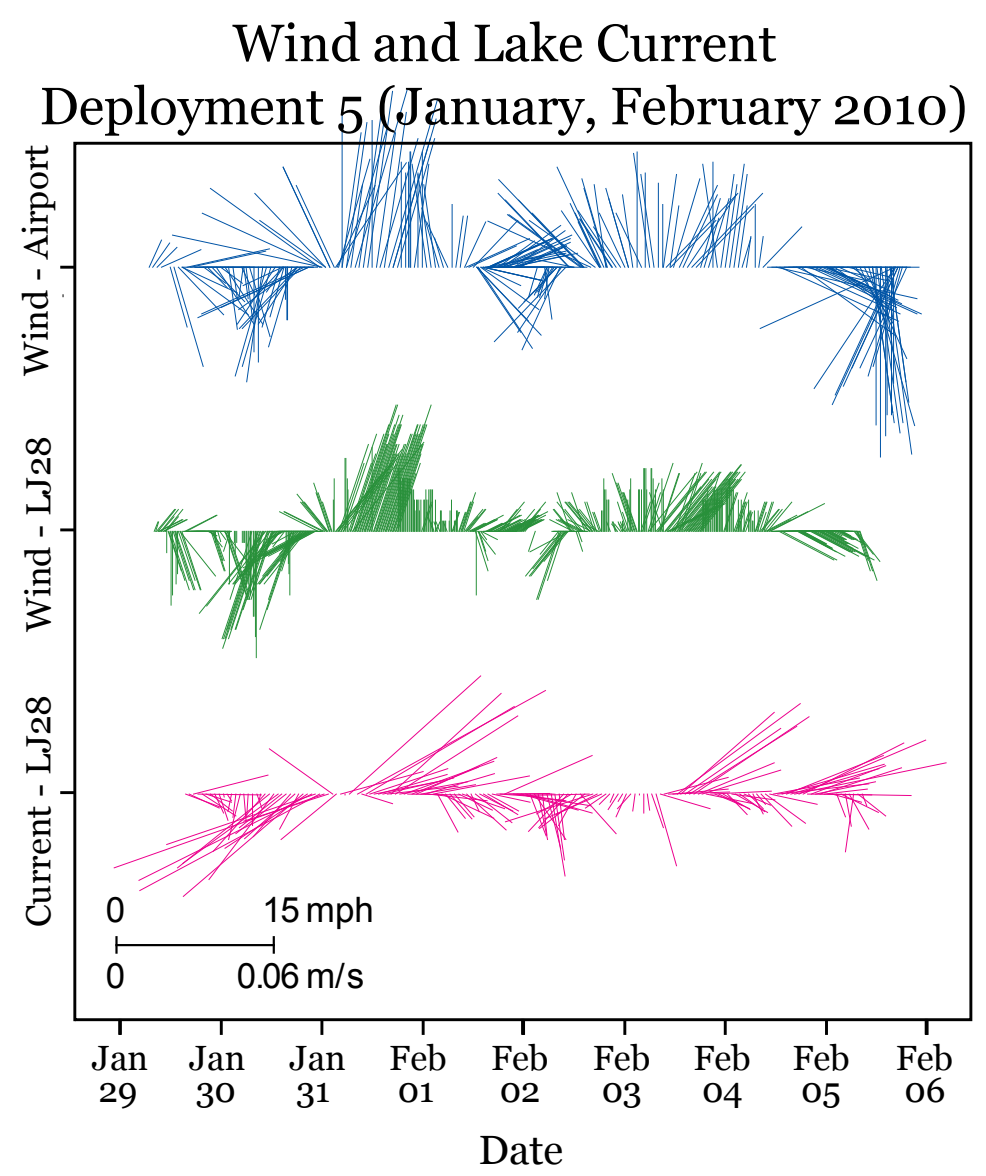

FIGURE A31. Stick plots of wind (LJ28 and Sanford Airport) and current for Deployment 5. 


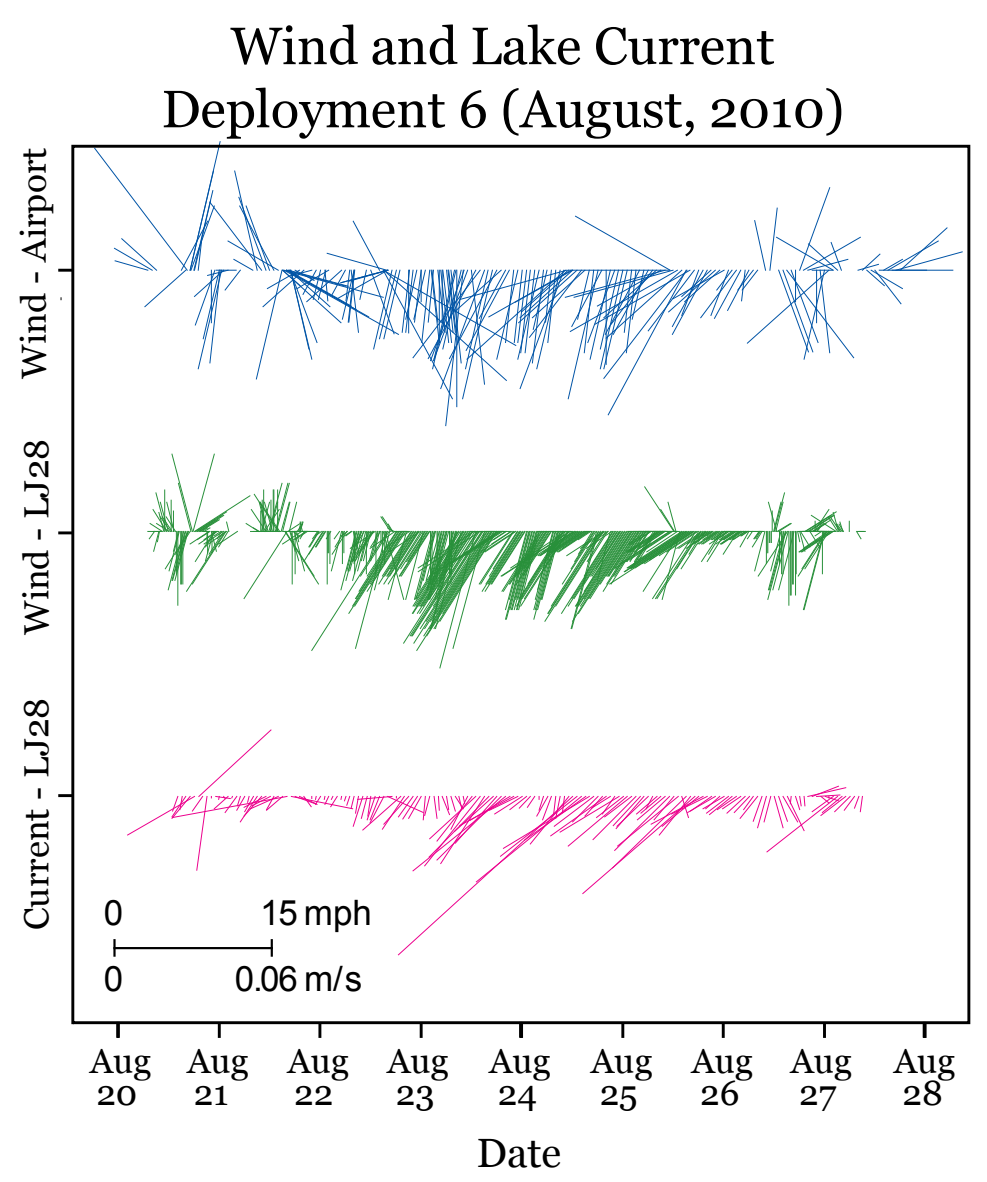

FIGURE A32. Stick plots of wind (LJ28 and Sanford Airport) and current for Deployment 6. 


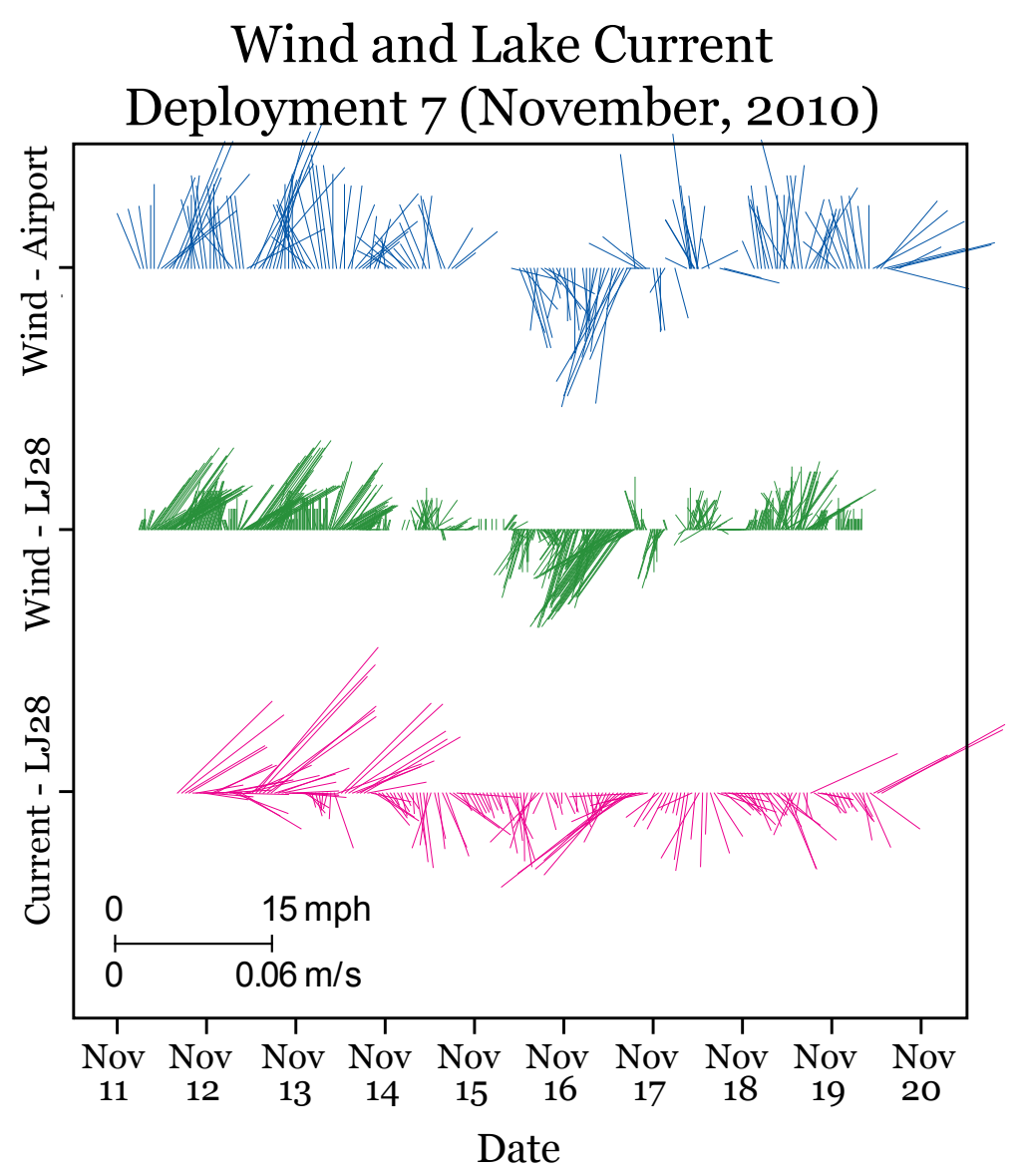

FIGURE A33. Stick plots of wind (LJ28 and Sanford Airport) and current for Deployment 7. 


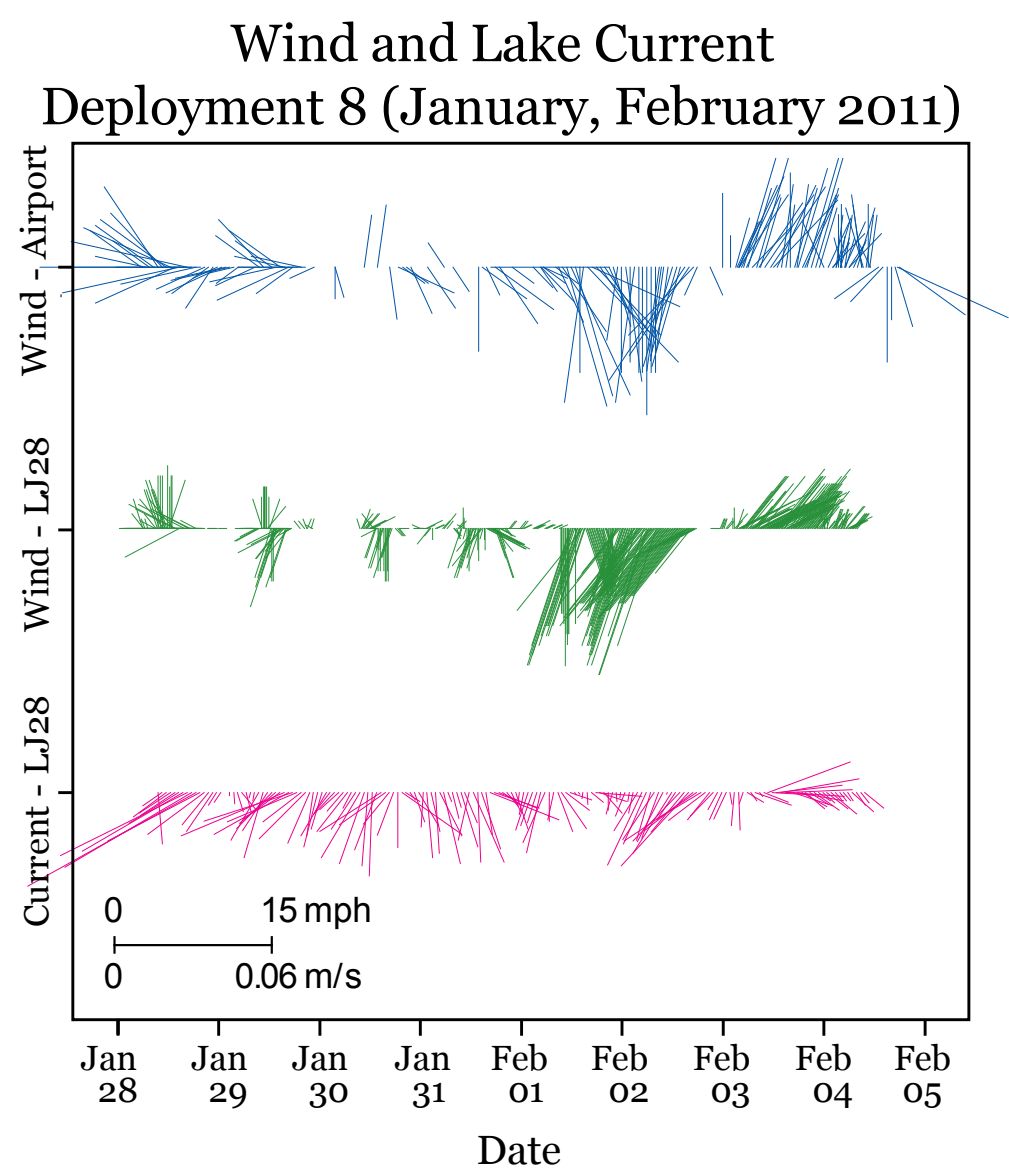

FIGURE A34. Stick plots of wind (LJ28 and Sanford Airport) and current for Deployment 8. 


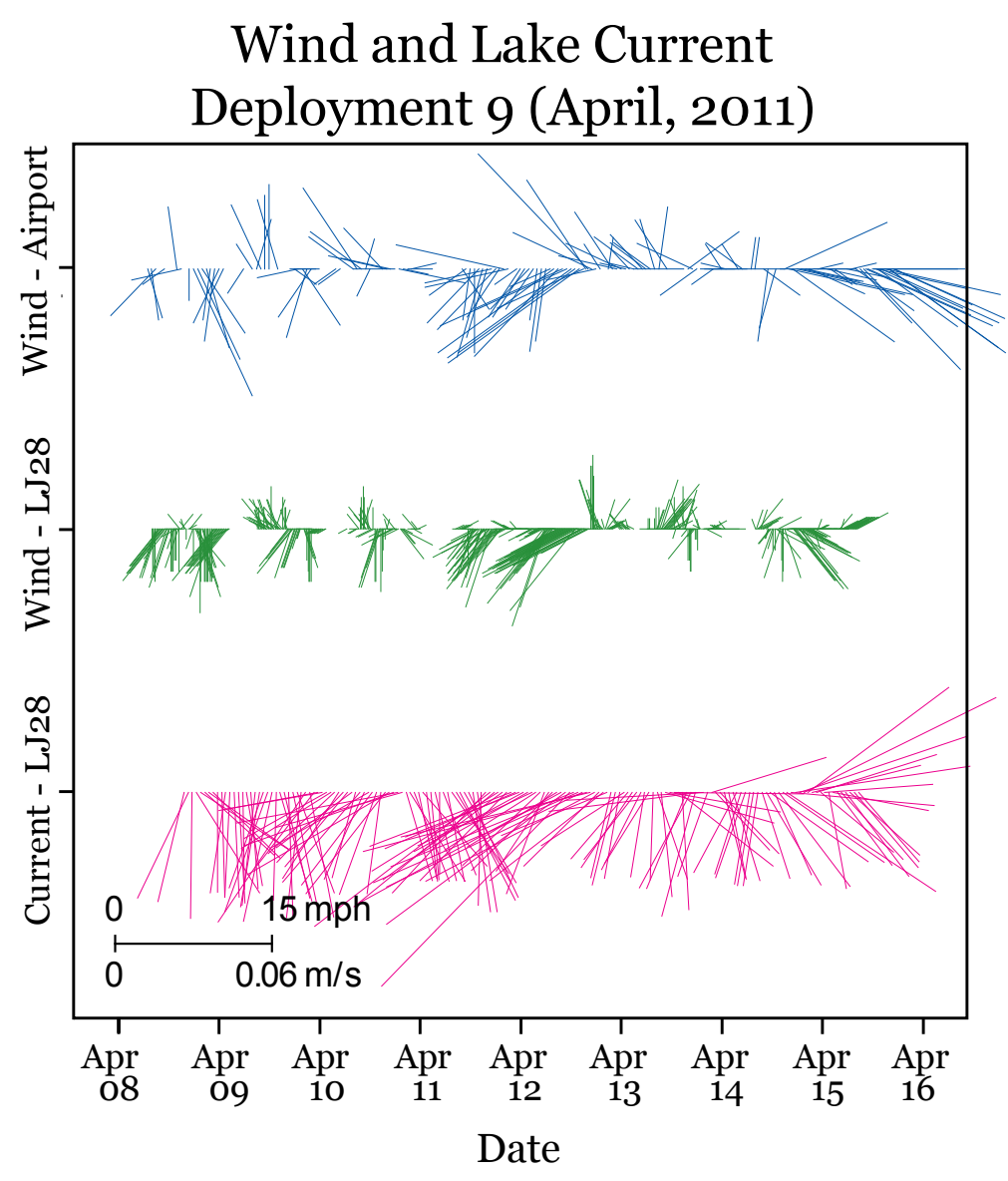

FIGURE A35. Stick plots of wind (LJ28 and Sanford Airport) and current for Deployment 9. 

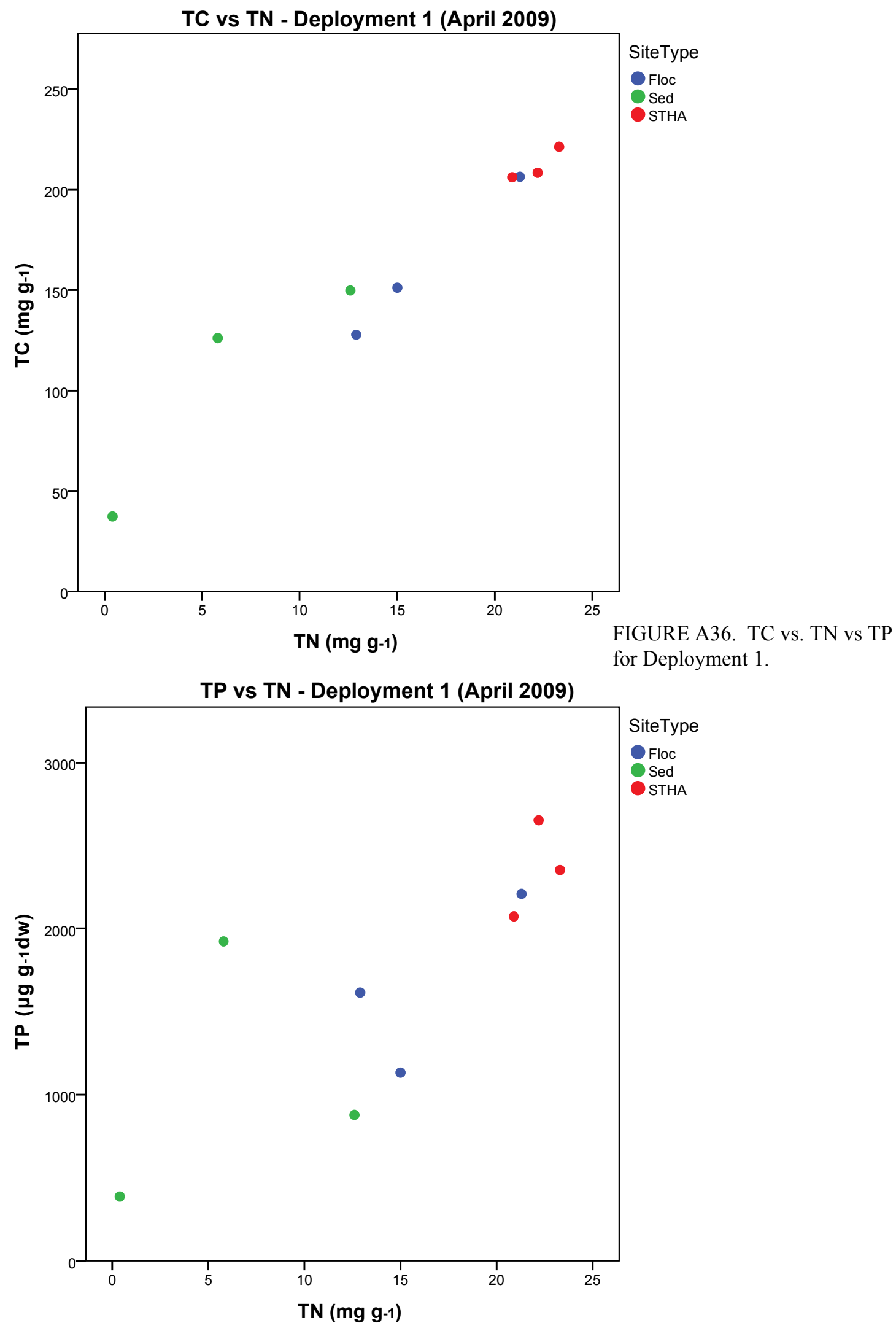


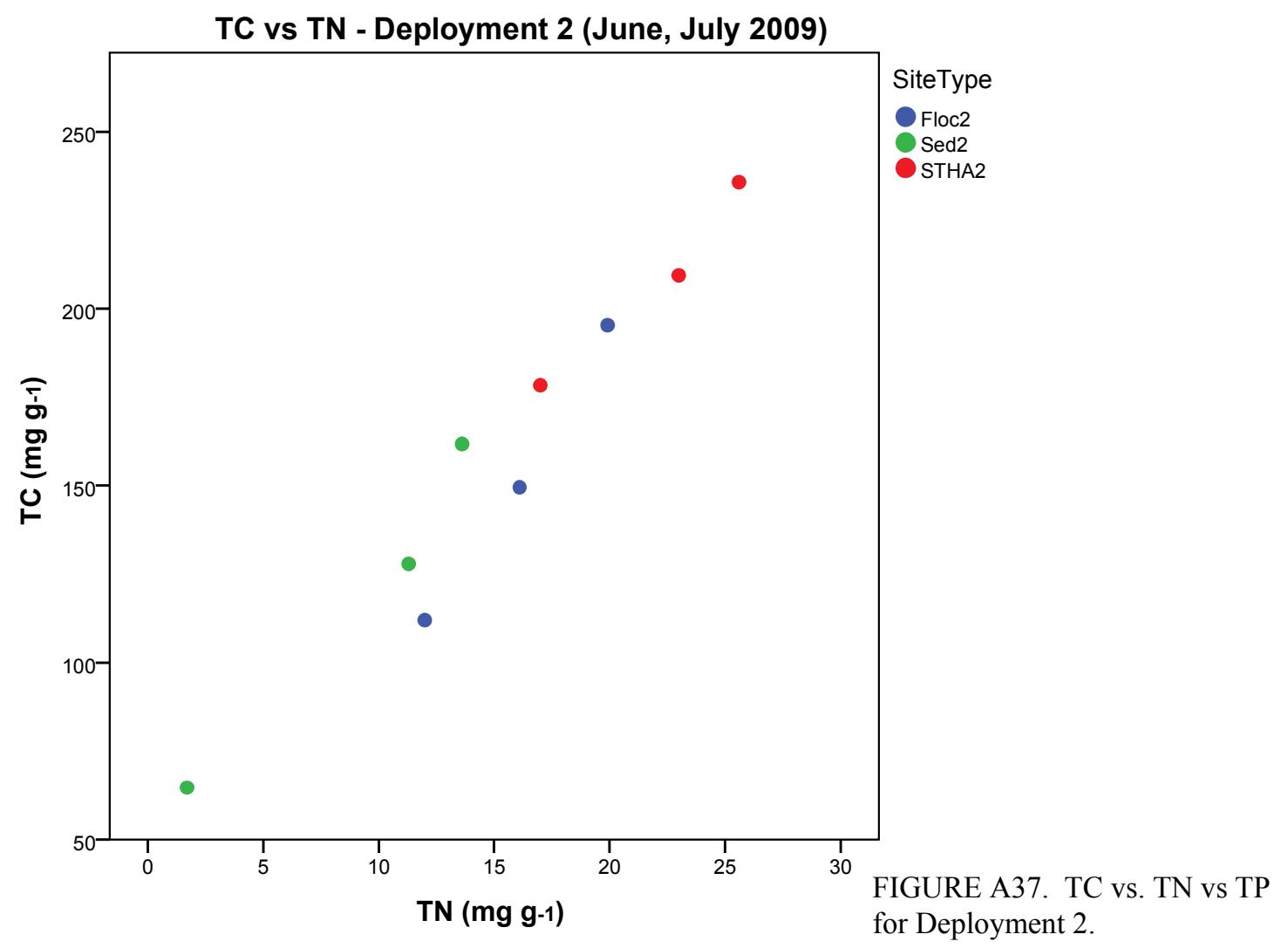




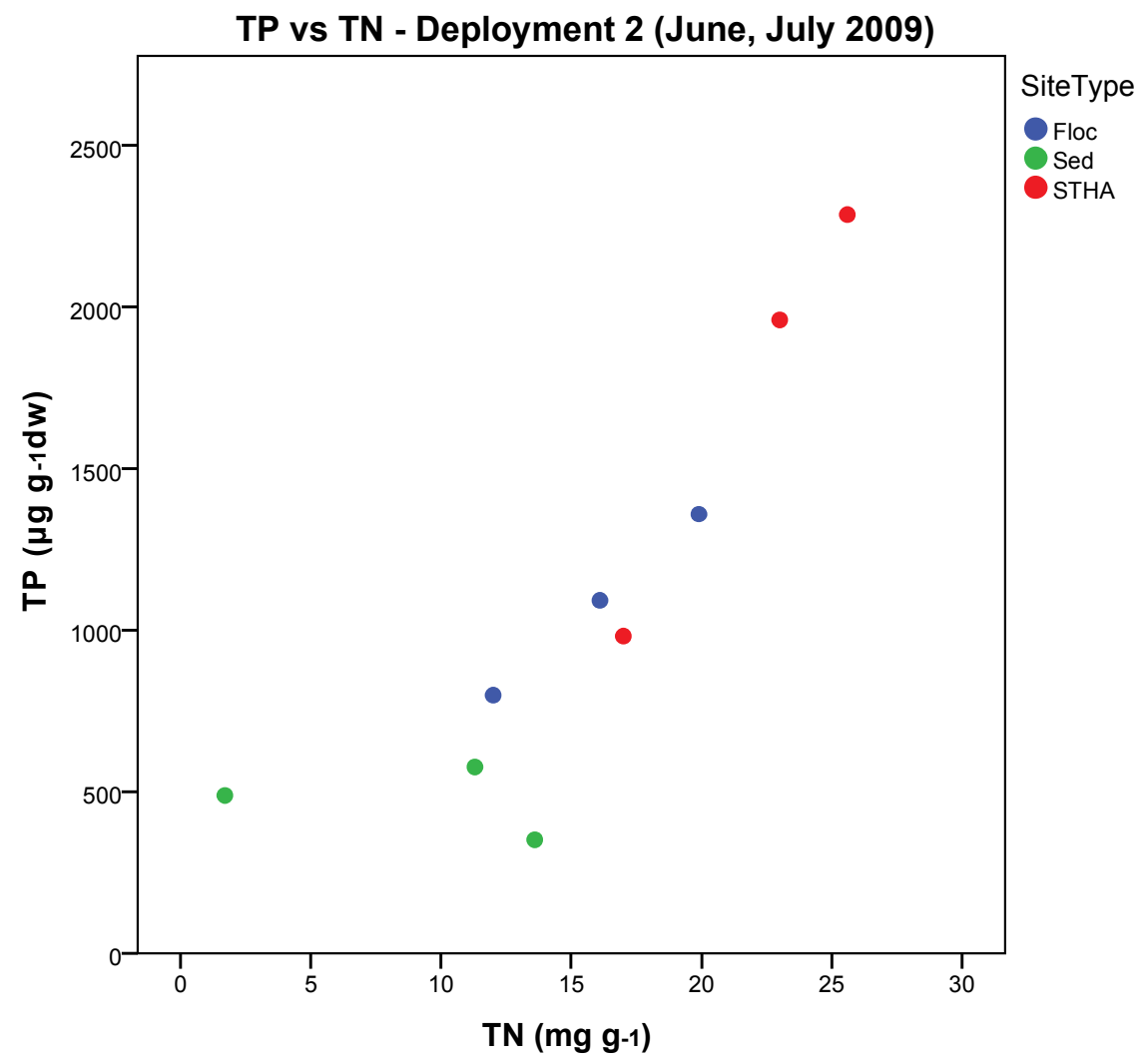




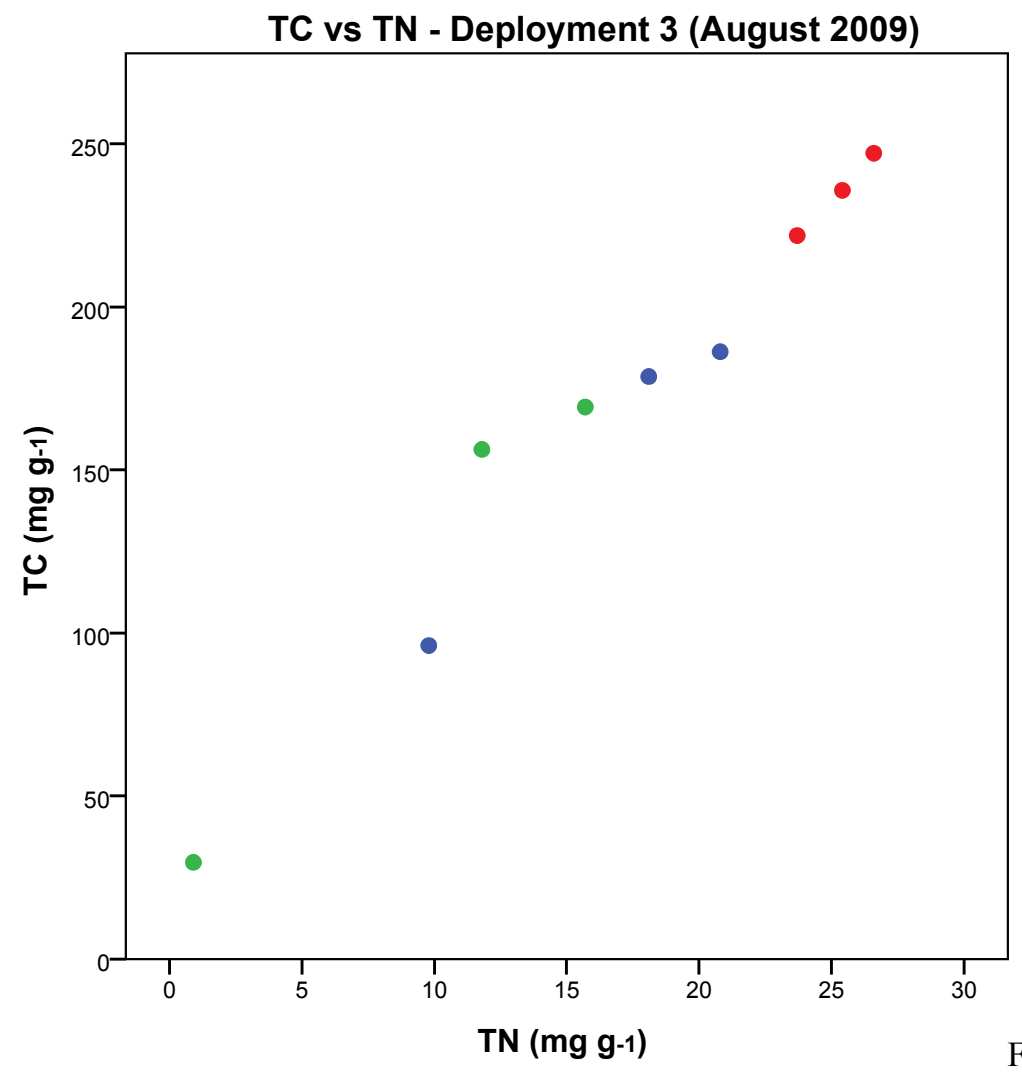

SiteType
Floc

Sloc

STHA

FIGURE A38 TC vs. TN vs TP

TP vs TN - Deployment 3 (August,2009)

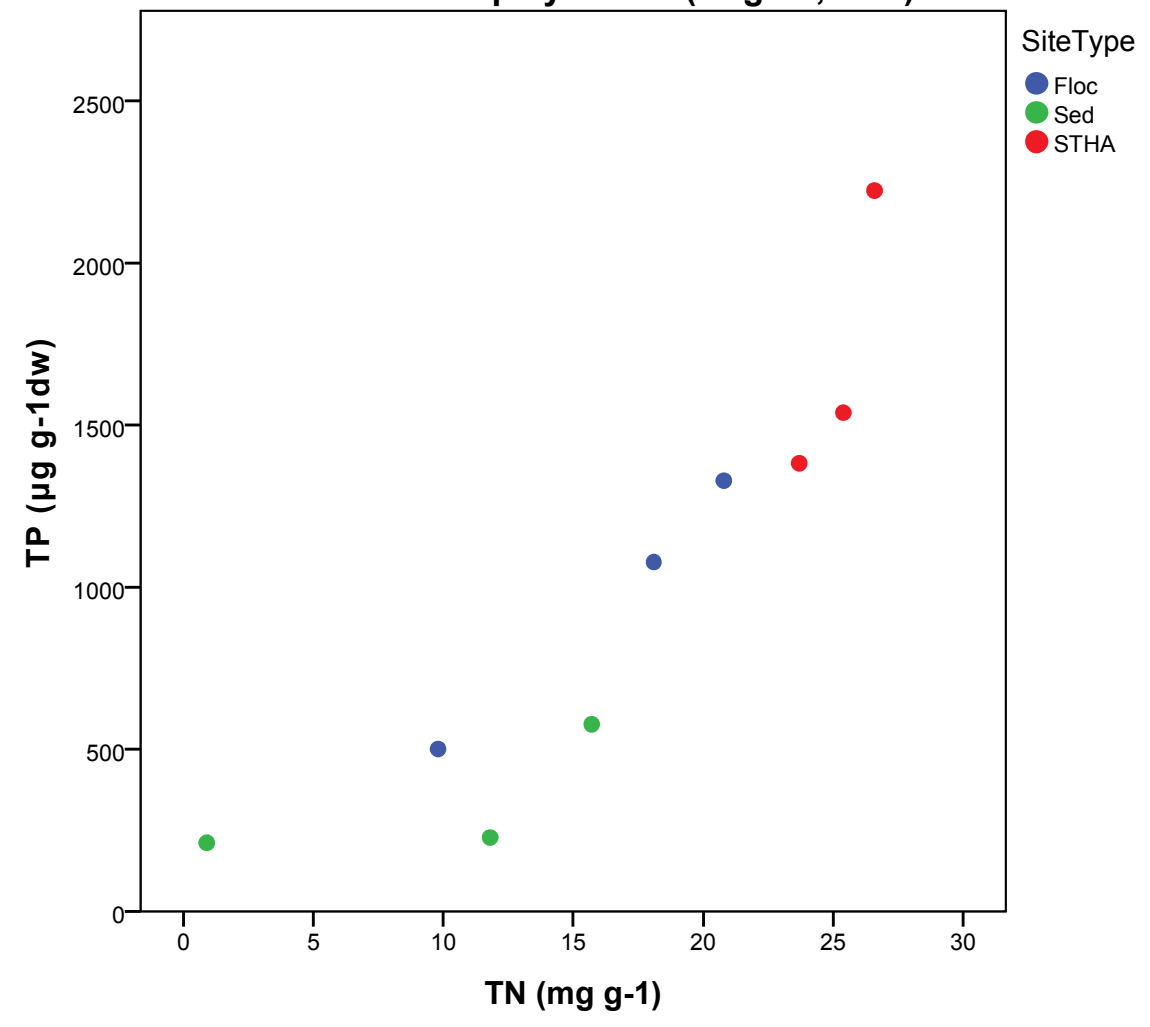




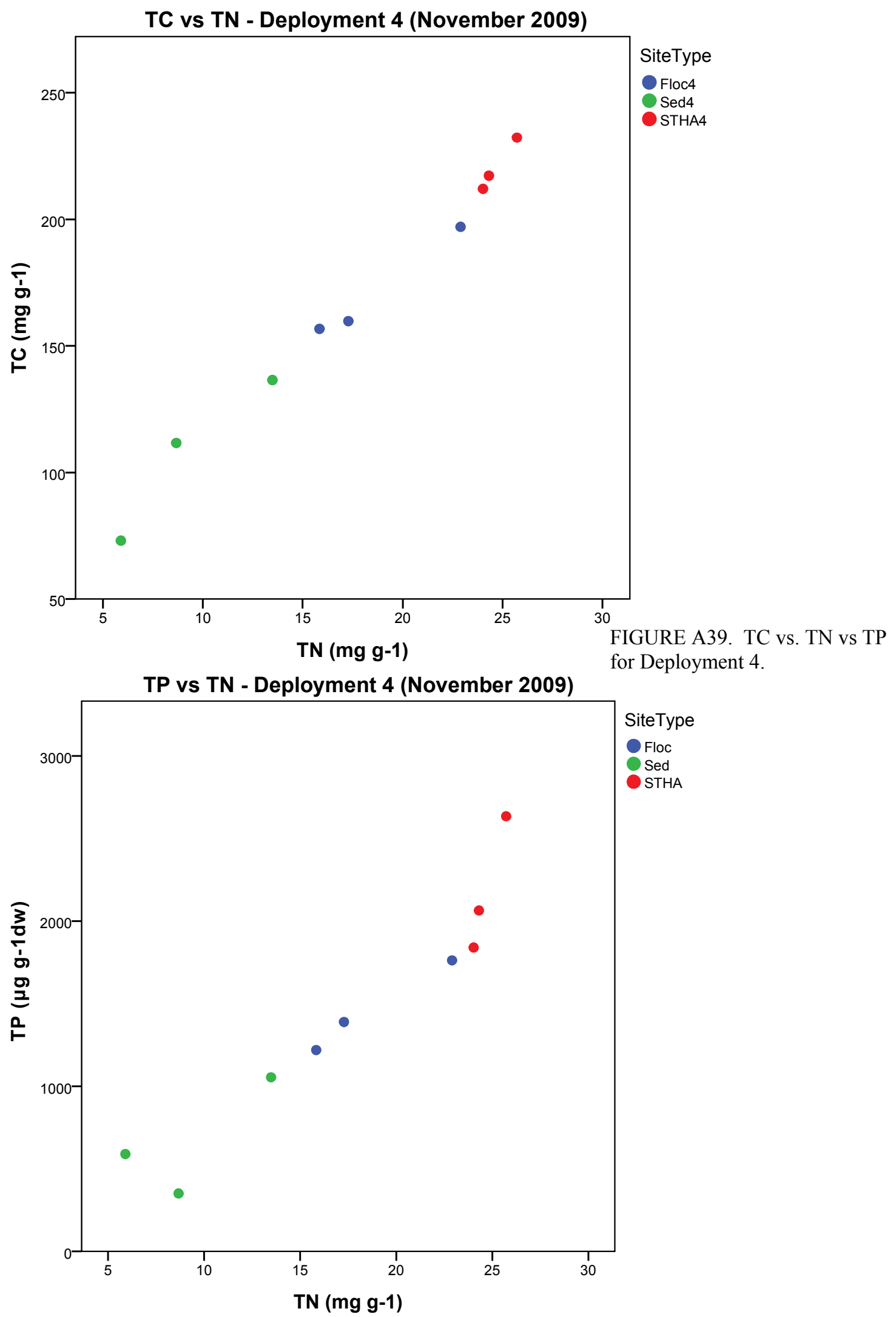




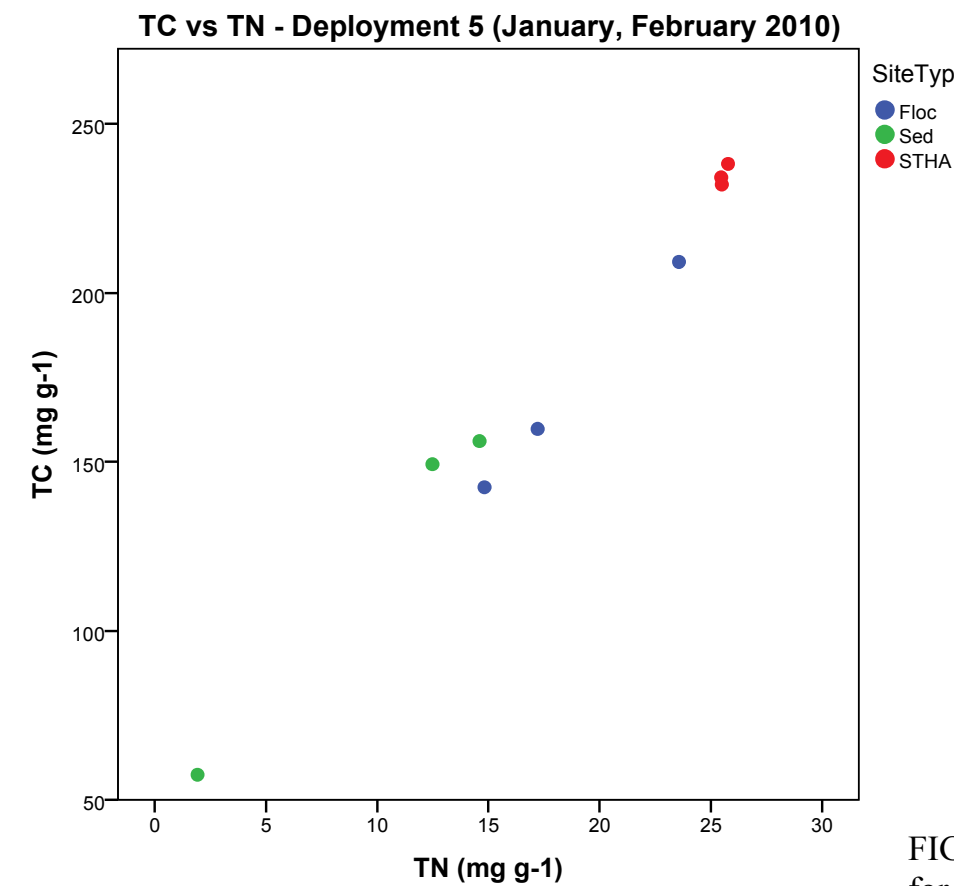

FIGURE A40. TC vs. TN vs TP for Deployment 5.

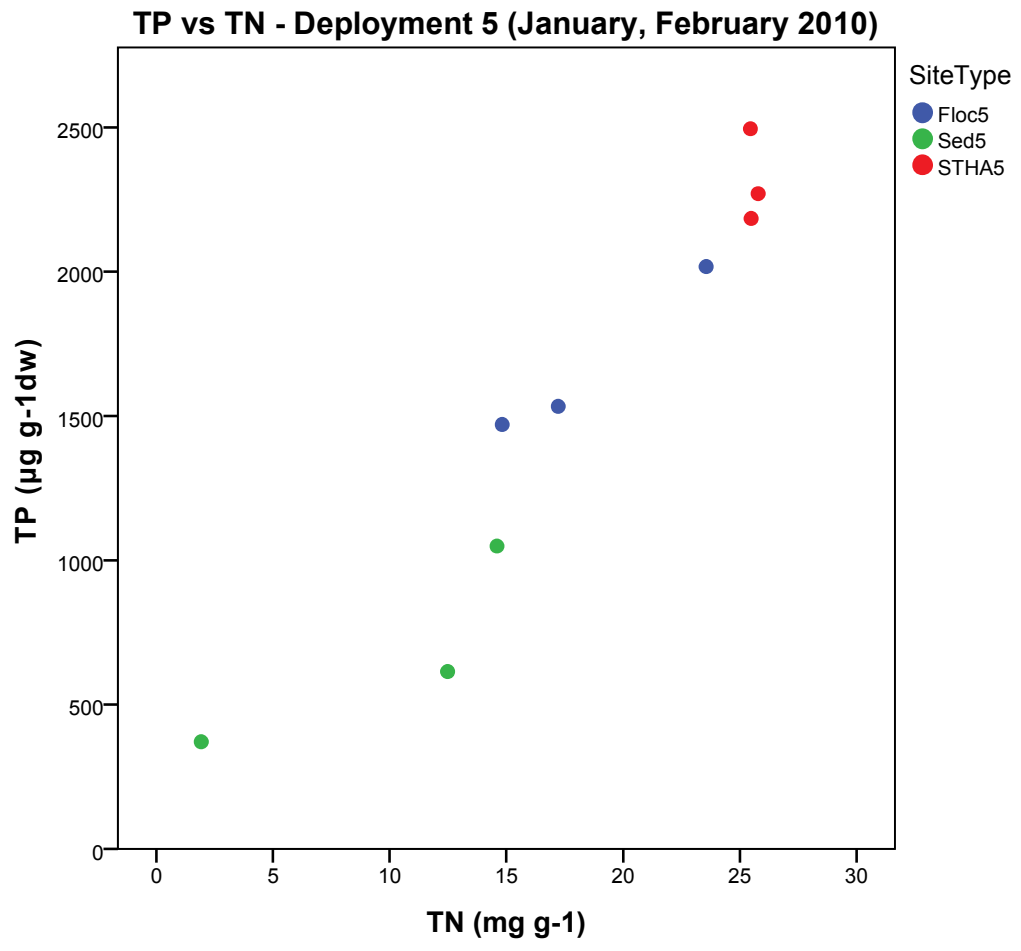



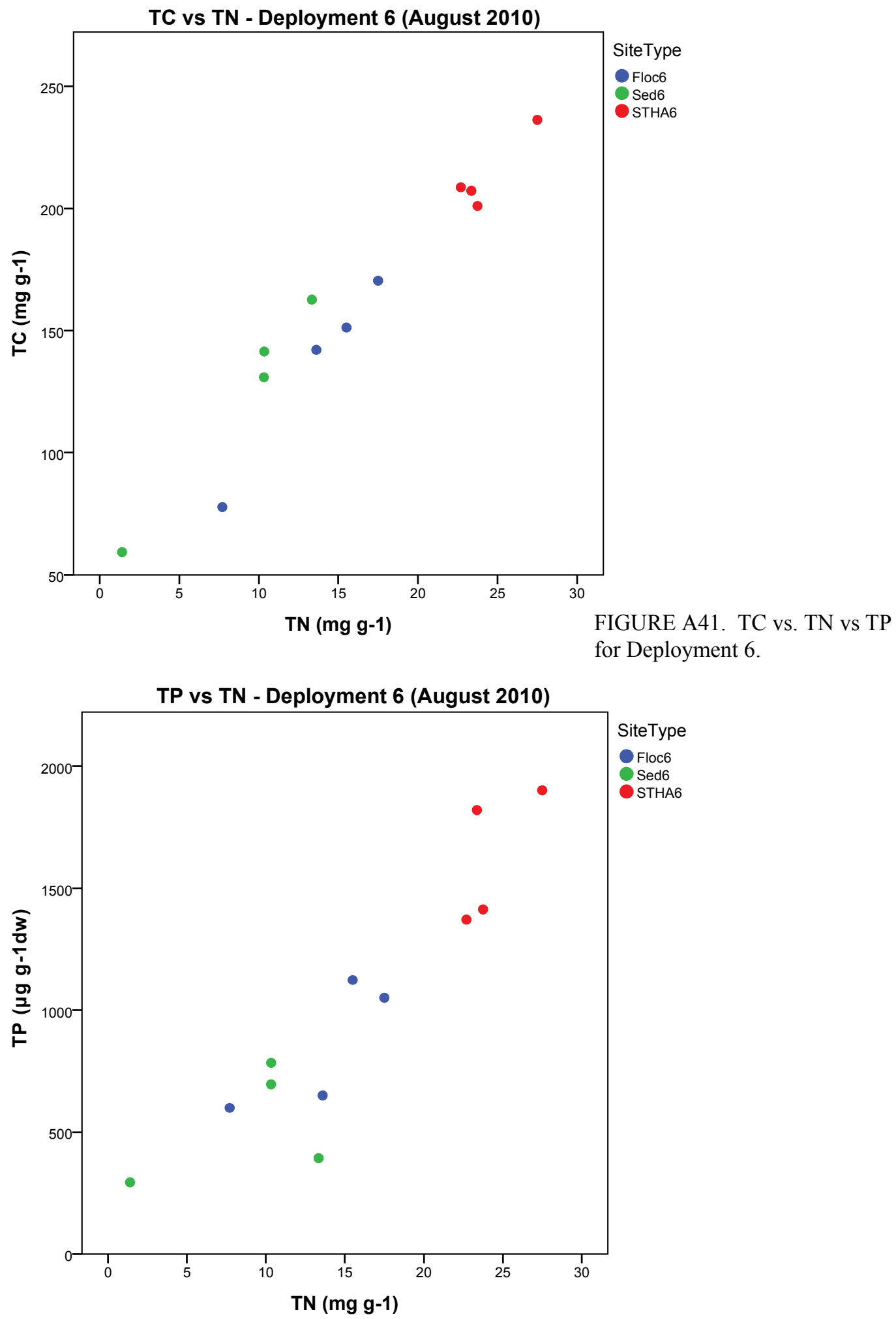

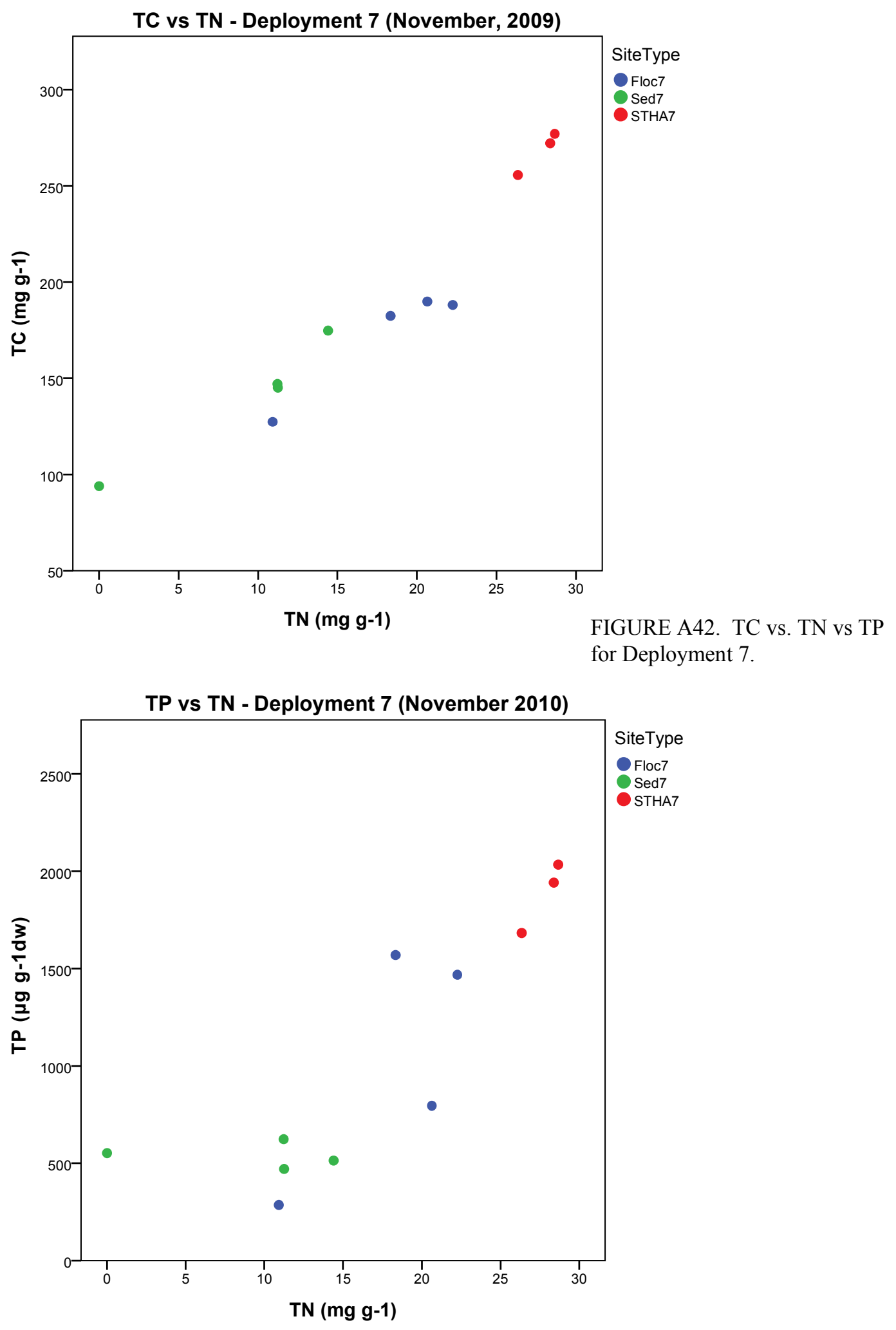


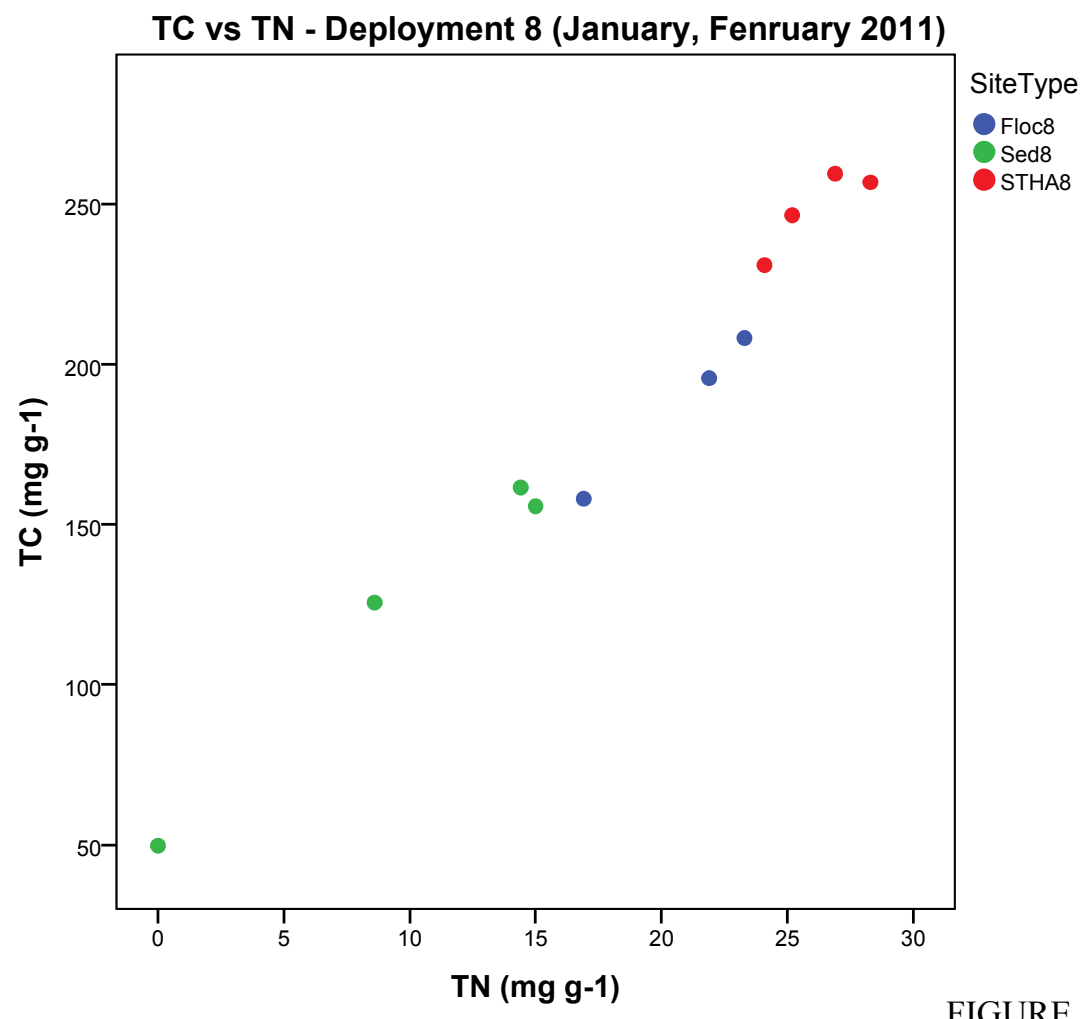

FIGURE A43. TC vs. TN vs TP for Deployment 8.

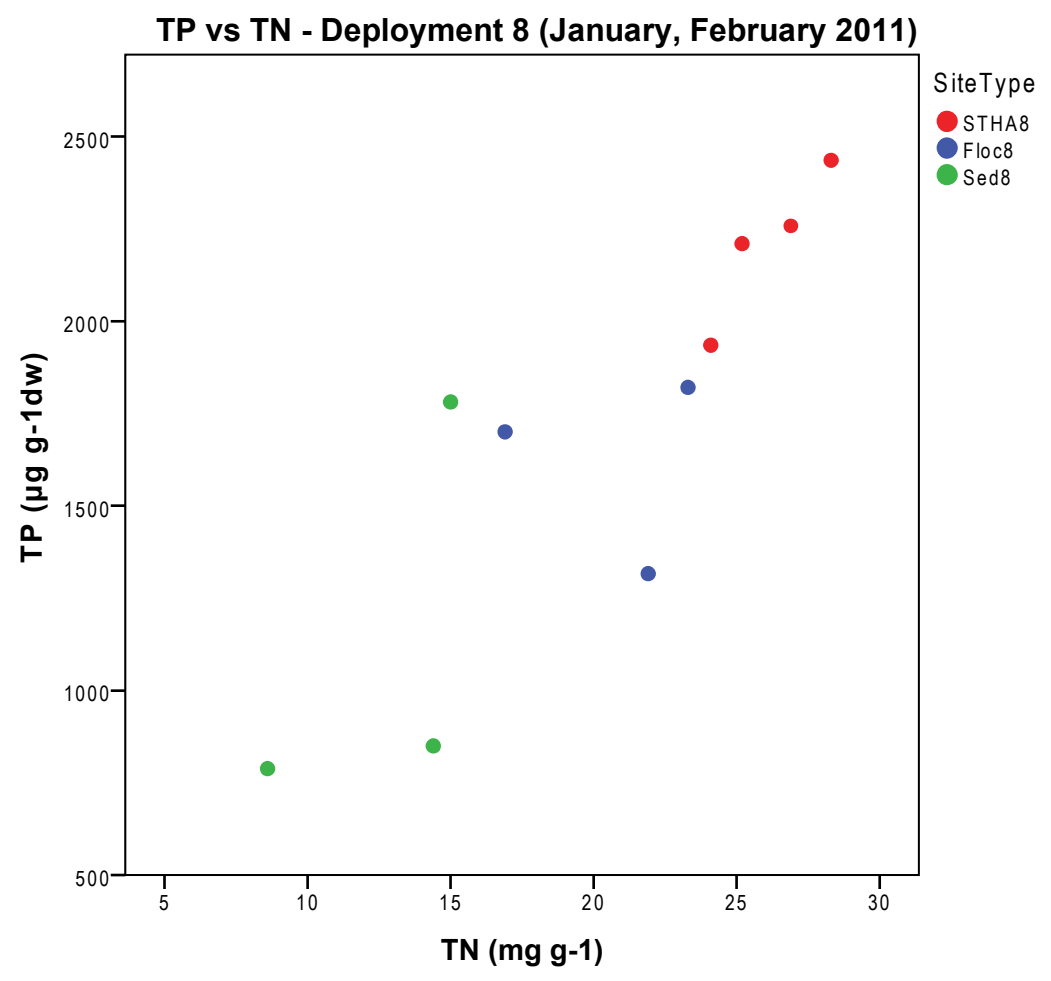



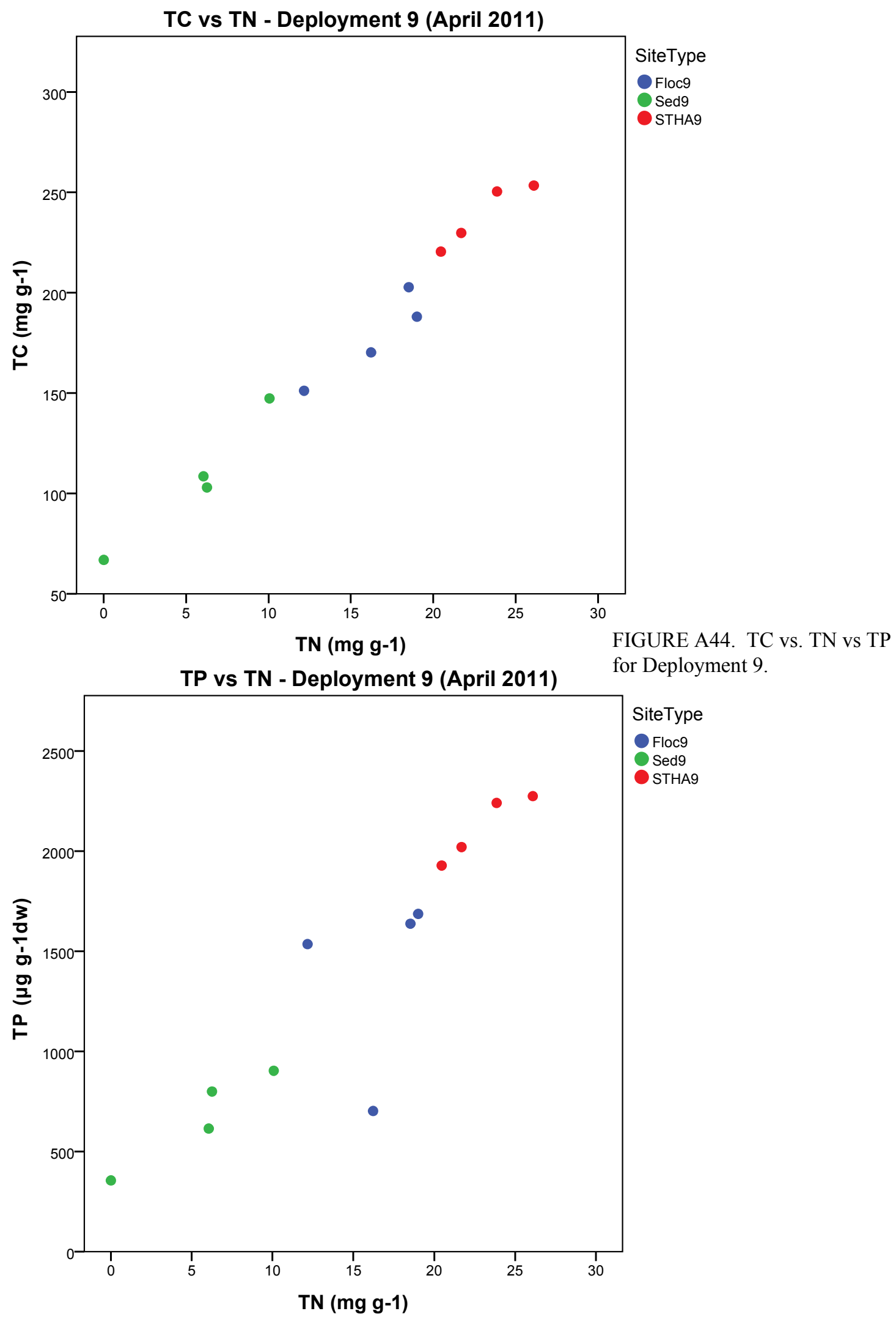


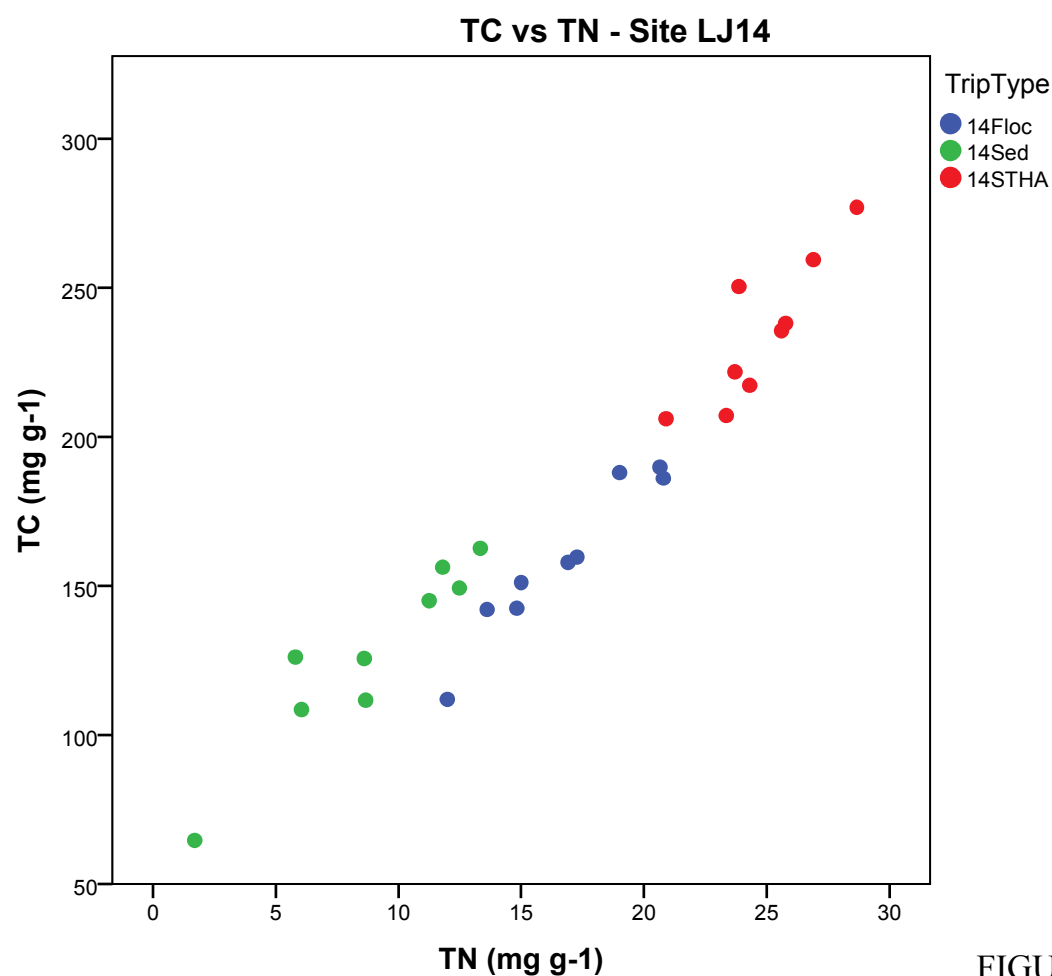

FIGURE A45. TC vs. TN vs TP for site LJ14.

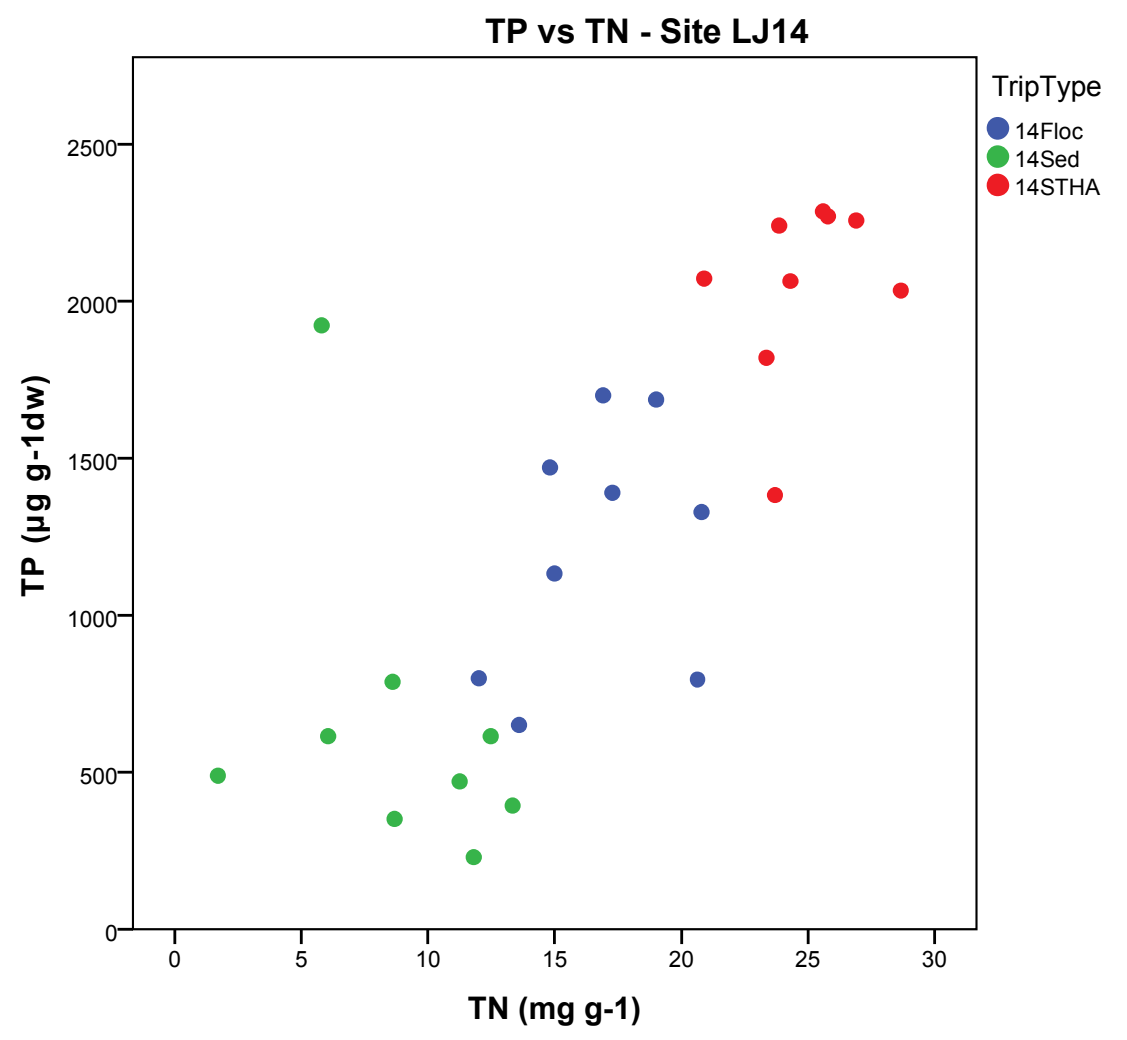




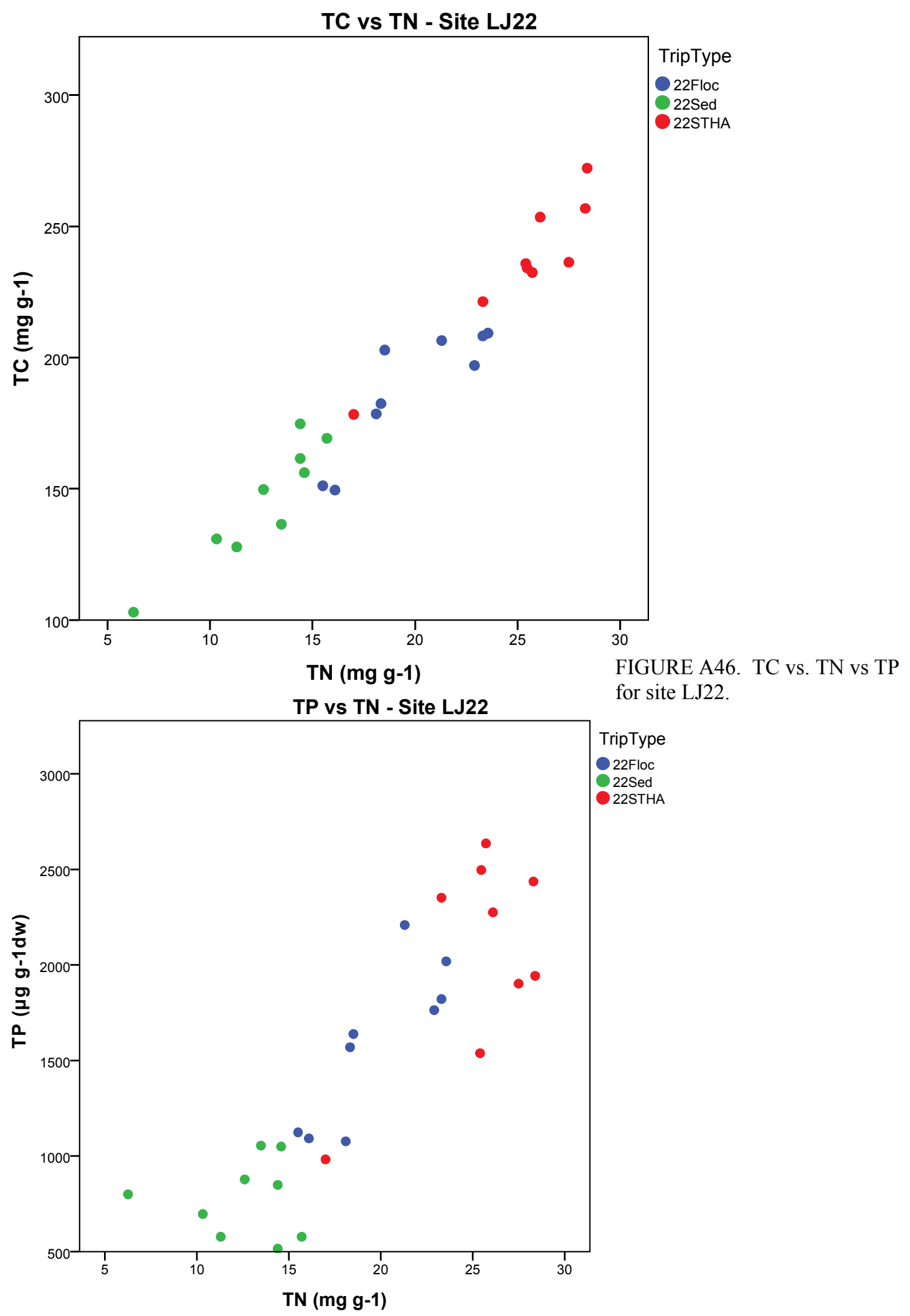




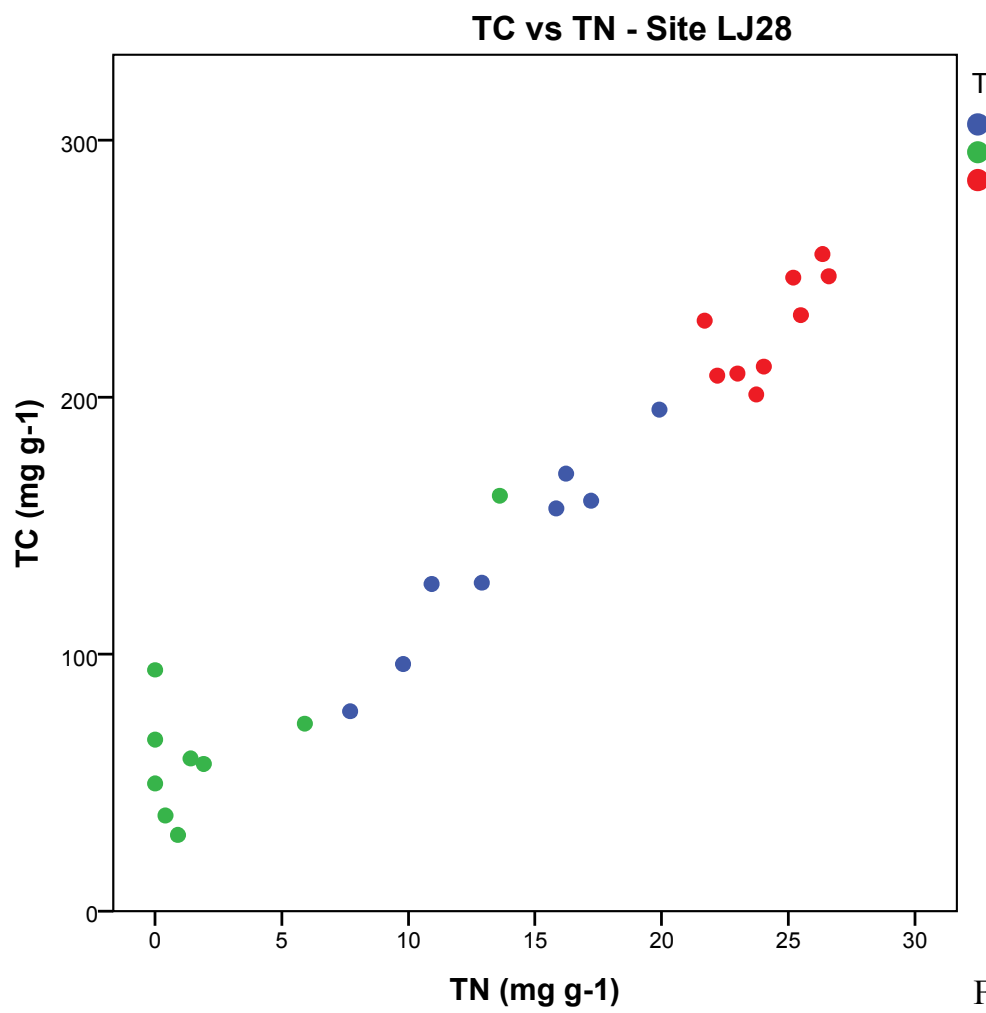

TripType

28Sed

28STHA

FIGURE A47. TC vs. TN vs TP for site LJ28.

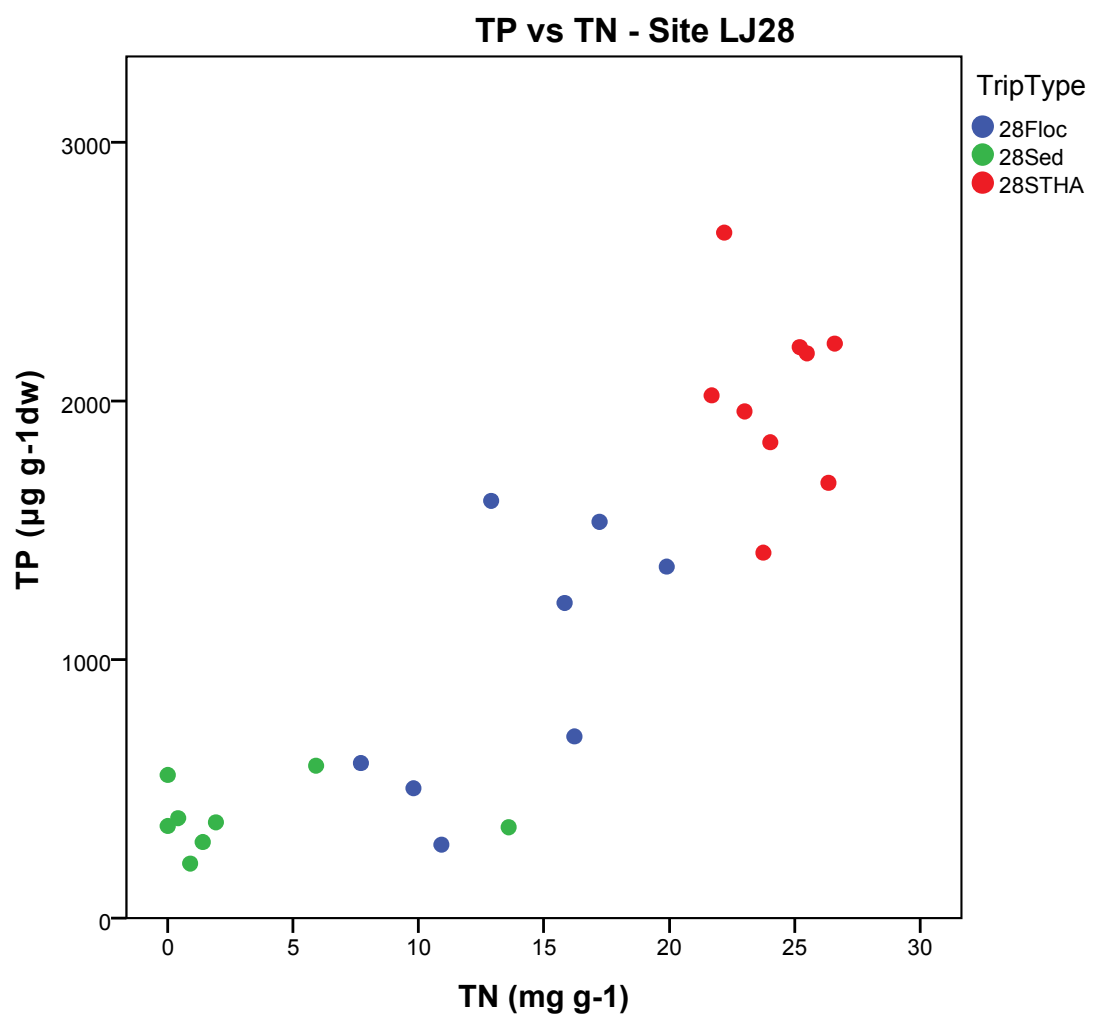




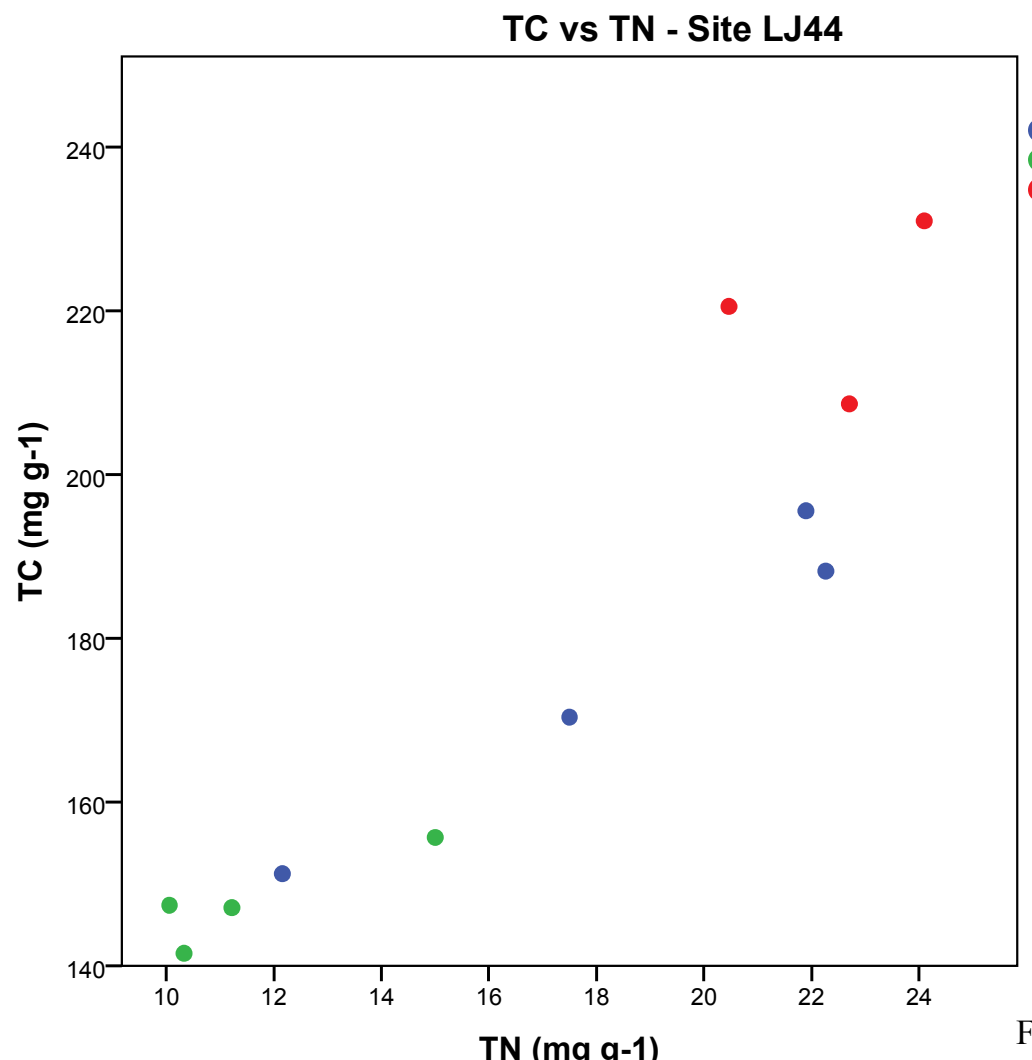

FIGURE A48. TC vs. TN vs TP for site LJ44.

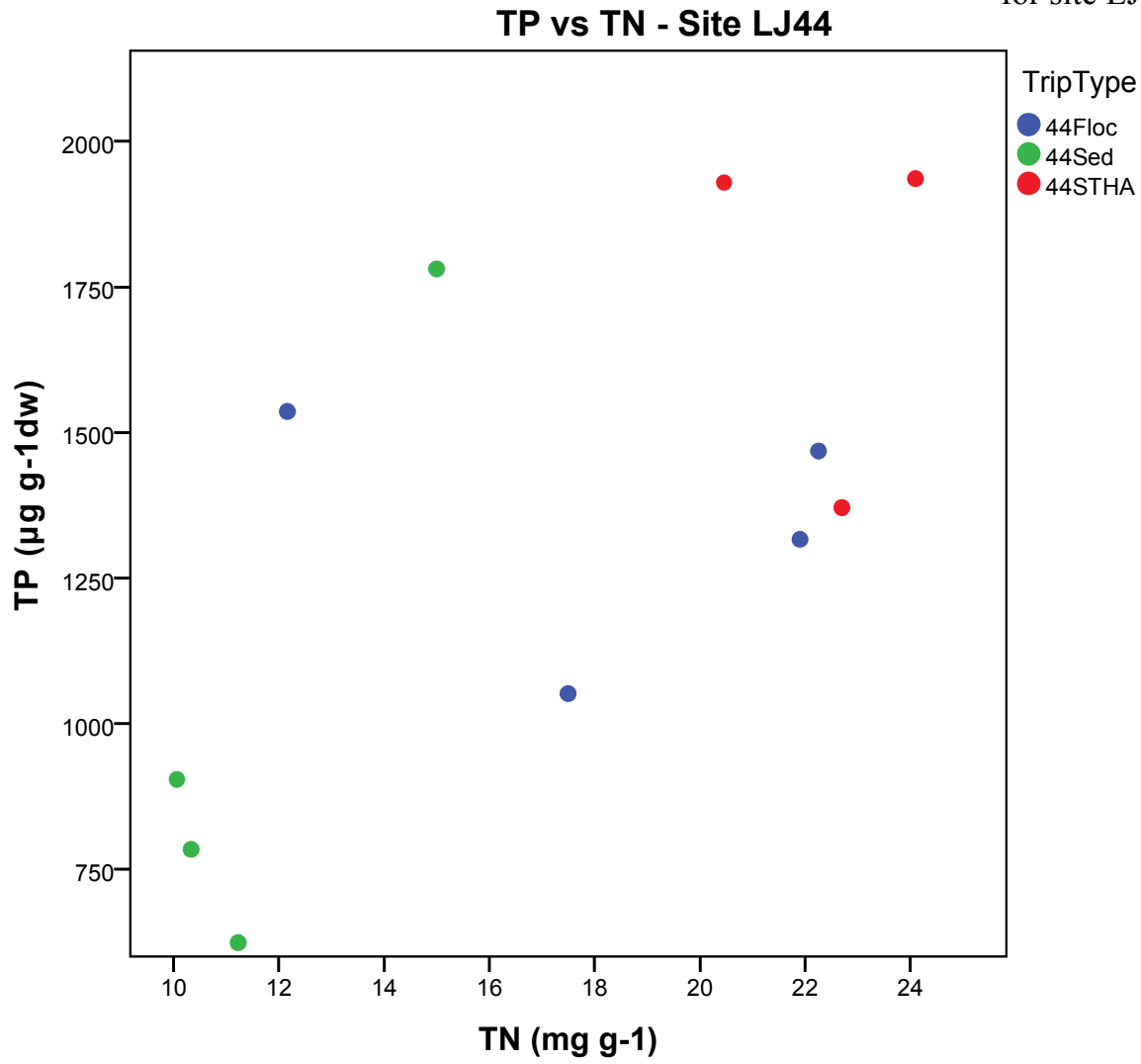




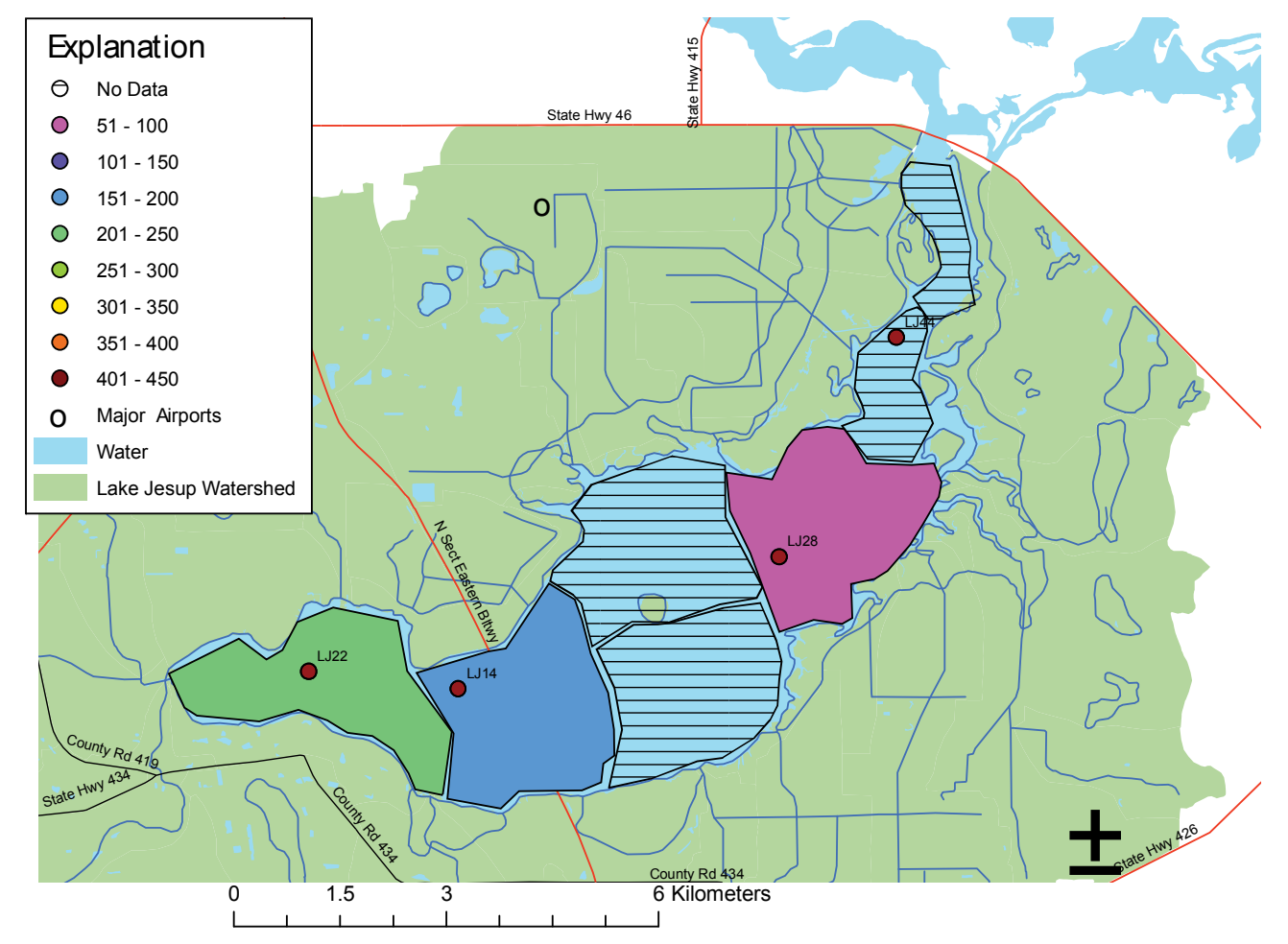

FIGURE A49. Spatial variations of MAR for Deployment 3. 


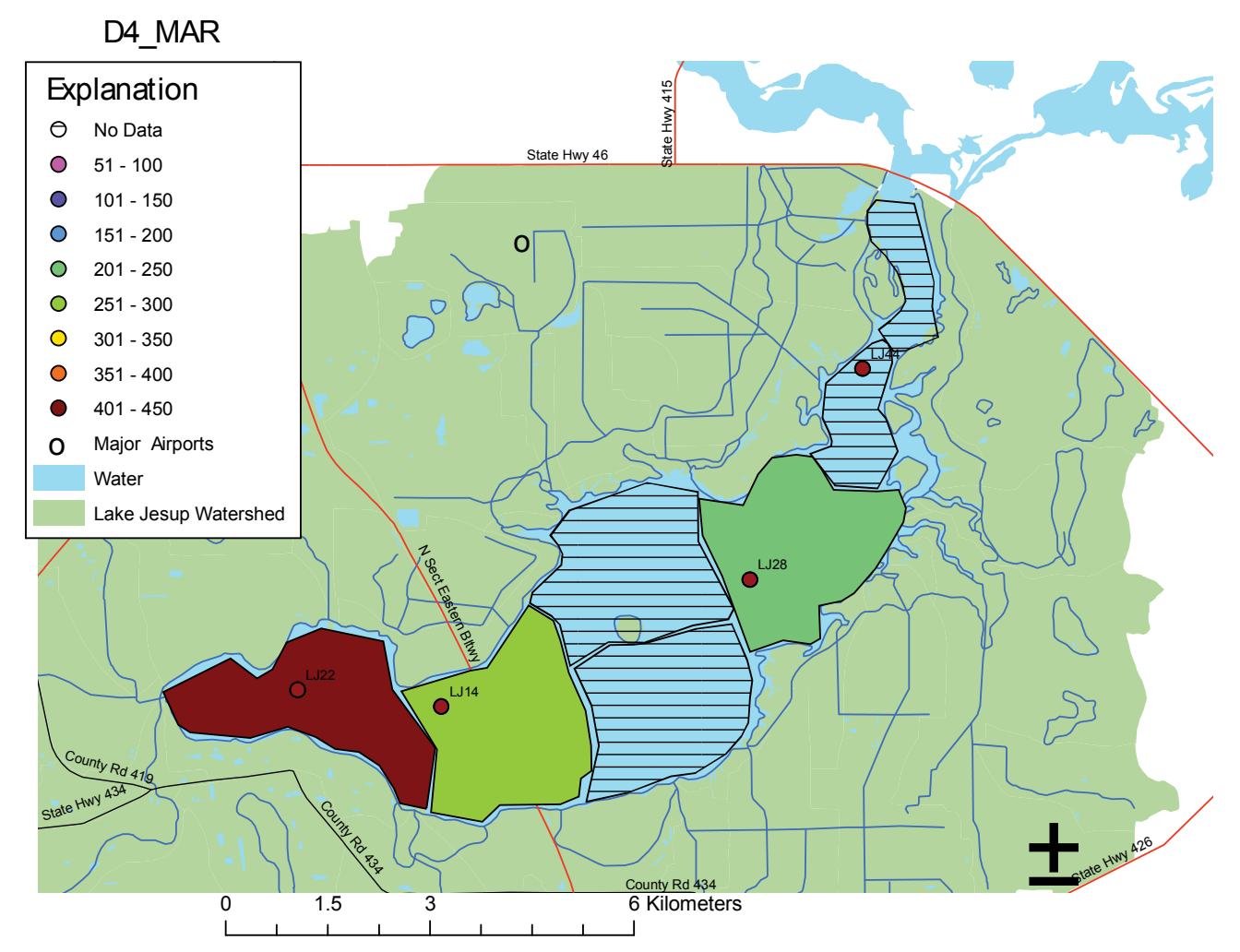

FIGURE A50. Spatial variations of MAR for Deployment 4. 


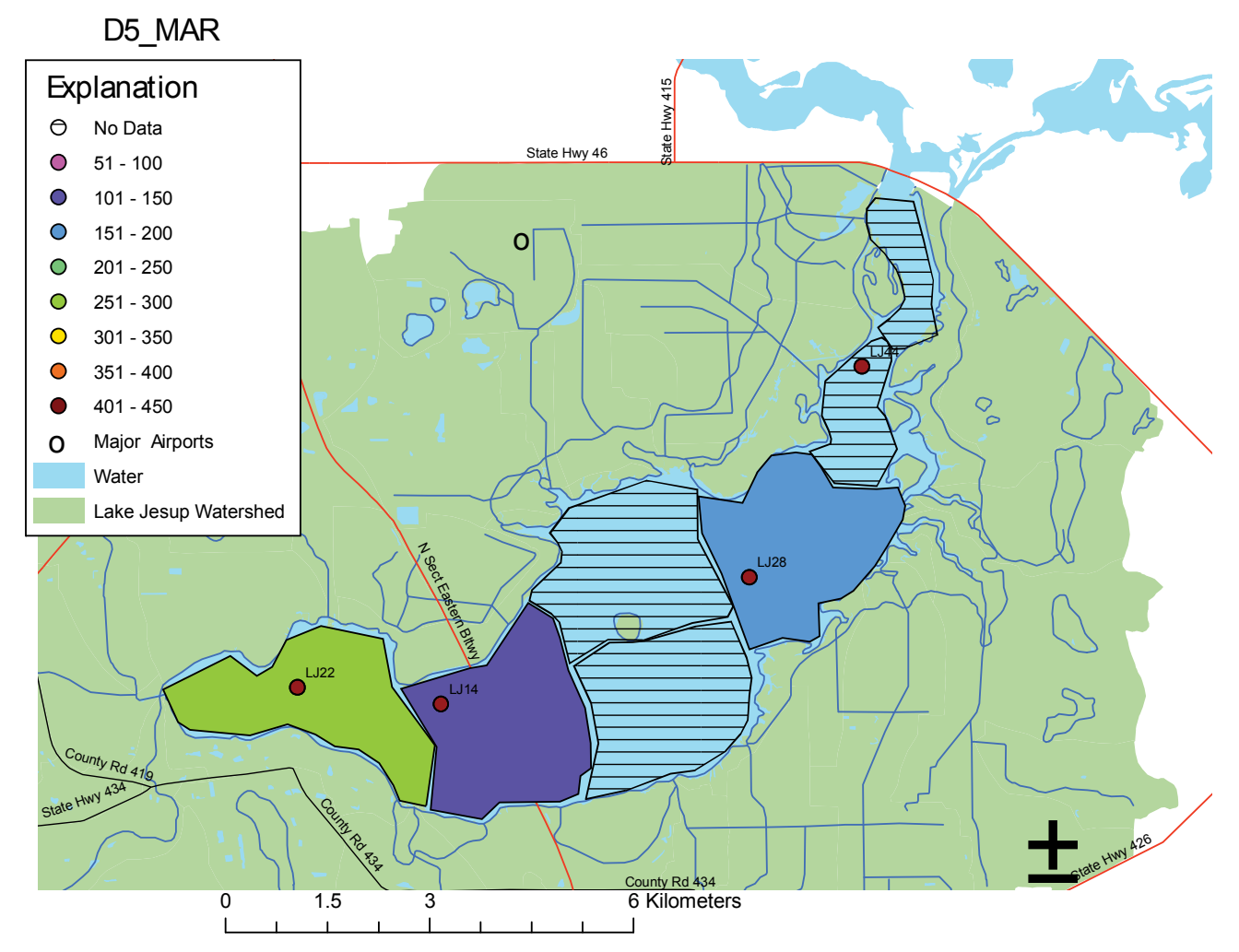

FIGURE A51. Spatial variations of MAR for Deployment 5. 


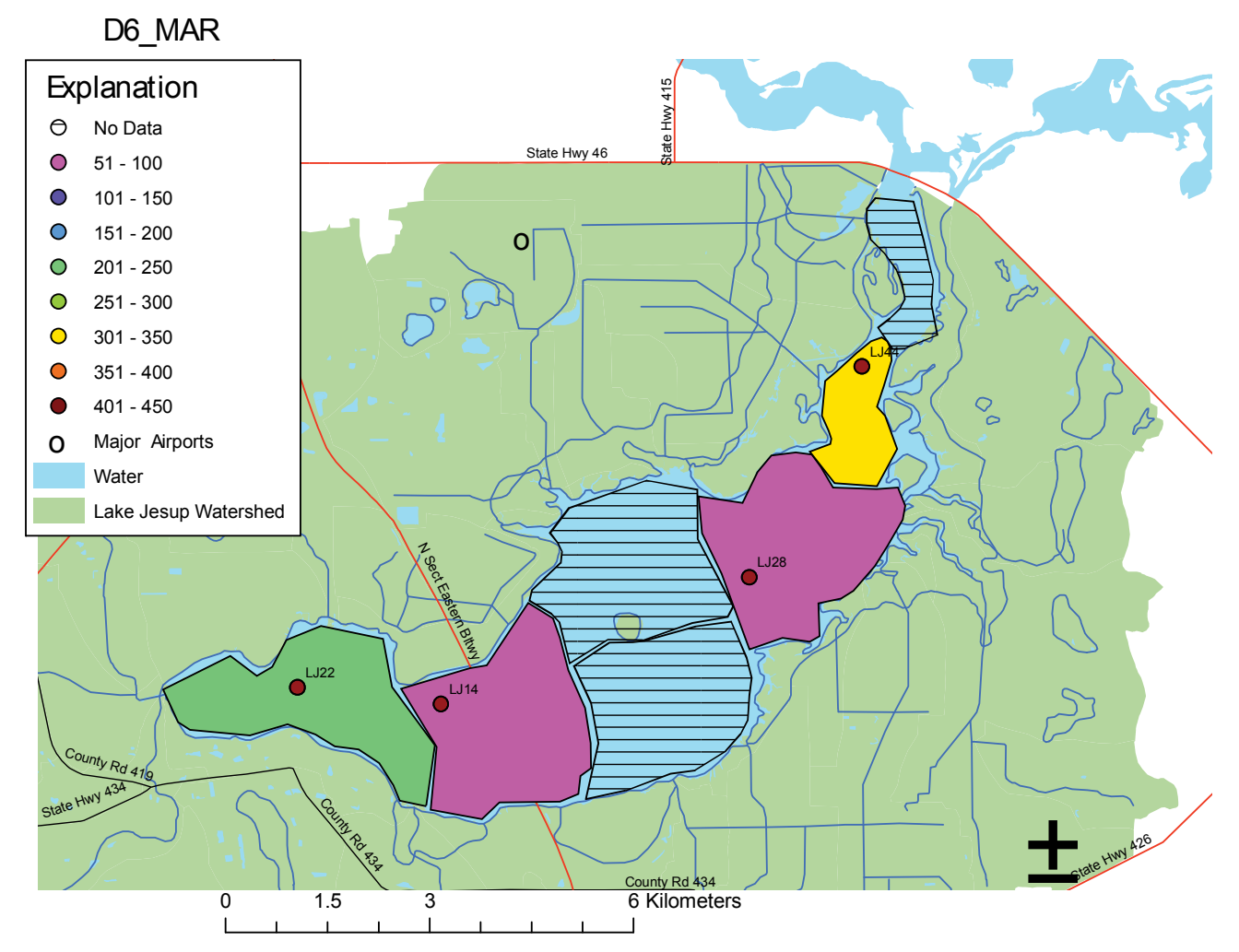

FIGURE A52. Spatial variations of MAR for Deployment 6. 


\section{D7_MAR}

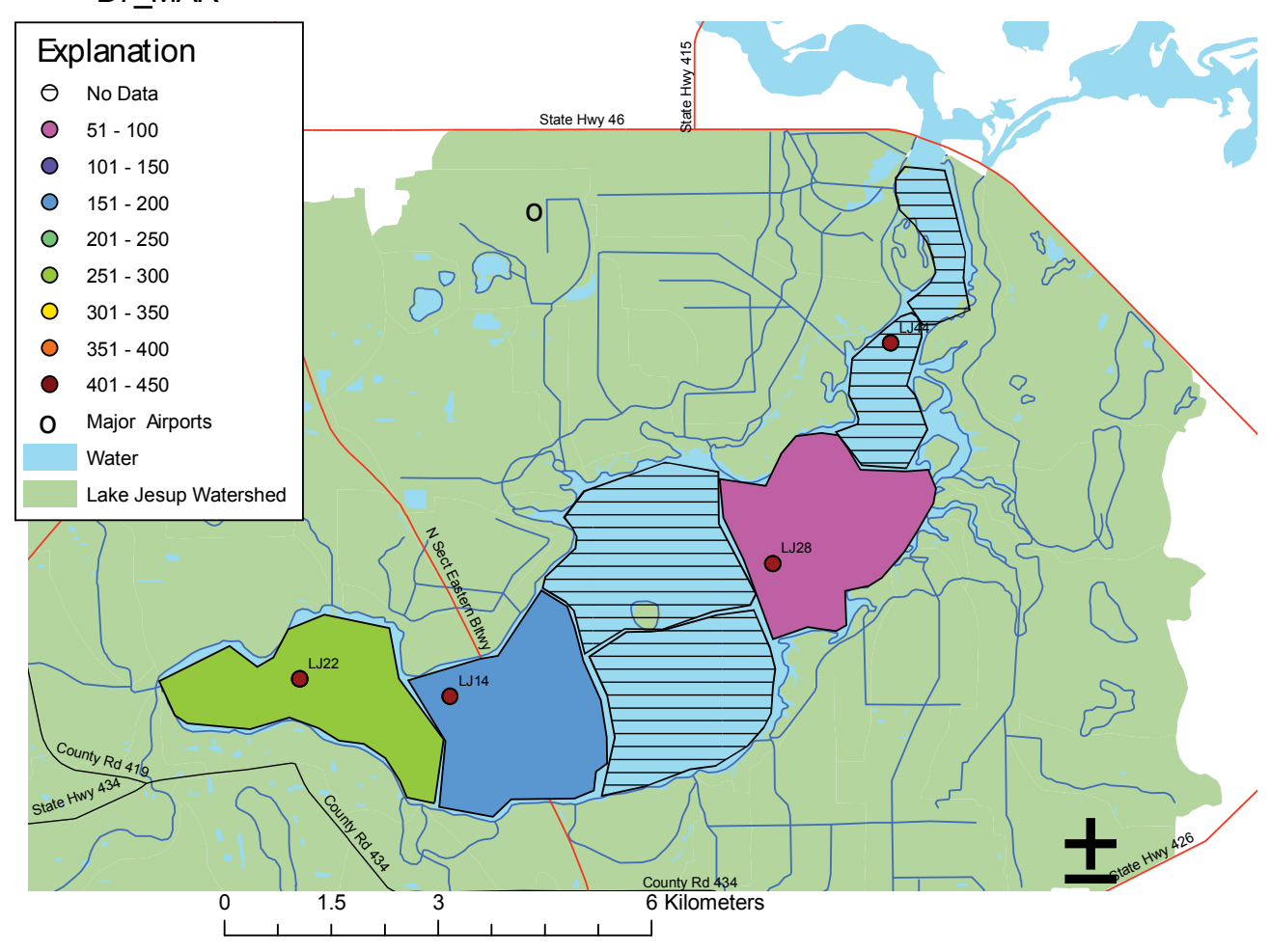

FIGURE A52. Spatial variations of MAR for Deployment 7. 


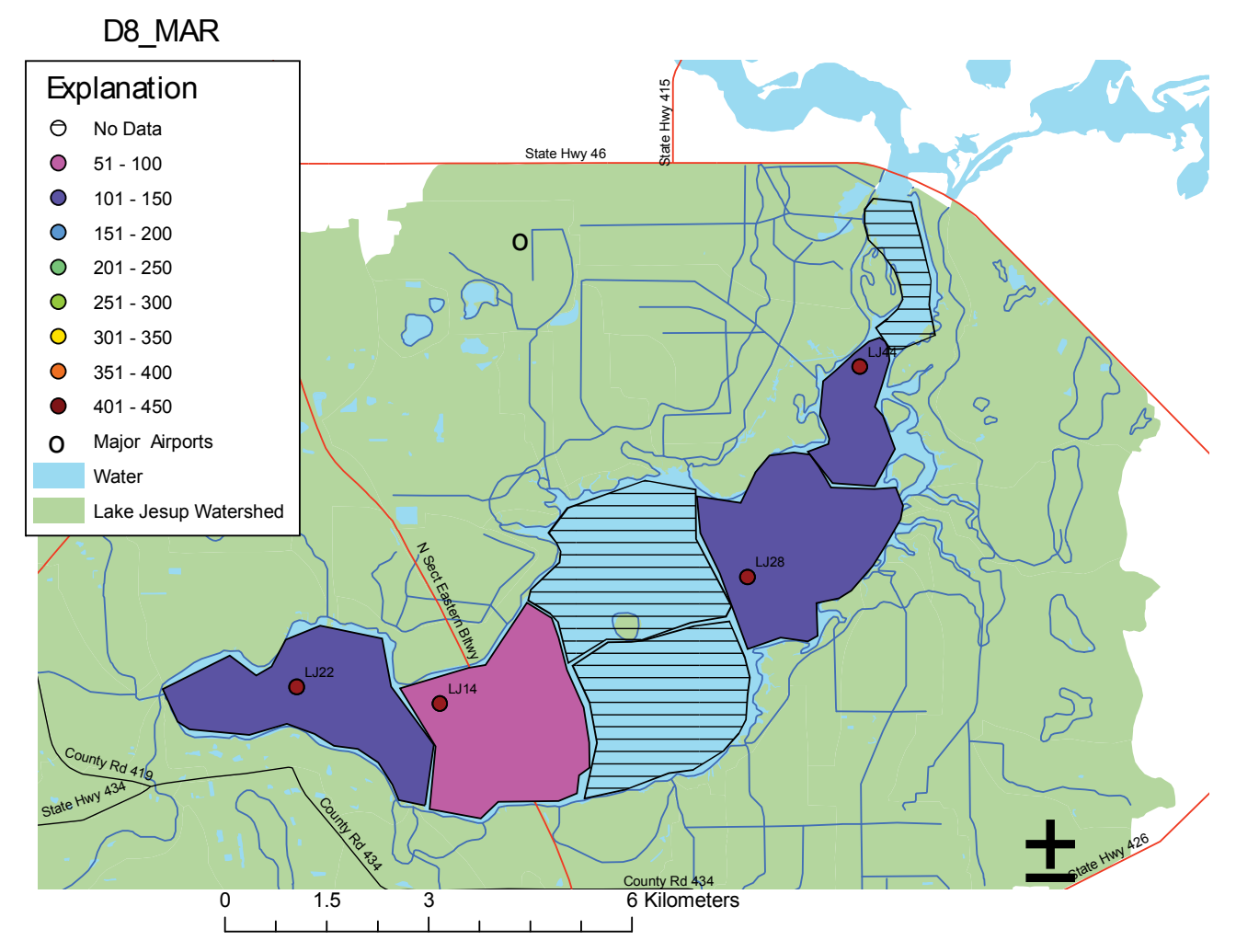

FIGURE A53. Spatial variations of MAR for Deployment 8. 


\section{D9 MAR}

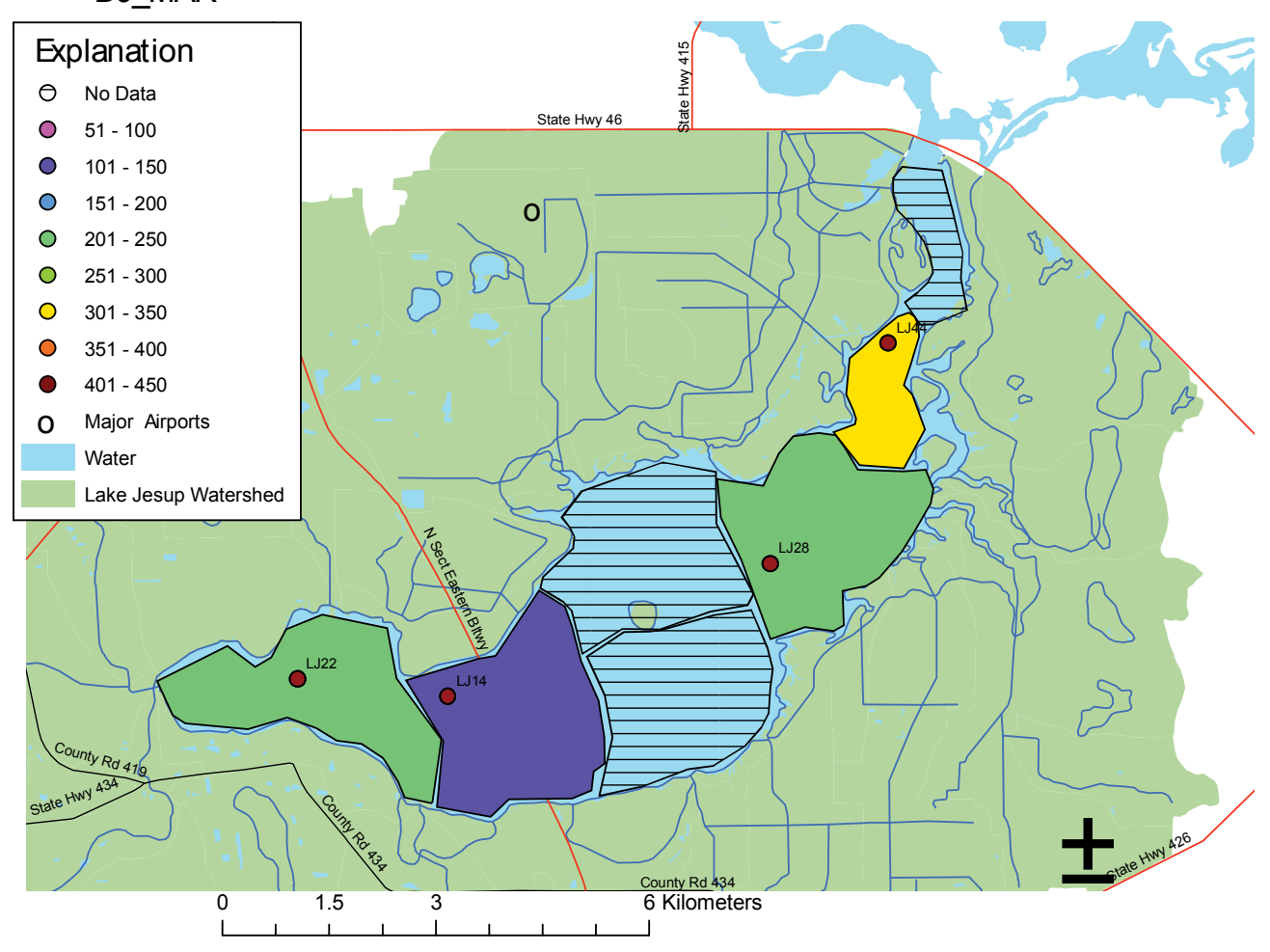

FIGURE A54. Spatial variations of MAR for Deployment 8. 


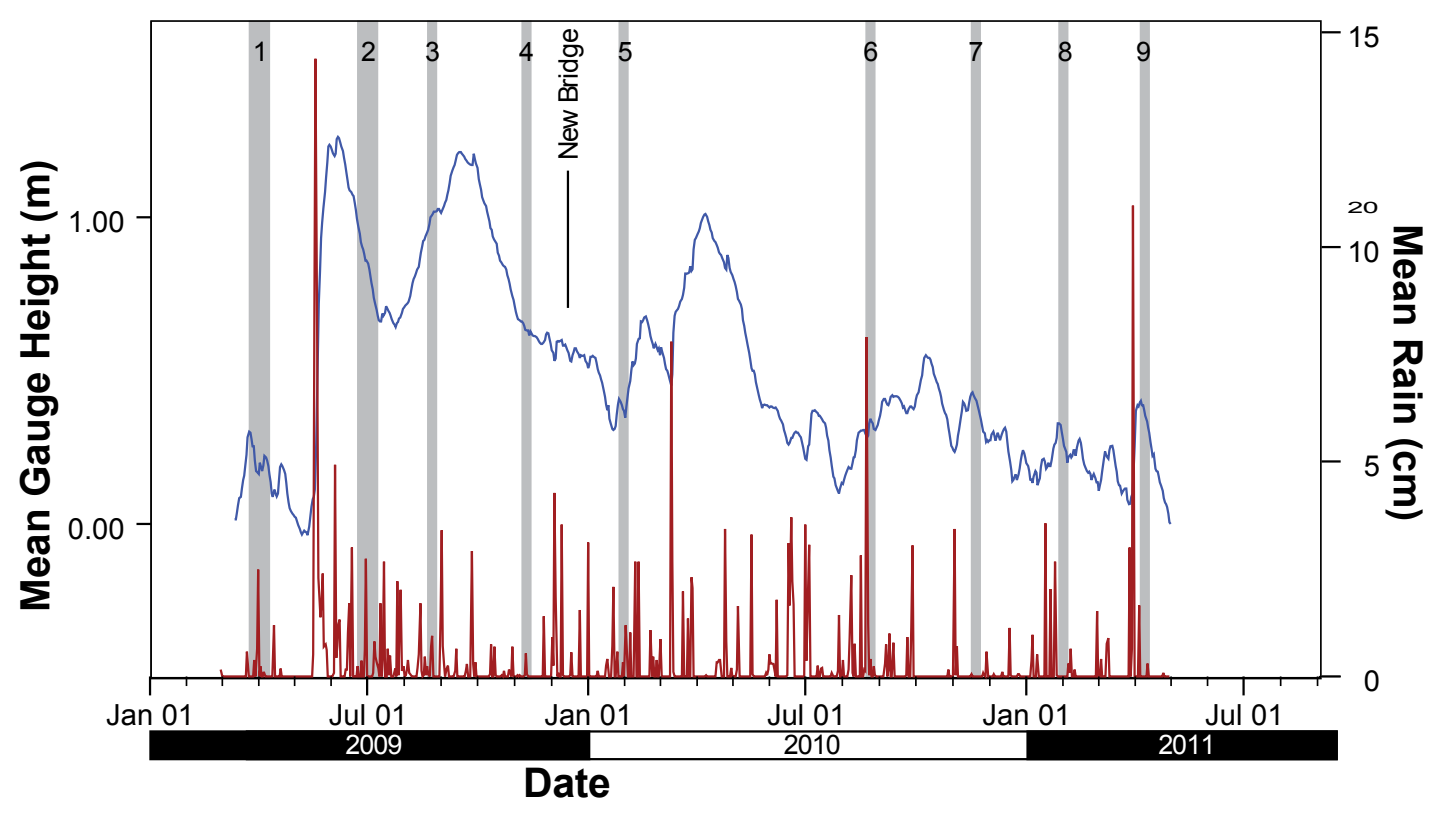

FIGURE A55. Lake level (blue) and precipitation (red) for the two year period of project sampling. 


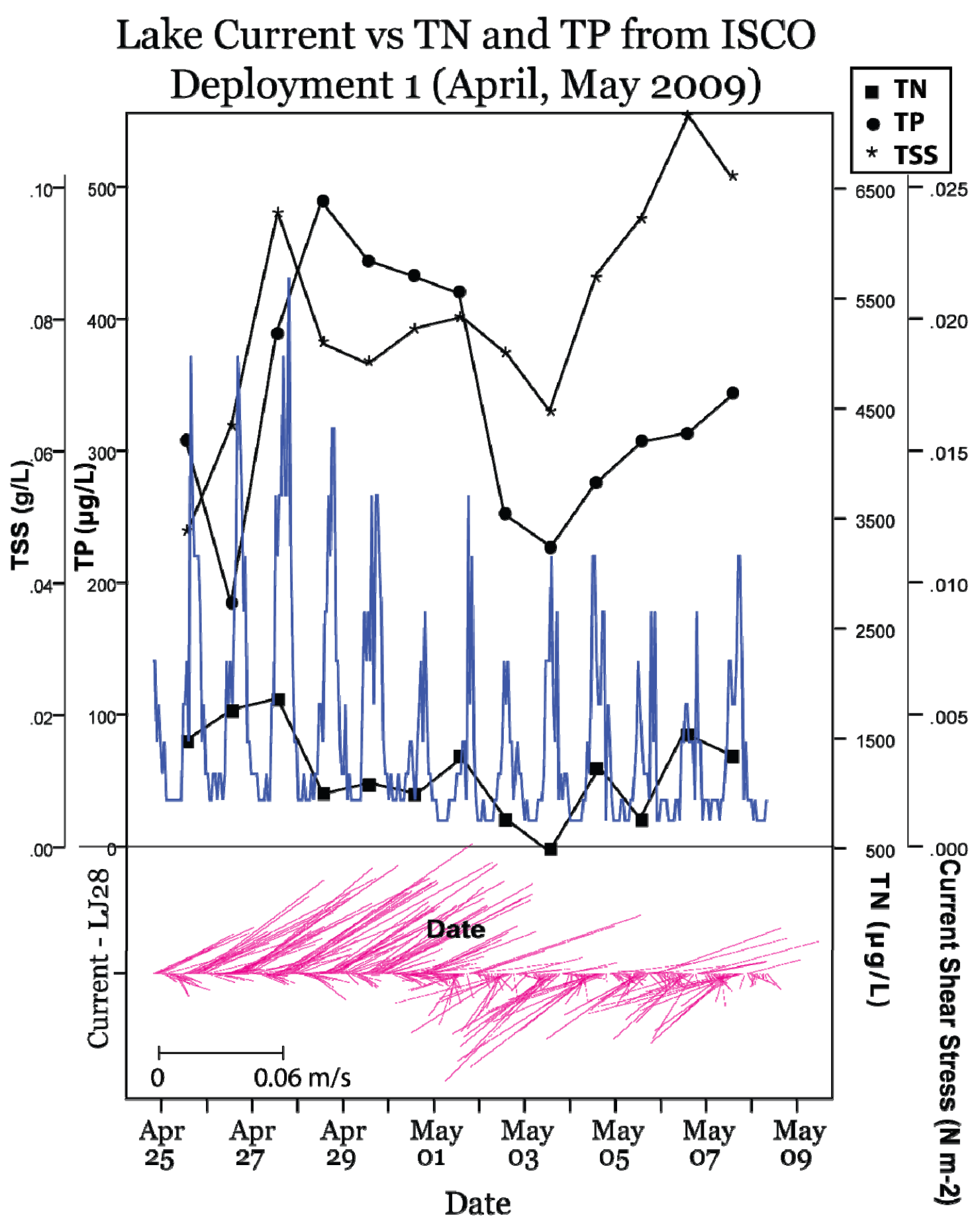

FIGURE A56. Time-series of current shear stress (blue), current stick plots (pink), TP, TN and TSS for Deployment 1. 


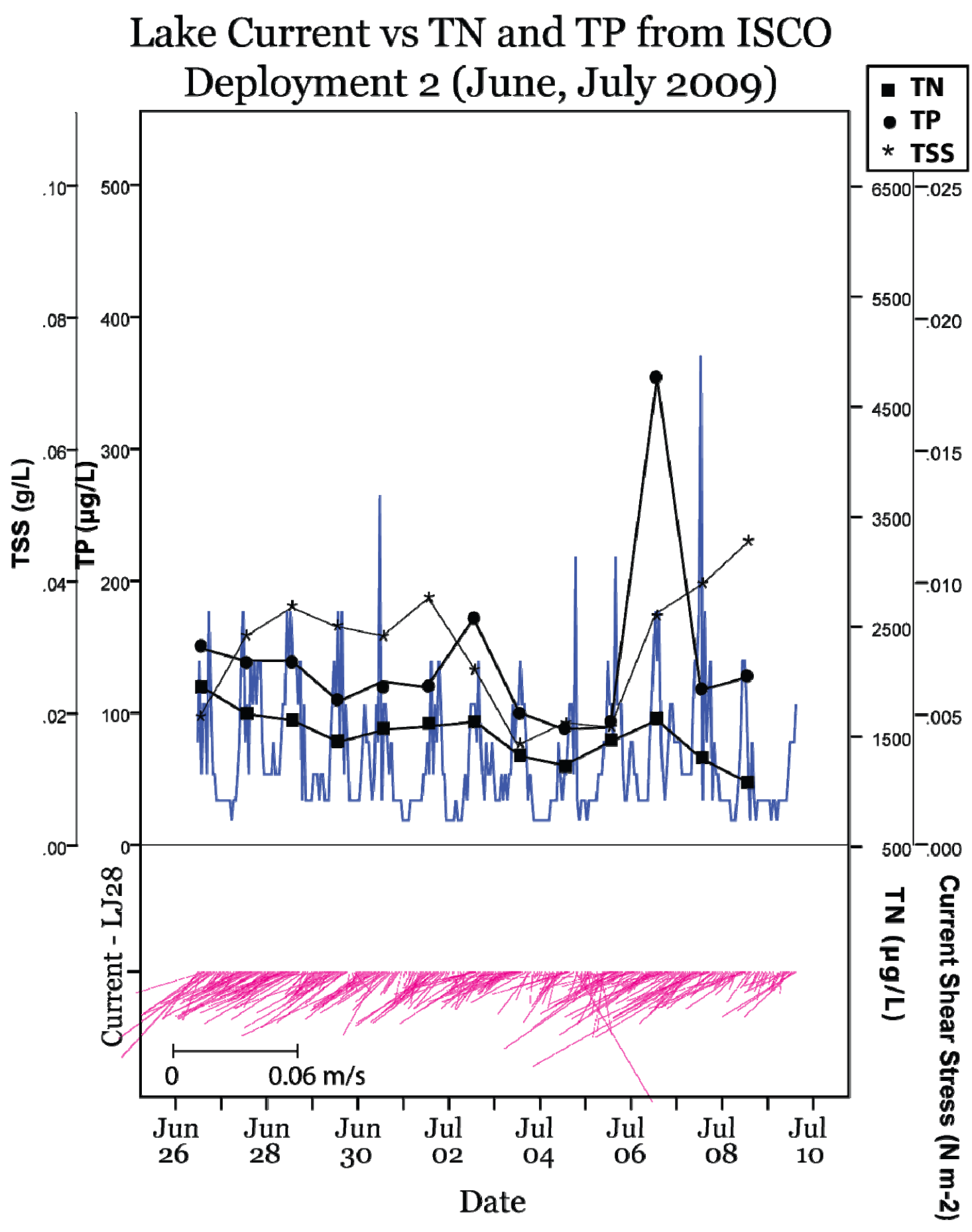

FIGURE A57. Time-series of current shear stress (blue), current stick plots (pink), TP, TN and TSS for Deployment 2. 


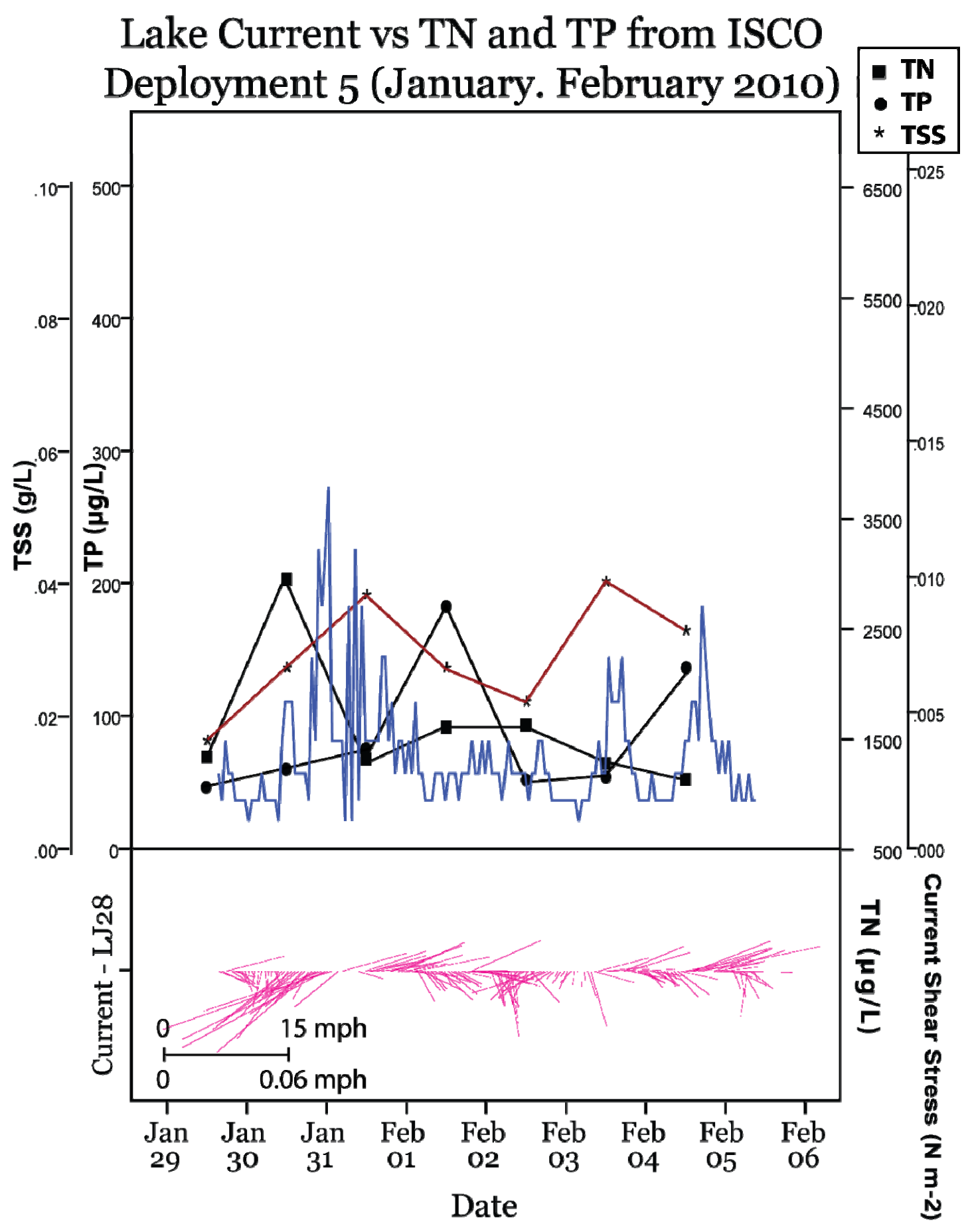

FIGURE A58. Time-series of current shear stress (blue), current stick plots (pink), TP, TN and TSS for Deployment 5. 


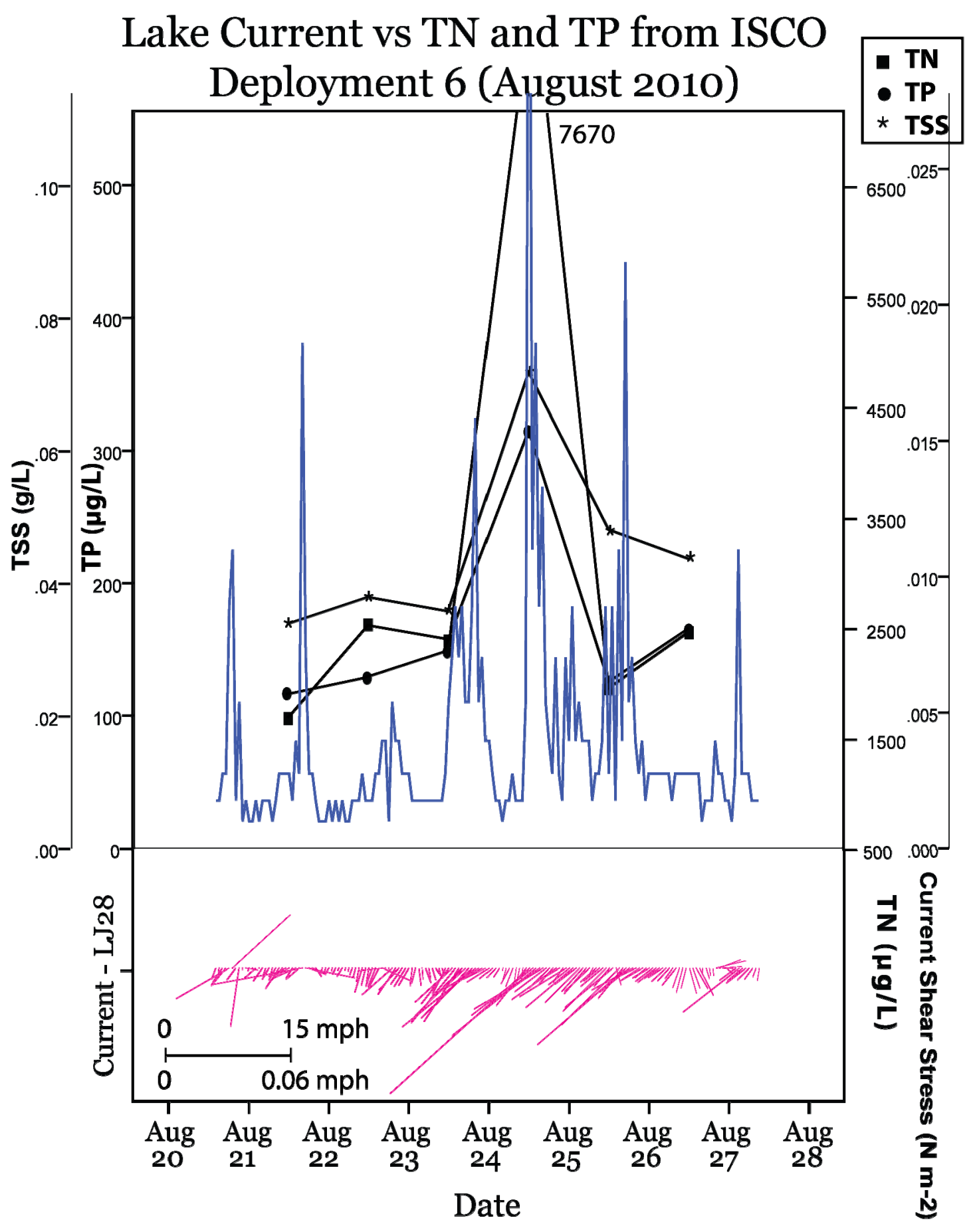

FIGURE A59. Time-series of current shear stress (blue), current stick plots (pink), TP, TN and TSS for Deployment 6. 


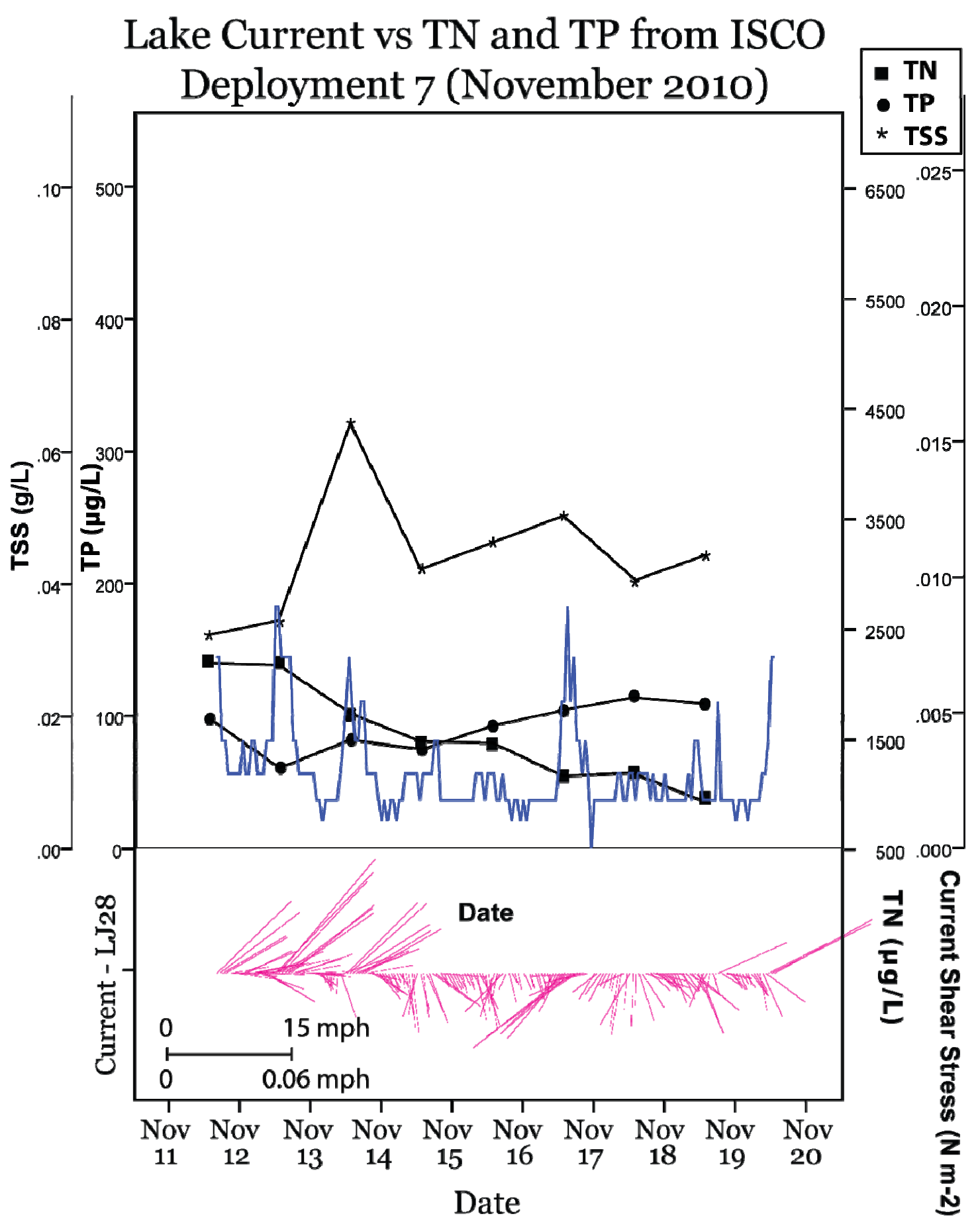

FIGURE A60. Time-series of current shear stress (blue), current stick plots (pink), TP, TN and TSS for Deployment 7. 


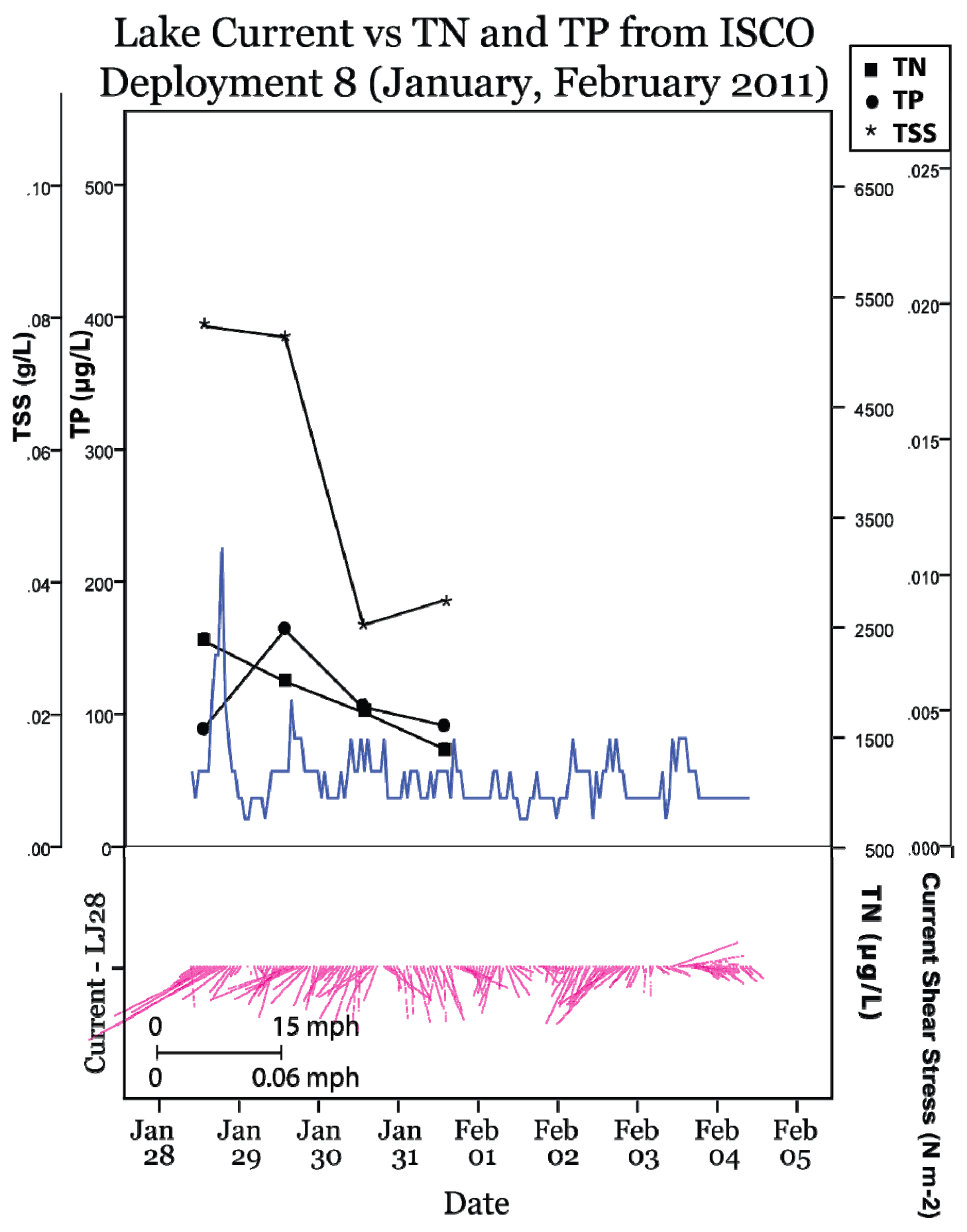

FIGURE A61. Time-series of current shear stress (blue), current stick plots (pink), TP, TN and TSS for Deployment 8. 


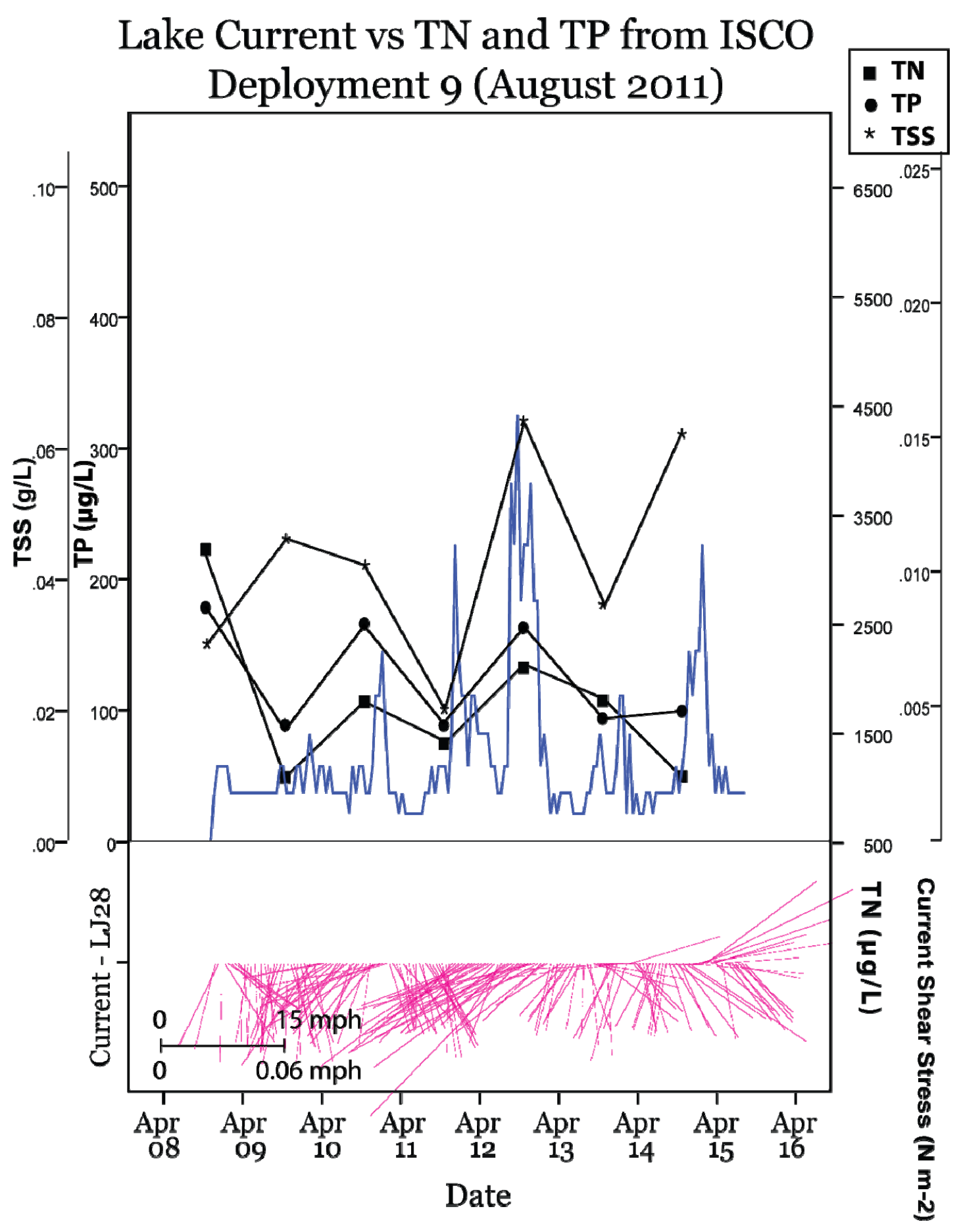

FIGURE A62. Time-series of current shear stress (blue), current stick plots (pink), TP, TN and TSS for Deployment 9. 